OAK RIDGE

NATIONAL LABORATORY

MANAGED BY UT-BATTELLE

FOR THE DEPARTMENT OF ENERGY

\title{
Investigation of Burnup Credit Modeling Issues Associated With BWR Fuel
}

\author{
J. C. Wagner \\ M. D. DeHart \\ B. L. Broadhead
}

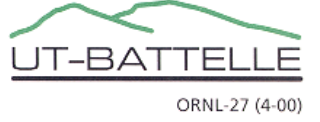


This report has been reproduced from the best available copy.

Reports are available to the public from the following source.

National Technical Information Service

5285 Port Royal Road

Springfield, VA 22161

Telephone 703-605-6000 (1-800-553-6847)

TDD 703-487-4639

Fax 703-605-6900

E-mailorders@ntis.fedworld.gov

web site http://wWw.ntis.gov/ordering.htm

Reports are available to U.S. Department of Energy (DOE) employees, DOE contractors, Energy Technology Data Exchange (ETDE) representatives, and International Nuclear Information System (INIS) representatives from the following source.

Office of Scientific and Technical Information

P.O. Box 62

Oak Ridge, TN 37831

Telephone 423-576-8401

Fax 423-576-5728

E-mai reports@adonis.osti.gov

Web sitehttp://WWW.osti.gov/products/sources.html

Reports produced after January 1, 1996, are generally available via the DOE Information Bridge. web site http://WwW.doe.gov/bridge

This report was prepared as an account of work sponsored by an agency of the United States government. Neither the United States government nor any agency thereof, nor any of their employees, makes any warranty, express or implied, or assumes any legal liability or responsibility for the accuracy, completeness, or usefulness of any information, apparatus, product, or process disclosed, or represents that its use would not infringe privately owned rights. Reference herein to any specific commercial product, process, or service by trade name, trademark, manufacturer, or otherwise, does not necessarily constitute or imply its endorsement, recommendation, or favoring by the United States government or any agency thereof. The views and opinions of authors expressed herein do not necessarily state or reflect those of the United States government or any agency thereof. 
ORNL/TM-1999/193

Computational Physics and Engineering Division (10)

\section{Investigation of Burnup Credit Modeling Issues Associated with BWR Fuel}

J. C. Wagner, M. D. DeHart, and B. L. Broadhead

Date Published: October 2000

Prepared by the

OAK RIDGE NATIONAL LABORATORY

Oak Ridge, Tennessee 37831

UT-Battelle, LLC,

for the

U.S. DEPARTMENT OF ENERGY

under contract DE-AC05-00OR22725 


\section{CONTENTS}

\begin{tabular}{|c|c|}
\hline LIST OF FIGURES. & $\mathrm{v}$ \\
\hline LIST OF TABLES & $x i$ \\
\hline ACKNOWLEDGMENTS. & xiii \\
\hline
\end{tabular}

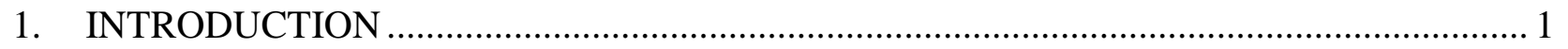

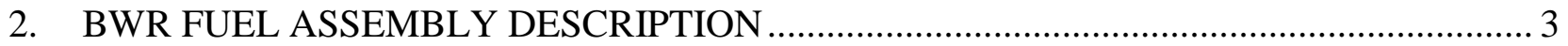

3. INVESTIGATION OF BWR DEPLETION CALCULATIONS WITH SAS2H .................. 5

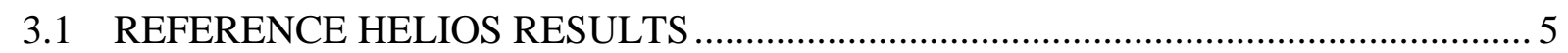

3.2 COMPARISON OF SAS2H AND HELIOS RESULTS FOR VARIOUS

MODELING APPROACHES

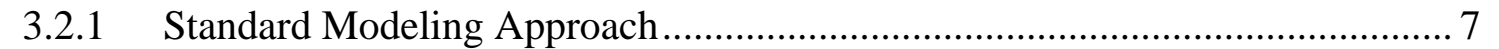

3.2.1.1 Reactivity Behavior of BWR Fuel as a Function of Burnup.............. 13

3.2.2 Investigation of Alternative Modeling Approaches.................................... 13

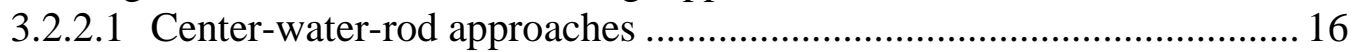

3.2.2.1.1 Single-fuel-region models ................................... 16

3.2.2.1.2 Two-fuel-region models ......................................... 23

3.2.2.1.3 Three-fuel-region model ....................................... 29

3.2.2.2 Corrections to the SAS2H sequence .......................................... 29

3.2.3 Comparison of Modeling Approaches at Various Burnups.......................... 32

3.2.4 Variation of Bypass Moderator Thickness ............................................. 46

3.2.5 Effect of Uniform Fuel Enrichment in SAS2H ...................................... 56

3.3 MODELING RECOMMENDATIONS AND CONCLUSIONS ........................... 62

4. EFFECT OF DEPLETION PARAMETERS ON CALCULATED ISOTOPICS

AND REACTIVITY ............................................................................................... 65

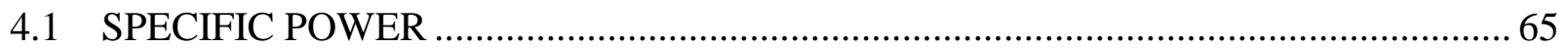

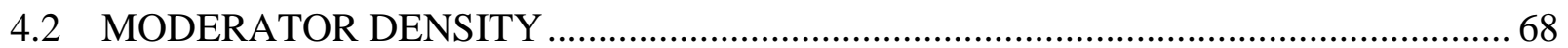

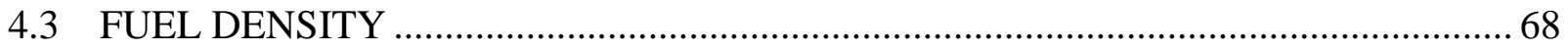

$4.4 \quad$ FUEL TEMPERATURE ……………………….................................................... 76

$4.5 \quad$ FREQUENCY OF CROSS-SECTION LIBRARY UPDATES ..................................... 76

5. EFFECT OF DEPLETION ASSUMPTIONS ON THREE-DIMENSIONAL

CRITICALITY CALCULATIONS........................................................................ 85

$5.1 \quad$ THE AXIAL-BURNUP MODEL ………………………………………………8 85

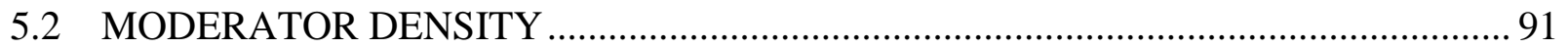

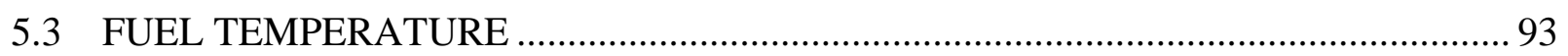

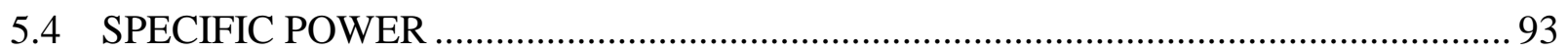

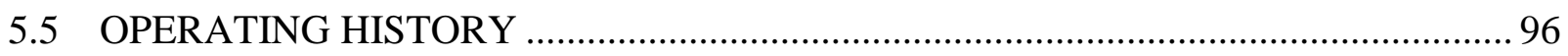




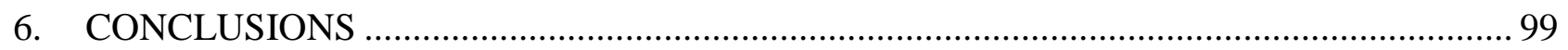

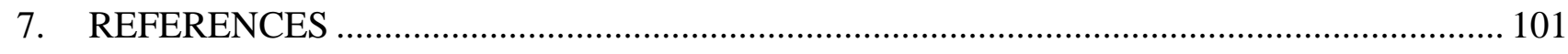

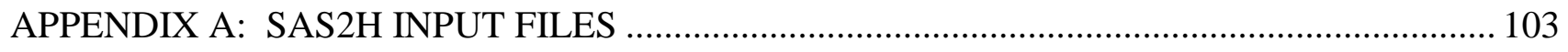




\section{LIST OF FIGURES}

\section{Figure}

Page

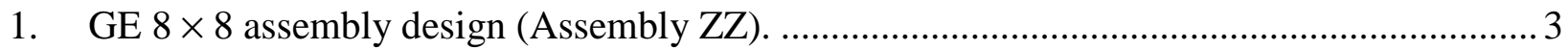

2. $\quad$ SAS2H SMA model for BWR fuel assembly (not drawn to scale) . ............................. 8

3. Percentage difference (relative to HELIOS) between SAS2H and HELIOS calculated nuclide densities at 40-GWd/MTU burnup and 5-year cooling.

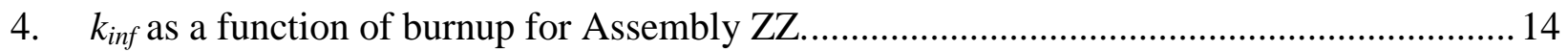

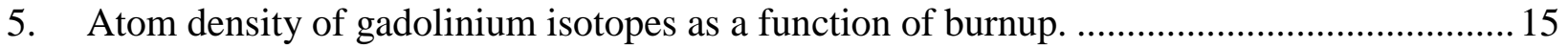

6. $\quad$ Basic center-water-rod SAS2H model for Assembly ZZ (not drawn to scale)................... 17

7. Percentage differences (relative to HELIOS) between SAS2H and HELIOS calculated actinide densities for the single-fuel-region models at 40-GWd/MTU burnup and

5-year cooling time (SMA results included for comparison).

8. $\quad$ Percentage differences (relative to HELIOS) between SAS2H and HELIOS calculated fission-product densities for the single-fuel-region models at 40-GWd/MTU burnup and 5-year cooling time (SMA results included for comparison).

9. $\quad$ Two-fuel-region SAS2H model for Assembly ZZ (not drawn to scale).........................24

10. Percentage differences (relative to HELIOS) between SAS2H and HELIOS calculated actinide densities for the two-fuel-region models at 40-GWd/MTU burnup and 5-year cooling time (SMA results included for comparison).

11. Percentage differences (relative to HELIOS) between SAS2H and HELIOS calculated fission-product densities for the two-fuel-region models at 40-GWd/MTU burnup and 5-year cooling time (SMA results included for comparison).....

12. Three-fuel-region SAS2H model for Assembly ZZ (not drawn to scale).........................30

13. Summary of percentage differences (relative to HELIOS) between SAS2H and HELIOS calculated actinide densities for the various modeling approaches (at 40-GWd/MTU burnup, 5-year cooling time).

14. Summary of percentage differences (relative to HELIOS) between SAS2H and HELIOS calculated fission-product densities for the various modeling approaches (at 40-GWd/MTU burnup, 5-year cooling time) 


\section{LIST OF FIGURES (continued)}

Figure

Page

15. Percentage differences (relative to HELIOS) between SAS2H (SMA model) and HELIOS calculated actinide densities for various burnups.

16. Percentage differences (relative to HELIOS) between SAS2H (SMA model) and HELIOS calculated fission-product densities for various burnups...............................36

17. Summary of percentage differences (relative to HELIOS) between SAS2H and HELIOS calculated actinide densities for the various modeling approaches (at 5-GWd/MTU burnup, 5-year cooling time).

18. Summary of percentage differences (relative to HELIOS) between SAS2H and HELIOS calculated fission-product densities for the various modeling approaches (at 5-GWd/MTU burnup, 5-year cooling time).

19. Summary of percentage differences (relative to HELIOS) between SAS2H and HELIOS calculated actinide densities for the various modeling approaches (at 10-GWd/MTU burnup, 5-year cooling time).

20. Summary of percentage differences (relative to HELIOS) between SAS2H and HELIOS calculated fission-product densities for the various modeling approaches (at 10-GWd/MTU burnup, 5-year cooling time).

21. Summary of percentage differences (relative to HELIOS) between SAS2H and HELIOS calculated actinide densities for the various modeling approaches (at 20-GWd/MTU burnup, 5-year cooling time).

22. Summary of percentage differences (relative to HELIOS) between SAS2H and HELIOS calculated fission-product densities for the various modeling approaches (at 20-GWd/MTU burnup, 5-year cooling time).

23. Summary of percentage differences (relative to HELIOS) between SAS2H and HELIOS calculated actinide densities for the various modeling approaches (at 30-GWd/MTU burnup, 5-year cooling time).

24. Summary of percentage differences (relative to HELIOS) between SAS2H and HELIOS calculated fission-product densities for the various modeling approaches (at 30-GWd/MTU burnup, 5-year cooling time).

25. Calculated $k_{\text {inf }}$ values as a function of burnup based on actinide-only isotopics from both HELIOS and SAS2H (zero cooling time). 


\section{LIST OF FIGURES (continued)}

Figure

$\underline{\text { Page }}$

26. Calculated $k_{\text {inf }}$ values as a function of burnup based on actinide-plus-fissionproduct isotopics from both HELIOS and SAS2H (zero cooling time)....

27. Percentage differences (relative to HELIOS) between SAS2H- and HELIOS-calculated atom densities for ${ }^{155} \mathrm{Gd}$ as a function of burnup.

28. Percentage differences (relative to HELIOS) between SAS2H- and HELIOS-calculated atom densities for ${ }^{157} \mathrm{Gd}$ as a function of burnup.

29. Effect of varying the bypass moderator thickness on the calculated actinide densities (relative to the reference SMA results) at 40-GWd/MTU burnup and 5-year cooling time

30. Effect of varying the bypass moderator thickness on the calculated fission-product densities (relative to the reference SMA results) at 40-GWd/MTU burnup and 5-year cooling time

31. Effect of varying the bypass moderator thickness on the calculated actinide densities (relative to the reference HELIOS results) at 40-GWd/MTU burnup and 5-year cooling time.

32. Effect of varying the bypass moderator thickness on the calculated fission-product densities (relative to the reference HELIOS results) at 40-GWd/MTU burnup and 5-year cooling time.

33. Effect of the average-enrichment assumption on calculated actinide densities for various burnups (HELIOS-to-HELIOS comparison).

34. Effect of the average-enrichment assumption on calculated fission-product densities for various burnups (HELIOS-to-HELIOS comparison).

35. Effect of the average-enrichment assumption (without gadolinium rods present) on calculated actinide densities for various burnups. Percentage differences are between actinide densities calculated by HELIOS with the assembly-average enrichment (without gadolinium present) and those calculated by HELIOS with the explicit pin enrichments (without gadolinium present). The latter case is used as the reference. 


\section{LIST OF FIGURES (continued)}

Figure

Page

36. Effect of the average-enrichment assumption (without gadolinium rods present) on calculated fission-product densities for various burnups. Percentage differences are between fission-product densities calculated by HELIOS with the assembly-average enrichment (without gadolinium present) and those calculated by HELIOS with the explicit pin enrichments (without gadolinium present). The latter case is used as the reference.

37. Effect of specific power during depletion on actinide densities (40-GWd/MTU burnup, 5-year cooling).

38. Effect of specific power during depletion on fission-product densities (40-GWd/MTU burnup, 5-year cooling).

39. Effect of specific power during depletion on SNF $k_{\text {inf }}$ (40-GWd/MTU burnup, 5-year cooling).

40. Effect of moderator density during depletion on actinide densities (40-GWd/MTU burnup, 5-year cooling).

41. Effect of moderator density during depletion on fission-product densities (40-GWd/MTU burnup, 5-year cooling).

42. Effect of moderator density during depletion on $k_{\text {inf }}$ (40-GWd/MTU burnup, 5-year cooling).

43. Effect of fuel density on actinide densities (40-GWd/MTU burnup, 5-year cooling).........73

44. Effect of fuel density on fission-product densities (40-GWd/MTU burnup, 5-year cooling)

45. Effect of fuel density on $k_{\text {inf }}$ (40-GWd/MTU burnup, 5-year cooling).....

46. Effect of fuel temperature during depletion on actinide densities (40-GWd/MTU burnup, 5-year cooling).

47. Effect of fuel temperature during depletion on fission-product densities (40-GWd/MTU burnup, 5-year cooling).

48. Effect of fuel temperature during depletion on $k_{\text {inf }}$ (40-GWd/MTU burnup, 5-year cooling) 


\section{LIST OF FIGURES (continued)}

Figure

$\underline{\text { Page }}$

49. Effect of the number of SAS2H libraries used during depletion on actinide densities (40-GWd/MTU burnup, 5-year cooling).

50. Effect of the number of SAS2H libraries used during depletion on fission-product densities (40-GWd/MTU burnup, 5-year cooling).

51. Effect of the number of SAS2H libraries used during depletion on $k_{\text {inf }}$ (40-GWd/MTU burnup, 5-year cooling).

52. Axial-burnup profiles for various state points (SP) of Assembly ZZ. ......................... 87

53. Axial-moderator-density profiles for various state points (SP) of Assembly ZZ............. 88

54. Axial-fuel-temperature profiles for various state points (SP) of Assembly ZZ............... 89

55. Value of SNF $k_{\text {inf }}$ as a function of the number of axial zone ..................................... 90

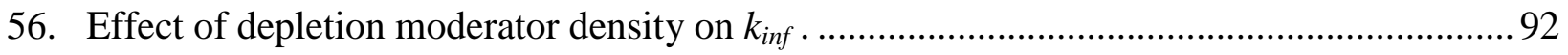

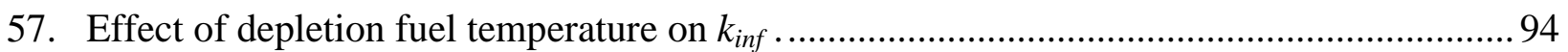

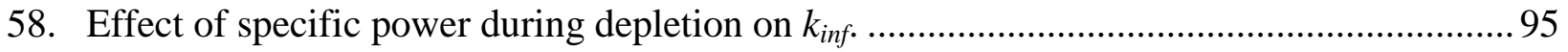

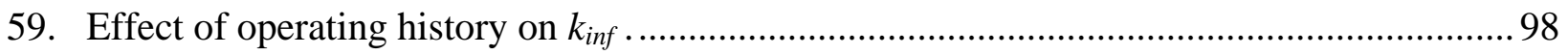




\section{LIST OF TABLES}

$\underline{\text { Table }}$

$\underline{\text { Page }}$

1. $\quad$ Dimensional specifications for Assembly ZZ ........................................................... 4

2. Reference nuclide densities (in gram-atoms) calculated with HELIOS for various discharge burnups and 5-year cooling...

3. $\quad$ SAS2H SMA model dimensions for Assembly ZZ ............................................. 8

4. Comparison of calculated nuclide densities (in gram-atoms) from SAS2H with the standard modeling approach and HELIOS at 40-GWd/MTU burnup and 5-year cooling time

5. $\quad$ Listing of actinides and fission products included in criticality calculations .................... 12

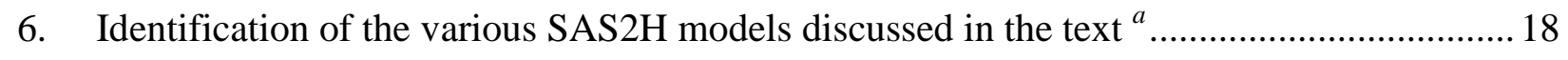

7. Comparison of calculated nuclide densities (in gram-atoms) from HELIOS and SAS2H with the single-fuel-region models (at 40-GWd/MTU burnup,

5-year cooling time)

8. Percentage differences (relative to HELIOS) in calculated nuclide densities from $\mathrm{SAS} 2 \mathrm{H}$ with the standard modeling approach and the single-fuel-region models (at 40-GWd/MTU burnup and 5-year cooling time).

9. Calculated nuclide densities (in gram-atoms) from $\mathrm{SAS} 2 \mathrm{H}$ with the two-fuel-region models (at 40-GWd/MTU burnup, 5-year cooling time).....

10. Percentage differences (relative to HELIOS) in calculated nuclide densities from $\mathrm{SAS} 2 \mathrm{H}$ with the standard modeling approach and the two-fuel-region models (at 40-GWd/MTU burnup, 5-year cooling time)......

11. Calculated nuclide densities (in gram-atoms) from SAS2H with the three-fuel-region model and percentage differences relative to HELIOS (at 40-GWd/MTU burnup, 5-year cooling time).

12. Comparison of calculated $k_{\text {inf }}$ values as a function of burnup for the various models at 5-year cooling time.....

13 Calculated $k_{\text {inf }}$ values as a function of burnup based on isotopics from HELIOS, assuming assembly-average enrichment and 5-year cooling time....

14. Description of operating histories analyzed 


\section{ACKNOWLEDGMENTS}

The authors express their sincere appreciation to several individuals who have contributed to this work. Particular thanks go to David Henderson and company at Framatome Cogema Fuels for their contribution to this effort through discussions and review, and for supplying the physical and operational fuel assembly data. Gratitude is extended to I. C. Gauld and B. D. Murphy for their insightful comments on the draft report and subsequent useful discussions. The authors acknowledge C. V. Parks for providing guidance for this work and valuable comments on the draft report. Finally, the authors express their sincere appreciation to C. H. Shappert for editing the document and to W. C. Carter for her efforts in formatting and release of this document.

This work was performed at Oak Ridge National Laboratory with financial support from the U.S. Department of Energy's (DOE) Office of Civilian Radioactive Waste Management (OCRWM). Oak Ridge National Laboratory is managed by UT-Battelle, LLC, under contract number DE-AC05-00OR22725 for the U.S. Department of Energy. 


\begin{abstract}
This report investigates various calculational modeling issues associated with boilingwater-reactor (BWR) fuel depletion relevant to burnup credit. To date, most of the efforts in burnup-credit studies in the United States have focused on issues related to pressurized-waterreactor (PWR) fuel. However, requirements for the permanent disposal of BWR fuel have necessitated the development of methods for predicting the spent fuel contents for such fuels. Concomitant with such analyses, validation is also necessary. This report provides a summary of initial efforts to better understand and validate away-from-reactor spent fuel analysis methods for BWR fuel. These efforts include: assessment of SAS2H for BWR depletion calculations by code-to-code comparisons with HELIOS, investigation of SAS2H modeling issues and depletion assumptions, and finally, analysis of the sensitivity of three-dimensional criticality calculations to depletion assumptions.

The one-dimensional assembly model approximation within SAS2H appears to yield consistent results such that a reasonable bias and uncertainty could be determined in the estimation of assembly-averaged isotopic concentrations. In general, SAS2H overpredicts nuclide concentrations relative to HELIOS, with the significant exception of ${ }^{235} \mathrm{U}$. The underestimation of ${ }^{235} \mathrm{U}$ is shown to be associated with the single fuel enrichment limitation in SAS2H and increases as a function of burnup. Finally, the effects of variations in the depletion parameters on the calculated reactivity were observed to be consistent with those shown in a previous study of PWR depletion modeling.
\end{abstract}




\section{INTRODUCTION}

Although significant effort has been dedicated to the study of burnup-credit issues over the past decade, U.S. studies to-date have primarily focused on spent pressurized-water-reactor (PWR) fuel. ${ }^{1-5}$ The current licensing approach taken by the U.S. Department of Energy for burnup credit in transportation seeks approval for PWR fuel only $\sqrt{5}$ Burnup credit for boilingwater-reactor (BWR) fuel has not yet been formally sought. Burnup credit for PWR fuel was pursued first because: (1) nearly two-fhirds (by mass) of the total discharged commercial spent fuel in the United States is PWR fuel, $(2)$ it can substantially increase the fuel assembly capacity with respect to current designs for PWR storage and transportation casks, and (3) fuel depletion in PWRs is generally less complicated than fuel depletion in BWRs. However, due to international needs, the increased enrichment of modern BWR fuels, and criticality safety issues related to permanent disposal within the United States, more attention has recently focused on spent BWR fuel. Specifically, credit for fuel burnup in the criticality safety analysis for longterm disposal 7 of spent nuclear fuel enables improved design efficiency, which, due to the large mass of fissile material that will be stored in the repository, can have substantial financial benefits.

For criticality safety purposes, current PWR storage and transportation canister designs employ flux traps between assemblies. Credit for fuel burnup will eliminate the need for these flux traps, and thus, significantly increase the PWR assembly capacity (for a fixed canister volume). Increases in assembly capacity of approximately one-third are expected. In contrast, current BWR canister designs do not require flux traps for criticality safety, and thus, are already at their maximum capacity in terms of physical storage. Therefore, benefits associated with burnup credit for BWR storage and transportation casks may be limited to increasing the enrichment capacity and/or decreasing the neutron absorber concentration. However, regulations associated with permanent disposal require consideration of scenarios and/or package conditions that are not relevant or credible for storage or transportation, and as a result, necessitate credit for burnup in BWR fuel to maintain capacity objectives.

Burnup credit relies on depletion calculations to provide a conservative estimate of spent fuel contents and subsequent criticality calculations to assess the value of $k_{\text {eff }}$ for a spent fuel cask or a fuel configuration under a variety of postulated conditions. Therefore, validation is necessary to quantify biases and uncertainties between analytic predictions and measured isotopics. However, the design and operational aspects of BWRs result in a more heterogeneous and time-varying reactor configuration than those of PWRs. Thus, BWR spent fuel analyses and validation efforts are significantly more complicated than those of their PWR counterparts. BWR spent fuel assemblies are manufactured with variable enrichments, both radially and axially, are exposed to time- and spatially-varying void distributions, contain integral burnable absorber rods, and are subject to partial control-blade insertion during operation. The latter is especially true in older fuel assemblies. Away-from-reactor depletion tools used for characterization of spent fuel have typically been developed and validated for more homogeneous PWR fuel assemblies without integral burnable absorber rods, and thus must be reassessed for BWR configurations to determine a conservative methodology for estimating the isotopic content of spent BWR fuel. 
This report examines the use of SAS2 8 for calculating spent BWR fuel isotopics for burnup-credit criticality safety analyses and assesses the adequacy of SAS2H for this task. The effects of SAS2H modeling assumptions on calculated spent BWR fuel isotopics and the effects of depletion assumptions on calculated $k_{\text {inf }}$ values are investigated. Detailed twodimensional (2-D) HELIOS9 assembly calculations are compared to one-dimensional (1-D) cylindrical approximations performed using the SAS2H sequence of SCALE ${ }^{10}$ SAS2H uses a 1-D transport solution (XSDRNPM) to generate three-group fuel-averaged fluxes, which are used in the point depletion ORIGEN-S code. Studies focused on the effect of geometric modeling with approximate 1-D models and the effect of variations in relevant depletion parameters are presented. Then, using the 1-D SAS2H approach to calculate number densities for a set of axially varying burnups, three-dimensional (3-D) KENO V.a criticality calculations were performed to assess the effect of various axial zoning schemes and depletion assumptions on the calculated value of $k_{\text {inf }}$ for an infinite array of fuel assemblies. The analyses documented in this report represent an attempt to gain greater physical understanding of BWR fuel depletion calculations, assess the adequacy of $\mathrm{SAS} 2 \mathrm{H}$ for this task, and subsequently refine the calculational methodology. 


\section{BWR FUEL ASSEMBLY DESCRIPTION}

Depletion calculations for this study were performed based on a GE $8 \times 8$ assembly design, as illustrated in Fig. 1. Assembly and operating history data applied in this analysis are based on neutronic and thermal-hydraulic data for a fuel assembly burned in Quad Cities Unit 2 during Cycles 10 through 14. The data supplied to ORNL were modified to protect proprietary information, 11 but nonetheless represent operational data for an actual BWR assembly. For identification purposes, this assembly has been designated as "Assembly ZZ." The physical dimensions of Assembly $\mathrm{ZZ}$ are listed in Table 1

With an average enrichment of 3.2-wt \% ${ }^{235} \mathrm{U}$, Assembly $\mathrm{ZZ}$ contains 60 fuel rods with 11 different enrichments, including 9 rods containing 3-wt $\% \quad \mathrm{Gd}_{2} \mathrm{O}_{3}$. The various initial enrichments and locations of the fuel are indicated in Fig. 1. This assembly design also contains a large central water hole and an outer Zircaloy channel. Additionally, the assembly has a nonuniform axial loading, composed of a main central fuel region with uniform enrichment and gadolinium loading (as shown in Fig. 1) and natural uranium reflectors comprising the last $15.24 \mathrm{~cm}$ of each end. This assembly does not have axially varying enrichment or gadolinium loading in the central fuel region, which is common in current BWR fuel designs. Nevertheless, the non-uniform and asymmetric fuel loading of this assembly are expected to provide a severe test of the modeling limitations of the SAS2H sequence.
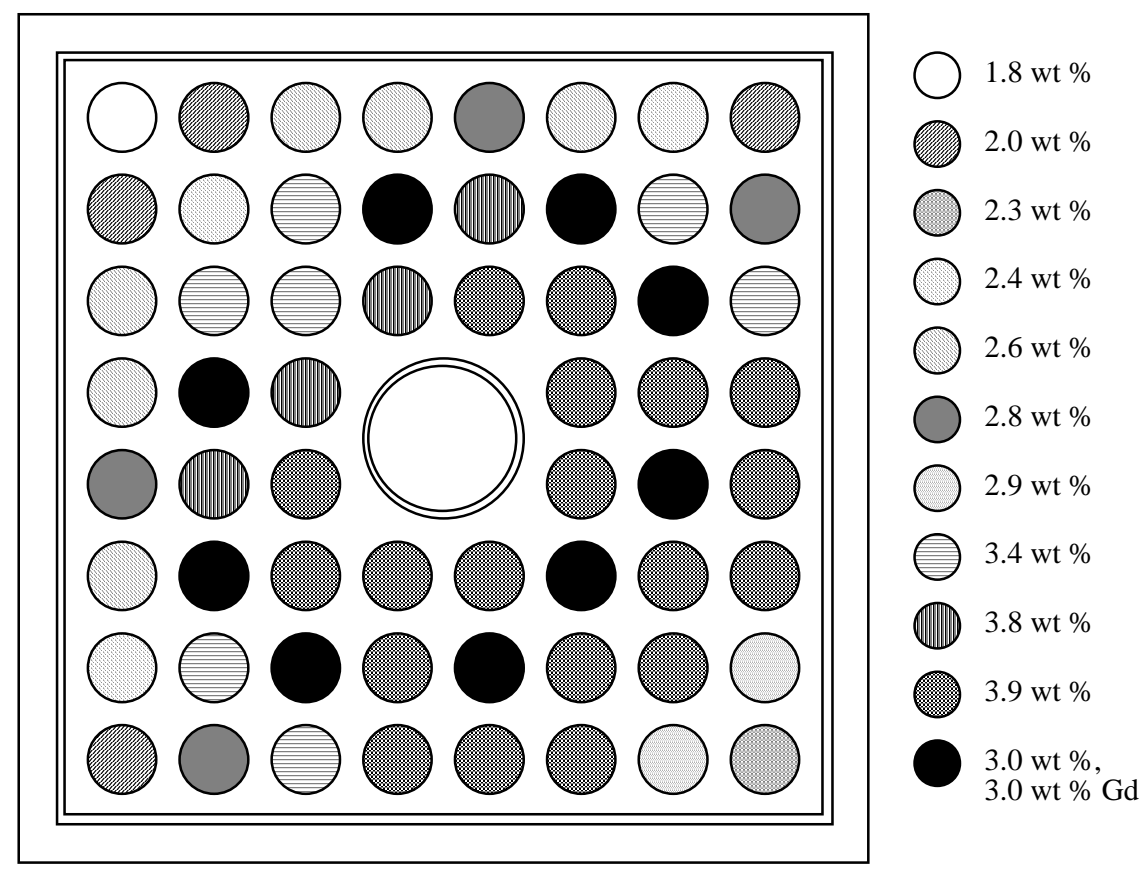

Fig. 1. GE $8 \times 8$ assembly design (Assembly ZZ). 
Table 1. Dimensional specifications for Assembly ZZ

\begin{tabular}{lc}
\hline \multicolumn{1}{c}{ Parameter } & Data \\
\hline Fuel array size & $8 \times 8$ \\
No. of fuel rods & 60 \\
No. of water rods & 1 \\
No. of $\mathrm{UO}_{2} / \mathrm{Gd}_{2} \mathrm{O}_{3}$ rods & 9 \\
Assembly average enrichment (wt $\left.\%{ }^{235} \mathrm{U}\right)$ & 3.2 \\
Pellet diameter, cm (in.) & $1.0566(0.4160)$ \\
Fuel rod ID, cm (in.) & $1.0642(0.4190)$ \\
Fuel rod OD, cm (in.) & $1.2268(0.4830)$ \\
Water rod ID, cm (in.) & $3.2004(1.2600)$ \\
Water rod OD, cm (in.) & $3.4036(1.3400)$ \\
Fuel rod ptch, cm (in.) & $1.6256(0.6400)$ \\
Channel ID, cm (in.) & $13.0048(5.1200)$ \\
Channel OD, cm (in.) & $13.4112(5.2800)$ \\
Assembly pitch, cm (in.) & $15.1032(5.9461)$ \\
\hline
\end{tabular}




\section{INVESTIGATION OF BWR DEPLETION CALCULATIONS WITH SAS2H}

To assess the depletion capability of SAS2H for this heterogeneous BWR fuel assembly, depletion calculations were performed using both SAS2H and the HELIOS computer code package. Comparisons between these two codes, in tandem with variations in the HELIOS assembly model, were performed to assess the effect of assembly heterogeneity. HELIOS is a widely used tool for reactor fuel management analysis and has been validated for a number of reactor types, including many BWR fuel designs 12 While SAS2H is limited to simple, 1-D transport analysis, assuming a single fuel type (i.e., rod dimensions and enrichment), HELIOS can perform pin-by-pin depletion calculations based on a 2-D transport solution. Although a code-to-code comparison lacks the quantification of a direct comparison to measured spent fuel data, such a comparison does enable a study of the relative behavior of the two codes. In addition, the code-to-code comparison can provide an understanding of the effect and magnitude of the modeling approximations required for the $\mathrm{SAS} 2 \mathrm{H}$ analysis.

All SAS2H calculations were performed on a DEC AlphaStation 500. HELIOS calculations were executed on an IBM RISC 580. The SAS2H calculations used the SCALE 44-group (ENDF/B-V) library; the HELIOS calculations used a 34-group neutron library based on ENDF/B-VI data. Although the effect is assumed to be minor for this study, it is important to note that SAS2H and HELIOS are not using the same cross sections. The depletion calculations were performed using typical operational parameters for temperatures $\left(\mathrm{T}_{\mathrm{f}}=1128.2 \mathrm{~K}, \mathrm{~T}_{\mathrm{m}}=\right.$ $559.1 \mathrm{~K}$ ) and a moderator density of $0.74 \mathrm{~g} / \mathrm{cm}^{3}$, which correspond to an axial location below the midplane. Continuous operation at a power level of 30.9 MW/MTU was assumed for all calculations. Although the majority of results discussed in this report correspond to an accumulated burnup of $40 \mathrm{GWd} / \mathrm{MTU}$ and a 5-year cooling time, results for discharge burnups less than $40 \mathrm{GWd} / \mathrm{MTU}$ were also considered.

This section is organized as follows: the reference HELIOS results are given in Subsect. 3.1. Calculations to assess the performance of SAS2H relative to HELIOS with various geometric modeling approximations are presented in Subsect. 3.2. Calculations to assess the agreement between SAS2H and HELIOS as a function of burnup and an investigation of the effect of assembly heterogeneity are also included in Subsect. 3.2. Finally, modeling conclusions and recommendations are provided in Subsect. 3.3.

\subsection{REFERENCE HELIOS RESULTS}

HELIOS is a 2-D, generalized-geometry transport theory code based on the method of collision probabilities with current coupling. Because HELIOS is able to model geometric effects explicitly, the HELIOS model of the BWR assembly is exactly as shown in Fig. 1. No geometric or fuel enrichment approximations are necessary. Results for selected nuclides are given in Table 2 for assembly-averaged isotopics calculated by HELIOS at various burnups, followed by a 5-year cooling time. With the exception of Cs-133, which is not available in the HELIOS library, the selected nuclides include all of the actinide and fission-product nuclides identified in ref. 3 as being important to burnup credit. 
Table 2. Reference nuclide densities (in gram-atoms) calculated with HELIOS for various discharge burnups and 5-year cooling

\begin{tabular}{|c|c|c|c|c|c|}
\hline \multirow{2}{*}{ Nuclide } & \multicolumn{5}{|c|}{ Burnup (GWd/MTU) } \\
\hline & 5 & 10 & 20 & 30 & 40 \\
\hline $\mathrm{U}-234$ & $1.07 \mathrm{E}+00$ & $1.01 \mathrm{E}+00$ & $8.71 \mathrm{E}-01$ & $7.36 \mathrm{E}-01$ & $6.01 \mathrm{E}-01$ \\
\hline U-235 & $1.11 \mathrm{E}+02$ & $9.17 \mathrm{E}+01$ & $5.88 \mathrm{E}+01$ & $3.39 \mathrm{E}+01$ & $1.69 \mathrm{E}+01$ \\
\hline $\mathrm{U}-236$ & $4.56 \mathrm{E}+00$ & $7.85 \mathrm{E}+00$ & $1.31 \mathrm{E}+01$ & $1.67 \mathrm{E}+01$ & $1.88 \mathrm{E}+01$ \\
\hline $\mathrm{U}-238$ & $4.00 \mathrm{E}+03$ & $3.99 \mathrm{E}+03$ & $3.96 \mathrm{E}+03$ & $3.94 \mathrm{E}+03$ & $3.90 \mathrm{E}+03$ \\
\hline $\mathrm{Pu}-238$ & $4.35 \mathrm{E}-03$ & $2.09 \mathrm{E}-02$ & $1.12 \mathrm{E}-01$ & $3.05 \mathrm{E}-01$ & $5.85 \mathrm{E}-01$ \\
\hline $\mathrm{Pu}-239$ & $7.64 \mathrm{E}+00$ & $1.15 \mathrm{E}+01$ & $1.46 \mathrm{E}+01$ & $1.50 \mathrm{E}+01$ & $1.43 \mathrm{E}+01$ \\
\hline $\mathrm{Pu}-240$ & $7.43 \mathrm{E}-01$ & $2.14 \mathrm{E}+00$ & $5.28 \mathrm{E}+00$ & $8.11 \mathrm{E}+00$ & $1.01 \mathrm{E}+01$ \\
\hline $\mathrm{Pu}-241$ & $1.09 \mathrm{E}-01$ & $4.76 \mathrm{E}-01$ & $1.54 \mathrm{E}+00$ & $2.47 \mathrm{E}+00$ & $3.03 \mathrm{E}+00$ \\
\hline $\mathrm{Pu}-242$ & $6.12 \mathrm{E}-03$ & $5.84 \mathrm{E}-02$ & $4.58 \mathrm{E}-01$ & $1.37 \mathrm{E}+00$ & $2.80 \mathrm{E}+00$ \\
\hline Am-241 & $3.03 \mathrm{E}-02$ & $1.36 \mathrm{E}-01$ & $4.61 \mathrm{E}-01$ & $7.59 \mathrm{E}-01$ & $9.36 \mathrm{E}-01$ \\
\hline Am-242m & $5.69 \mathrm{E}-06$ & $7.38 \mathrm{E}-05$ & $5.57 \mathrm{E}-04$ & $1.22 \mathrm{E}-03$ & $1.59 \mathrm{E}-03$ \\
\hline Am-243 & $1.27 \mathrm{E}-04$ & $2.40 \mathrm{E}-03$ & $3.98 \mathrm{E}-02$ & $1.82 \mathrm{E}-01$ & $4.86 \mathrm{E}-01$ \\
\hline $\mathrm{Np}-237$ & $1.03 \mathrm{E}-01$ & $2.45 \mathrm{E}-01$ & $6.17 \mathrm{E}-01$ & $1.04 \mathrm{E}+00$ & $1.46 \mathrm{E}+00$ \\
\hline Mo-95 & $1.36 \mathrm{E}+00$ & $2.67 \mathrm{E}+00$ & $5.12 \mathrm{E}+00$ & $7.35 \mathrm{E}+00$ & $9.34 \mathrm{E}+00$ \\
\hline Tc-99 & $1.31 \mathrm{E}+00$ & $2.59 \mathrm{E}+00$ & $5.03 \mathrm{E}+00$ & $7.30 \mathrm{E}+00$ & $9.35 \mathrm{E}+00$ \\
\hline Ru-101 & $1.14 \mathrm{E}+00$ & $2.29 \mathrm{E}+00$ & $4.58 \mathrm{E}+00$ & $6.85 \mathrm{E}+00$ & $9.10 \mathrm{E}+00$ \\
\hline Rh-103 & $7.34 \mathrm{E}-01$ & $1.48 \mathrm{E}+00$ & $2.89 \mathrm{E}+00$ & $4.10 \mathrm{E}+00$ & $5.03 \mathrm{E}+00$ \\
\hline Ag-109 & $3.52 \mathrm{E}-02$ & $1.02 \mathrm{E}-01$ & $2.99 \mathrm{E}-01$ & $5.62 \mathrm{E}-01$ & $8.70 \mathrm{E}-01$ \\
\hline Sm-147 & $3.35 \mathrm{E}-01$ & $6.33 \mathrm{E}-01$ & $1.12 \mathrm{E}+00$ & $1.47 \mathrm{E}+00$ & $1.66 \mathrm{E}+00$ \\
\hline Sm-149 & $1.69 \mathrm{E}-02$ & $1.68 \mathrm{E}-02$ & $1.73 \mathrm{E}-02$ & $1.70 \mathrm{E}-02$ & $1.65 \mathrm{E}-02$ \\
\hline Sm-150 & $2.33 \mathrm{E}-01$ & $4.98 \mathrm{E}-01$ & $1.06 \mathrm{E}+00$ & $1.62 \mathrm{E}+00$ & $2.15 \mathrm{E}+00$ \\
\hline Sm-151 & $3.74 \mathrm{E}-02$ & $4.43 \mathrm{E}-02$ & $4.95 \mathrm{E}-02$ & $5.24 \mathrm{E}-02$ & $5.45 \mathrm{E}-02$ \\
\hline Sm-152 & $1.22 \mathrm{E}-01$ & $2.76 \mathrm{E}-01$ & $5.73 \mathrm{E}-01$ & $8.41 \mathrm{E}-01$ & $1.08 \mathrm{E}+00$ \\
\hline Nd-143 & $1.20 \mathrm{E}+00$ & $2.24 \mathrm{E}+00$ & $3.89 \mathrm{E}+00$ & $4.90 \mathrm{E}+00$ & $5.24 \mathrm{E}+00$ \\
\hline Nd-145 & $8.22 \mathrm{E}-01$ & $1.60 \mathrm{E}+00$ & $3.03 \mathrm{E}+00$ & $4.28 \mathrm{E}+00$ & $5.35 \mathrm{E}+00$ \\
\hline Eu-151 & $1.51 \mathrm{E}-03$ & $1.80 \mathrm{E}-03$ & $2.00 \mathrm{E}-03$ & $2.11 \mathrm{E}-03$ & $2.18 \mathrm{E}-03$ \\
\hline Eu-153 & $4.79 \mathrm{E}-02$ & $1.17 \mathrm{E}-01$ & $3.17 \mathrm{E}-01$ & $5.76 \mathrm{E}-01$ & $8.63 \mathrm{E}-01$ \\
\hline Gd-155 & $1.82 \mathrm{E}-03$ & $3.19 \mathrm{E}-03$ & $7.50 \mathrm{E}-03$ & $1.42 \mathrm{E}-02$ & $2.22 \mathrm{E}-02$ \\
\hline
\end{tabular}




\subsection{COMPARISON OF SAS2H AND HELIOS RESULTS FOR VARIOUS MODELING APPROACHES}

A SAS2H model of a fuel assembly is limited to a 1-D radial model with a single smeared fuel region. Geometric modeling approximations are made in an effort to achieve a reasonable assembly-averaged neutron energy spectrum during the depletion process. The SAS2H approach utilizes two distinct geometric models. The first model, referred to as the PathA model, is a pincell model with white boundary conditions, which represents an infinite lattice of fuel pins. Cross sections are processed with this model using a resonance self-shielding calculation, followed by a 1-D discrete-ordinates transport computation (XSDRNPM) for the neutron flux. The cell-weighted cross sections produced with the pin-cell model are then applied to the fuel region of the Path-B model, which is a larger unit-cell model used to represent part or all of a fuel assembly. The concept of using cell-weighted data in the 1-D transport analysis of the Path$\mathrm{B}$ model is an approximate method for including the 2-D assembly effects. The Path-B model is used by SAS2H to calculate an "assembly-averaged" fuel region flux that includes the effects of the Path-A model and the overall assembly characteristics (e.g., water holes, burnable poison rods, etc.).

The Path-B model is intended to represent a larger unit cell within an infinite lattice. The SAS2H manual provides examples and/or guidelines for describing PWR and BWR fuel assemblies within the SAS2H geometric modeling capabilities. The following subsections will discuss various approaches to modeling Assembly $\mathrm{ZZ}$ with SAS2H and compare results from these models to the reference HELIOS results listed in Table 2.

\subsubsection{Standard Modeling Approach}

The SAS2H modeling approach for BWR fuel with fixed burnable absorbers (e.g., $\mathrm{Gd}_{2} \mathrm{O}_{3}$ ) described in the SAS2H manual is illustrated here in Fig. 2. For referencing purposes, this modeling approach is designated herein as the "Standard Modeling Approach" or, simply, SMA.

Because it is not possible to explicitly represent the spatially distributed gadoliniumbearing fuel rods (Gd rods), which are present in Assembly ZZ (see Fig. 1), with SAS2H, some approximate representation must be developed. The SAS2H SMA for this type of configuration assumes a single $\mathrm{UO}_{2} / \mathrm{Gd}_{2} \mathrm{O}_{3}$ rod in the center, surrounded by smeared fuel that represents part of the assembly fuel volume, bounded by corresponding volumes of the assembly channel and bypass moderator materials. In order to preserve the fuel-to- $\mathrm{Gd}_{2} \mathrm{O}_{3}$ ratio, the assembly fuel volume, as well as the corresponding volumes of the assembly channel and bypass moderator materials, are reduced by the inverse of the number of gadolinium-bearing rods. For example, Assembly ZZ has nine gadolinium-bearing rods, and thus, the fuel, channel, and bypass moderator volumes are based on one-ninth of the assembly.

Because it is impossible to include both a $\mathrm{UO}_{2} / \mathrm{Gd}_{2} \mathrm{O}_{3}$ rod and a central water hole (present in Assembly ZZ, see Fig. 1) in the center of the model, the volume of water associated with the water hole (reduced by the inverse of the number of gadolinium-bearing rods) is included in the bypass moderator. The smeared fuel mixture includes fuel (with the assembly

average enrichment, 3.2-wt $\%{ }^{235} \mathrm{U}$ for Assembly ZZ), clad, and moderator. Calculations are performed to obtain cell-weighted cross-sections for the corresponding pin-cell model. Hence, 
only a single fuel enrichment is possible. The SMA Path-B model dimensions for Assembly ZZ are listed in Table 3. The SAS2H input file is provided in Appendix A.

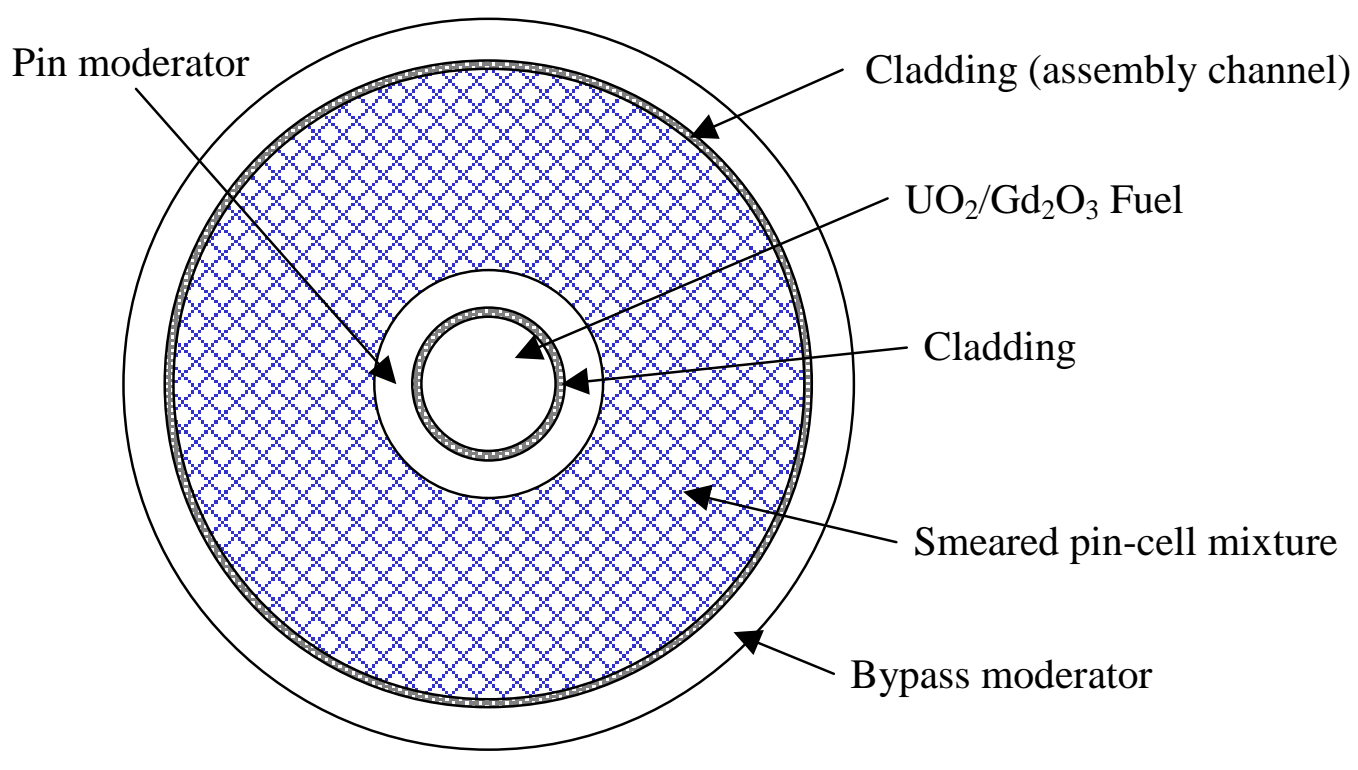

Fig. 2. SAS2H SMA model for BWR fuel assembly (not drawn to scale).

Table 3. SAS2H SMA model dimensions for Assembly ZZ

\begin{tabular}{clc}
\hline Radial zone & \multicolumn{1}{c}{ Material } & Radius, cm \\
\hline 1 & $\mathrm{UO}_{2} / \mathrm{Gd}_{2} \mathrm{O}_{3}$ fuel rod & 0.53210 \\
2 & Fuel rod clad & 0.61340 \\
3 & Moderator outside fuel rod in unit cell & 0.91715 \\
4 & Homogenized fuel, clad, and moderator (of Path-A) & 2.36806 \\
5 & Channel & 2.44692 \\
6 & Bypass moderator (moderator outside channel) & 2.84036 \\
\hline
\end{tabular}


Results for selected nuclides are given in Table 4 for assembly-averaged isotopics calculated by both HELIOS and SAS2H, along with the percentage difference between the two (SAS2H relative to HELIOS). The listed results correspond to an accumulated burnup of $40 \mathrm{GWd} / \mathrm{MTU}$ and a subsequent 5-year cooling-time. In spite of the considerable approximations associated with the SAS2H model, the SAS2H isotopic results are generally within $10 \%$ of the HELIOS predictions for the important actinides and fission products (i.e., those nuclides ranked in the top 10 in ref. 3). However, considerable differences $(>15 \%)$ are observed for some of the less-important nuclides. Figure 3 shows the percentage differences (relative to HELIOS) in graphical form.

In general, SAS2H is overpredicting nuclide concentrations relative to HELIOS, with the significant exception of ${ }^{235} \mathrm{U}$. The fact that ${ }^{235} \mathrm{U}$ is underpredicted and ${ }^{238} \mathrm{U}$ is overpredicted in the SAS2H calculation seems to indicate a softer spectrum in the SAS2H model. However, this is contradicted by the higher plutonium concentrations predicted by the SAS2H model. The exact reason for this behavior is unclear. Therefore, additional calculations are performed in the following sections in an attempt to understand these differences.

SAS2H has been compared to HELIOS in earlier validation work for $\mathrm{UO}_{2}$ fuel samples obtained from a MOX assembly design. 13 Note that the differences between actinides in the earlier work are consistent with those shown in Table 4. Additionally, for several actinides $\left({ }^{238} \mathrm{Pu},{ }^{240} \mathrm{Pu}\right.$, and $\left.{ }^{237} \mathrm{~Np}\right)$, SAS2H was in better agreement with experimental measurement than HELIOS. Thus, code-to-code differences shown in Table 4 do not necessarily indicate limitations in the SAS2H approach for BWR spent fuel characterization.

The ultimate goal of a burnup-credit criticality safety analysis is the accurate prediction of $k_{\text {eff }}$ for spent fuel. Hence, burnup credit relies on depletion calculations to provide an accurate estimate of the spent fuel contents. Although it is desirable to calculate all nuclide concentrations accurately, many nuclides do not have a significant impact on reactivity. Therefore, it is informative to compare calculated $k_{\text {inf }}$ values based on the calculated spent fuel isotopics. Calculated $k_{\text {inf }}$ values, based on spent fuel isotopics from both HELIOS and SAS2H, and corresponding 1- $\sigma$ statistical uncertainties, are listed in the bottom rows of Table 4. Although relatively large differences were observed in several of the calculated nuclide densities (see Fig. 3), the calculated $k_{\text {inf }}$ values are within $0.3 \%$. This close agreement can be attributed to offsetting differences in the isotopics calculated with SAS2H (e.g., the underestimation of ${ }^{235} \mathrm{U}$ is offset by an overestimation of ${ }^{239} \mathrm{Pu}$ and ${ }^{241} \mathrm{Pu}$ ) and the low importance of several of the nuclides for which large differences in concentrations were observed (e.g., ${ }^{238} \mathrm{Pu},{ }^{243} \mathrm{Am},{ }^{109} \mathrm{Ag}$ and $\left.{ }^{151} \mathrm{Eu}\right)$.

All criticality calculations in this section were performed with $\mathrm{KENO} \mathrm{V.a} \mathrm{at} 20^{\circ} \mathrm{C}$, utilizing the SCALE 44-group (ENDF/B-V) library. The actinides and fission products included in these calculations are listed in Table 5. The KENO V.a model for the criticality calculations is a 2-D assembly model with reflective boundary conditions on all sides, which represents an infinite radial array of infinite length fuel assemblies. The burnable poison (gadolinium) concentrations are tracked by ORIGEN-S in the SAS2H sequence as light elements, which enables the burnable poison inventory to be determined separately from the fission products for regions containing both burnable poisons and fissionable material. This feature allows the burnable poison (gadolinium) inventory to be determined separately from the fission product gadolinium, and distributed heterogeneously in the appropriate $\mathrm{Gd}_{2} \mathrm{O}_{3} / \mathrm{UO}_{2}$ pins in the assembly model, allowing a detailed assembly representation for the criticality calculations. Note that the gadolinium inventory is also tracked separately in HELIOS. 
Table 4. Comparison of calculated nuclide densities (in gram-atoms) from SAS2H with the standard modeling approach and HELIOS at 40-GWd/MTU burnup and 5-year cooling time

\begin{tabular}{|c|c|c|c|}
\hline Nuclide & HELIOS & SAS2H & $\begin{array}{c}\text { Percentage difference } \\
(\%)\end{array}$ \\
\hline U-234 & $6.01 \mathrm{E}-01$ & $6.47 \mathrm{E}-01$ & 7.57 \\
\hline $\mathrm{U}-235$ & $1.69 \mathrm{E}+01$ & $1.61 \mathrm{E}+01$ & -4.81 \\
\hline U-236 & $1.88 \mathrm{E}+01$ & $1.92 \mathrm{E}+01$ & 2.20 \\
\hline $\mathrm{U}-238$ & $3.90 \mathrm{E}+03$ & $3.97 \mathrm{E}+03$ & 1.79 \\
\hline $\mathrm{Pu}-238$ & $5.85 \mathrm{E}-01$ & $6.80 \mathrm{E}-01$ & 16.24 \\
\hline $\mathrm{Pu}-239$ & $1.43 \mathrm{E}+01$ & $1.52 \mathrm{E}+01$ & 6.20 \\
\hline $\mathrm{Pu}-240$ & $1.01 \mathrm{E}+01$ & $1.04 \mathrm{E}+01$ & 2.66 \\
\hline $\mathrm{Pu}-241$ & $3.03 \mathrm{E}+00$ & $3.26 \mathrm{E}+00$ & 7.44 \\
\hline $\mathrm{Pu}-242$ & $2.80 \mathrm{E}+00$ & $3.21 \mathrm{E}+00$ & 14.68 \\
\hline Am-241 & $9.36 \mathrm{E}-01$ & $1.01 \mathrm{E}+00$ & 8.12 \\
\hline Am-242m & $1.59 \mathrm{E}-03$ & $2.01 \mathrm{E}-03$ & 26.48 \\
\hline Am-243 & $4.86 \mathrm{E}-01$ & $6.18 \mathrm{E}-01$ & 27.16 \\
\hline Np-237 & $1.46 \mathrm{E}+00$ & $1.79 \mathrm{E}+00$ & 23.03 \\
\hline Mo-95 & $9.34 \mathrm{E}+00$ & $9.64 \mathrm{E}+00$ & 3.20 \\
\hline Tc-99 & $9.35 \mathrm{E}+00$ & $9.59 \mathrm{E}+00$ & 2.58 \\
\hline Ru-101 & $9.10 \mathrm{E}+00$ & $9.26 \mathrm{E}+00$ & 1.77 \\
\hline Rh-103 & $5.03 \mathrm{E}+00$ & $5.21 \mathrm{E}+00$ & 3.63 \\
\hline Ag-109 & $8.70 \mathrm{E}-01$ & $1.01 \mathrm{E}+00$ & 16.59 \\
\hline Sm-147 & $1.66 \mathrm{E}+00$ & $1.66 \mathrm{E}+00$ & -0.07 \\
\hline Sm-149 & $1.65 \mathrm{E}-02$ & $1.78 \mathrm{E}-02$ & 7.93 \\
\hline $\mathrm{Sm}-150$ & $2.15 \mathrm{E}+00$ & $2.53 \mathrm{E}+00$ & 17.59 \\
\hline Sm-151 & $5.45 \mathrm{E}-02$ & $6.88 \mathrm{E}-02$ & 26.23 \\
\hline Sm-152 & $1.08 \mathrm{E}+00$ & $1.13 \mathrm{E}+00$ & 4.88 \\
\hline Nd-143 & $5.24 \mathrm{E}+00$ & $5.45 \mathrm{E}+00$ & 3.90 \\
\hline Nd-145 & $5.35 \mathrm{E}+00$ & $5.51 \mathrm{E}+00$ & 2.99 \\
\hline Eu-151 & $2.18 \mathrm{E}-03$ & $2.75 \mathrm{E}-03$ & 26.24 \\
\hline Eu-153 & $8.63 \mathrm{E}-01$ & $9.69 \mathrm{E}-01$ & 12.21 \\
\hline Gd-155 & $2.22 \mathrm{E}-02$ & $2.46 \mathrm{E}-02$ & 10.97 \\
\hline$k_{\text {inf }}$ & HELIOS & SAS2H & Difference $^{b}$ \\
\hline Actinide-only & $0.93549(0.00028)^{c}$ & $0.93805(0.00030)$ & 0.00256 \\
\hline Actinide + fission products & $0.83696(0.00030)$ & $0.83407(0.00028)$ & -0.00289 \\
\hline
\end{tabular}




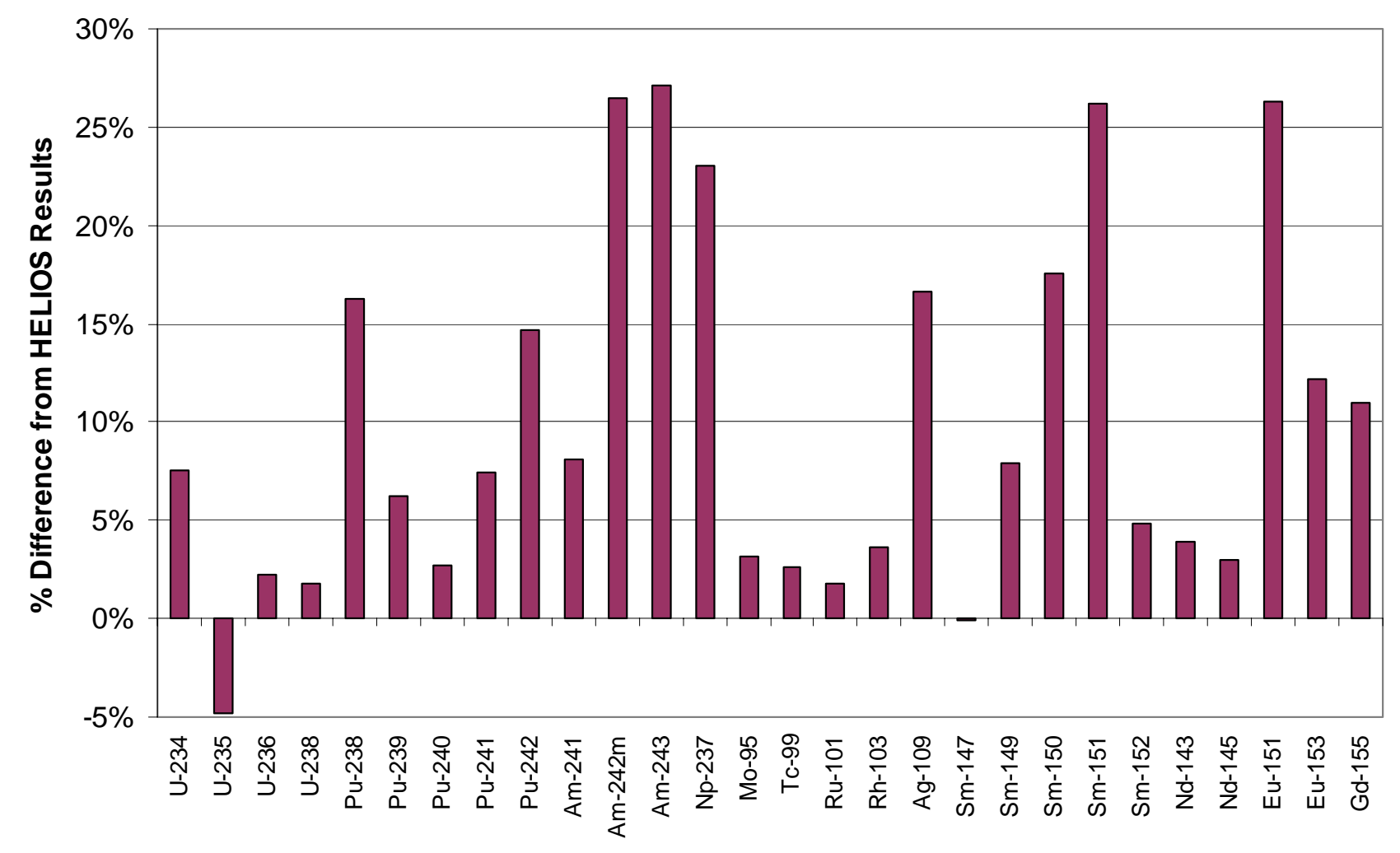

Fig. 3. Percentage difference (relative to HELIOS) between SAS2H and HELIOS calculated nuclide densities at 40-GWd/MTU burnup and 5-year cooling. 
Table 5. Listing of actinides and fission products included in criticality calculations

\begin{tabular}{cc}
\hline Actinides & Fission products \\
\hline $\mathrm{U}-234$ & Mo-95 \\
$\mathrm{U}-235$ & Tc-99 \\
$\mathrm{U}-236$ & $\mathrm{Ru}-101$ \\
$\mathrm{U}-238$ & $\mathrm{Rh}-103$ \\
$\mathrm{Pu}-238$ & $\mathrm{Ag}-109$ \\
$\mathrm{Pu}-239$ & $\mathrm{Sm}-147$ \\
$\mathrm{Pu}-240$ & $\mathrm{Sm}-149$ \\
$\mathrm{Pu}-241$ & $\mathrm{Sm}-150$ \\
$\mathrm{Pu}-242$ & $\mathrm{Sm}-151$ \\
$\mathrm{Am}-241$ & $\mathrm{Sm}-152$ \\
$\mathrm{Am}-242 \mathrm{~m}$ & $\mathrm{Nd}-143$ \\
$\mathrm{Am}-243$ & $\mathrm{Nd}-145$ \\
$\mathrm{~Np}-237$ & $\mathrm{Eu}-151$ \\
& $\mathrm{Eu}-153$ \\
& $\mathrm{Gd}-155$ \\
\hline
\end{tabular}




\subsubsection{Reactivity Behavior of BWR Fuel as a Function of Burnup}

To gain a greater understanding of the depletion problem for BWR fuel, it is useful to consider the reactivity behavior as a function of burnup. For PWR fuels (without integrated burnable absorbers), the reactivity decreases monotonically with burnup in a nearly linear fashion. In contrast, for BWR fuels (with integrated burnable absorbers) the reactivity increases as fuel burnup proceeds, reaches a maximum at a burnup where the absorber (gadolinium) is nearly depleted, and then decreases monotonically with burnup in a nearly linear fashion. The initial period of burnup (i.e., before the gadolinium is depleted and the reactivity peaks) adds an additional complication to BWR depletion that is not present in the depletion of PWR fuels (without integrated burnable absorbers). The reactivity behavior as a function of burnup (based on spent fuel isotopics from SAS2H) for Assembly ZZ (assuming an infinite array of assemblies) is plotted in Fig. 4. For comparison, cases with and without fission products are shown in Fig. 4 to illustrate the increasing negative reactivity worth of the fission products with increased burnup. This figure shows the characteristic increase in reactivity with burnup to the maximum at approximately $7 \mathrm{GWd} / \mathrm{MTU}$, where the gadolinium is nearly depleted. In general, the burnup at which the reactivity peaks is not dependent on the presence of fission products and increases with increasing enrichment.

The SAS2H calculated atom densities of the gadolinium isotopes as a function of burnup are illustrated in Fig. 5. This figure shows the depletion of the two most important gadolinium isotopes, ${ }^{155} \mathrm{Gd}$ and ${ }^{15} \mathrm{Gd}$, which have thermal absorption cross sections of approximately 61,000 and 256,000 barns, respectively. Because these isotopes have much larger thermal cross sections than ${ }^{235} \mathrm{U}$ (approximately 700 barns), they are depleted much faster, as is evident by the reactivity peak shown in Fig. 4. The remaining gadolinium isotopes have relatively small thermal absorption cross sections, and thus, are not important to reactivity.

\subsubsection{Investigation of Alternative Modeling Approaches}

Limitations in the geometric modeling capabilities of SAS2H require the development of approximate modeling approaches like the SMA described in the previous subsection. In this subsection, alternative geometric modeling approaches are investigated and assessed based on comparisons to the reference HELIOS results.

The main difficulty associated with modeling heterogeneous BWR fuel assemblies with SAS2H involves the representation of both the gadolinium rods and the water rod(s) in a single model. Additionally, explicit representation of the distributed pin enrichments is not possible in the 1-D model, thereby requiring the use of the assembly-average enrichment.

The SMA represents the gadolinium rods by explicitly including one gadolinium rod at the center and reducing the volume of the outer regions by the inverse of the number of gadolinium rods present in the assembly. This approach results in a reasonably good physical representation of a portion of the assembly. However, this approach results in an infinite array of reduced-size assemblies, all of which are bordered by correspondingly reduced-size channels and bypass moderators. Further, the volume of water associated with the water rod, if present, is somewhat arbitrarily added to the bypass moderator. Therefore, attempts have been made to explore alternative modeling variations - some intended to achieve greater physical 
representation; others, to explore trends. These attempts are described in the following subsections.

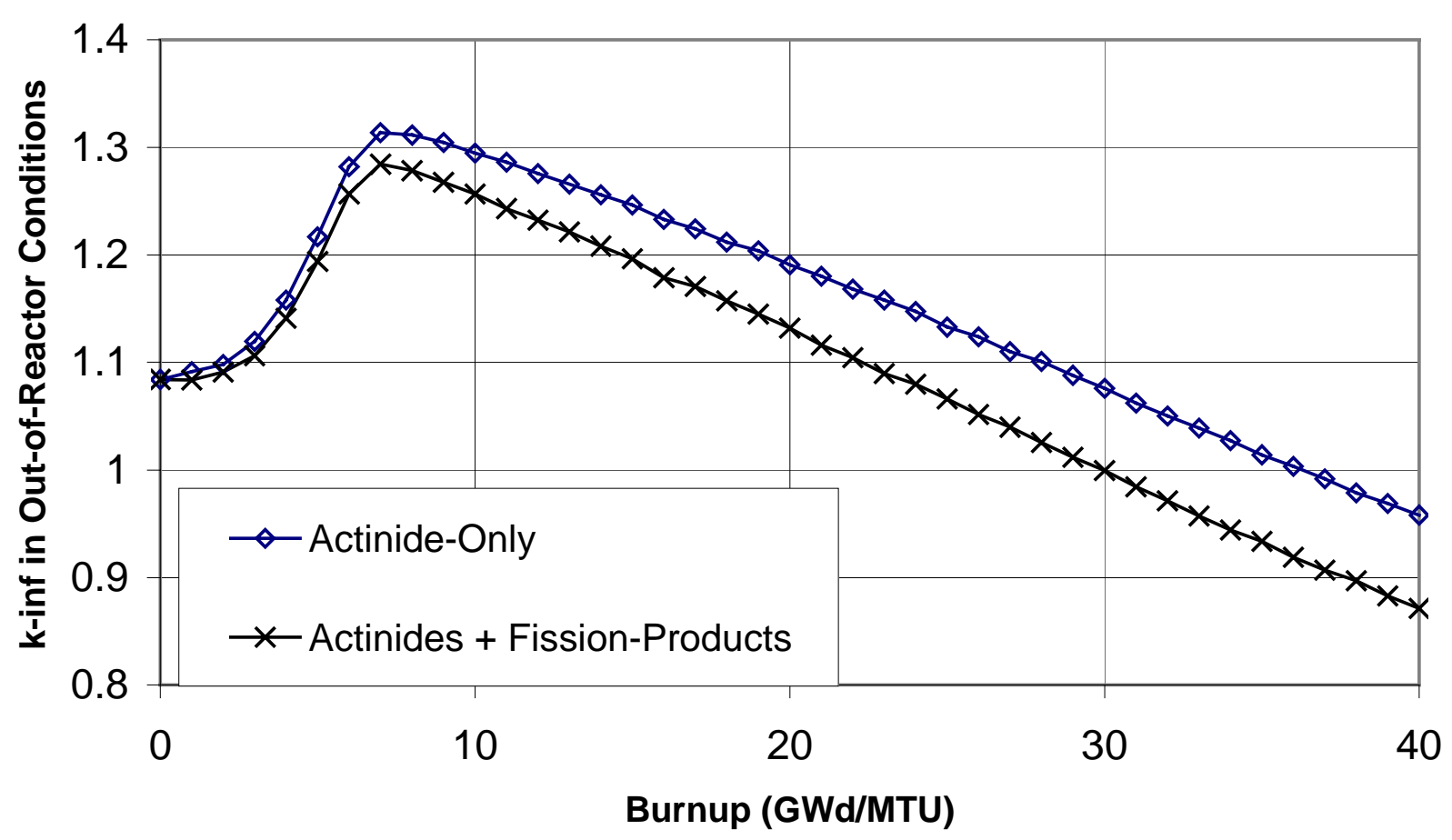

Fig. 4. $k_{i n f}$ as a function of burnup for Assembly ZZ. 


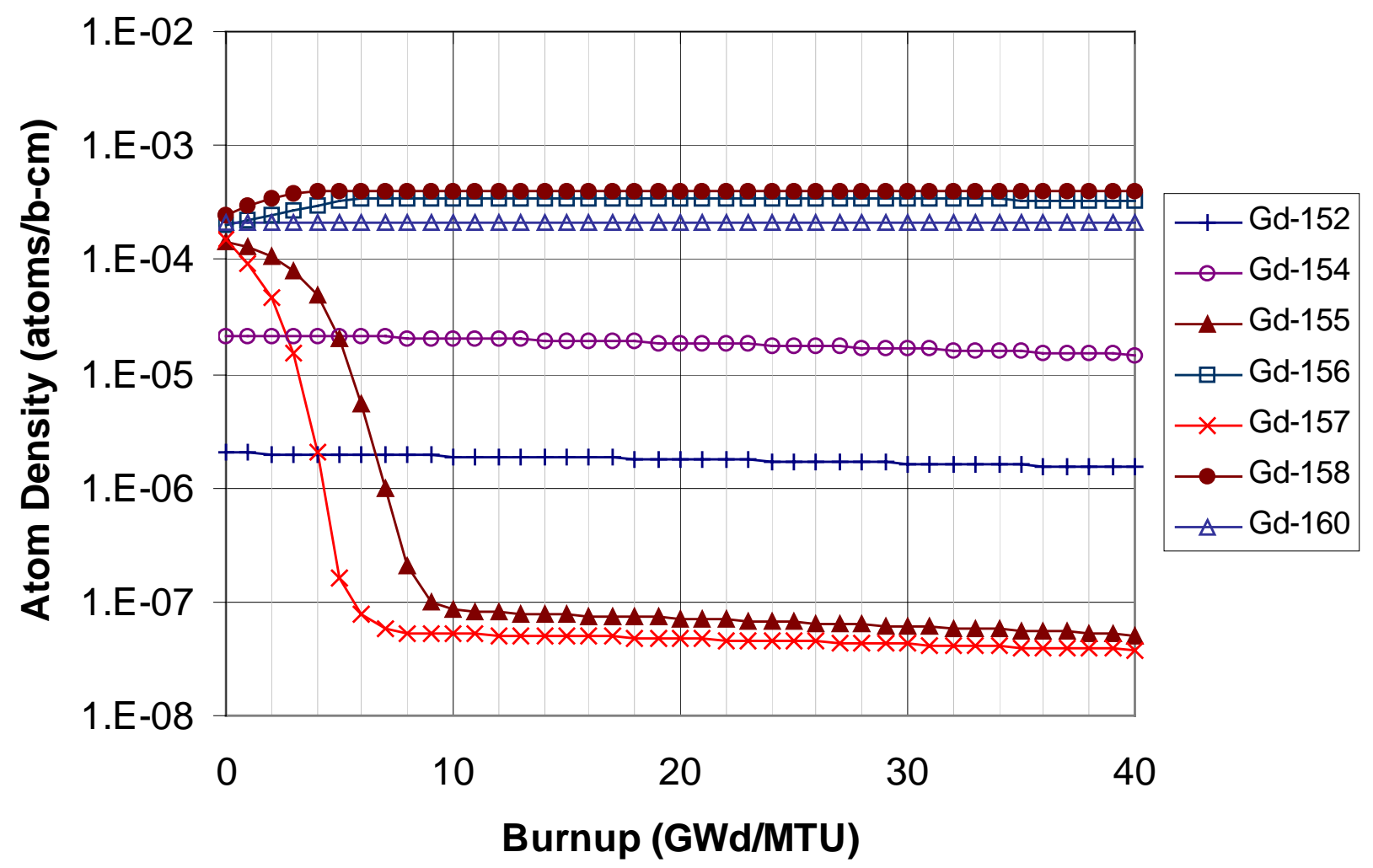

Fig. 5. Atom density of gadolinium isotopes as a function of burnup. 


\subsubsection{Center-water-rod approaches}

In an attempt to preserve the effect of the center water rod in Assembly ZZ and the physical size of the assembly, models were developed with the water rod in the center. Note that while BWR fuel assembly designs vary, the majority of assembly designs include one or more water rods at or near the center. All of the models presented in this subsection include the water rod at the center of the model, surrounded by smeared fuel that represents the total assembly fuel volume, bounded by the channel and bypass moderator. Although variations in this model will be presented, the basic center-water-rod model is shown in Fig. 6.

Although including the water rod at the center of the model allows the entire assembly volume to be included in the Path-B model, thereby approximately preserving the assembly size and outer boundary, it leads to difficulty representing the gadolinium rods. Several model variations were developed with different strategies to include the effect of the gadolinium rods. Within this center-water-rod modeling approach, three general classifications, associated with how the gadolinium rods are modeled, were developed and are described below. For identification purposes, the various models are designated and described in Table 6. Even though these models attempt to more closely represent the assembly, the two- and three-fuelregion models suffer from the fact that, because the gadolinium is not included in the Path-A model, the gadolinium cross sections are not properly self-shielded in the SAS2H calculations. The gadolinium cross sections are properly self-shielded in the SMA and the single-fuel-region models.

\subsection{Single-fuel-region models}

Models 1FR01 and 1FR02 (1 Fuel Region, cases 01 and 02) have single fuel regions, as shown in Fig. 6. The 1FR01 model includes the gadolinium from the nine gadolinium rods by smearing it throughout the fuel region. To investigate the effect of neglecting the gadolinium altogether, the 1FR02 model does not include any gadolinium. The results from these two models for the selected nuclides are listed in Table 7. Percentage differences from the HELIOS results are provided in Table 8 for the selected nuclides and are represented graphically in Figs. 7 and 8 for the important actinides and fission products, respectively. In general, the results from the 1FR01 model show very modest improvements in the agreement with HELIOS in comparison to the SMA results. However, a notable overestimation of ${ }^{155} \mathrm{Gd}$ is observed. As expected, the absence of gadolinium in the 1FR02 model results in a significant increase in the underestimation of ${ }^{235} \mathrm{U}$. However, it is interesting to note that the remaining nuclides, with the exception of ${ }^{155} \mathrm{Gd}$, are not significantly affected. The overestimation of ${ }^{155} \mathrm{Gd}$, which was observed with the 1FR01 model, is not observed with the 1FR02 model, and thus, is apparently related to the homogenization of the gadolinium in the fuel.

Calculated $k_{\text {inf }}$ values, based on the calculated spent fuel isotopics, are compared in the bottom rows of Table 7. For the actinide-only case, the isotopics from the 1FR01 model result in nearly a $1 \%$ overestimation of $k_{\text {inf }}$, as compared with the $k_{\text {inf }}$ result based on isotopics from HELIOS. Because of the notable overestimation of ${ }^{155} \mathrm{Gd}$, the agreement is much better when fission products are included. The large underestimation of ${ }^{235} \mathrm{U}$ by the 1 FR 02 model leads to underestimations in the corresponding $k_{\text {inf }}$ values.

SAS2H input files for models 1FR01 and 1FR02 are provided in Appendix A. 


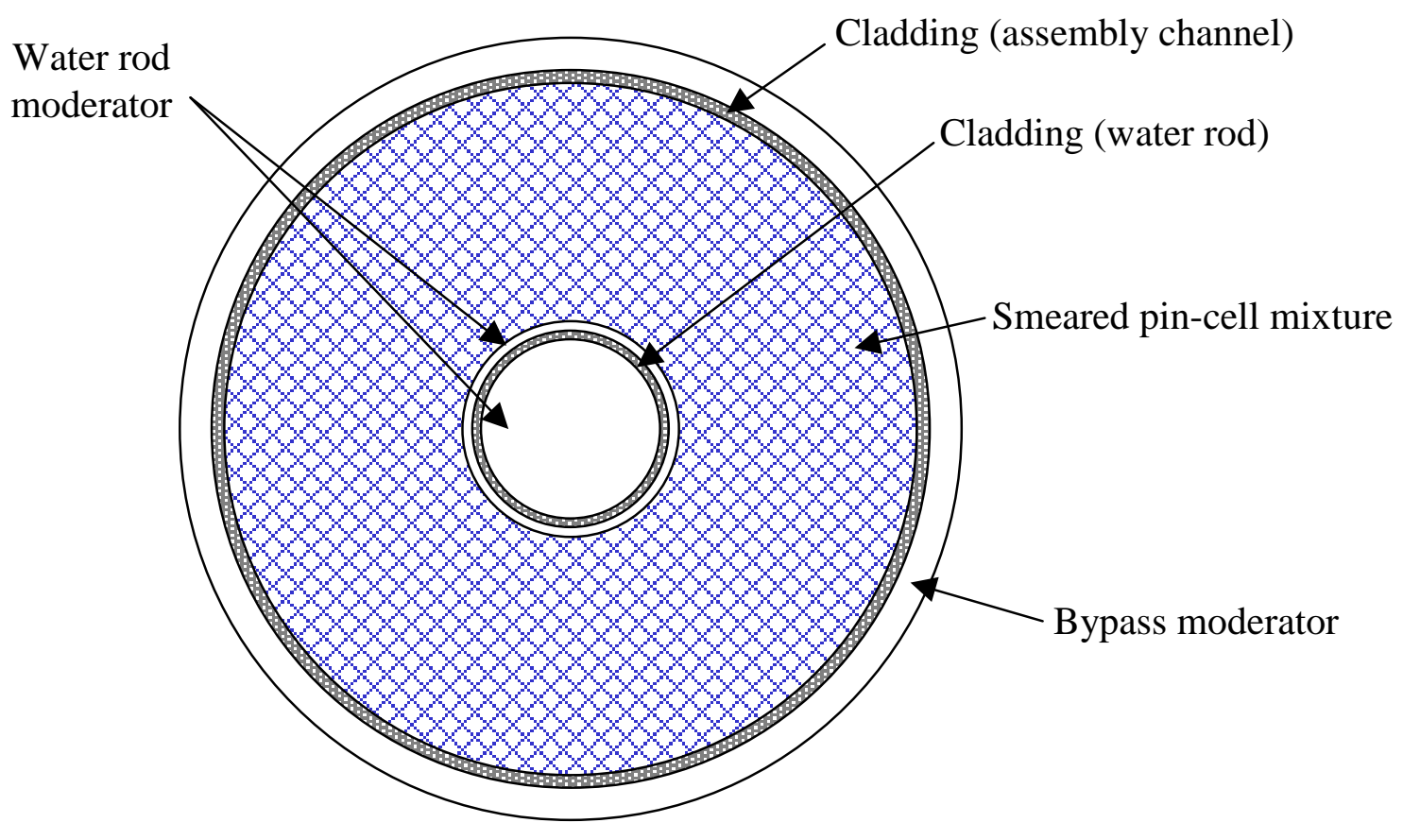

Fig. 6. Basic center-water-rod SAS2H model for Assembly ZZ (not drawn to scale). 
Table 6. Identification of the various SAS2H models discussed in the text ${ }^{a}$

\begin{tabular}{|c|c|}
\hline Model designation & Description \\
\hline SMA & Standard Modeling Approach Model $-\mathrm{UO}_{2} / \mathrm{Gd}_{2} \mathrm{O}_{3}$ rod in the center \\
\hline 1FR01 & $\begin{array}{l}\text { Single-Fuel-Region Model - water rod in the center with the Gd } \\
\text { smeared throughout single fuel region }\end{array}$ \\
\hline 1FR02 & $\begin{array}{l}\text { Single-Fuel-Region Model - water rod in the center, the Gd is not } \\
\text { included in the model }\end{array}$ \\
\hline 2FR01 & $\begin{array}{l}\text { Two-Fuel-Region Model - water rod in the center with Gd included as a } \\
\text { thin cylindrical shell with inner radius corresponding to the equivalent } \\
\text { inner radius of the central fuel "box" }\end{array}$ \\
\hline 2FR02 & $\begin{array}{l}\text { Two-Fuel-Region Model - water rod in the center with Gd included as a } \\
\text { thin cylindrical shell with radial-center corresponding to the equivalent } \\
\text { radial-center of the central fuel "box" }\end{array}$ \\
\hline 2FR03 & $\begin{array}{l}\text { Two-Fuel-Region Model - water rod in the center with Gd included as a } \\
\text { thin cylindrical shell with outer radius corresponding to the equivalent } \\
\text { outer radius of the central fuel "box" }\end{array}$ \\
\hline 3FR01 & $\begin{array}{l}\text { Three-Fuel-Region Model - water rod in the center with Gd smeared } \\
\text { throughout the central cylindrical fuel region, which corresponds to the } \\
\text { central fuel "box" }\end{array}$ \\
\hline
\end{tabular}

${ }^{a}$ See Subsect. 3.2 for additional discussion. 
Table 7. Comparison of calculated nuclide densities (in gram-atoms) from HELIOS and SAS2H with the single-fuel-region models (at 40-GWd/MTU burnup, 5-year cooling time)

\begin{tabular}{|c|c|c|c|}
\hline \multirow{2}{*}{ Nuclide } & \multirow[b]{2}{*}{ HELIOS } & \multicolumn{2}{|c|}{ SAS2H } \\
\hline & & 1FR01 & 1FR02 \\
\hline U-234 & $6.01 \mathrm{E}-01$ & $6.50 \mathrm{E}-01$ & $6.49 \mathrm{E}-01$ \\
\hline U-235 & $1.69 \mathrm{E}+01$ & $1.61 \mathrm{E}+01$ & $1.52 \mathrm{E}+01$ \\
\hline $\mathrm{U}-236$ & $1.88 \mathrm{E}+01$ & $1.92 \mathrm{E}+01$ & $1.91 \mathrm{E}+01$ \\
\hline $\mathrm{U}-238$ & $3.90 \mathrm{E}+03$ & $3.97 \mathrm{E}+03$ & $3.97 \mathrm{E}+03$ \\
\hline $\mathrm{Pu}-238$ & $5.85 \mathrm{E}-01$ & $6.67 \mathrm{E}-01$ & $6.63 \mathrm{E}-01$ \\
\hline $\mathrm{Pu}-239$ & $1.43 \mathrm{E}+01$ & $1.52 \mathrm{E}+01$ & $1.51 \mathrm{E}+01$ \\
\hline $\mathrm{Pu}-240$ & $1.01 \mathrm{E}+01$ & $1.04 \mathrm{E}+01$ & $1.04 \mathrm{E}+01$ \\
\hline $\mathrm{Pu}-241$ & $3.03 \mathrm{E}+00$ & $3.23 \mathrm{E}+00$ & $3.19 \mathrm{E}+00$ \\
\hline $\mathrm{Pu}-242$ & $2.80 \mathrm{E}+00$ & $3.16 \mathrm{E}+00$ & $3.16 \mathrm{E}+00$ \\
\hline Am-241 & $9.36 \mathrm{E}-01$ & $1.00 \mathrm{E}+00$ & $9.88 \mathrm{E}-01$ \\
\hline Am-242m & $1.59 \mathrm{E}-03$ & $1.97 \mathrm{E}-03$ & $1.90 \mathrm{E}-03$ \\
\hline Am-243 & $4.86 \mathrm{E}-01$ & $6.06 \mathrm{E}-01$ & $6.04 \mathrm{E}-01$ \\
\hline $\mathrm{Np}-237$ & $1.46 \mathrm{E}+00$ & $1.77 \mathrm{E}+00$ & $1.77 \mathrm{E}+00$ \\
\hline Mo-95 & $9.34 \mathrm{E}+00$ & $9.62 \mathrm{E}+00$ & $9.67 \mathrm{E}+00$ \\
\hline Tc-99 & $9.35 \mathrm{E}+00$ & $9.59 \mathrm{E}+00$ & $9.62 \mathrm{E}+00$ \\
\hline $\mathrm{Ru}-101$ & $9.10 \mathrm{E}+00$ & $9.24 \mathrm{E}+00$ & $9.27 \mathrm{E}+00$ \\
\hline $\mathrm{Rh}-103$ & $5.03 \mathrm{E}+00$ & $5.22 \mathrm{E}+00$ & $5.20 \mathrm{E}+00$ \\
\hline Ag-109 & $8.70 \mathrm{E}-01$ & $1.01 \mathrm{E}+00$ & $1.01 \mathrm{E}+00$ \\
\hline Sm-147 & $1.66 \mathrm{E}+00$ & $1.67 \mathrm{E}+00$ & $1.67 \mathrm{E}+00$ \\
\hline Sm-149 & $1.65 \mathrm{E}-02$ & $1.78 \mathrm{E}-02$ & $1.76 \mathrm{E}-02$ \\
\hline Sm-150 & $2.15 \mathrm{E}+00$ & $2.52 \mathrm{E}+00$ & $2.53 \mathrm{E}+00$ \\
\hline Sm-151 & $5.45 \mathrm{E}-02$ & $6.89 \mathrm{E}-02$ & $6.81 \mathrm{E}-02$ \\
\hline Sm-152 & $1.08 \mathrm{E}+00$ & $1.13 \mathrm{E}+00$ & $1.14 \mathrm{E}+00$ \\
\hline Nd-143 & $5.24 \mathrm{E}+00$ & $5.44 \mathrm{E}+00$ & $5.38 \mathrm{E}+00$ \\
\hline Nd-145 & $5.35 \mathrm{E}+00$ & $5.50 \mathrm{E}+00$ & $5.52 \mathrm{E}+00$ \\
\hline Eu-151 & $2.18 \mathrm{E}-03$ & $2.76 \mathrm{E}-03$ & $2.72 \mathrm{E}-03$ \\
\hline Eu-153 & $8.63 \mathrm{E}-01$ & $9.71 \mathrm{E}-01$ & $9.67 \mathrm{E}-01$ \\
\hline Gd-155 & $2.22 \mathrm{E}-02$ & $2.61 \mathrm{E}-02$ & $2.47 \mathrm{E}-02$ \\
\hline$k_{i n f}$ & HELIOS & 1FR01 & 1FR02 \\
\hline Actinide-only & $0.93549(0.00028)^{a}$ & $0.94364(0.00034)$ & $0.93389(0.00036)$ \\
\hline $\begin{array}{l}\text { Actinide }+ \text { fission } \\
\text { products }\end{array}$ & $0.83696(0.00030)$ & $0.83830(0.00026)$ & $0.82917(0.00030)$ \\
\hline
\end{tabular}

${ }^{a}$ Numbers in parentheses are $1-\sigma$ uncertainties. 
Table 8. Percentage differences (relative to HELIOS) in calculated nuclide densities from SAS2H with the standard modeling approach and the single-fuel-region models (at 40-GWd/MTU burnup, 5-year cooling time)

\begin{tabular}{|c|c|c|c|}
\hline Nuclide & SMA & 1FR01 & 1FR02 \\
\hline U-234 & $7.57 \%$ & $8.03 \%$ & $7.98 \%$ \\
\hline U-235 & $-4.81 \%$ & $-4.65 \%$ & $-10.47 \%$ \\
\hline U-236 & $2.20 \%$ & $2.06 \%$ & $1.81 \%$ \\
\hline U-238 & $1.79 \%$ & $1.66 \%$ & $1.81 \%$ \\
\hline $\mathrm{Pu}-238$ & $16.24 \%$ & $13.99 \%$ & $13.38 \%$ \\
\hline $\mathrm{Pu}-239$ & $6.20 \%$ & $6.21 \%$ & $5.27 \%$ \\
\hline $\mathrm{Pu}-240$ & $2.66 \%$ & $3.04 \%$ & $2.80 \%$ \\
\hline $\mathrm{Pu}-241$ & $7.44 \%$ & $6.40 \%$ & $5.22 \%$ \\
\hline $\mathrm{Pu}-242$ & $14.68 \%$ & $12.92 \%$ & $12.99 \%$ \\
\hline Am-241 & $8.12 \%$ & $7.06 \%$ & $5.58 \%$ \\
\hline Am-242m & $26.48 \%$ & $24.35 \%$ & $19.61 \%$ \\
\hline Am-243 & $27.16 \%$ & $24.80 \%$ & $24.32 \%$ \\
\hline $\mathrm{Np}-237$ & $23.03 \%$ & $21.69 \%$ & $21.37 \%$ \\
\hline Mo-95 & $3.20 \%$ & $2.97 \%$ & $3.50 \%$ \\
\hline Tc-99 & $2.58 \%$ & $2.52 \%$ & $2.88 \%$ \\
\hline $\mathrm{Ru}-101$ & $1.77 \%$ & $1.49 \%$ & $1.92 \%$ \\
\hline Rh-103 & $3.63 \%$ & $3.73 \%$ & $3.34 \%$ \\
\hline Ag-109 & $16.59 \%$ & $16.26 \%$ & $16.20 \%$ \\
\hline Sm-147 & $-0.07 \%$ & $0.50 \%$ & $0.16 \%$ \\
\hline Sm-149 & $7.93 \%$ & $7.67 \%$ & $6.88 \%$ \\
\hline Sm-150 & $17.59 \%$ & $17.09 \%$ & $17.47 \%$ \\
\hline Sm-151 & $26.23 \%$ & $26.32 \%$ & $24.89 \%$ \\
\hline Sm-152 & $4.88 \%$ & $5.24 \%$ & $5.59 \%$ \\
\hline $\mathrm{Nd}-143$ & $3.90 \%$ & $3.71 \%$ & $2.64 \%$ \\
\hline $\mathrm{Nd}-145$ & $2.99 \%$ & $2.82 \%$ & $3.16 \%$ \\
\hline Eu-151 & $26.24 \%$ & $26.33 \%$ & $24.84 \%$ \\
\hline Eu-153 & $12.21 \%$ & $12.49 \%$ & $11.99 \%$ \\
\hline Gd-155 & $10.97 \%$ & $17.79 \%$ & $11.24 \%$ \\
\hline
\end{tabular}




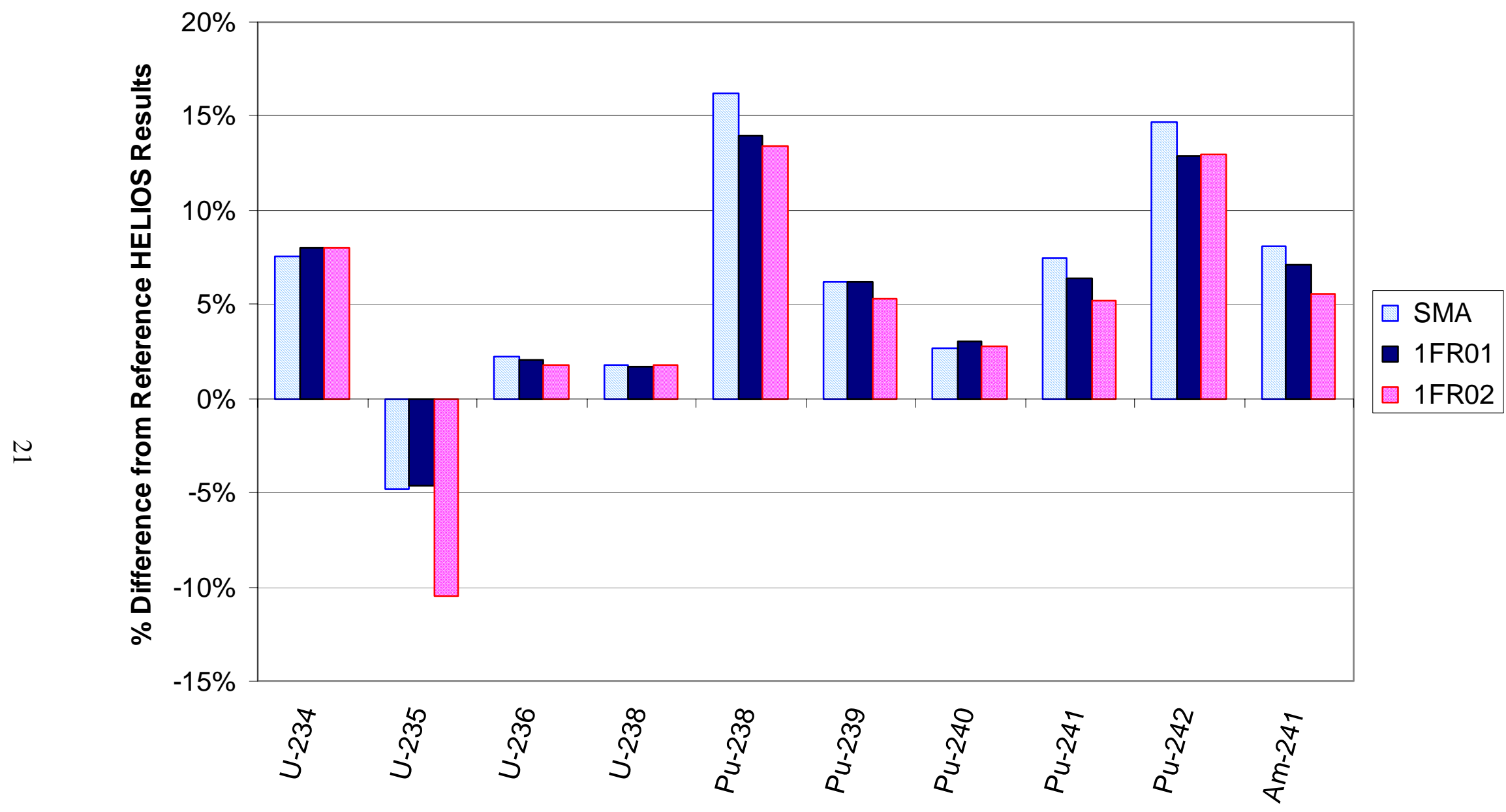

Fig. 7. Percentage differences (relative to HELIOS) between SAS2H and HELIOS calculated actinide densities for the single-fuel-region models at 40-GWd/MTU burnup and 5-year cooling time (SMA results included for comparison). 


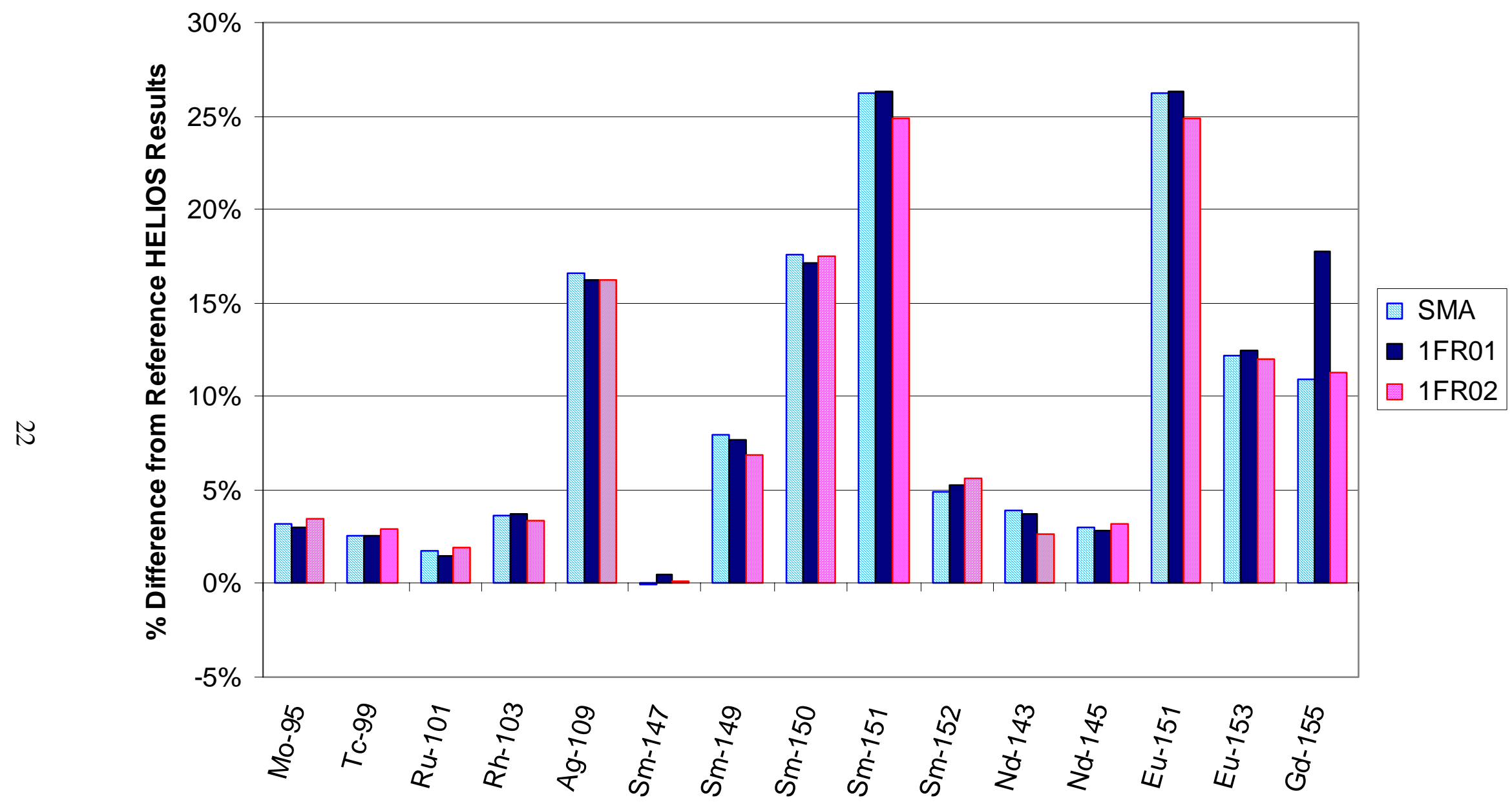

Fig. 8. Percentage differences (relative to HELIOS) between SAS2H and HELIOS calculated fission-product densities for the single-fuel-region models at 40-GWd/MTU burnup and 5-year cooling time (SMA results included for comparison). 


\subsection{Two-fuel-region models}

Models 2FR01 through 2FR03 (2 Fuel Regions, cases 01 through 03) each have two smeared fuel regions, separated by a thin cylindrical shell of $\mathrm{Gd}_{2} \mathrm{O}_{3}$, the dimensions of which are based on the volume of $\mathrm{Gd}_{2} \mathrm{O}_{3}$ in the nine gadolinium rods. The volume of the gadolinium shell is constant in all models. The basic model is illustrated in Fig. 9. The only difference between the three models is the radial placement of the gadolinium shell.

Examination of fuel Assembly ZZ, shown in Fig. 1, reveals that the assembly can be described as a center water rod, taking the place of 4 unit-cells, surrounded by three "boxes" of fuel rods, which contain 12, 20, and 28 fuel rods, respectively. All but 1 of the gadolinium rods are located in the center "box" of fuel rods. Thus, the gadolinium shell position in the SAS2H model should correspond to this region. Based on the pin-cell size and the number of fuel rods in each "box" of the assembly, the equivalent radii of the fuel boxes were calculated. Models 2FR01, 2FR02, and 2FR03 include the gadolinium ring at the inner surface, effective radialcenter, and outer surface of the center ring of fuel, respectively.

Results from these three models for the selected nuclides are listed in Table 9. Percentage differences from the HELIOS results are provided in Table 10 for the selected nuclides. For comparison purposes, Table 10 also lists the percentage difference from the HELIOS results for the SMA results. The percentage differences for the important actinides and fission products are represented graphically in Figs. 10 and 11, respectively. The following conclusions may be drawn from these results: (1) the values from the 2FR models show very close agreement with the SMA values, (2) the values from the three different 2FR models are nearly identical, indicating little sensitivity to the location of the gadolinium shell (within the fuel region), and (3) ${ }^{235} \mathrm{U}$ appears to increase (albeit by a very small amount) as the gadolinium shell is moved outward.

Calculated $k_{\text {inf }}$ values, based on the calculated spent fuel isotopics, are compared in the bottom rows of Table 9 . In all cases, the agreement is within approximately $0.3 \%$, as compared to the $k_{\text {inf }}$ values based on isotopics from HELIOS (see Table 4). Therefore, for this burnup- and cooling-time combination, the two-fuel-region models yield good agreement similar to that obtained with the SMA model.

SAS2H input files for two-fuel-region models are provided in Appendix A. 


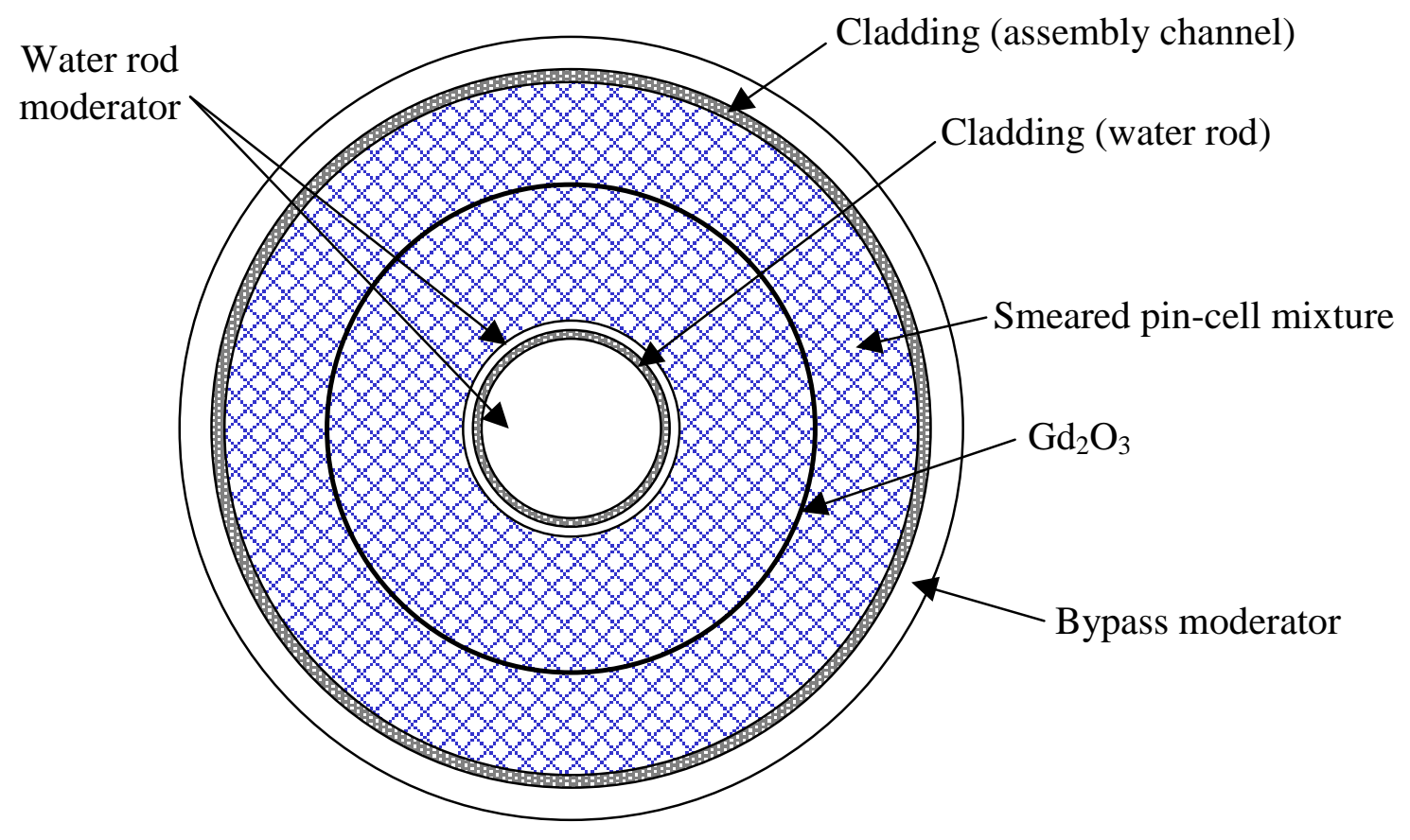

Fig. 9. Two-fuel-region SAS2H model for Assembly ZZ (not drawn to scale). 
Table 9. Calculated nuclide densities (in gram-atoms) from SAS2H with the two-fuel-region models (at 40-GWd/MTU burnup, 5-year cooling time)

\begin{tabular}{|c|c|c|c|}
\hline Nuclide & 2FR01 & 2FR02 & 2FR03 \\
\hline $\mathrm{U}-234$ & $6.50 \mathrm{E}-01$ & $6.50 \mathrm{E}-01$ & $6.50 \mathrm{E}-01$ \\
\hline U-235 & $1.61 \mathrm{E}+01$ & $1.62 \mathrm{E}+01$ & $1.63 \mathrm{E}+01$ \\
\hline $\mathrm{U}-236$ & $1.92 \mathrm{E}+01$ & $1.92 \mathrm{E}+01$ & $1.92 \mathrm{E}+01$ \\
\hline $\mathrm{U}-238$ & $3.97 \mathrm{E}+03$ & $3.97 \mathrm{E}+03$ & $3.97 \mathrm{E}+03$ \\
\hline $\mathrm{Pu}-238$ & $6.72 \mathrm{E}-01$ & $6.73 \mathrm{E}-01$ & $6.73 \mathrm{E}-01$ \\
\hline $\mathrm{Pu}-239$ & $1.52 \mathrm{E}+01$ & $1.52 \mathrm{E}+01$ & $1.52 \mathrm{E}+01$ \\
\hline $\mathrm{Pu}-240$ & $1.05 \mathrm{E}+01$ & $1.05 \mathrm{E}+01$ & $1.05 \mathrm{E}+01$ \\
\hline $\mathrm{Pu}-241$ & $3.24 \mathrm{E}+00$ & $3.24 \mathrm{E}+00$ & $3.24 \mathrm{E}+00$ \\
\hline $\mathrm{Pu}-242$ & $3.18 \mathrm{E}+00$ & $3.18 \mathrm{E}+00$ & $3.18 \mathrm{E}+00$ \\
\hline Am-241 & $1.01 \mathrm{E}+00$ & $1.01 \mathrm{E}+00$ & $1.01 \mathrm{E}+00$ \\
\hline Am-242m & $1.99 \mathrm{E}-03$ & $1.99 \mathrm{E}-03$ & $2.00 \mathrm{E}-03$ \\
\hline Am-243 & $6.10 \mathrm{E}-01$ & $6.11 \mathrm{E}-01$ & $6.11 \mathrm{E}-01$ \\
\hline $\mathrm{Np}-237$ & $1.78 \mathrm{E}+00$ & $1.78 \mathrm{E}+00$ & $1.78 \mathrm{E}+00$ \\
\hline Mo-95 & $9.64 \mathrm{E}+00$ & $9.64 \mathrm{E}+00$ & $9.64 \mathrm{E}+00$ \\
\hline Tc-99 & $9.61 \mathrm{E}+00$ & $9.61 \mathrm{E}+00$ & $9.61 \mathrm{E}+00$ \\
\hline Ru-101 & $9.26 \mathrm{E}+00$ & $9.26 \mathrm{E}+00$ & $9.26 \mathrm{E}+00$ \\
\hline $\mathrm{Rh}-103$ & $5.23 \mathrm{E}+00$ & $5.23 \mathrm{E}+00$ & $5.24 \mathrm{E}+00$ \\
\hline Ag-109 & $1.02 \mathrm{E}+00$ & $1.02 \mathrm{E}+00$ & $1.02 \mathrm{E}+00$ \\
\hline Sm-147 & $1.68 \mathrm{E}+00$ & $1.68 \mathrm{E}+00$ & $1.68 \mathrm{E}+00$ \\
\hline Sm-149 & $1.78 \mathrm{E}-02$ & $1.78 \mathrm{E}-02$ & $1.78 \mathrm{E}-02$ \\
\hline Sm-150 & $2.53 \mathrm{E}+00$ & $2.53 \mathrm{E}+00$ & $2.53 \mathrm{E}+00$ \\
\hline Sm-151 & $6.90 \mathrm{E}-02$ & $6.90 \mathrm{E}-02$ & $6.91 \mathrm{E}-02$ \\
\hline Sm-152 & $1.14 \mathrm{E}+00$ & $1.14 \mathrm{E}+00$ & $1.14 \mathrm{E}+00$ \\
\hline $\mathrm{Nd}-143$ & $5.45 \mathrm{E}+00$ & $5.46 \mathrm{E}+00$ & $5.46 \mathrm{E}+00$ \\
\hline $\mathrm{Nd}-145$ & $5.51 \mathrm{E}+00$ & $5.51 \mathrm{E}+00$ & $5.51 \mathrm{E}+00$ \\
\hline Eu-151 & $2.76 \mathrm{E}-03$ & $2.76 \mathrm{E}-03$ & $2.77 \mathrm{E}-03$ \\
\hline Eu-153 & $9.65 \mathrm{E}-01$ & $9.64 \mathrm{E}-01$ & $9.64 \mathrm{E}-01$ \\
\hline Gd-155 & $2.46 \mathrm{E}-02$ & $2.46 \mathrm{E}-02$ & $2.46 \mathrm{E}-02$ \\
\hline$k_{i n f}$ & 2FR01 & 2FR02 & 2FR03 \\
\hline Actinide-only & $0.93712(0.00030)^{a}$ & $0.93821(0.00037)$ & $0.93869(0.00033)$ \\
\hline $\begin{array}{l}\text { Actinide }+ \text { fission } \\
\text { products }\end{array}$ & $0.83394(0.00031)$ & $0.83439(0.00026)$ & $0.83592(0.00034)$ \\
\hline
\end{tabular}

\footnotetext{
${ }^{a}$ Numbers in parentheses are $1-\sigma$ uncertainties.
} 
Table 10. Percentage differences (relative to HELIOS) in calculated nuclide densities from SAS2H with the standard modeling approach and the two-fuel-region models (at 40-GWd/MTU burnup, 5-year cooling time)

\begin{tabular}{|c|c|c|c|c|}
\hline Nuclide & SMA & 2FR01 & 2FR02 & 2FR03 \\
\hline U-234 & $7.57 \%$ & $8.17 \%$ & $8.17 \%$ & $8.19 \%$ \\
\hline U-235 & $-4.81 \%$ & $-4.61 \%$ & $-4.19 \%$ & $-3.71 \%$ \\
\hline U-236 & $2.20 \%$ & $2.19 \%$ & $2.25 \%$ & $2.31 \%$ \\
\hline $\mathrm{U}-238$ & $1.79 \%$ & $1.79 \%$ & $1.79 \%$ & $1.79 \%$ \\
\hline $\mathrm{Pu}-238$ & $16.24 \%$ & $14.95 \%$ & $14.97 \%$ & $14.98 \%$ \\
\hline $\mathrm{Pu}-239$ & $6.20 \%$ & $6.34 \%$ & $6.40 \%$ & $6.47 \%$ \\
\hline $\mathrm{Pu}-240$ & $2.66 \%$ & $3.44 \%$ & $3.47 \%$ & $3.48 \%$ \\
\hline $\mathrm{Pu}-241$ & $7.44 \%$ & $6.73 \%$ & $6.80 \%$ & $6.89 \%$ \\
\hline $\mathrm{Pu}-242$ & $14.68 \%$ & $13.57 \%$ & $13.63 \%$ & $13.65 \%$ \\
\hline Am-241 & $8.12 \%$ & $7.44 \%$ & $7.54 \%$ & $7.66 \%$ \\
\hline Am-242m & $26.48 \%$ & $25.19 \%$ & $25.56 \%$ & $25.94 \%$ \\
\hline Am-243 & $27.16 \%$ & $25.65 \%$ & $25.81 \%$ & $25.90 \%$ \\
\hline $\mathrm{Np}-237$ & $23.03 \%$ & $22.20 \%$ & $22.21 \%$ & $22.22 \%$ \\
\hline Mo-95 & $3.20 \%$ & $3.22 \%$ & $3.20 \%$ & $3.17 \%$ \\
\hline Tc-99 & $2.58 \%$ & $2.77 \%$ & $2.77 \%$ & $2.76 \%$ \\
\hline $\mathrm{Ru}-101$ & $1.77 \%$ & $1.78 \%$ & $1.78 \%$ & $1.76 \%$ \\
\hline Rh-103 & $3.63 \%$ & $4.03 \%$ & $4.08 \%$ & $4.13 \%$ \\
\hline Ag-109 & $16.59 \%$ & $16.77 \%$ & $16.82 \%$ & $16.85 \%$ \\
\hline Sm-147 & $-0.07 \%$ & $0.66 \%$ & $0.73 \%$ & $0.79 \%$ \\
\hline Sm-149 & $7.93 \%$ & $7.70 \%$ & $7.75 \%$ & $7.83 \%$ \\
\hline Sm-150 & $17.59 \%$ & $17.37 \%$ & $17.33 \%$ & $17.27 \%$ \\
\hline Sm-151 & $26.23 \%$ & $26.52 \%$ & $26.60 \%$ & $26.69 \%$ \\
\hline Sm-152 & $4.88 \%$ & $5.56 \%$ & $5.55 \%$ & $5.53 \%$ \\
\hline $\mathrm{Nd}-143$ & $3.90 \%$ & $3.96 \%$ & $4.04 \%$ & $4.13 \%$ \\
\hline Nd-145 & $2.99 \%$ & $3.07 \%$ & $3.07 \%$ & $3.06 \%$ \\
\hline $\mathrm{Eu}-151$ & $26.24 \%$ & $26.54 \%$ & $26.62 \%$ & $26.71 \%$ \\
\hline Eu-153 & $12.21 \%$ & $11.72 \%$ & $11.70 \%$ & $11.67 \%$ \\
\hline Gd-155 & $10.97 \%$ & $10.88 \%$ & $10.83 \%$ & $10.72 \%$ \\
\hline
\end{tabular}




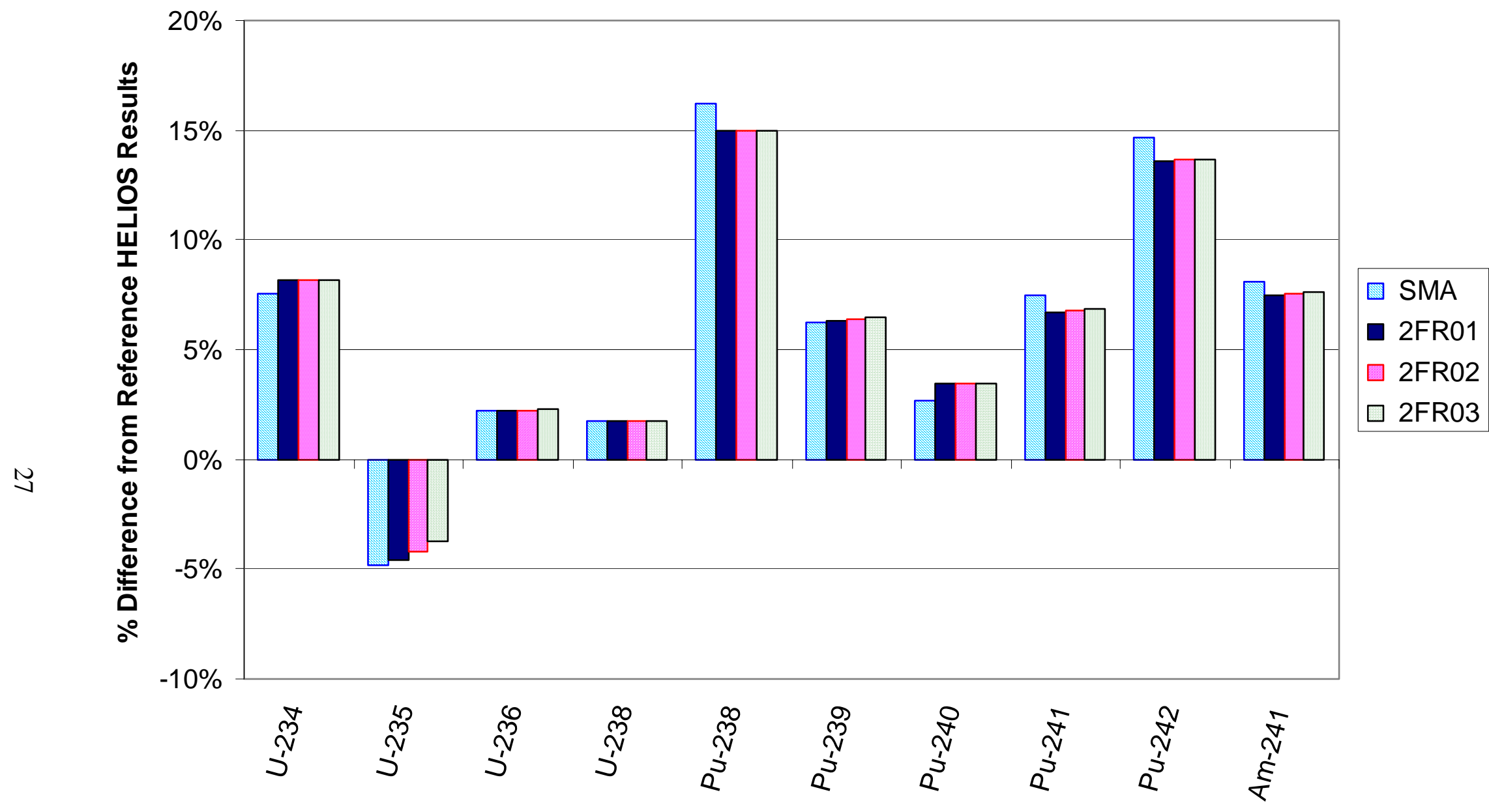

Fig. 10. Percentage differences (relative to HELIOS) between SAS2H and HELIOS calculated actinide densities for the two-fuel-region models at 40-GWd/MTU burnup and 5-year cooling time (SMA results included for comparison). 


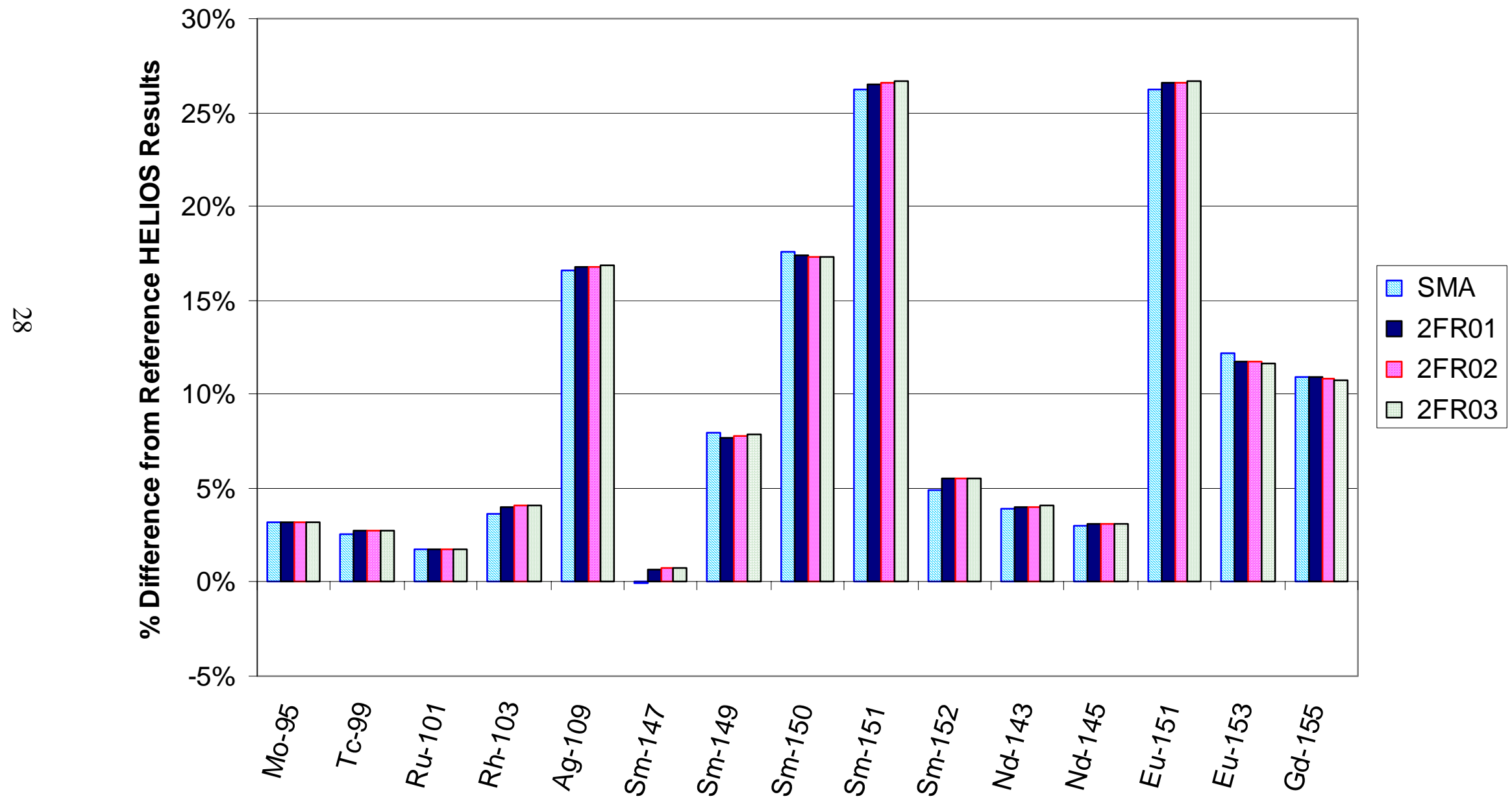

Fig. 11. Percentage differences (relative to HELIOS) between SAS2H and HELIOS calculated fission-product densities for the two-fuel-region models at 40-GWd/MTU burnup and 5-year cooling time (SMA results included for comparison). 


\subsection{Three-fuel-region model}

This approach attempts to exploit a little known feature of SAS2H, namely, the ability to include alternative mixtures within a fuel region that will be depleted through the use of material Nos. 50-59 $\stackrel{8}{.}$ This capability allows additional flexibility for spatial arrangement and, thus, may be used in attempts to better estimate the average flux (computed by XSDRNPM) that is utilized in ORIGEN-S. However, ORIGEN-S uses only one fuel material, one set of fission products, and one set of light elements. Thus, the materials entered in a material number between 50 and 59 are lumped in with the fuel in mixture 500, and the materials are depleted together. The caveat with this capability is that in using a mixture between 50 and 59, the cross sections for those materials are being weighted by the spectrum of the pin-cell. In the case of fission products or weak absorber materials, this weighting should not introduce significant error. However, for a normal gadolinium rod, the absorption is so strong that it has a significant effect on the flux, and cross sections are not self-shielded correctly when weighted by the pin-cell flux. Thus, the viability of this approach is explored in this subsection.

In an effort to more closely preserve the physical characteristics of the actual fuel assembly, the 50-59 material feature was used to divide the fuel region into three distinct regions, namely, three fuel regions corresponding to the three fuel "boxes," with the gadolinium smeared throughout the center fuel region. The model is illustrated in Fig. 12, and the SAS2H input file is provided in Appendix A.

Results from this model for selected nuclides are given in Table 11, along with the percentage differences between the two (SAS2H relative to HELIOS). Percentage difference results from the SMA are also listed for comparison. As with the previous modeling approaches, the 3FR results are in close agreement with the SMA results, and thus, do not show any significant improvement relative to the SMA. The effect of improper gadolinium self-shielding on the calculated isotopics, at this relatively high burnup, appears to be minimal. However, the effect is expected to be more significant at lower burnups, where the gadolinium is still present. The behavior for lower burnups is investigated in Subsection 3.2.3. Calculated $k_{\text {inf }}$ values, based on the calculated spent fuel isotopics, are listed in the bottom rows of Table 11. The agreement is within a few-tenths of a percent, as compared to the $k_{\text {inf }}$ values based on isotopics from HELIOS. Therefore, for this burnup and cooling-time combination, the three-fuel-region model also yields fairly good agreement, similar to that obtained with the SMA model.

\subsubsection{Corrections to the SAS2H sequence}

During the course of this modeling investigation, two errors were identified in the SAS2H sequence in SCALE version 4.4. The first error was exposed by the modeling approach involving two fuel regions divided by a cylindrical gadolinium shell. Specifically, the presence of two fuel regions (in SAS2H terminology, two 500 regions) resulted in an improper adjustment to the light-element material masses in the ORIGEN-S portion of the SAS2H sequence. The materials were being improperly increased (by the ratio of the total fuel volume over the volume of fuel in the outermost fuel region) in the transition from XSDRNPM to ORIGEN-S. Because the gadolinium is included in the light-element materials, this error resulted in a significant (about a factor of 2) increase in the amount of gadolinium included in the ORIGEN-S model. 


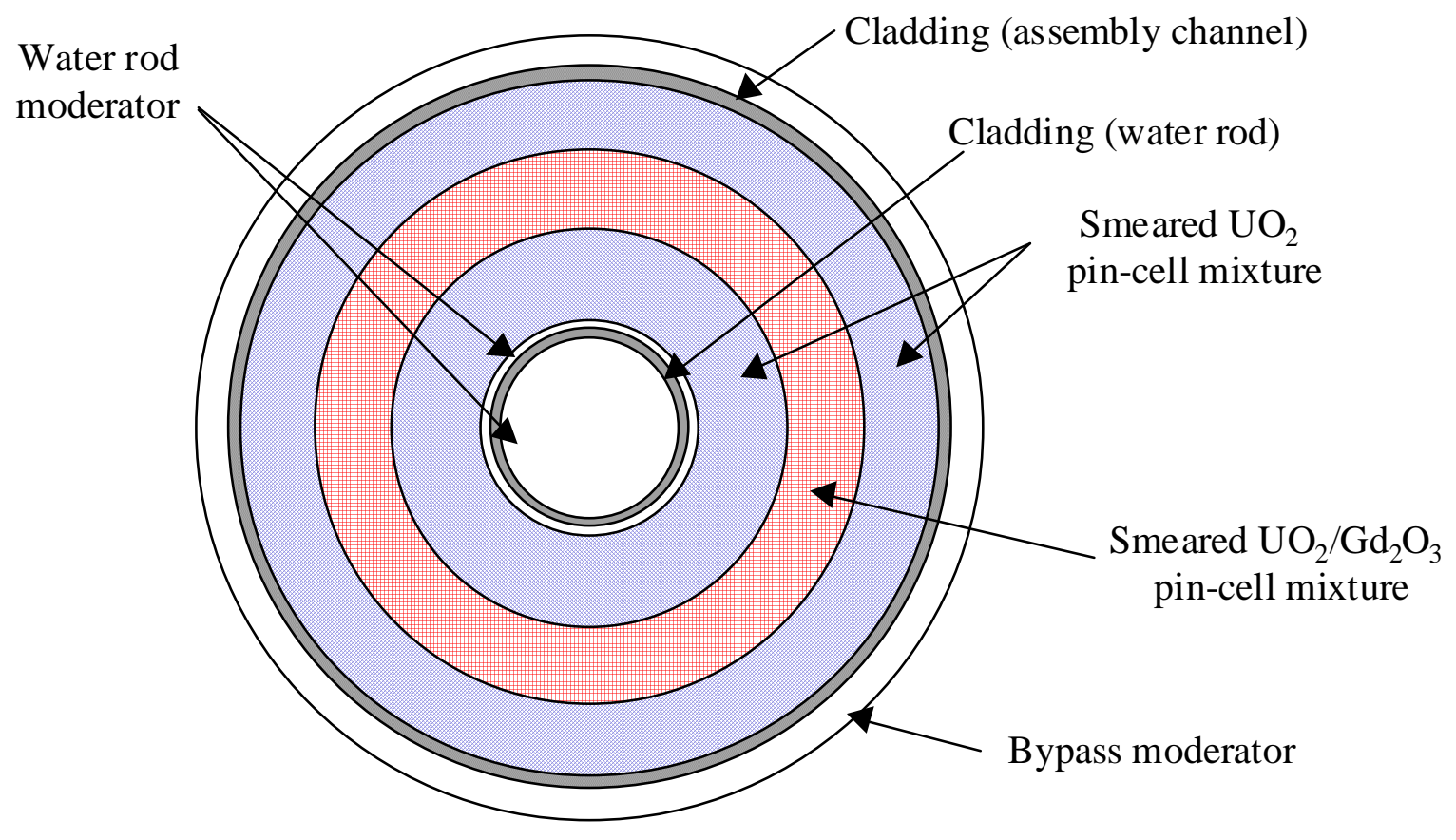

Fig. 12. Three-fuel-region SAS2H model for Assembly ZZ (not drawn to scale). 
Table 11. Calculated nuclide densities (in gram-atoms) from SAS2H with the three-fuel-region model and percentage differences relative to HELIOS (at 40-GWd/MTU burnup, 5-year cooling time)

\begin{tabular}{|c|c|c|c|}
\hline \multirow[b]{2}{*}{ Nuclide } & \multirow{2}{*}{$\begin{array}{c}\text { Nuclide density } \\
\text { (in gram-atoms) }\end{array}$} & \multicolumn{2}{|c|}{$\begin{array}{l}\text { Percentage difference } \\
\text { (relative to HELIOS) }\end{array}$} \\
\hline & & 3FR01 & SMA \\
\hline $\mathrm{U}-234$ & $6.51 \mathrm{E}-01$ & $8.22 \%$ & $7.57 \%$ \\
\hline $\mathrm{U}-235$ & $1.64 \mathrm{E}+01$ & $-3.33 \%$ & $-4.81 \%$ \\
\hline $\mathrm{U}-236$ & $1.92 \mathrm{E}+01$ & $2.36 \%$ & $2.20 \%$ \\
\hline $\mathrm{U}-238$ & $3.97 \mathrm{E}+03$ & $1.79 \%$ & $1.79 \%$ \\
\hline $\mathrm{Pu}-238$ & $6.72 \mathrm{E}-01$ & $14.84 \%$ & $16.24 \%$ \\
\hline $\mathrm{Pu}-239$ & $1.53 \mathrm{E}+01$ & $6.55 \%$ & $6.20 \%$ \\
\hline $\mathrm{Pu}-240$ & $1.05 \mathrm{E}+01$ & $3.45 \%$ & $2.66 \%$ \\
\hline $\mathrm{Pu}-241$ & $3.24 \mathrm{E}+00$ & $6.93 \%$ & $7.44 \%$ \\
\hline $\mathrm{Pu}-242$ & $3.18 \mathrm{E}+00$ & $13.56 \%$ & $14.68 \%$ \\
\hline Am-241 & $1.01 \mathrm{E}+00$ & $7.70 \%$ & $8.12 \%$ \\
\hline Am-242m & $2.00 \mathrm{E}-03$ & $26.14 \%$ & $26.48 \%$ \\
\hline Am-243 & $6.11 \mathrm{E}-01$ & $25.84 \%$ & $27.16 \%$ \\
\hline Np-237 & $1.78 \mathrm{E}+00$ & $22.18 \%$ & $23.03 \%$ \\
\hline Мo-95 & $9.64 \mathrm{E}+00$ & $3.12 \%$ & $3.20 \%$ \\
\hline Tc-99 & $9.61 \mathrm{E}+00$ & $2.73 \%$ & $2.58 \%$ \\
\hline Ru-101 & $9.25 \mathrm{E}+00$ & $1.71 \%$ & $1.77 \%$ \\
\hline Rh-103 & $5.24 \mathrm{E}+00$ & $4.13 \%$ & $3.63 \%$ \\
\hline Ag-109 & $1.02 \mathrm{E}+00$ & $16.79 \%$ & $16.59 \%$ \\
\hline Sm-147 & $1.68 \mathrm{E}+00$ & $0.82 \%$ & $-0.07 \%$ \\
\hline Sm-149 & $1.78 \mathrm{E}-02$ & $7.88 \%$ & $7.93 \%$ \\
\hline Sm-150 & $2.52 \mathrm{E}+00$ & $17.24 \%$ & $17.59 \%$ \\
\hline Sm-151 & $6.91 \mathrm{E}-02$ & $26.77 \%$ & $26.23 \%$ \\
\hline Sm-152 & $1.14 \mathrm{E}+00$ & $5.47 \%$ & $4.88 \%$ \\
\hline Nd-143 & $5.46 \mathrm{E}+00$ & $4.16 \%$ & $3.90 \%$ \\
\hline $\mathrm{Nd}-145$ & $5.51 \mathrm{E}+00$ & $3.02 \%$ & $2.99 \%$ \\
\hline $\mathrm{Eu}-151$ & $2.77 \mathrm{E}-03$ & $26.80 \%$ & $26.24 \%$ \\
\hline Eu-153 & $9.63 \mathrm{E}-01$ & $11.59 \%$ & $12.21 \%$ \\
\hline Gd-155 & $2.46 \mathrm{E}-02$ & $10.68 \%$ & $10.97 \%$ \\
\hline$k_{i n f}$ & 3FR01 & Difference $^{b}$ & \\
\hline Actinide-only & $0.93956(0.00033)^{c}$ & 0.00407 & \\
\hline $\begin{array}{l}\text { Actinide }+ \text { fission } \\
\text { products }\end{array}$ & $0.83576(0.00031)$ & -0.00120 & \\
\hline
\end{tabular}


$\mathrm{SAS} 2 \mathrm{H}$ has since been modified to correct this problem, and the corrected version of SAS2H has been included in the recent SCALE 4.4a code package release. Note that this problem can be corrected manually (in version 4.4) by decreasing the amount of gadolinium in the SAS2H model by the aforementioned ratio and implementing input level 3 (in SAS2H) to correct for the decreased mass in the XSDRNPM calculations. However, identifying the appropriate XSDRNPM intervals for the density adjustment is somewhat cumbersome. Fortunately, this problem does not have a significant effect on the isotopics at high burnup (e.g., $40 \mathrm{GWd} / \mathrm{MTU}$ ). However, larger errors would be expected in isotopics at lower burnups, where the gadolinium is still present. All two-fuel-region results cited in this report were generated with the corrected version of SAS2H.

The second error was uncovered by the three-fuel-region modeling approach, which utilized material Nos. 50-59. Relatively few details related to the use of materials 50-59 are provided in the SAS2H manual. However, it was initially assumed that including the gadolinium by way of a 50-59 material would result in the depletion of gadolinium. This was not the case, and as expected, very large errors in the isotopics resulted. This error has also been removed, and the corrected version of SAS2H is included in the SCALE 4.4a code package release. This error cannot be bypassed manually. All three-fuel-region results cited in this report were generated with the corrected version of SAS2H.

\subsubsection{Comparison of Modeling Approaches at Various Burnups}

Limitations in the geometric modeling capabilities of SAS2H motivated the investigation of alternative geometric modeling approaches described in the previous subsections. Specifically, better physical representation and better agreement with HELIOS, with respect to the SMA, were sought. A summary comparison of the important actinide and fission-product concentrations (relative to HELIOS) calculated with the various postulated modeling approaches corresponding to 40-GWd/MTU burnup and 5-year cooling, is provided in Figs. 13 and 14, respectively. Even though minor improvements (relative to HELIOS) over the SMA for some of the nuclides are shown, none of the modeling approaches considered represent a significant improvement over the SMA.

Although there are significant differences between the SMA model and the center-waterrod approaches investigated here, little effect on the calculated actinide and fission-product concentrations was observed. Also, with the exception of ${ }^{235} \mathrm{U}$, the SAS2H calculated nuclide densities were not observed to be very sensitive to the gadolinium concentration or placement (at 40-GWd/MTU burnup and 5-year cooling time).

To further assess the various SAS2H modeling approaches, SAS2H and HELIOS results for burnups of 5, 10, 20,30, and $40 \mathrm{GWd}$ /MTU with 5-year cooling time are compared in this subsection. The main goals of comparing results as a function of burnup include: (1) gaining insight into the differences observed at $40 \mathrm{GWd} / \mathrm{MTU}$, (2) assessing the accuracy of SAS2H for lower burnups, especially burnup values below approximately $10 \mathrm{GWd} / \mathrm{MTU}$, where the gadolinium is still present, and (3) identifying trends that may be important for burnups beyond $40 \mathrm{GWd} / \mathrm{MTU}$. Percentage differences, defined as (SAS2H/HELIOS -1), between SAS2H (SMA Model) and HELIOS results for the important actinides and fission products are graphically represented as a function of burnup in Figs. 15 and 16, respectively. These figures reveal that with the notable exception of ${ }^{235} \mathrm{U}$, the agreement between SAS2H and HELIOS for 


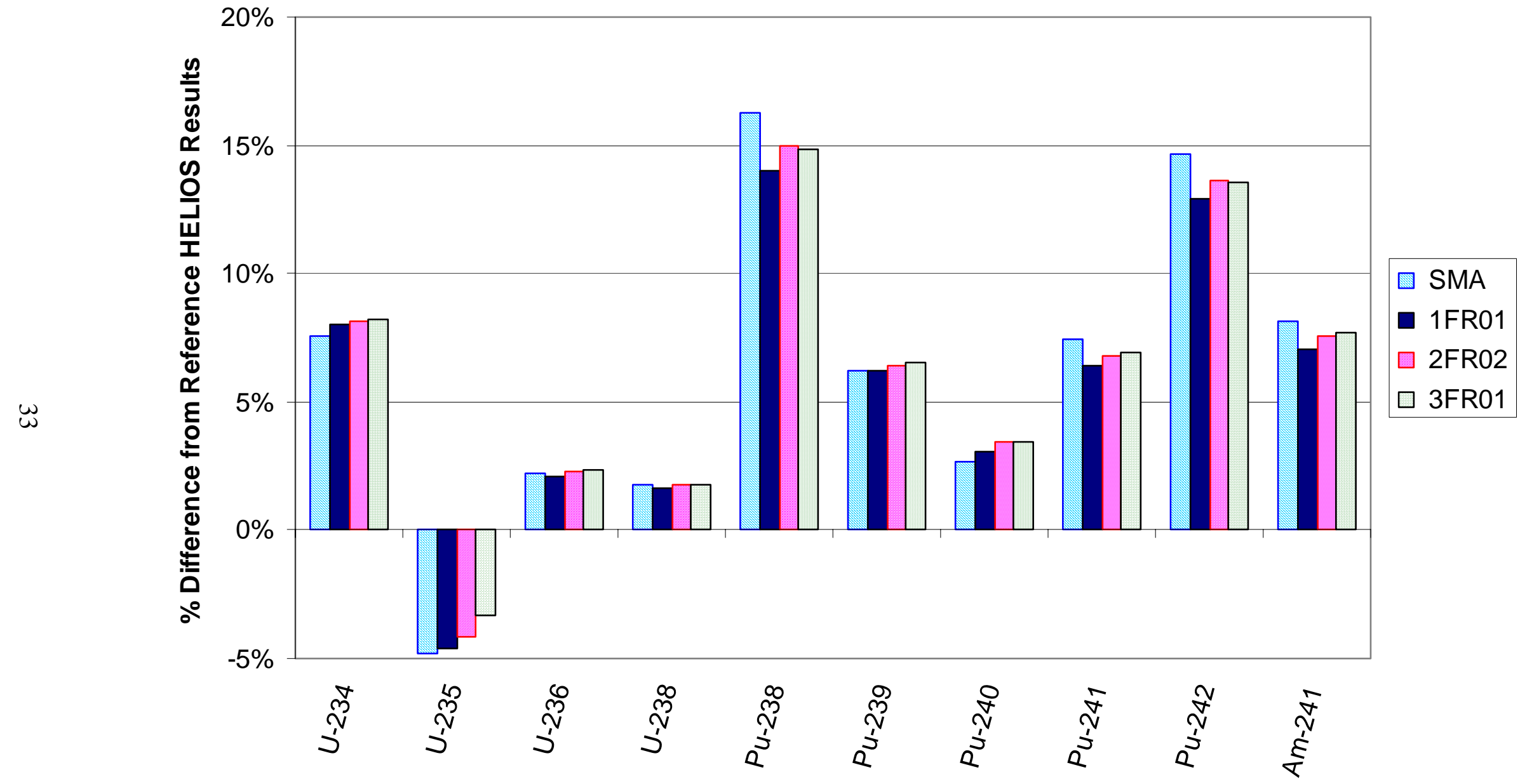

Fig. 13. Summary of percentage differences (relative to HELIOS) between SAS2H and HELIOS calculated actinide densities for the various modeling approaches (at 40-GWd/MTU burnup, 5-year cooling time). 


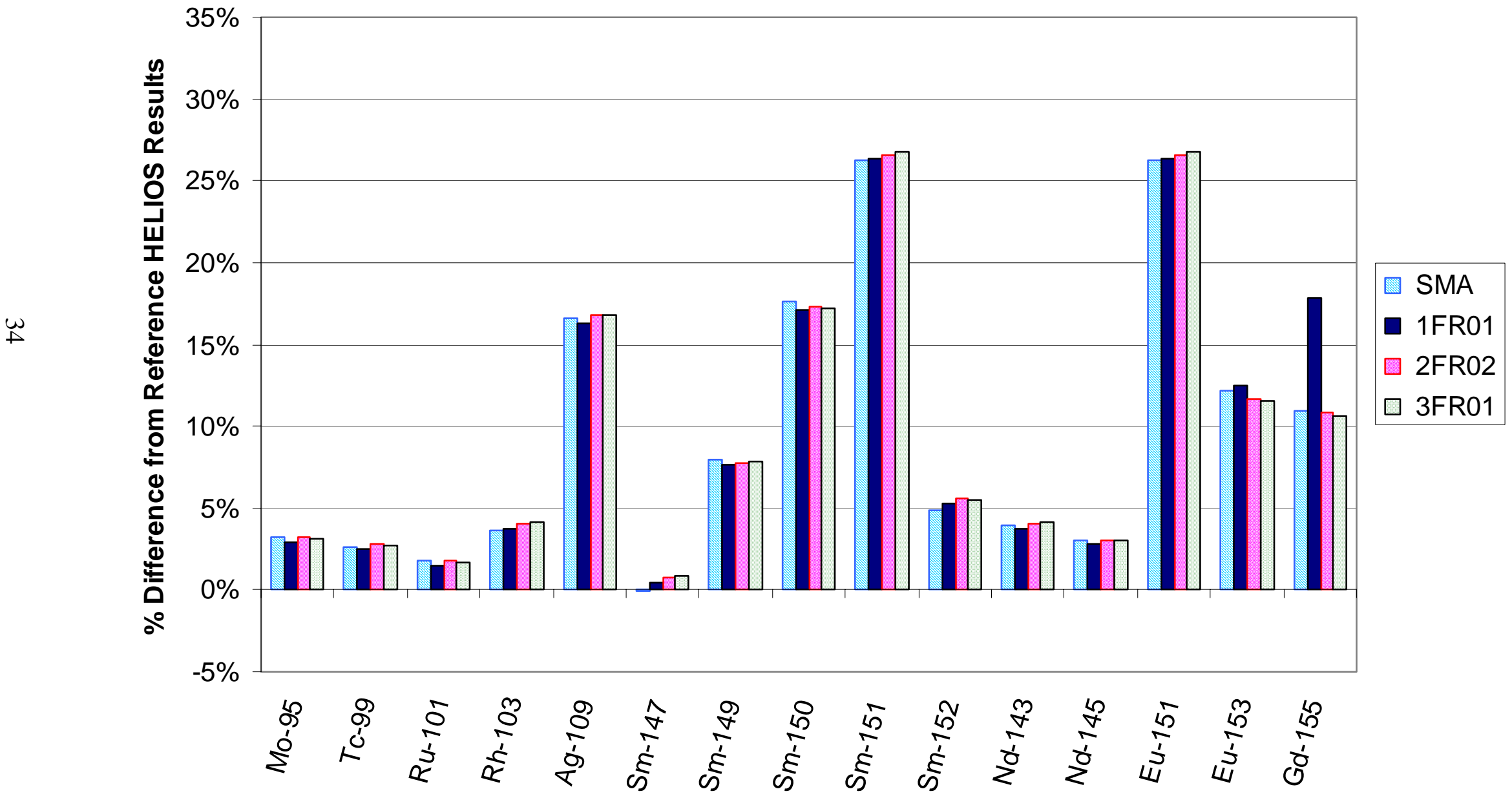

Fig. 14. Summary of percentage differences (relative to HELIOS) between SAS2H and HELIOS calculated fissionproduct densities for the various modeling approaches (at 40-GWd/MTU burnup, 5-year cooling time). 


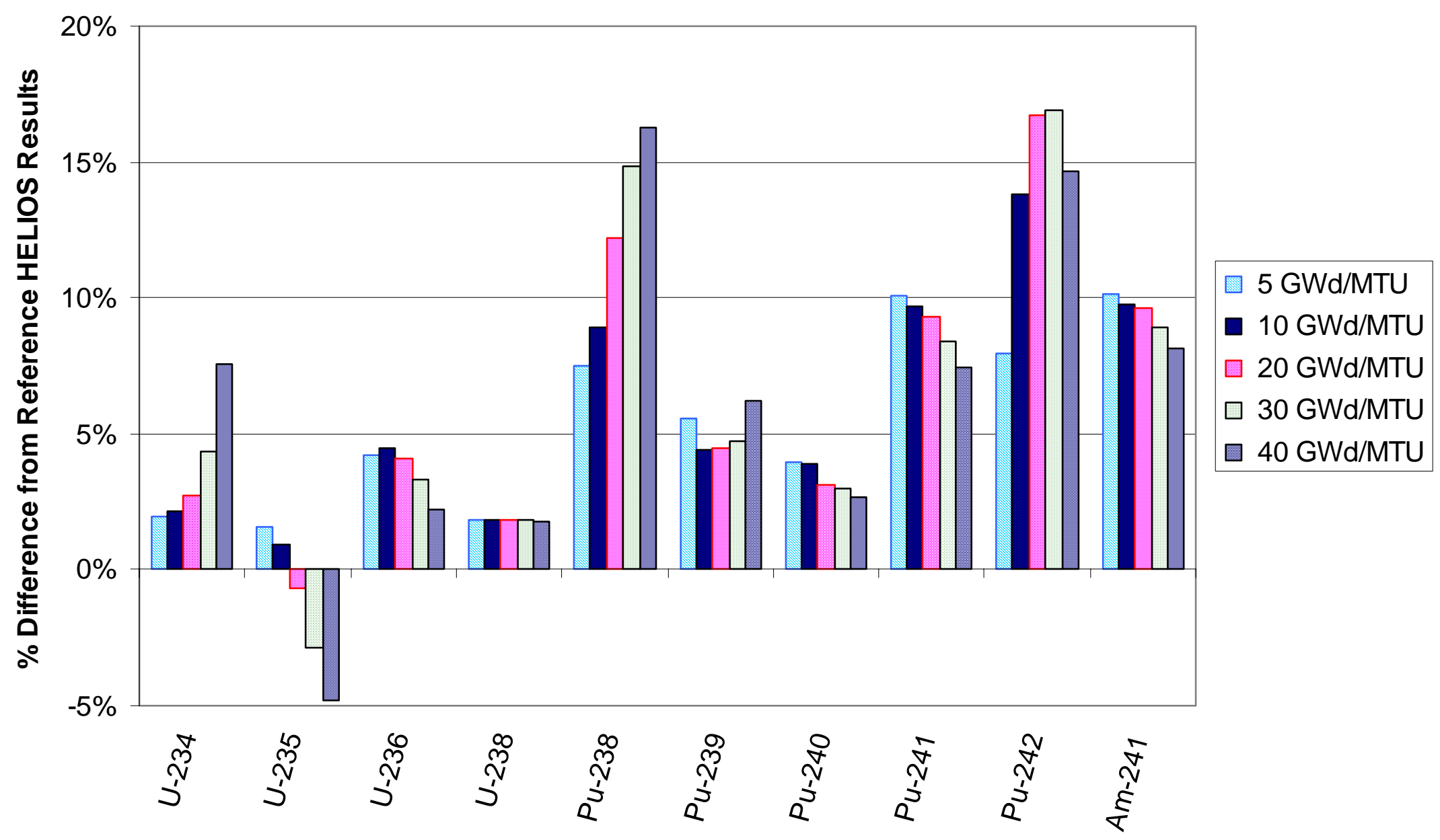

Fig. 15. Percentage differences (relative to HELIOS) between SAS2H (SMA model) and HELIOS calculated actinide densities for various burnups. 


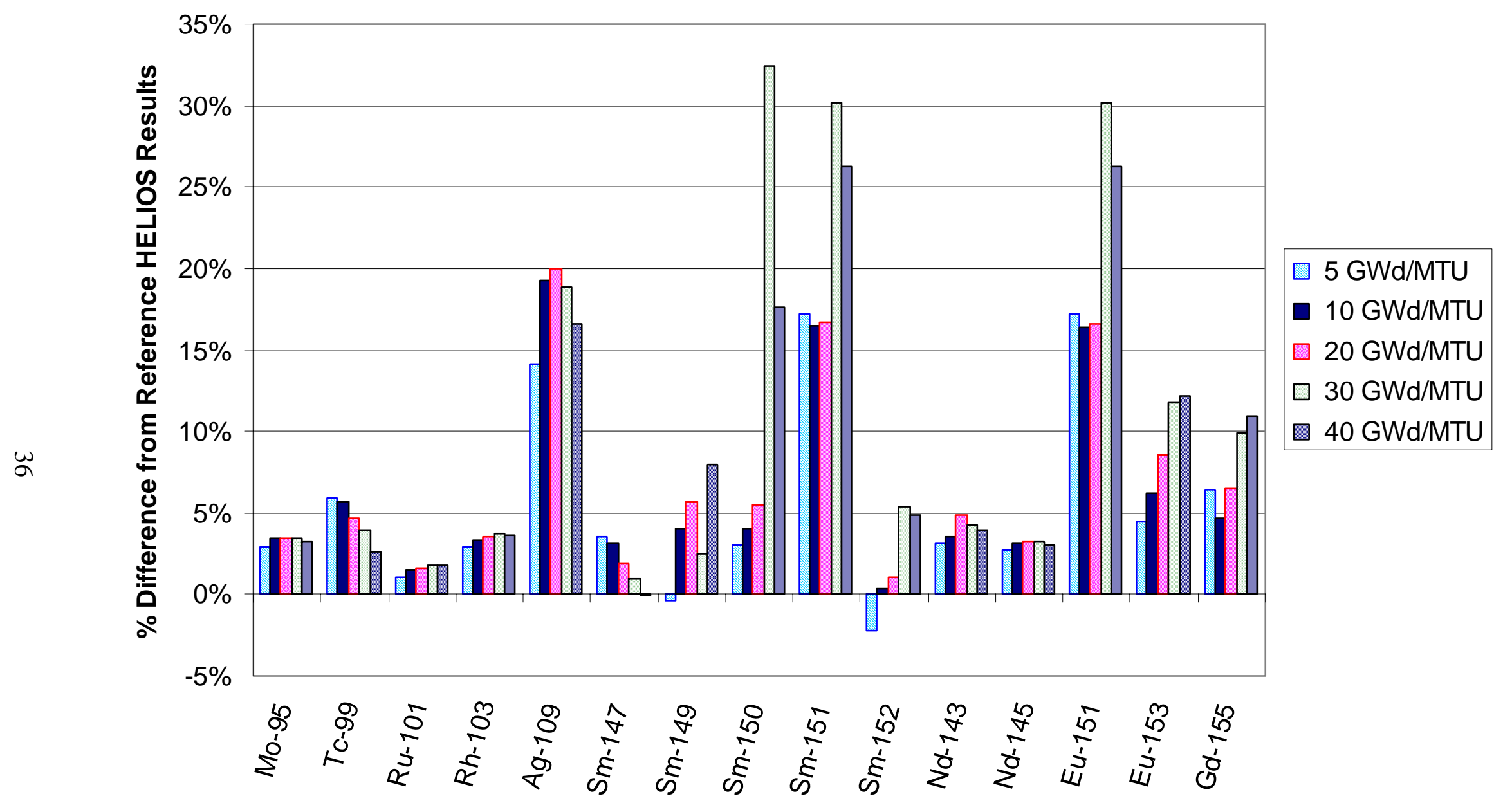

Fig. 16. Percentage differences (relative to HELIOS) between SAS2H (SMA model) and HELIOS calculated fissionproduct densities for various burnups. 
the most important actinides does not vary significantly as a function of burnup. The agreement is shown to diverge for ${ }^{234} \mathrm{U}$ and ${ }^{238} \mathrm{Pu}$ as a function of burnup, but these nuclides are not very significant to reactivity. The agreement at lower burnups, including the range in which the gadolinium is still present, is shown to be either better or within a few percent of the agreement observed at $40 \mathrm{GWd} / \mathrm{MTU}$. Also, other than the trend for ${ }^{235} \mathrm{U}$, no significant trends in important actinides are apparent that would suggest significant discrepancies (relevant to reactivity) at higher burnups.

Comparisons of the important actinide and fission-product concentrations (relative to HELIOS) as calculated with the various modeling approaches are provided in Figs. 17-24. The scale on the $y$-axis of these figures was purposely fixed to facilitate visual comparison. As a result, however, the magnitude of some of the differences is not shown.

The following important conclusions can be drawn from the results contained in Figs. 13 through 24 .

1. The SMA and two-fuel-region models behave similarly throughout burnup, and thus, the two-fuel-region model is as good, or nearly as good, as the SMA model throughout burnup for both actinides and fission products.

2. For burnups below $\sim 20 \mathrm{GWd} / \mathrm{MTU}$, the one-fuel-region model overestimates the actinides (in comparison to the SMA model). However, the agreement improves with burnup, and at $20 \mathrm{GWd} / \mathrm{MTU}$ and beyond, the actinides come into good agreement with the SMA model. The fission product agreement also improves with burnup and, with the notable exception of ${ }^{155} \mathrm{Gd}$, approaches the SMA results at $\sim 20 \mathrm{GWd} / \mathrm{MTU}$. In general, problems that occur during the first $10 \mathrm{GWd} / \mathrm{MTU}$ are probably associated with the gadolinium depletion and seem to be resolved as burnup increases.

3. For burnups below $\sim 20 \mathrm{GWd} / \mathrm{MTU}$, the three-fuel-region model overestimates the actinides (in comparison to the SMA model). However, the agreement improves with burnup, and at $20 \mathrm{GWd} / \mathrm{MTU}$ the actinide concentrations come into fairly good agreement with those predicted with the SMA model. In general, problems associated with the gadolinium depletion are resolved as burnup increases.

In summary, the one- and three-fuel-region models are less accurate for lower burnups due to the homogenization of the gadolinium in the fuel. The problem is magnified in the case of the three-fuel-region model because of the improper self-shielding for the gadolinium cross sections. Thus, the one- and three-fuel-region models do not appear promising for any future consideration. The two-fuel-region performs nearly as well as the SMA for all burnups, and thus, may find some use in the future. Finally, it is important to note that all of the models considered herein converge to nearly the same solutions after the effect of the gadolinium absorption is burned away. 


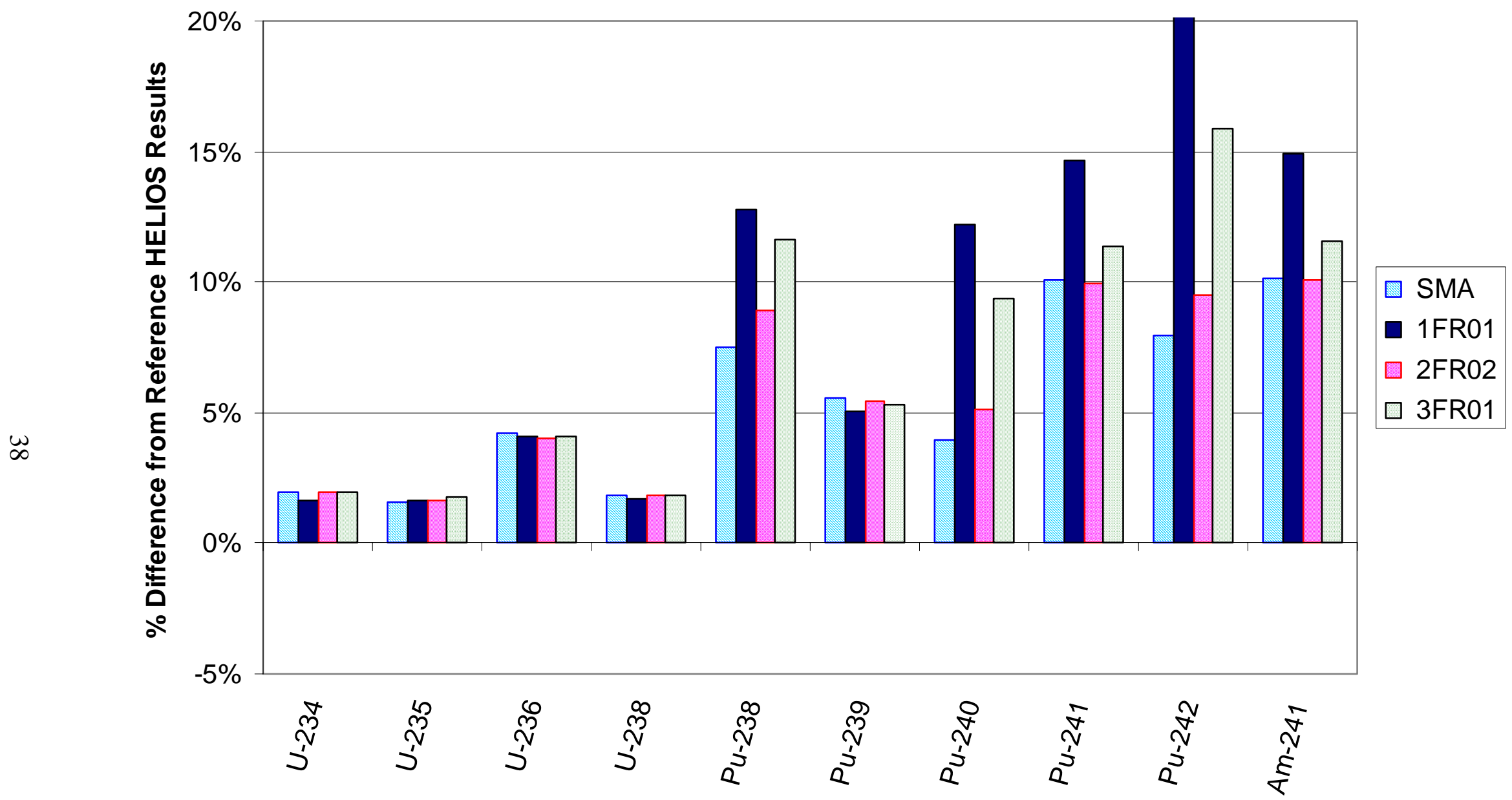

Fig. 17. Summary of percentage differences (relative to HELIOS) between SAS2H and HELIOS calculated actinide densities for the various modeling approaches (at 5-GWd/MTU burnup, 5-year cooling time). 


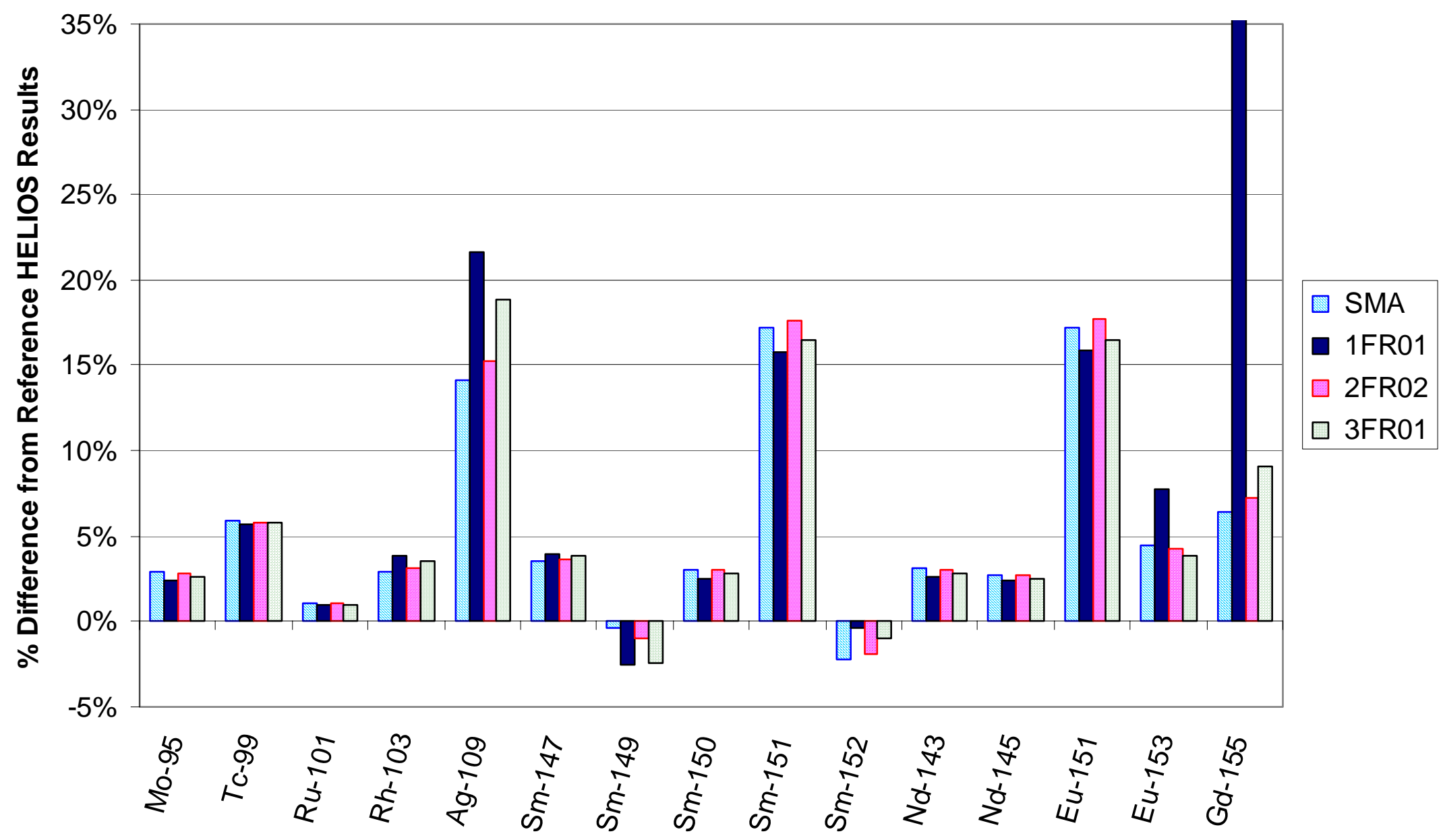

Fig. 18. Summary of percentage differences (relative to HELIOS) between SAS2H and HELIOS calculated fissionproduct densities for the various modeling approaches (at 5-GWd/MTU burnup, 5-year cooling time). 


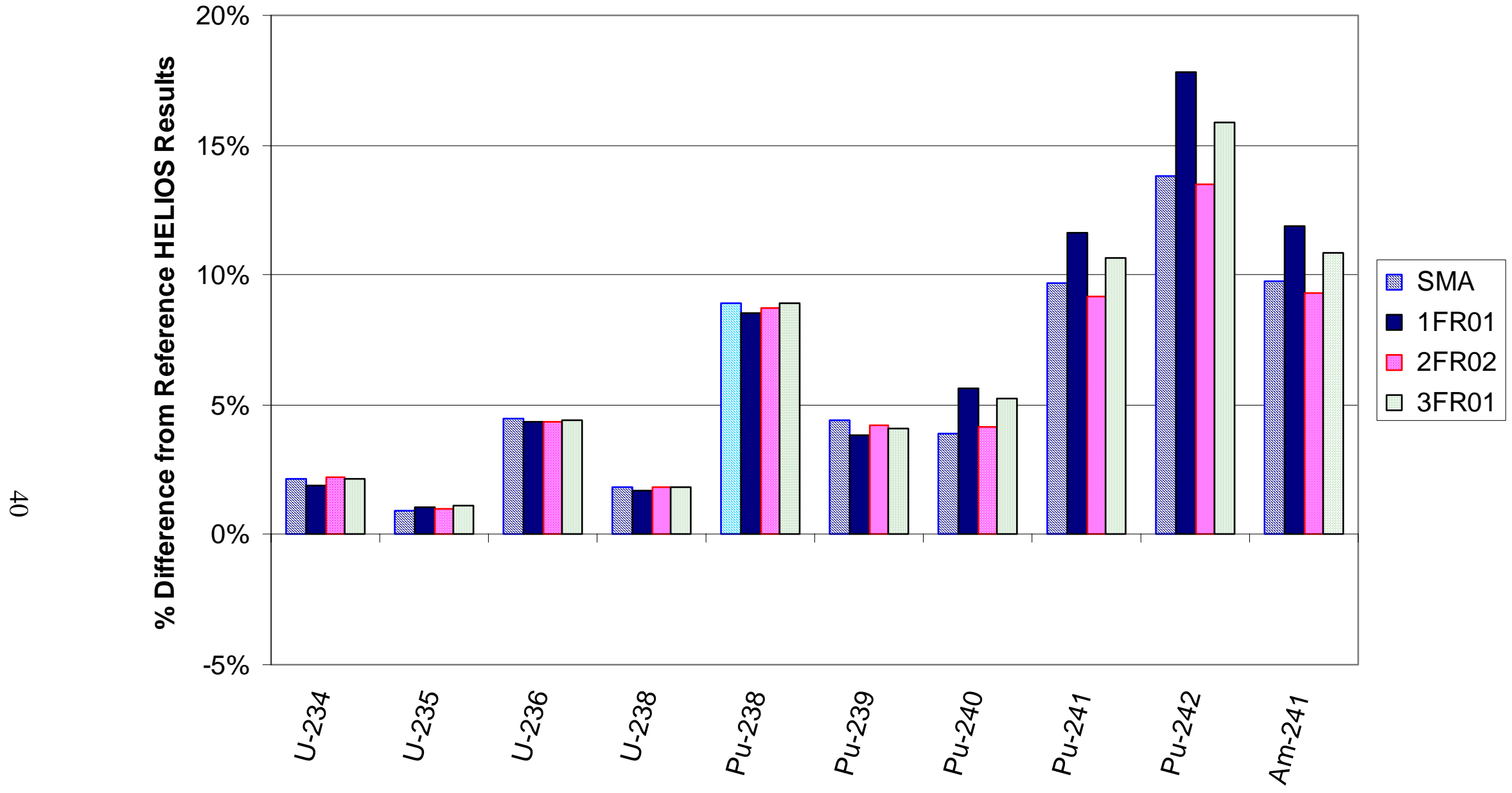

Fig. 19. Summary of percentage differences (relative to HELIOS) between SAS2H and HELIOS calculated actinide densities for the various modeling approaches (at 10-GWd/MTU burnup, 5-year cooling time). 


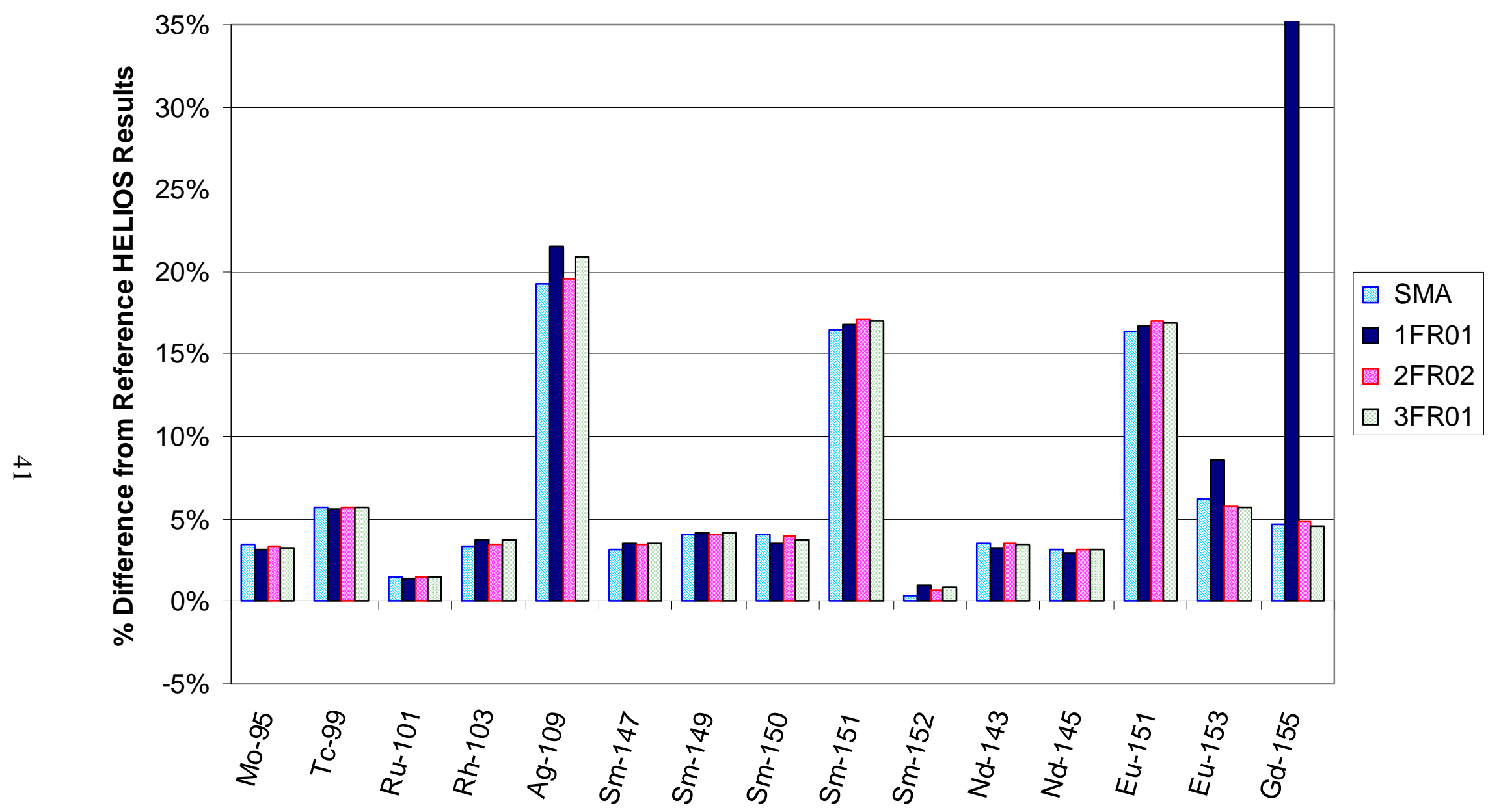

Fig. 20. Summary of percentage differences (relative to HELIOS) between SAS2H and HELIOS calculated fissionproduct densities for the various modeling approaches (at 10-GWd/MTU burnup, 5-year cooling time). 


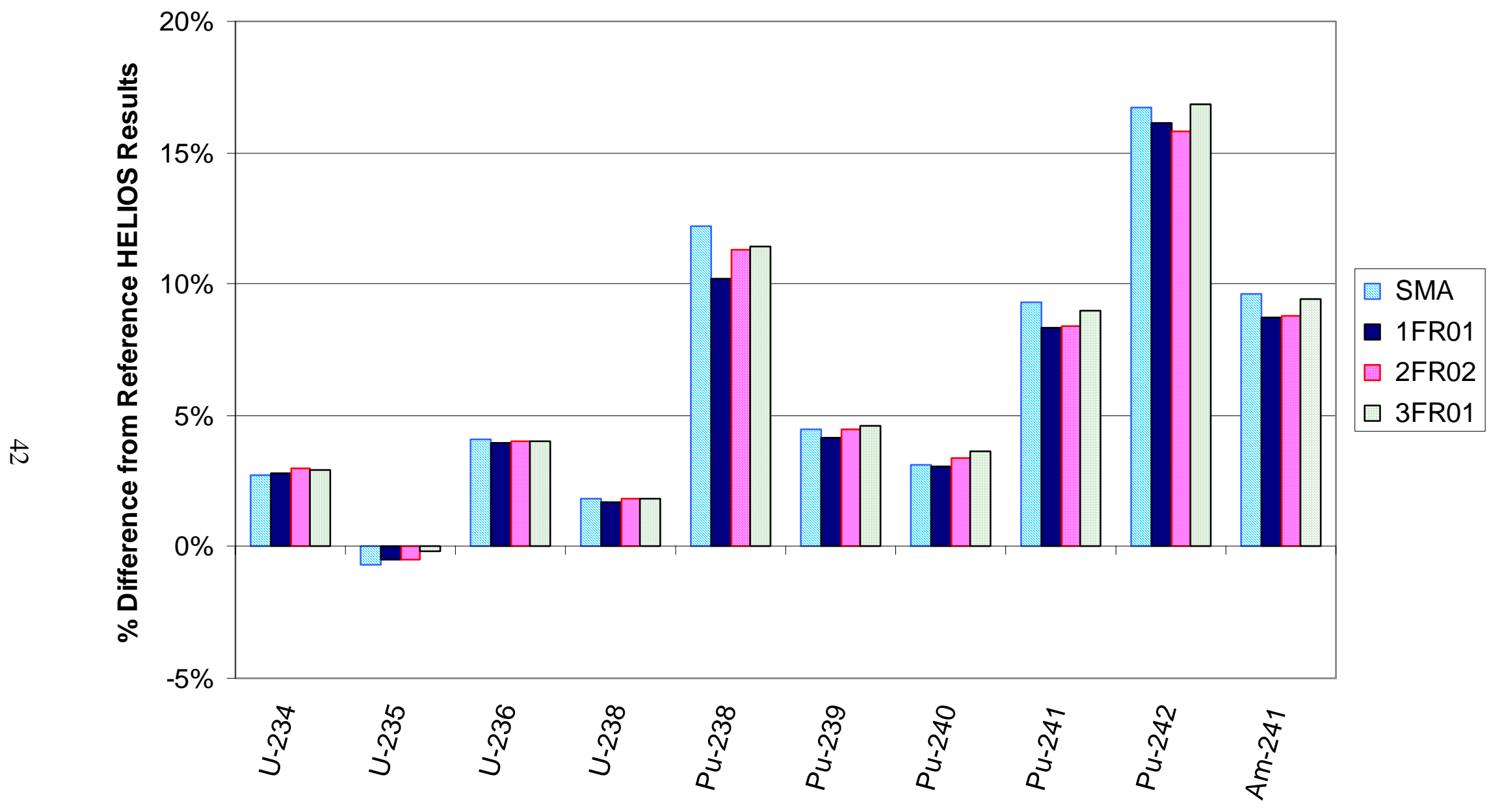

Fig. 21. Summary of percentage differences (relative to HELIOS) between SAS2H and HELIOS calculated actinide densities for the various modeling approaches (at 20-GWd/MTU burnup, 5-year cooling time). 


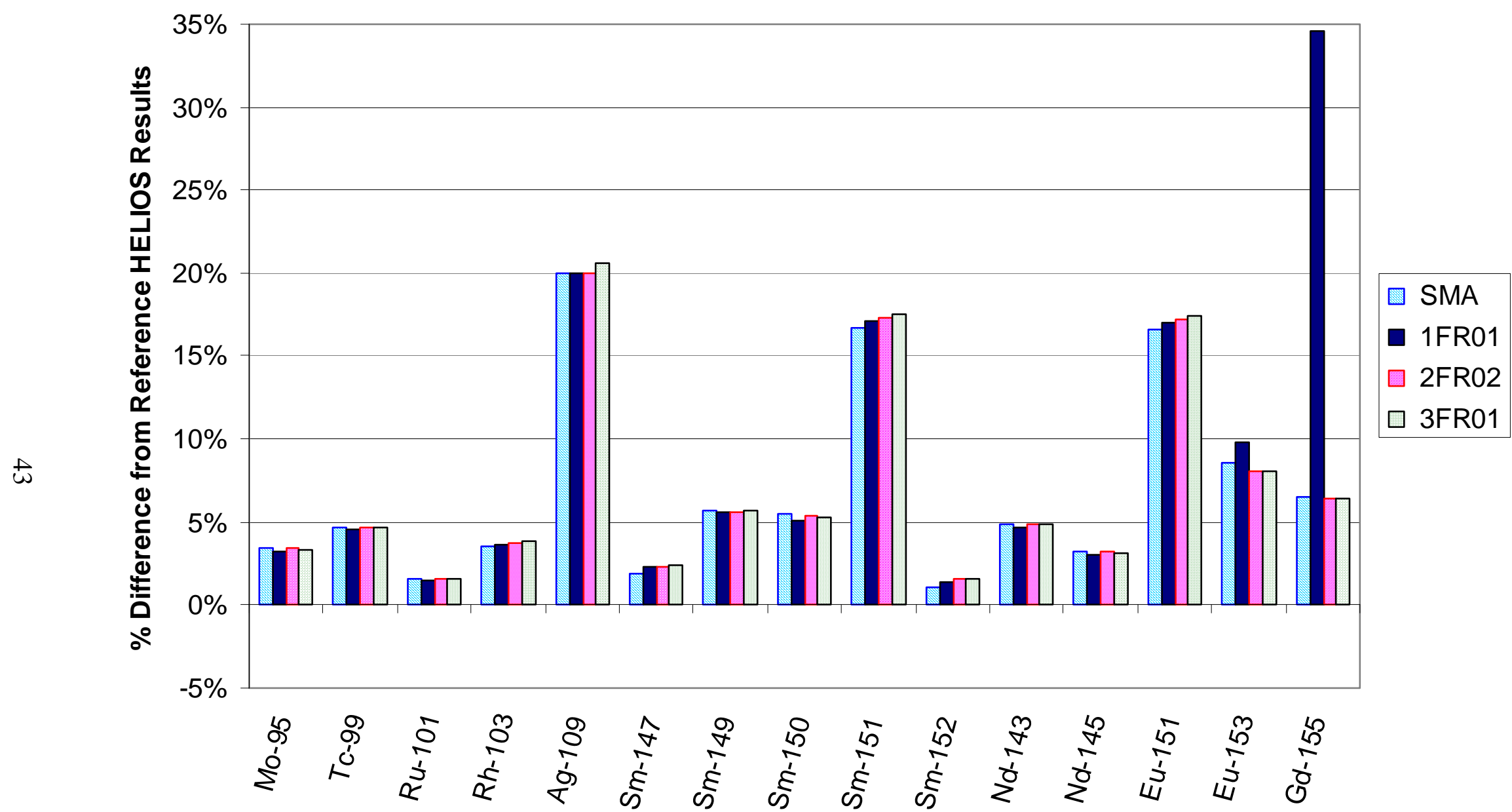

Fig. 22. Summary of percentage differences (relative to HELIOS) between SAS2H and HELIOS calculated fissionproduct densities for the various modeling approaches (at 20-GWd/MTU burnup, 5-year cooling time). 


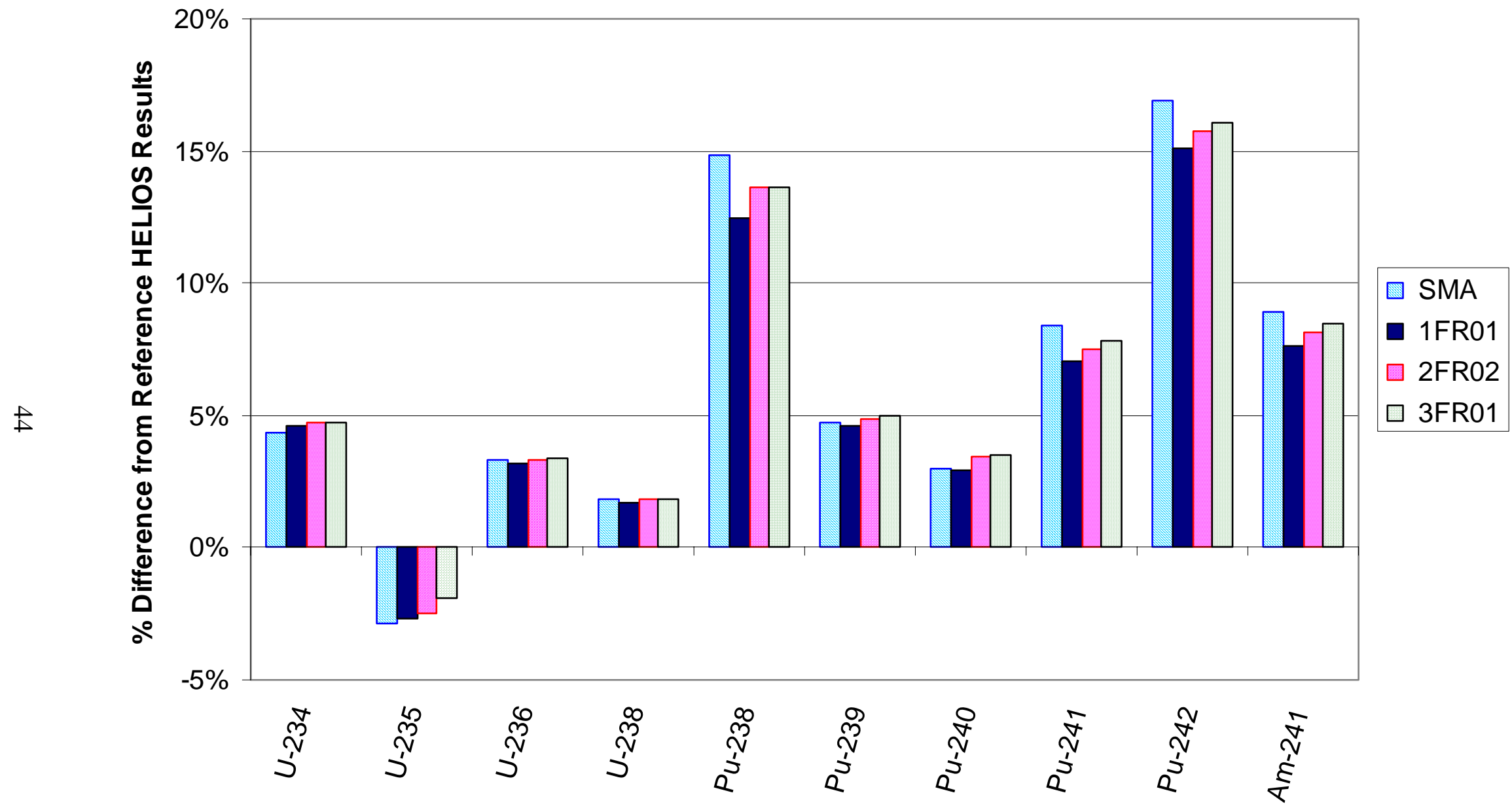

Fig. 23. Summary of percentage differences (relative to HELIOS) between SAS2H and HELIOS calculated actinide densities for the various modeling approaches (at 30-GWd/MTU burnup, 5-year cooling time). 


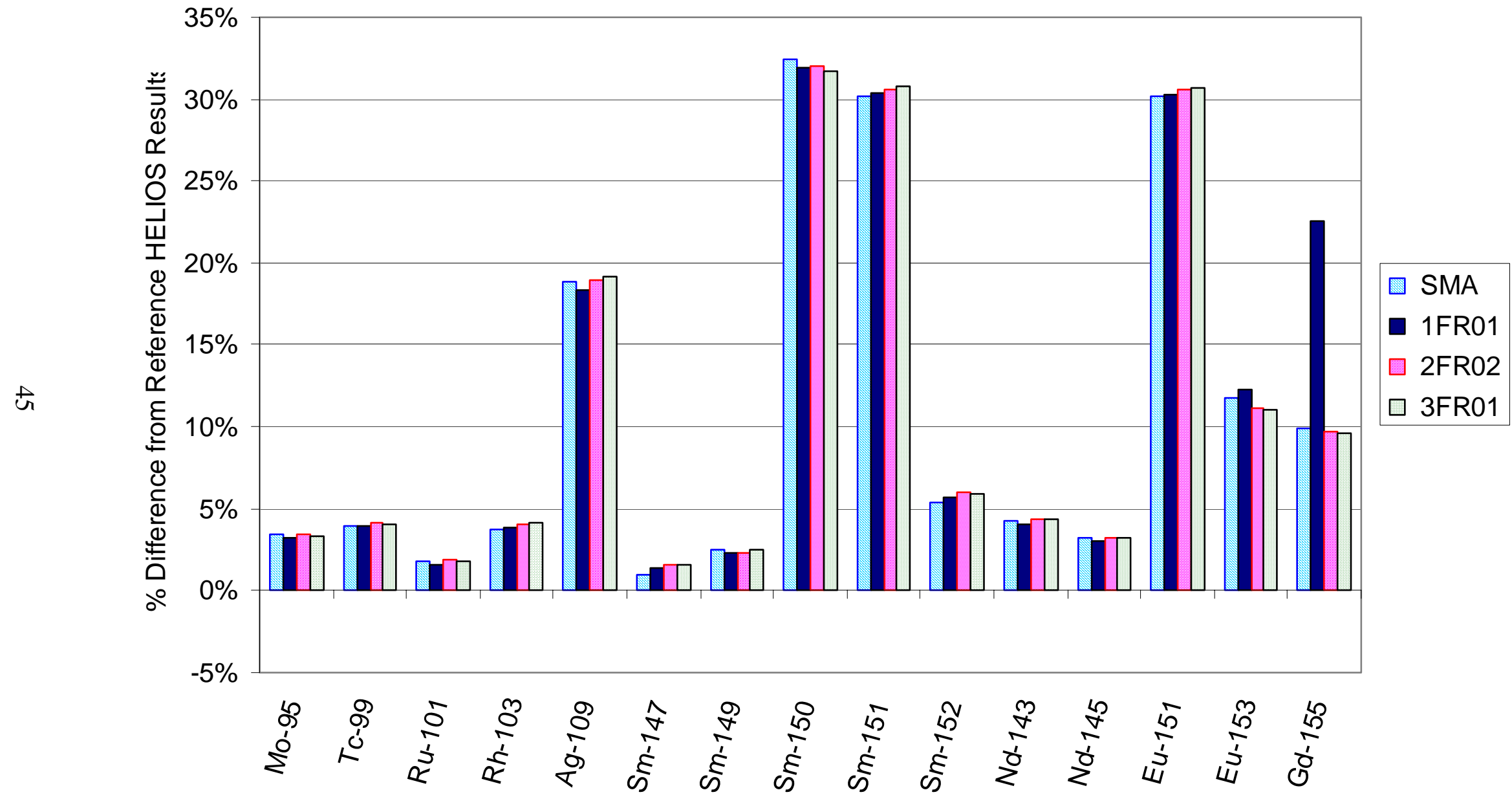

Fig. 24. Summary of percentage differences (relative to HELIOS) between SAS2H and HELIOS calculated fissionproduct densities for the various modeling approaches (at 30-GWd/MTU burnup, 5-year cooling time). 
As mentioned, the ultimate goal of a burnup-credit criticality safety analysis is the accurate prediction of $k_{\text {eff }}$ for spent fuel. Therefore, it is important to compare calculated $k_{\text {inf }}$ values based on the calculated spent fuel isotopics to further assess the various modeling approaches. Calculated $k_{i n f}$ values as a function of burnup, based on spent fuel isotopics from both HELIOS and the various SAS2H modeling approaches, are plotted in Figs. 25 and 26 for the actinide-only and actinide plus fission-product conditions, respectively. Because of the relatively poor agreement in isotopics, $k_{\text {inf }}$ values based on the one-fuel-region model are not shown. The $k_{\text {inf }}$ values are based on zero cooling time and out-of-reactor conditions. Although relatively large differences are observed at low burnups where the gadolinium is still present, the calculated $k_{\text {inf }}$ values for burnups beyond approximately $10 \mathrm{GWd} / \mathrm{MTU}$ are within $0.3 \%$ for the actinide-only cases and within $1 \%$ for the actinide plus fission-product cases. The differences in $k_{\text {inf }}$ values that are shown during the first $10 \mathrm{GWd} / \mathrm{MTU}$ are due to differences in the rate of gadolinium depletion in the various models. These differences in gadolinium depletion are illustrated in Figs. 27 and 28, which show the percentage differences (relative to HELIOS) in atom densities of ${ }^{155} \mathrm{Gd}$ and ${ }^{157} \mathrm{Gd}$, respectively, as a function of burnup for the various SAS2H modeling approaches. The differences in calculated gadolinium atom densities between HELIOS and the SAS2H models are shown to be quite large for low burnup, where the gadolinium is being rapidly depleted. In all cases, SAS2H is underpredicting the gadolinium concentrations relative to HELIOS, or, in other words, SAS2H is depleting the gadolinium at an accelerated rate compared to HELIOS. Note from Fig. 28, that for burnups beyond approximately $8 \mathrm{GWd} / \mathrm{MTU}$, the two- and three-region models achieve better agreement with HELIOS for the ${ }^{157} \mathrm{Gd}$ concentration than the SMA. The differences in the $k_{\text {inf }}$ values shown in Figs. 25 and 26 are a direct reflection of the differences in the gadolinium atom densities shown in Figs. 27 and 28.

Finally, calculated $k_{\text {inf }}$ values at 5-year cooling time, based on spent fuel isotopics from both HELIOS and the various SAS2H modeling approaches, are summarized and compared in Table 12.

\subsubsection{Variation of Bypass Moderator Thickness}

In the SMA, described in Subsect. 3.2.1, the volume of water associated with the water $\operatorname{rod}(\mathrm{s})$, where present, is added to the outer bypass moderator. Even though this approach may seem rather arbitrary, it may be defended by physical arguments related to the approximate equivalence between the model outside radius and the neutron mean free path, which suggest that the location of the water (inside or outside of the smeared fuel) is inconsequential and that it is the presence of the water and its effect on the neutron spectrum that are important. To investigate the effect of the bypass moderator thickness on the isotopic behavior, a series of calculations were performed, artificially varying the bypass moderator thickness.

The effects of artificially varying the bypass moderator thickness on the actinide and fission-product concentrations, relative to the reference SMA results, at 40-GWd/MTU burnup and 5-year cooling time are shown in Figs. 29 and 30. These figures clearly show that the bypass moderator thickness has a significant effect on several of the most important actinides (i.e., ${ }^{235} \mathrm{U}$, ${ }^{239} \mathrm{Pu},{ }^{240} \mathrm{Pu}$, and $\left.{ }^{241} \mathrm{Pu}\right)$ and fission products $\left({ }^{143} \mathrm{Nd},{ }^{149} \mathrm{Sm}\right.$, and $\left.{ }^{151} \mathrm{Sm}\right)$.

These results, along with the reference SMA results, are compared to the reference HELIOS results in Figs. 31 and 32. These figures show that even though the agreement for specific nuclides can be improved by increasing or decreasing the bypass moderator thickness, the differences in the nuclide concentrations for the collection of important actinides are 


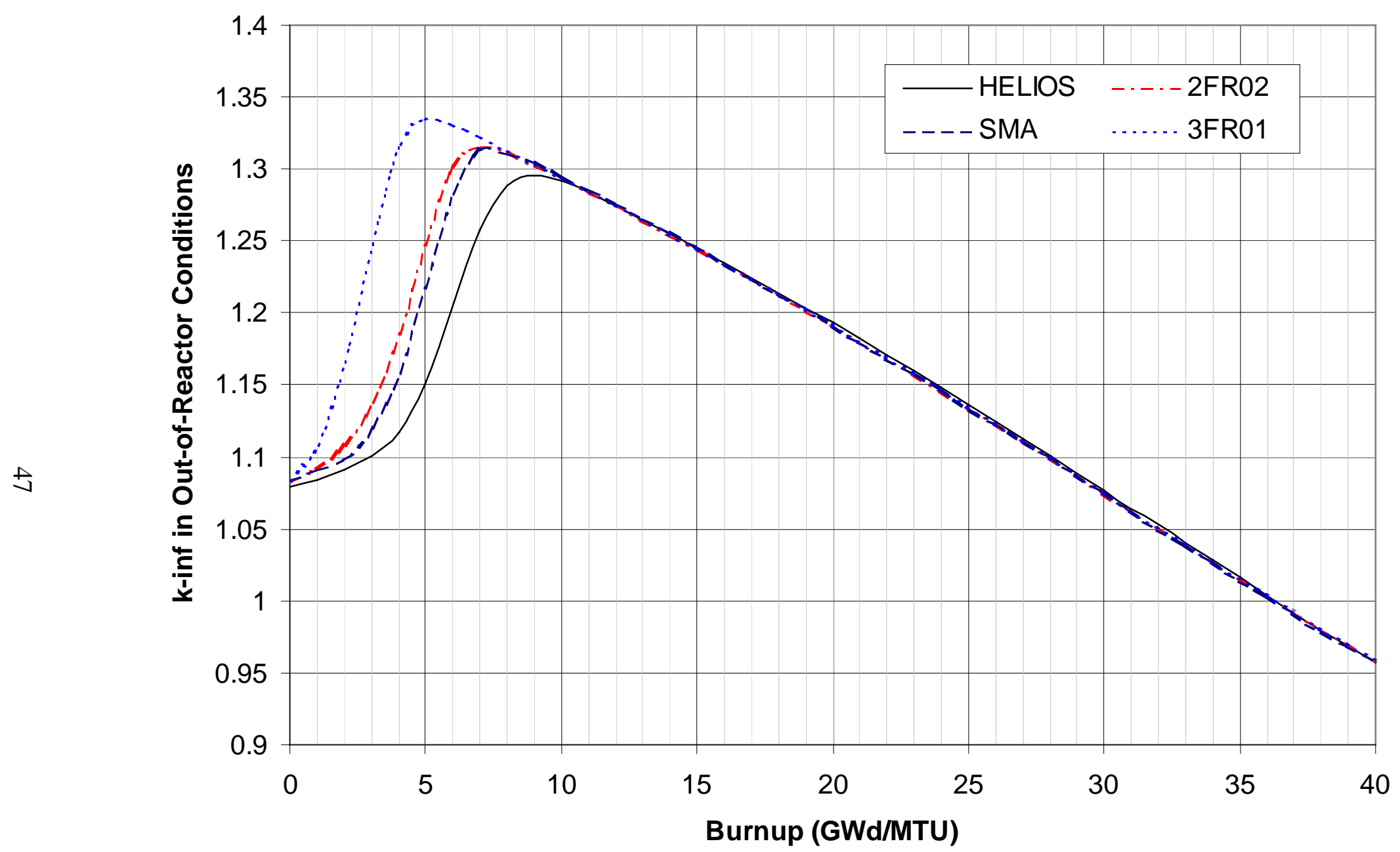

Fig. 25. Calculated $k_{\text {inf }}$ values as a function of burnup based on actinide-only isotopics from both HELIOS and SAS2H (zero cooling time). 


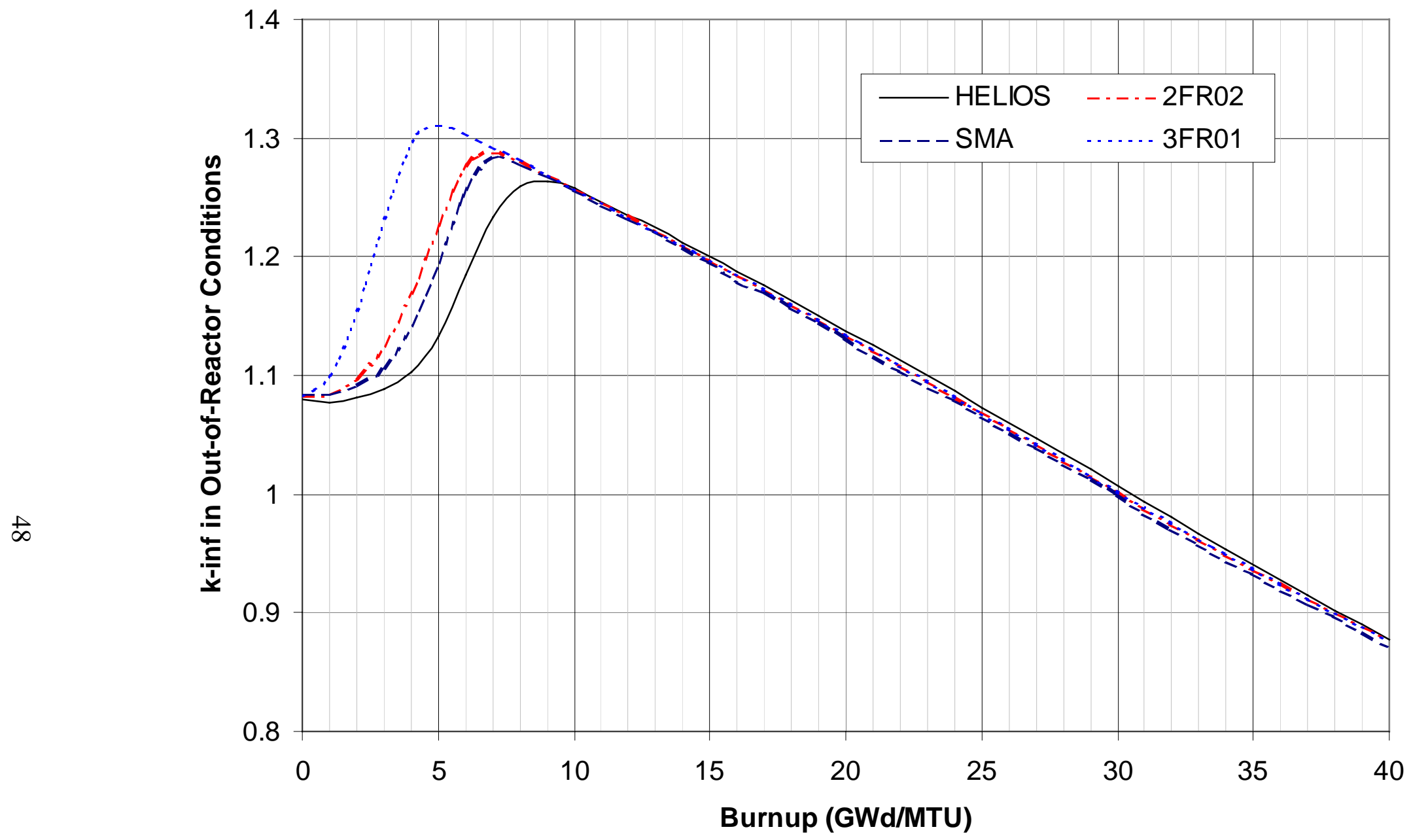

Fig. 26. Calculated $\boldsymbol{k}_{i n f}$ values as a function of burnup based on actinide-plus-fission-product isotopics from both HELIOS and SAS2H (zero cooling time). 


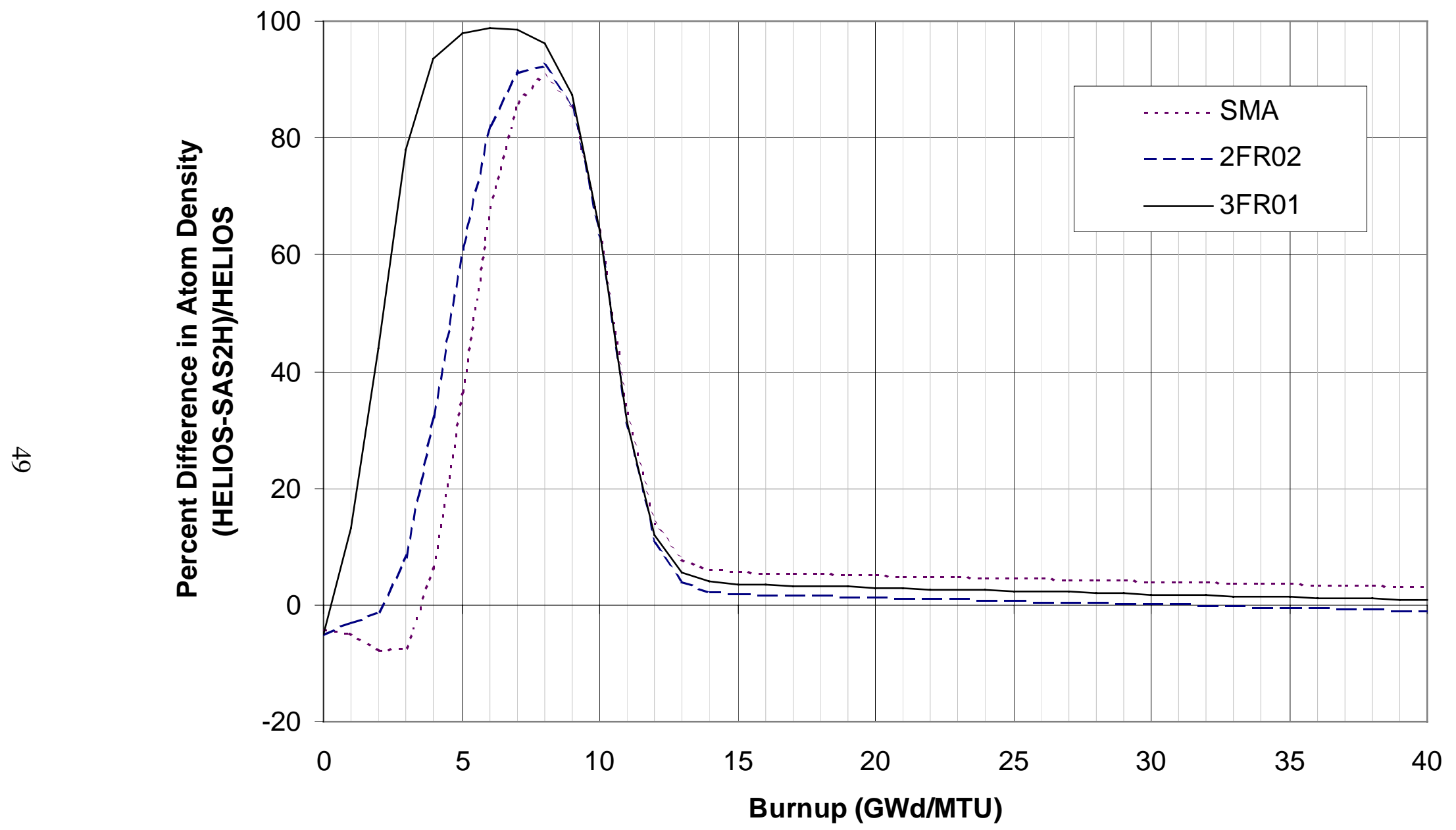

Fig. 27. Percentage differences (relative to HELIOS) between SAS2H- and HELIOS-calculated atom densities for ${ }^{155} \mathrm{Gd}$ as a function of burnup. 


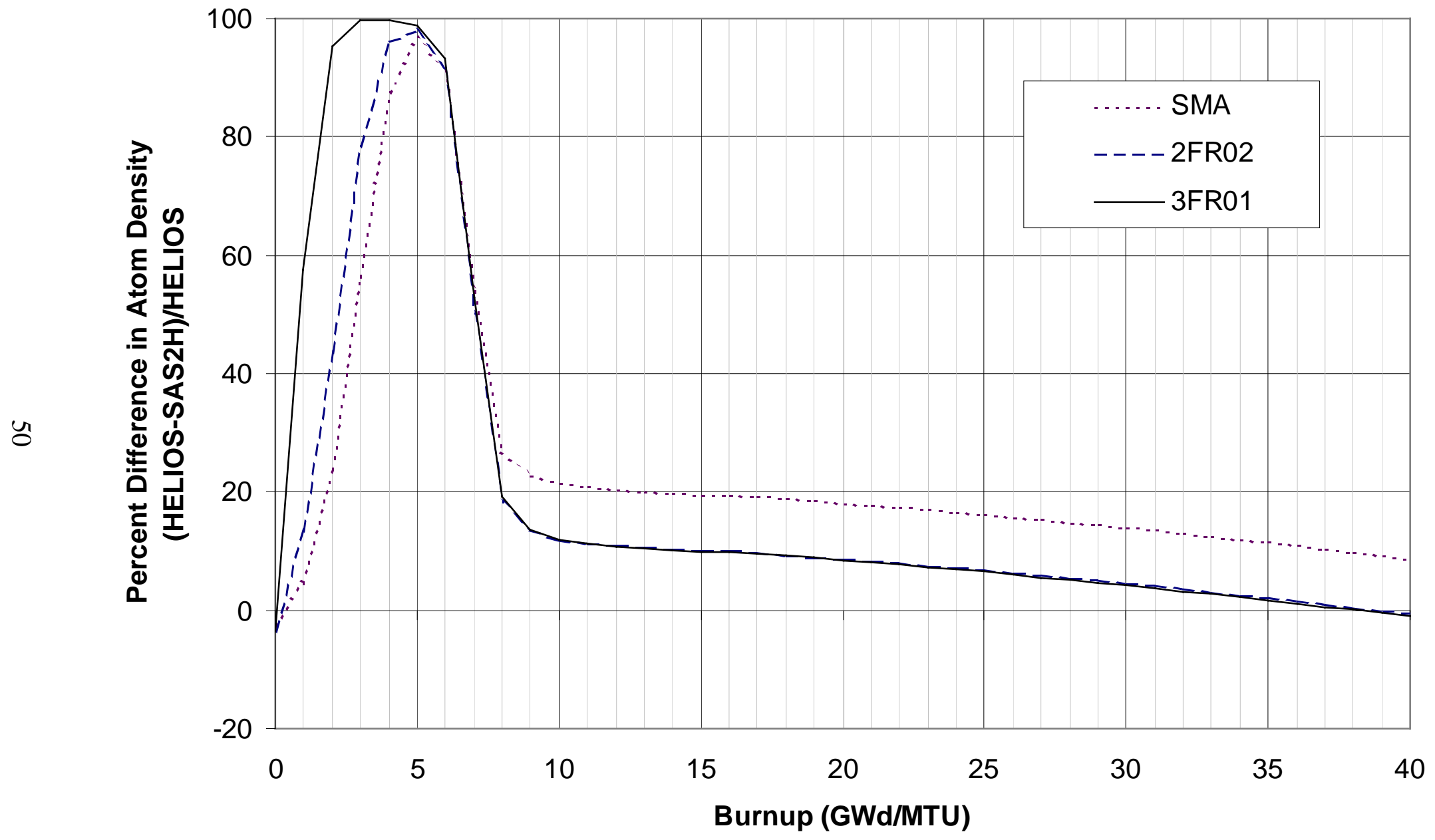

Fig. 28. Percentage differences (relative to HELIOS) between SAS2H- and HELIOS-calculated atom densities for ${ }^{157} \mathrm{Gd}$ as a function of burnup. 
Table 12. Comparison of calculated $\boldsymbol{k}_{\text {inf }}$ values as a function of burnup for the various models at 5-year cooling time

\begin{tabular}{|c|c|c|c|c|c|c|}
\hline & \multicolumn{3}{|c|}{ Actinide-only } & \multicolumn{3}{|c|}{ Actinide + fission-products } \\
\hline $\begin{array}{c}\text { Burnup } \\
(\mathrm{GWd} / \mathrm{MTU})\end{array}$ & $k_{i n f}$ & $\begin{array}{l}\text { Standard } \\
\text { deviation }\end{array}$ & $\begin{array}{c}\text { Difference } \\
\text { from HELIOS }\end{array}$ & $k_{i n f}$ & $\begin{array}{l}\text { Standard } \\
\text { deviation }\end{array}$ & $\begin{array}{c}\text { Difference } \\
\text { from HELIOS }\end{array}$ \\
\hline \multicolumn{7}{|c|}{ HELIOS } \\
\hline 5 & 1.14414 & 0.00037 & --- & 1.12166 & 0.00038 & --- \\
\hline 10 & 1.29003 & 0.00044 & --- & 1.24660 & 0.00036 & --- \\
\hline 20 & 1.18494 & 0.00037 & --- & 1.11793 & 0.00035 & --- \\
\hline 30 & 1.06246 & 0.00037 & --- & 0.97529 & 0.00031 & --- \\
\hline 40 & 0.93549 & 0.00028 & --- & 0.83696 & 0.00030 & --- \\
\hline \multicolumn{7}{|c|}{ SMA } \\
\hline 5 & 1.23432 & 0.00038 & 0.09018 & 1.20742 & 0.00035 & 0.08576 \\
\hline 10 & 1.29294 & 0.00042 & 0.00291 & 1.24761 & 0.00037 & 0.00101 \\
\hline 20 & 1.18428 & 0.00034 & -0.00066 & 1.11421 & 0.00034 & -0.00372 \\
\hline 30 & 1.05971 & 0.00037 & -0.00275 & 0.96889 & 0.00035 & -0.00640 \\
\hline 40 & 0.93805 & 0.00030 & 0.00256 & 0.83407 & 0.00028 & -0.00289 \\
\hline \multicolumn{7}{|c|}{ 1FR01 } \\
\hline 5 & 1.34746 & 0.00037 & 0.20332 & 1.31357 & 0.00039 & 0.19191 \\
\hline 10 & 1.30011 & 0.00036 & 0.01008 & 1.25303 & 0.00038 & 0.00643 \\
\hline 20 & 1.19149 & 0.00036 & 0.00655 & 1.11932 & 0.00034 & 0.00139 \\
\hline 30 & 1.06719 & 0.00033 & 0.00473 & 0.97350 & 0.00034 & -0.00179 \\
\hline 40 & 0.94364 & 0.00034 & 0.00815 & 0.83830 & 0.00026 & 0.00134 \\
\hline \multicolumn{7}{|c|}{ 2FR02 } \\
\hline 5 & 1.26441 & 0.00036 & 0.12027 & 1.23623 & 0.00035 & 0.11457 \\
\hline 10 & 1.29207 & 0.00035 & 0.00204 & 1.24701 & 0.00035 & 0.00041 \\
\hline 20 & 1.18454 & 0.00036 & -0.00040 & 1.11424 & 0.00032 & -0.00369 \\
\hline 30 & 1.05997 & 0.00038 & -0.00249 & 0.96866 & 0.00031 & -0.00663 \\
\hline 40 & 0.93821 & 0.00037 & 0.00272 & 0.83439 & 0.00026 & -0.00257 \\
\hline \multicolumn{7}{|c|}{ 3FR01 } \\
\hline 5 & 1.33565 & 0.00036 & 0.19151 & 1.30482 & 0.00034 & 0.18316 \\
\hline 10 & 1.29204 & 0.00038 & 0.00201 & 1.24712 & 0.00039 & 0.00052 \\
\hline 20 & 1.18483 & 0.00034 & -0.00011 & 1.11474 & 0.00034 & -0.00319 \\
\hline 30 & 1.06145 & 0.00032 & -0.00101 & 0.97039 & 0.00030 & -0.00490 \\
\hline 40 & 0.93956 & 0.00033 & 0.00407 & 0.83576 & 0.00031 & -0.00120 \\
\hline
\end{tabular}




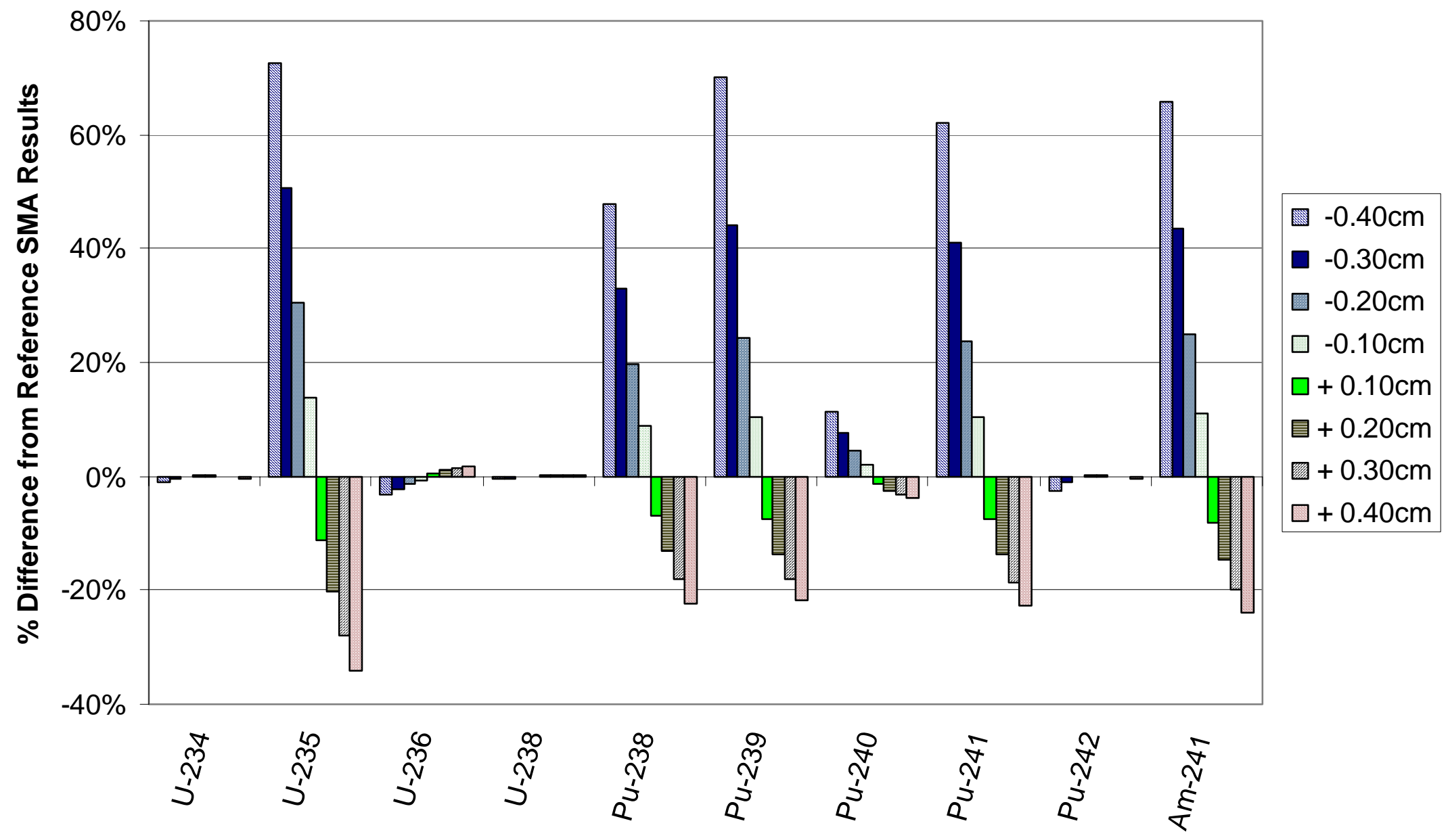

Fig. 29. Effect of varying the bypass moderator thickness on the calculated actinide densities (relative to the reference SMA results) at 40-GWd/MTU burnup and 5-year cooling time. 


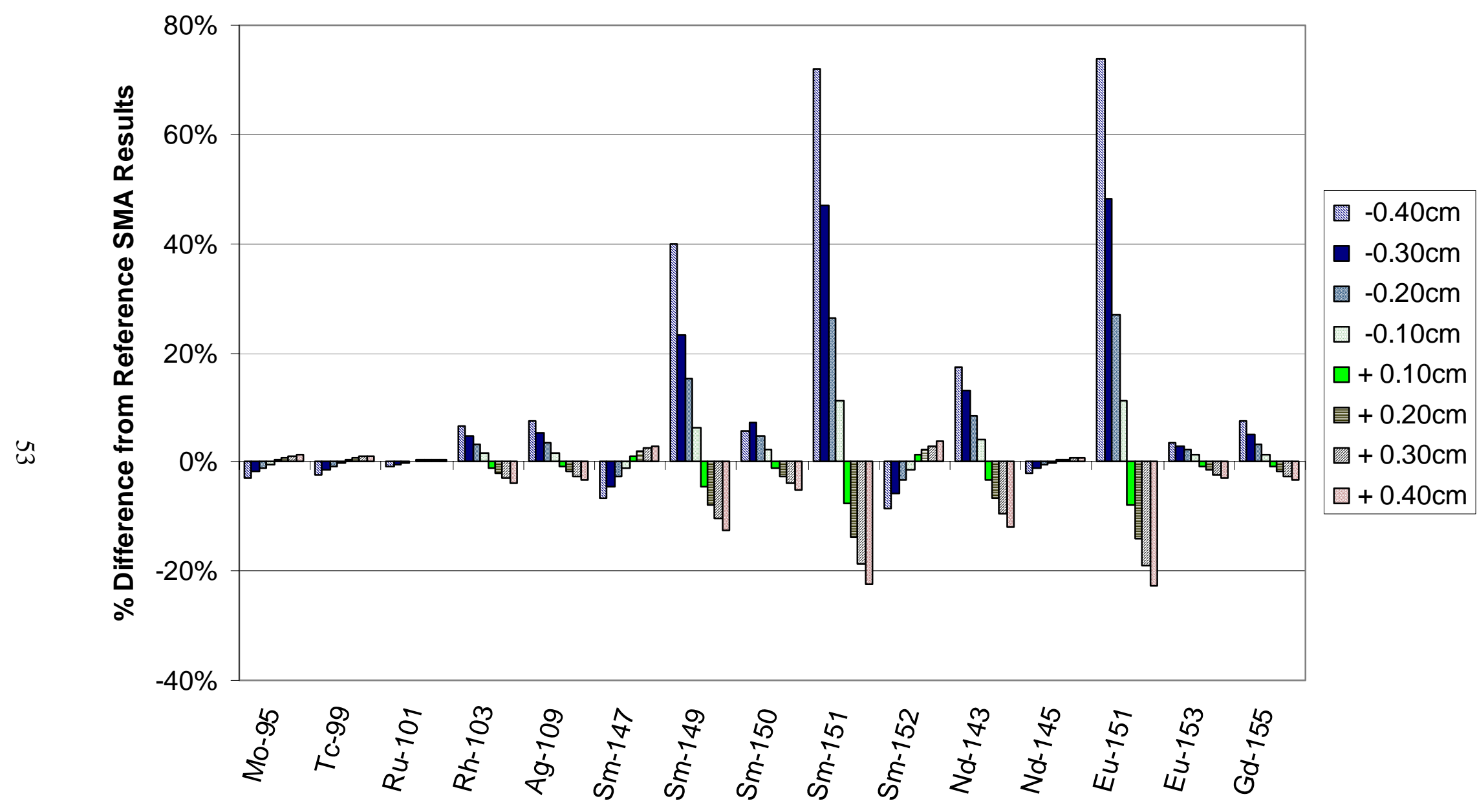

Fig. 30. Effect of varying the bypass moderator thickness on the calculated fission-product densities (relative to the reference SMA results) at 40-GWd/MTU burnup and 5-year cooling time. 


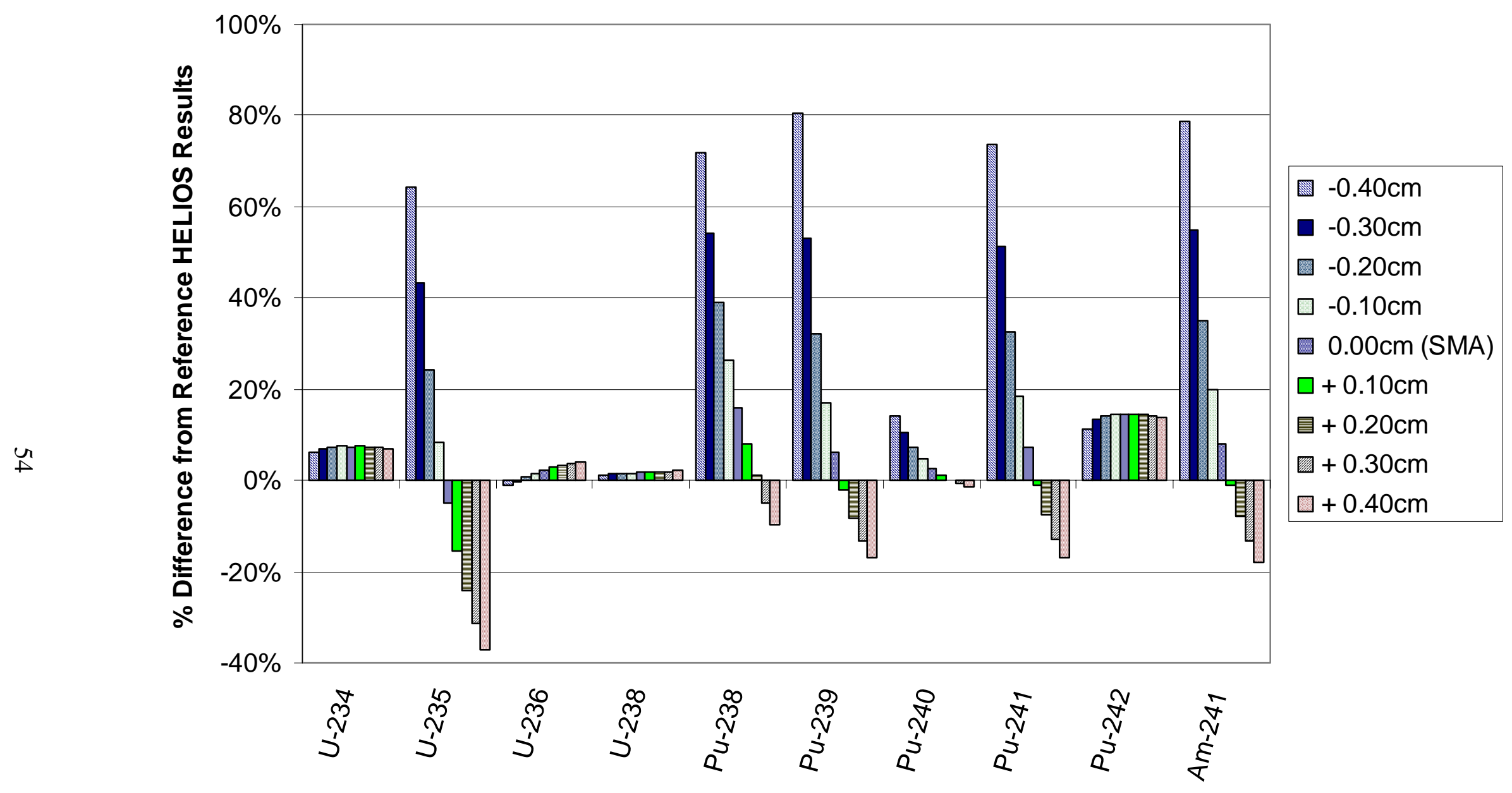

Fig. 31. Effect of varying the bypass moderator thickness on the calculated actinide densities (relative to the reference HELIOS results) at 40-GWd/MTU burnup and 5-year cooling time. 


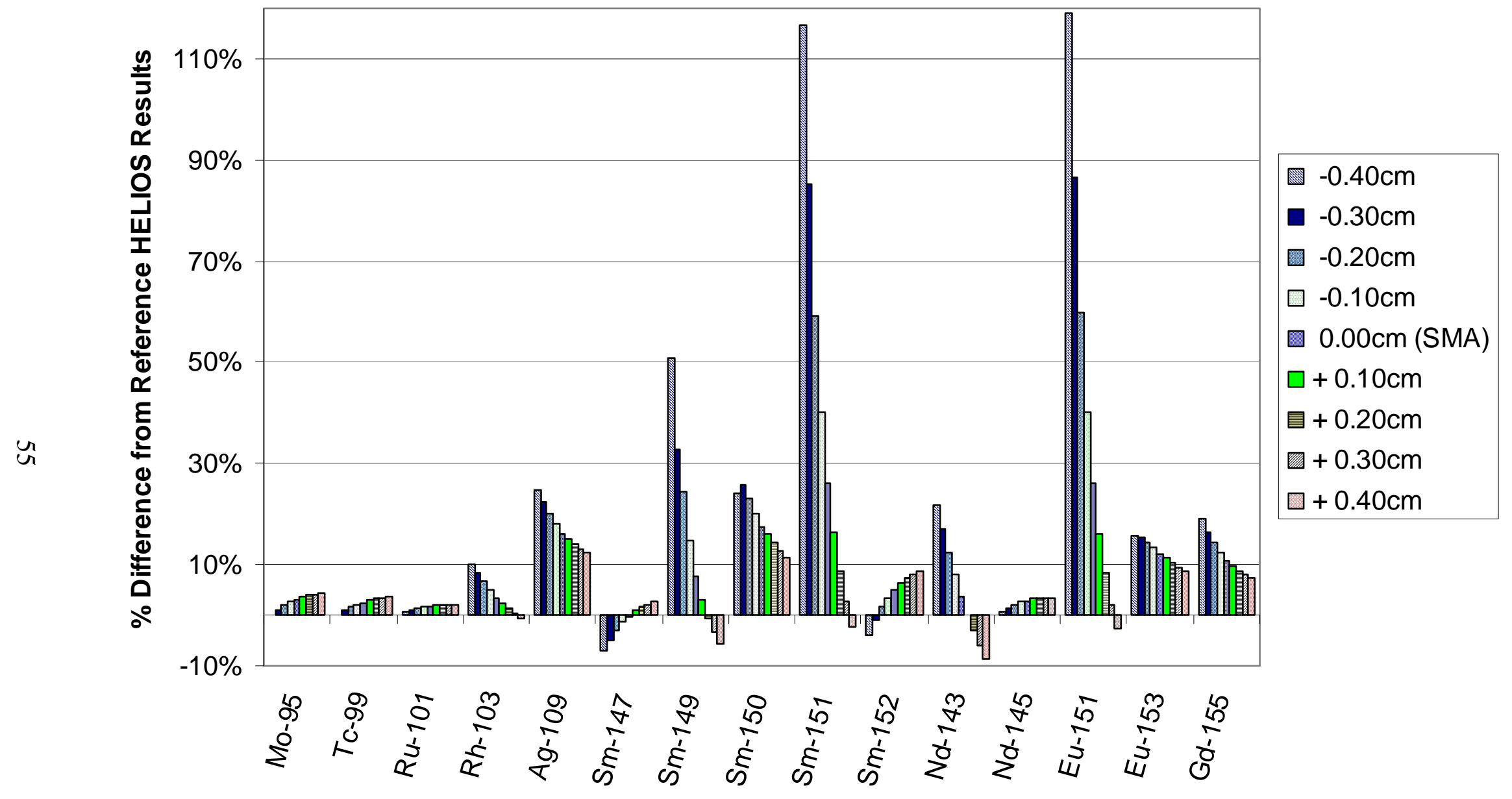

Fig. 32. Effect of varying the bypass moderator thickness on the calculated fission-product densities (relative to the reference HELIOS results) at 40-GWd/MTU burnup and 5-year cooling time. 
generally minimized with the SMA. Note, however, that the majority of the fission products are overestimated regardless of the bypass moderator thickness. No physical bases are apparent for increasing or decreasing the bypass moderator thickness. Therefore, the method for addressing water rods in the SMA appears to be justified. This can be attributed to the fact that the average neutron mean free path is approximately equivalent to the model outside radius. In the SMA model, the outside radius is dependent upon the number of gadolinium rods present in the assembly (see Subsect. 3.2.1). As the number of gadolinium rods decreases, the model outside radius increases. Therefore, the aforementioned condition may not always exist, and thus, this approach may not be acceptable for these cases (e.g., assemblies with very few gadolinium rods). Note, however, that the mean free path increases as the number of gadolinium rods decreases. A survey of recent BWR fuel designs suggests that this condition (relative equivalence between the mean free path and the model outer radius) will typically exist.

\subsubsection{Effect of Uniform Fuel Enrichment in SAS2H}

As discussed in previous sections, SAS2H is limited to a single fuel enrichment. In contrast, the distribution of fuel pin enrichments may be explicitly represented with HELIOS. Therefore, this difference in modeling may account for some of the observed differences in the results. To investigate the effect of this modeling difference, HELIOS calculations were performed with the assembly-average enrichment in all rods to emulate the SAS2H model. Nuclide densities for the important actinides and fission products as calculated by HELIOS with the assembly-average enrichment are compared to HELIOS results with the distributed pin enrichments (reference HELIOS results) in Figs. 33 and 34 respectively. These figures show that the use of the assembly-average enrichment results in generally lower calculated actinide densities, with the effect diminishing as burnup increases, and very minor reduction in the fission products. With the notable exception of ${ }^{235} \mathrm{U}$, the agreement for the most important actinides (i.e., ${ }^{235} \mathrm{U},{ }^{238} \mathrm{U},{ }^{239} \mathrm{Pu},{ }^{240} \mathrm{Pu}$, and ${ }^{241} \mathrm{Pu}$ ) improves with burnup (with the assembly-average enrichment approximation). The differences shown for ${ }^{235} \mathrm{U}$ are consistent with those shown in Fig. 15, and thus, suggest that the observed differences in ${ }^{235} \mathrm{U}$ between HELIOS and SAS2H are related to the assembly-average enrichment approximation in SAS2H. Further, the underestimation in ${ }^{235} \mathrm{U}$ clearly increases with burnup. The effect of the assembly-average enrichment approximation on reactivity is shown in Table 13, which compares calculated $k_{\text {inf }}$ values based on isotopics from HELIOS with the assembly-average enrichment approximation and with the distributed pin enrichments (reference HELIOS results). The increasing underestimation of ${ }^{235} \mathrm{U}$ with increasing burnup, due to the assembly-average enrichment approximation, results in an increasing underestimation of $k_{\text {inf }}$ with increasing burnup. Although the SAS2H models yield similar underestimations in ${ }^{235} \mathrm{U}$, similar differences in the calculated $k_{\text {inf }}$ values were not observed due to offsetting differences in the isotopics calculated with SAS2H (i.e., the underestimation of ${ }^{235} \mathrm{U}$ is offset by an overestimation of ${ }^{239} \mathrm{Pu}$ and ${ }^{241} \mathrm{Pu}$ ). 


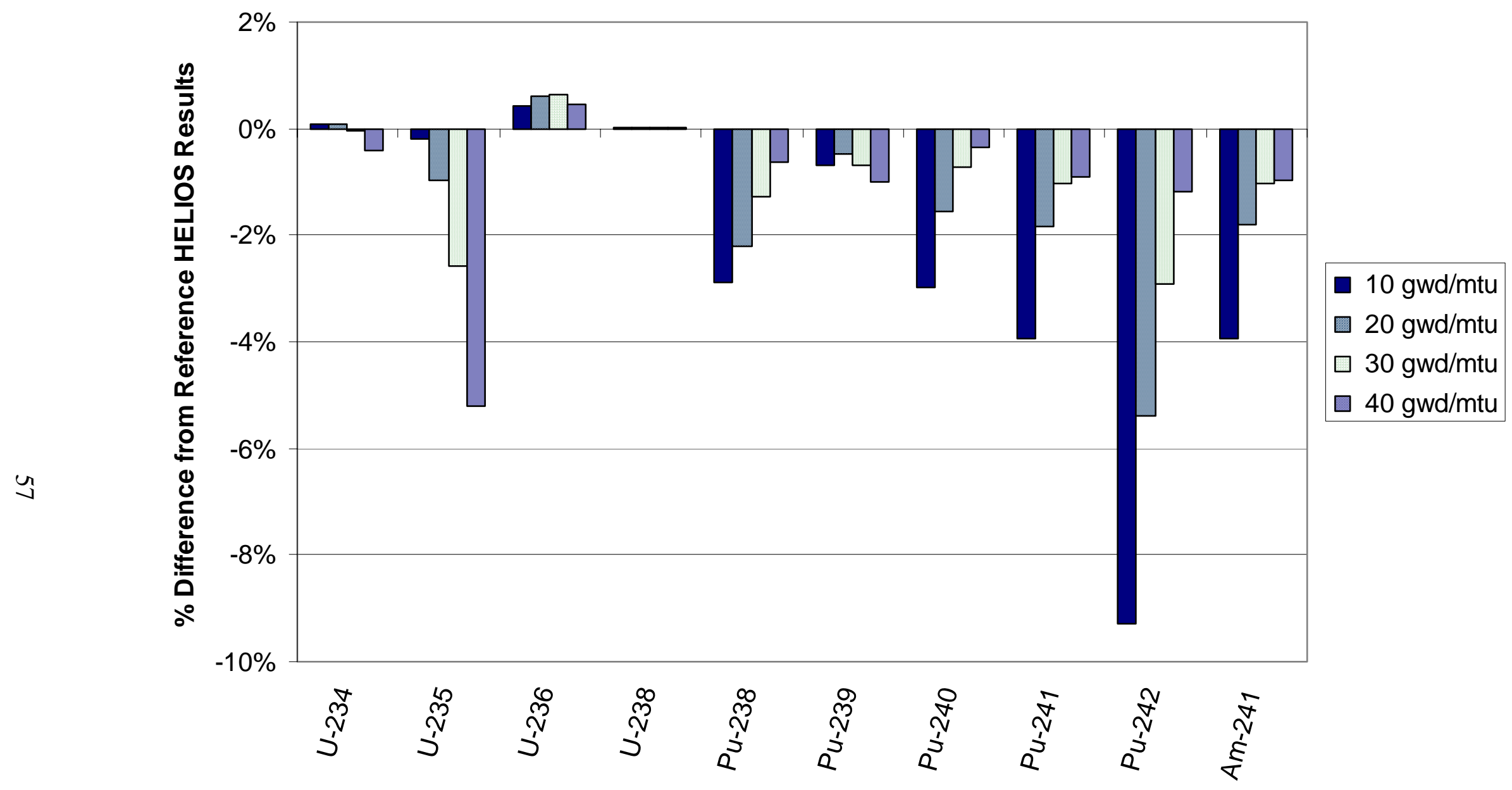

Fig. 33. Effect of the average-enrichment assumption on calculated actinide densities for various burnups (HELIOS-toHELIOS comparison). 


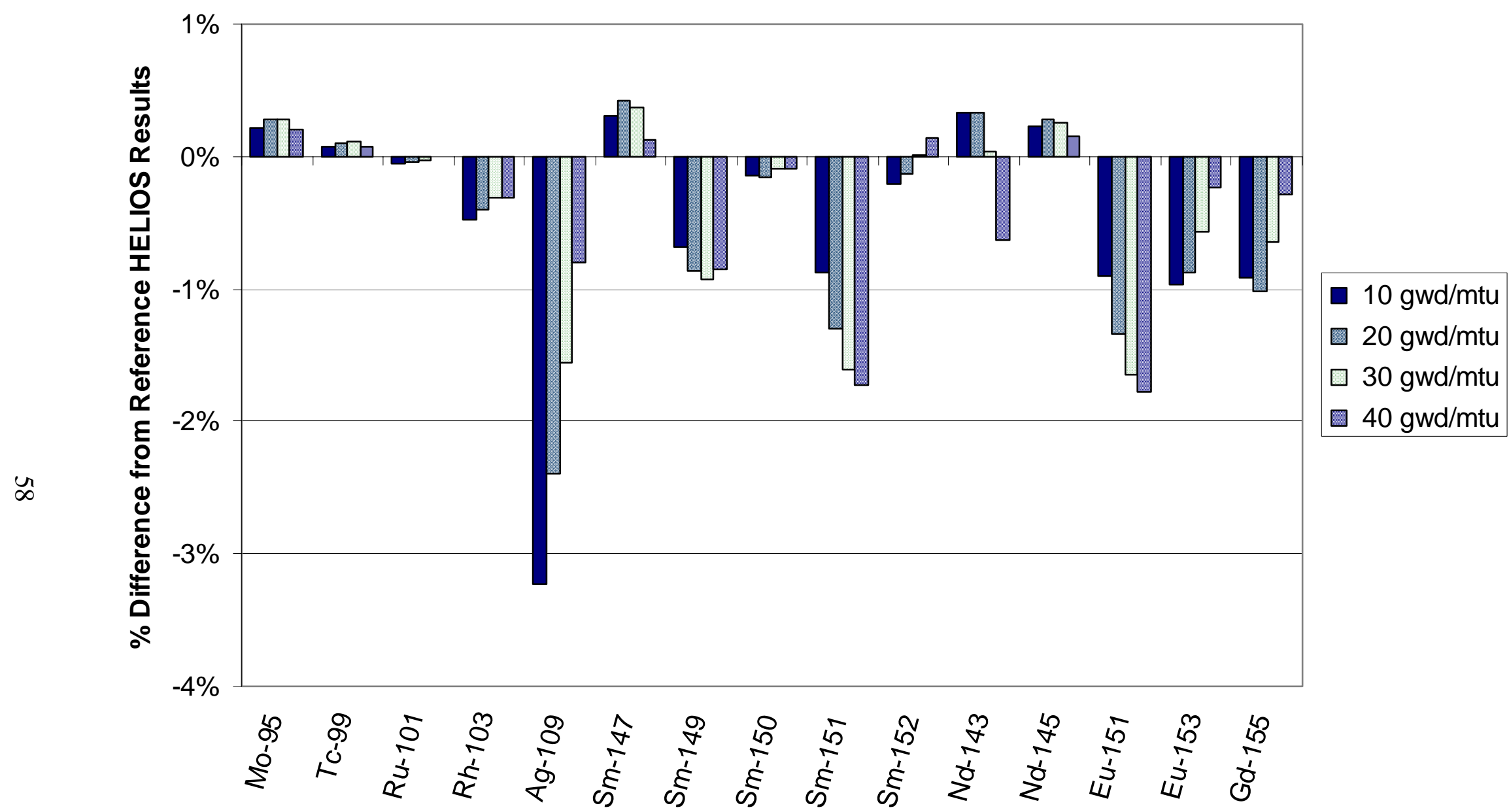

Fig. 34. Effect of the average-enrichment assumption on calculated fission-product densities for various burnups (HELIOS-to-HELIOS comparison). 
Table 13 Calculated $\boldsymbol{k}_{\text {inf }}$ values as a function of burnup based on isotopics from HELIOS, assuming assembly-average enrichment and 5-year cooling time

\begin{tabular}{|c|c|c|c|c|c|c|}
\hline & \multicolumn{3}{|c|}{ Actinide-only } & \multicolumn{3}{|c|}{ Actinide + fission-products } \\
\hline $\begin{array}{c}\text { Burnup } \\
(\mathrm{GWd} / \mathrm{MTU})\end{array}$ & $k_{\text {inf }}$ & $\begin{array}{l}\text { Standard } \\
\text { deviation }\end{array}$ & $\begin{array}{l}\text { Difference } \\
\text { from } \\
\text { reference } \\
\text { HELIOS }\end{array}$ & $k_{\text {inf }}$ & $\begin{array}{l}\text { Standard } \\
\text { deviation }\end{array}$ & $\begin{array}{c}\begin{array}{c}\text { Difference } \\
\text { from }\end{array} \\
\text { reference } \\
\text { HELIOS }\end{array}$ \\
\hline \multicolumn{7}{|c|}{ HELIOS, assuming assembly-average enrichment } \\
\hline 10 & 1.29074 & 0.00036 & 0.00071 & 1.24750 & 0.00037 & 0.00090 \\
\hline 20 & 1.18425 & 0.00036 & -0.00069 & 1.11572 & 0.00036 & -0.00221 \\
\hline 30 & 1.05655 & 0.00032 & -0.00591 & 0.97027 & 0.00033 & -0.00502 \\
\hline 40 & 0.92641 & 0.00031 & -0.00908 & 0.82808 & 0.00027 & -0.00888 \\
\hline
\end{tabular}

It is postulated that the average enrichment approximation, which artificially increases the enrichment on the assembly periphery where the neutron spectrum is softer, results in an increase in ${ }^{235} \mathrm{U}$ depletion. However, the average enrichment approximation also artificially reduces the enrichment in the inner region of the assembly where the gadolinium rods are located, and thus, may reduce the effect of the gadolinium and subsequently contribute to the increase in ${ }^{235} \mathrm{U}$ depletion. To investigate this behavior further and attempt to isolate the cause of the discrepancy, the following two additional HELIOS calculations were performed: (1) explicit distributed pin enrichments without gadolinium present and (2) assembly-average enrichment without gadolinium present. Calculated nuclide densities for the important actinides and fission products are compared in Figs. 35 and 36, respectively. Figures 33 and 35 are nearly identical, which indicates that the difference observed in the actinide concentrations are due to the assembly-average enrichment approximation and not to the presence of the gadolinium rods. Comparison of Figs. 34 and 36 show that while not identical, most of the differences observed in the fission-product concentrations are also due to the assembly-average enrichment approximations. Thus, the observed differences in ${ }^{235} \mathrm{U}$ between HELIOS and SAS2H are attributed to the assembly-average enrichment approximation in SAS2H. 


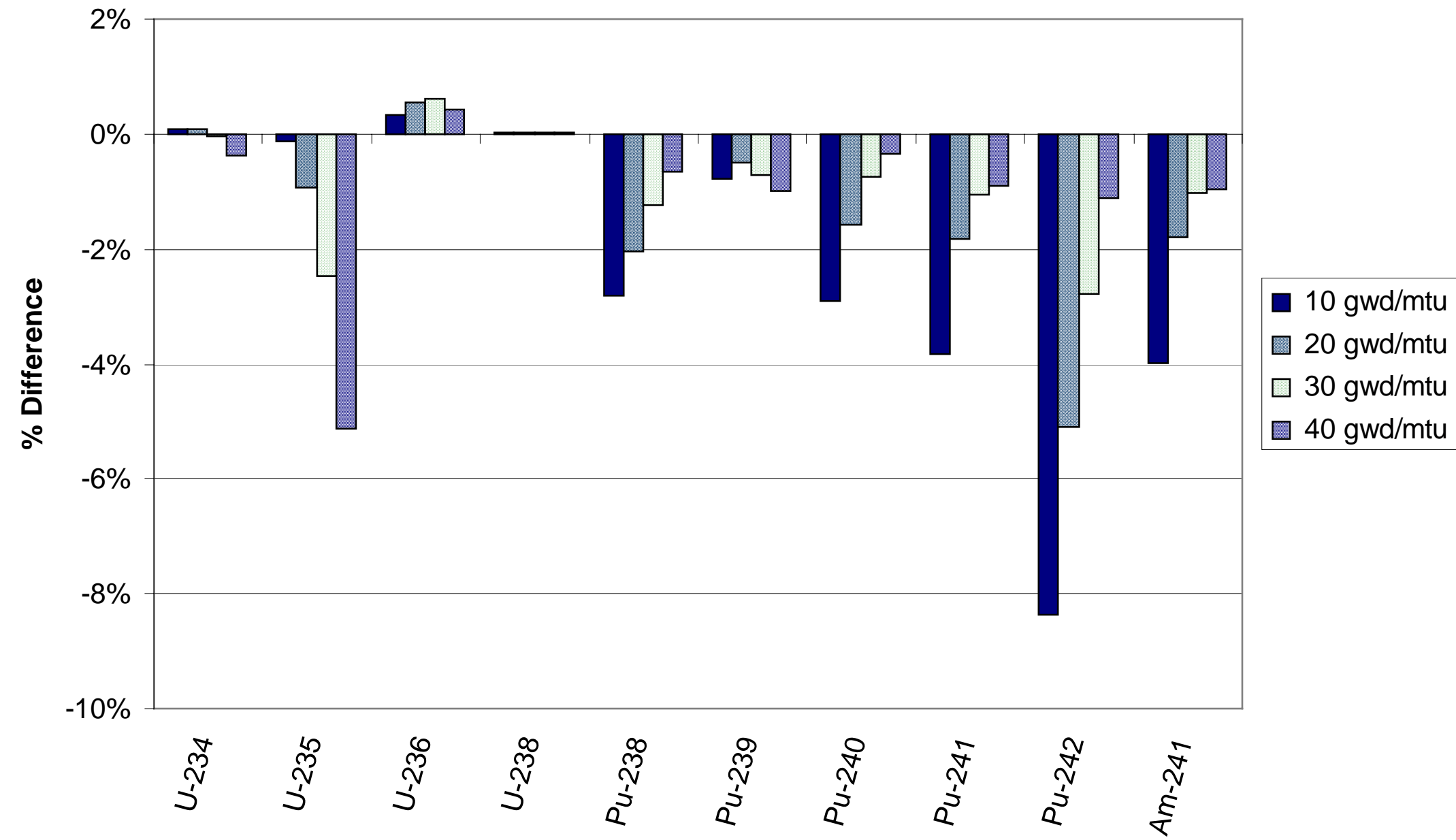

Fig. 35. Effect of the average-enrichment assumption (without gadolinium rods present) on calculated actinide densities for various burnups. Percentage differences are between actinide densities calculated by HELIOS with the assemblyaverage enrichment (without gadolinium present) and those calculated by HELIOS with the explicit pin enrichments (without gadolinium present). The latter case is used as the reference. 


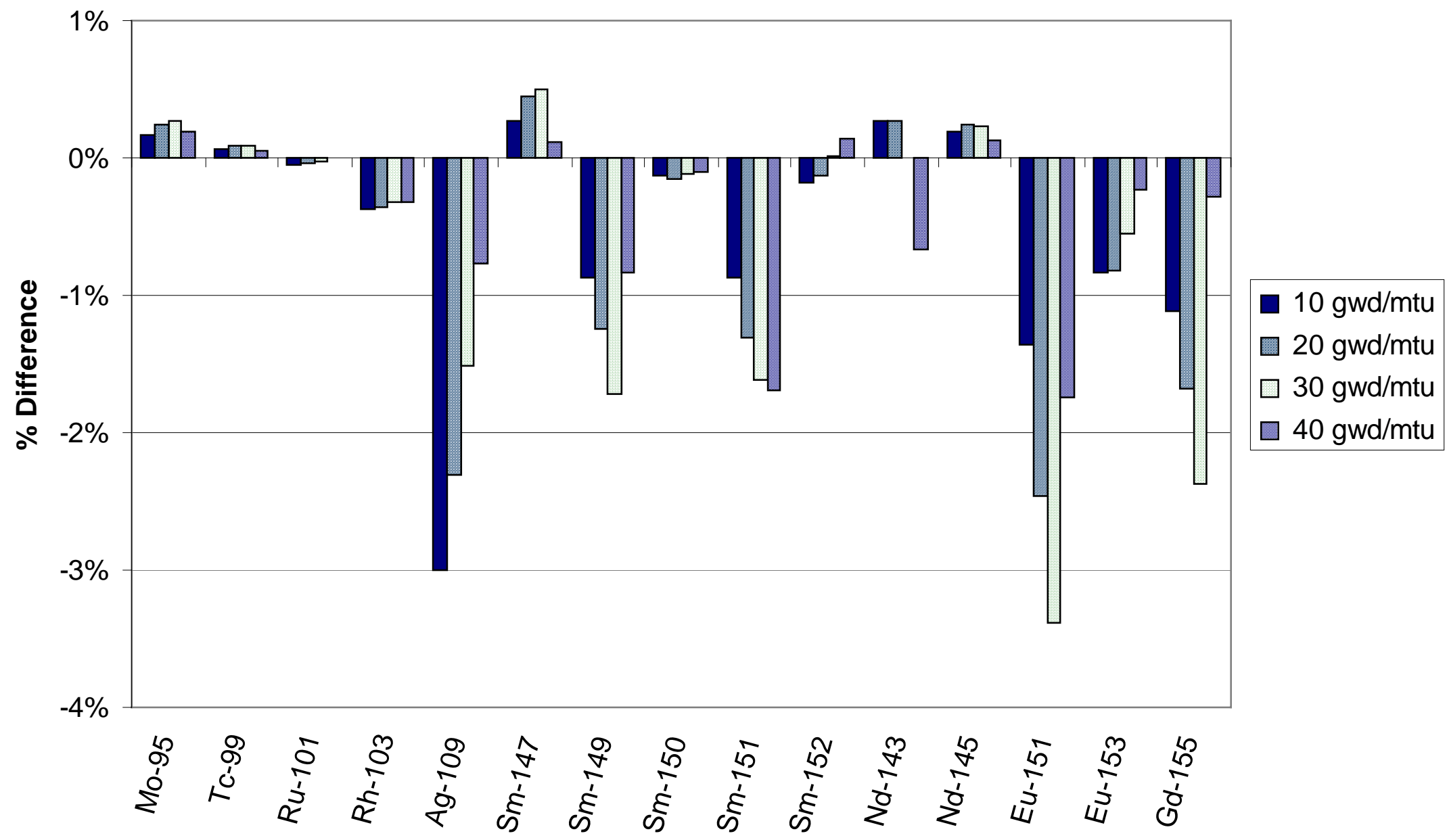

Fig. 36. Effect of the average-enrichment assumption (without gadolinium rods present) on calculated fission-product densities for various burnups. Percentage differences are between fission-product densities calculated by HELIOS with the assembly-average enrichment (without gadolinium present) and those calculated by HELIOS with the explicit pin enrichments (without gadolinium present). The latter case is used as the reference. 


\subsection{MODELING RECOMMENDATIONS AND CONCLUSIONS}

Limitations in the geometric modeling capabilities of SAS2H motivated the investigation of alternative geometric modeling approaches. Specifically, better physical representation and better agreement with HELIOS, with respect to the SMA, were sought. Although minor improvements (relative to HELIOS) over the SMA for some of the nuclides were shown, none of the modeling approaches considered represent a significant improvement over the SMA.

The SMA and two-fuel-region models were shown to behave similarly throughout burnup, and thus, the two-fuel region model is as good or nearly as good as the SMA model throughout burnup for the actinides and fission products considered. Thus, the two-fuel-region modeling approach may find some application in the future. The one- and three-fuel-region models were shown to be less accurate for lower burnups due to the homogenization of the gadolinium in the fuel. The problem is magnified in the case of the three-fuel region model because of the lack of self-shielding for the gadolinium cross sections. Thus, the one- and threefuel-region models do not appear promising for any future consideration. Finally, note that all of the models considered herein converge to nearly the same solution after the effect of the gadolinium absorption is burned away.

In general, SAS2H is overpredicting nuclide concentrations relative to HELIOS, with the significant exception of ${ }^{235} \mathrm{U}$. The underestimation of ${ }^{235} \mathrm{U}$ was found to be associated with the limitation of a single fuel enrichment in the SAS2H model and was shown to increase as a function of burnup. Although relatively large differences were observed in some of the calculated nuclide densities, the calculated $k_{\text {inf }}$ values based on isotopics from HELIOS were found to be in generally good agreement with those based on isotopics from SAS2H. This good agreement can be attributed to offsetting differences in the isotopics calculated with SAS2H (e.g., the underestimation of ${ }^{235} \mathrm{U}$ is offset by an overestimation of ${ }^{239} \mathrm{Pu}$ and ${ }^{241} \mathrm{Pu}$ ), and the low importance of several of the nuclides for which large differences in concentrations were observed (e.g., ${ }^{238} \mathrm{Pu},{ }^{243} \mathrm{Am},{ }^{109} \mathrm{Ag}$ and ${ }^{151} \mathrm{Eu}$ ).

The approach for including the effect of the water rod(s) in the SMA was investigated and found to be justified. Finally, during the course of this investigation, two errors in the SAS2H sequence of SCALE version 4.4 that affect the two- and three-fuel-region modeling approaches were identified. These errors have been corrected in the version of SAS2H included in the SCALE 4.4a code package release, and thus, SCALE 4.4a should be used when employing those modeling approaches.

Based on the results presented in this section, the indication is that the approximations in the 1-D SAS2H model provide an adequate representation of depletion dynamics for a heterogeneous 2-D BWR assembly. Although not as accurate as an explicit model, the 1-D approximation appears to yield consistent results such that a reasonable bias and uncertainty could be determined in the estimation of assembly-averaged isotopic concentrations. The simplicity and relative speed of the SAS2H approach for modeling complicated systems are clear advantages over more rigorous approaches.

Similar to Assembly ZZ, newer BWR fuel designs have central moderator regions comprised of one or more large water rods, radially varying pin enrichments, and increasing reactivity as a function of burnup up to the point at which the gadolinium is nearly depleted. Therefore, the general configuration and depletion behavior are similar. In contrast to Assembly ZZ, newer BWR fuel designs typically employ larger arrays (e.g., $9 \times 9$ and $10 \times 10$ ) 
of smaller fuel rods with higher enrichments, increased gadolinium loading through higher concentrations and more gadolinium-bearing rods, and greater axial variation in enrichment and gadolinium loading. These differences in assembly designs are variations in the basic configuration, and thus, are not expected to significantly affect the conclusions of this modeling study. The axial variations in enrichment and gadolinium loading naturally necessitate separate calculations for unique axial segments and are important to the criticality calculations. 


\section{EFFECT OF DEPLETION PARAMETERS ON CALCULATED ISOTOPICS AND REACTIVITY}

In this section, the effects of various relevant depletion parameters on calculated isotopics and $k_{\text {inf }}$ are investigated. The studies are intended to gain additional understanding and identify trends that may be useful in selecting parameters that produce conservative estimations of spent fuel isotopics for depletion calculations. The parameters that were considered are discussed individually below. Although not particularly realistic, the specific parameters were varied independently while all other conditions were held constant (e.g., the fuel temperature was held constant while the specific power was varied). All calculations in this section were performed with SAS2H (SMA Model) and correspond to 40-GWd/MTU burnup and 5-year cooling time. Also, all criticality calculations in this section are 2-D, and thus, do not include axial effects. The sensitivity of 3-D criticality calculations, which include axial variations, to depletion assumptions is examined in Sect. 5.

The criticality calculations discussed in this section, and throughout this report, were performed with KENO V.a at $20^{\circ} \mathrm{C}$, utilizing the SCALE 44-group (ENDF/B-V) library. The actinides and fission products included in these calculations are listed in Table 5. Note, the KENO V.a model for the criticality calculations discussed in this section is a 2-D assembly model with reflective boundary conditions on all six sides, which represents an infinite radial array of infinite-length assemblies.

\subsection{SPECIFIC POWER}

SAS2H depletion calculations have been performed for axially averaged specific powers ranging from 10 to $50 \mathrm{MW} / \mathrm{MTU}$. Although variations in specific power will be axially and operationally time-dependent, the selected range should capture the relevant operating range. The calculated densities for the important actinides and fission products are compared in Figs. 37 and 38. For the purpose of comparison, the reference corresponds to $30 \mathrm{MW} / \mathrm{MTU}$, which is a typical value for the average specific power in a BWR. With the exceptions of ${ }^{238} \mathrm{Pu}$ and ${ }^{241} \mathrm{Am}$, the important actinide concentrations are not particularly sensitive to the variations in specific power. The aforementioned actinides are shown to increase significantly with decreasing specific power, which would tend to reduce reactivity. The fissile actinides ${ }^{235} \mathrm{U},{ }^{239} \mathrm{Pu}$, and ${ }^{241} \mathrm{Pu}$ are shown to decrease slightly with decreasing specific power, which would also tend to reduce reactivity. Almost all of the fission products shown in Fig. 38, including the important fission products ${ }^{149} \mathrm{Sm}$ and ${ }^{151} \mathrm{Sm}$, decrease with decreasing specific power, which would tend to increase reactivity. 


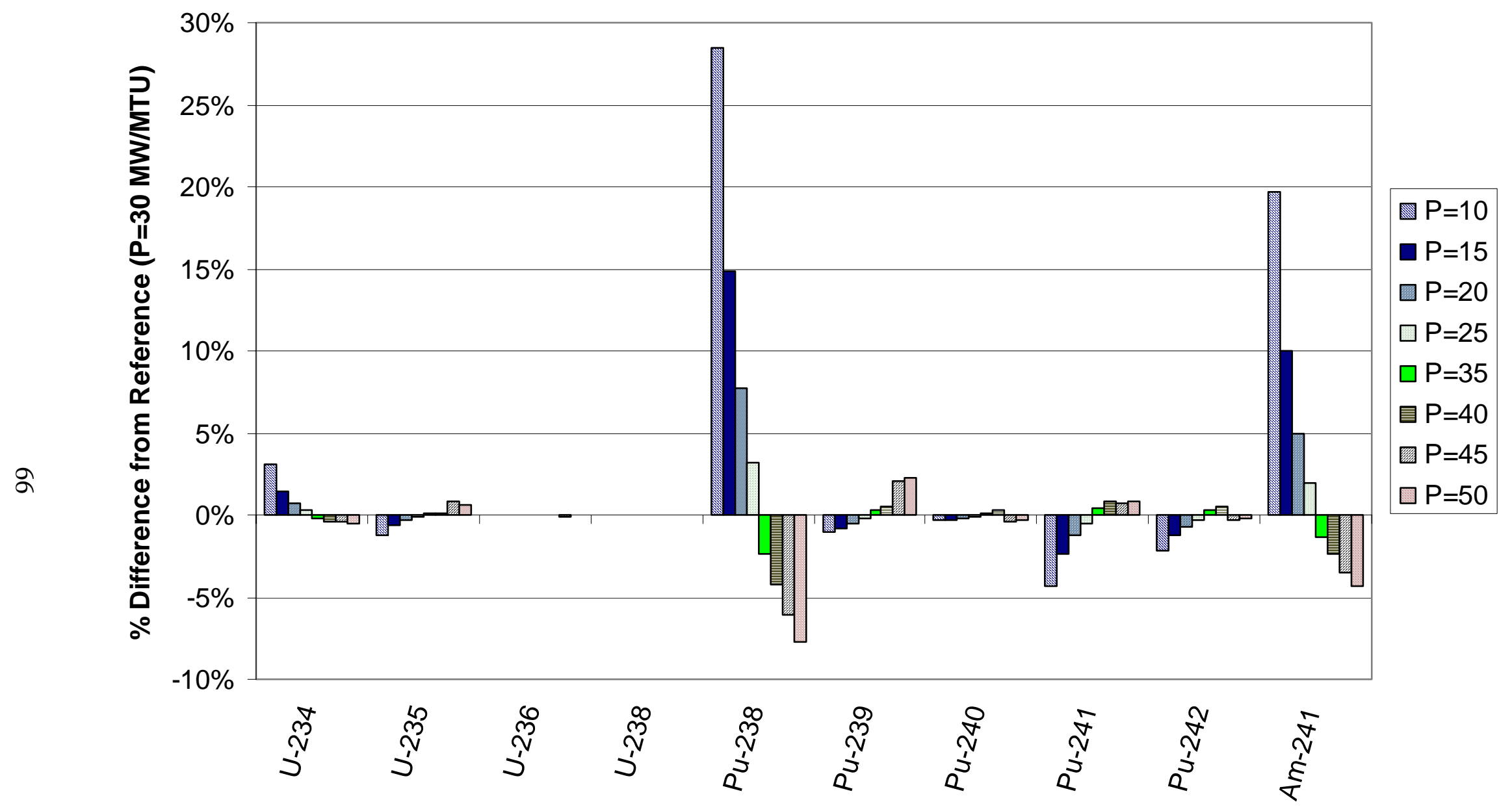

Fig. 37. Effect of specific power during depletion on actinide densities (40-GWd/MTU burnup, 5-year cooling). 


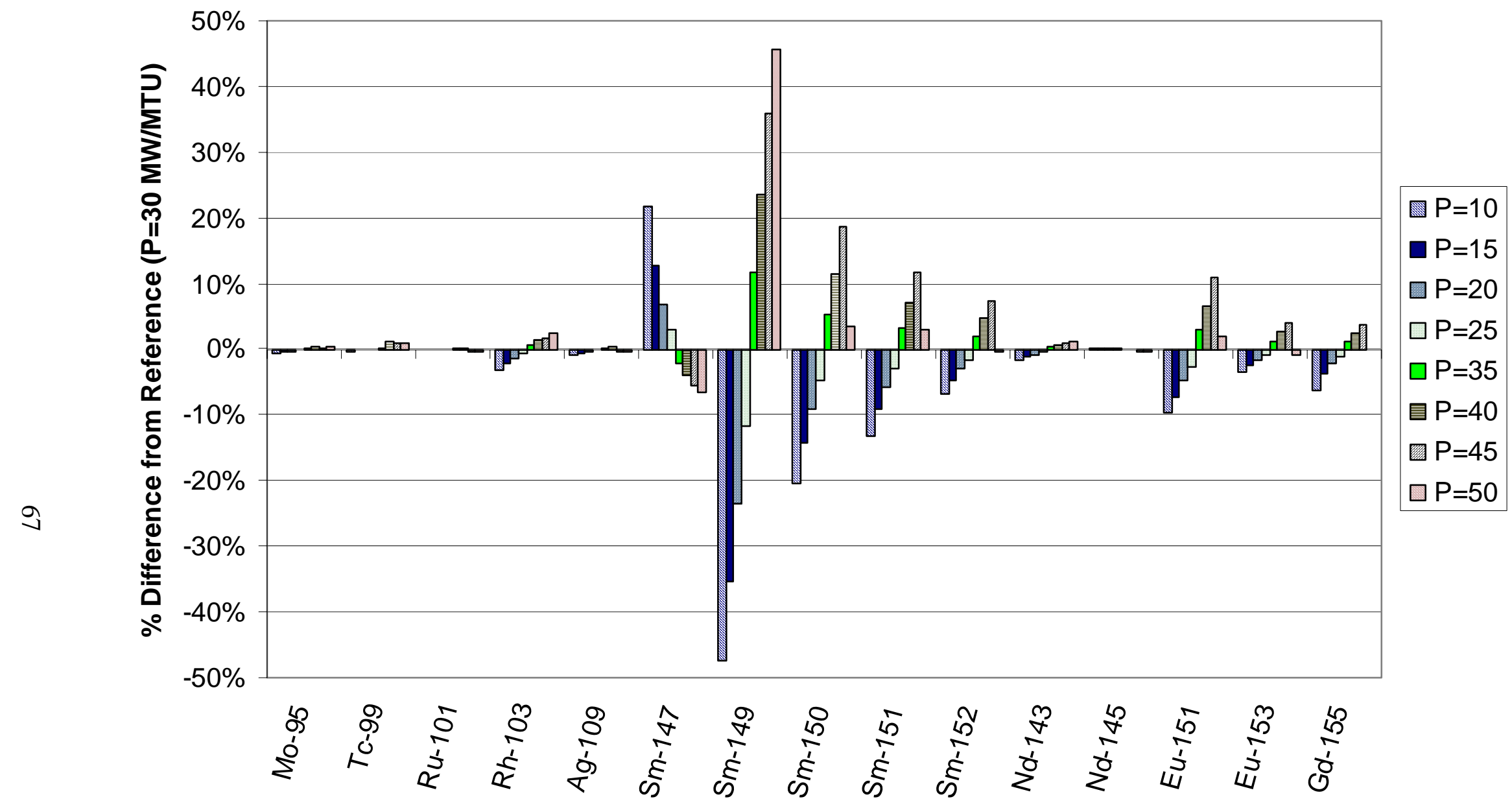

Fig. 38. Effect of specific power during depletion on fission-product densities (40-GWd/MTU burnup, 5-year cooling). 
The various effects are assembled in Fig. 39, which plots $k_{\text {inf }}$ (with and without fission products included) as a function of the specific power used during depletion. Consideration of only the actinides results in increasing reactivity with increasing specific power, which is consistent in behavior and magnitude with a previous study for PWR fuels. 3 However, inclusion of the fission products offsets the increase due to actinides, which is also consistent with the previous PWR work.

\subsection{MODERATOR DENSITY}

SAS2H depletion calculations have been performed for moderator densities ranging from 0.2 to $0.9 \mathrm{~g} / \mathrm{cm}^{3}$. The selected range is based on actual operating history data from Assembly ZZ. The calculated densities for the important actinides and fission products are compared in Figs. 40 and 41. For the purpose of comparison, the reference corresponds to $0.6 \mathrm{~g} / \mathrm{cm}^{3}$. As expected, and consistent with other studies, $3 / 14$ variations in the moderator density have a significant effect on the important actinides. Specifically, as the moderator density decreases, the fissile actinides $\left({ }^{235} \mathrm{U},{ }^{239} \mathrm{Pu}\right.$, and $\left.{ }^{241} \mathrm{Pu}\right)$ increase substantially, which would tend to increase reactivity. The rate of increase for these actinides is shown to be greater at lower moderator densities (i.e., the sensitivity increases as the moderator density decreases). With the exceptions of ${ }^{238} \mathrm{Pu}$ and ${ }^{241} \mathrm{Am}$ (and to a lesser extent, ${ }^{240} \mathrm{Pu}$ ), which increase with decreasing moderator density, the remaining important actinides are not significantly affected. Several important fission products, including ${ }^{149} \mathrm{Sm},{ }^{151} \mathrm{Sm},{ }^{143} \mathrm{Nd}$, and ${ }^{155} \mathrm{Gd}$, increase notably with decreasing moderator density, which would tend to reduce reactivity.

The effects are united in Fig. 42, which plots $k_{\text {inf }}$ (with and without fission products included) as a function of the moderator density used during depletion. In both cases (i.e., with or without fission products present), the reactivity increases substantially ( $40 \%$ over the range considered here) with decreasing moderator density, which is consistent with a previous study

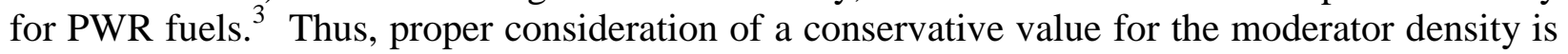
very important for burnup credit.

\subsection{FUEL DENSITY}

To examine the effect of fuel density, depletion calculations were performed for fuel densities ranging from 9.0 to $10.75 \mathrm{~g} / \mathrm{cc}$. The fuel length in SAS2H was varied to maintain a constant fuel mass. The actinide and fission-product densities are compared in Figs. 43 and 44. For the purpose of comparison, the reference corresponds to $10.0 \mathrm{~g} / \mathrm{cc}$. The effect of fuel density on the important actinide and fission product concentrations is shown to be relatively small (less than $15 \%$ ) over the entire range considered here. Naturally, the uranium and plutonium isotopes increase with increasing density. Several of the important fission products, including ${ }^{149} \mathrm{Sm}$, ${ }^{151} \mathrm{Sm}$, and ${ }^{143} \mathrm{Nd}$, are also shown to increase with increasing fuel density.

The effect of fuel density on reactivity is shown in Fig. 45. For the criticality calculations, the isotopic densities are extracted from SAS2H and input into the KENO V.a model, and thus the mass of fissile material is not held constant. Consequently, the calculated reactivity effect is not solely due to the change in fuel density. As expected, increased fuel density results in increased reactivity. Although the authors are not aware of any similar fuel density studies for PWR fuel, similar behavior is expected. 


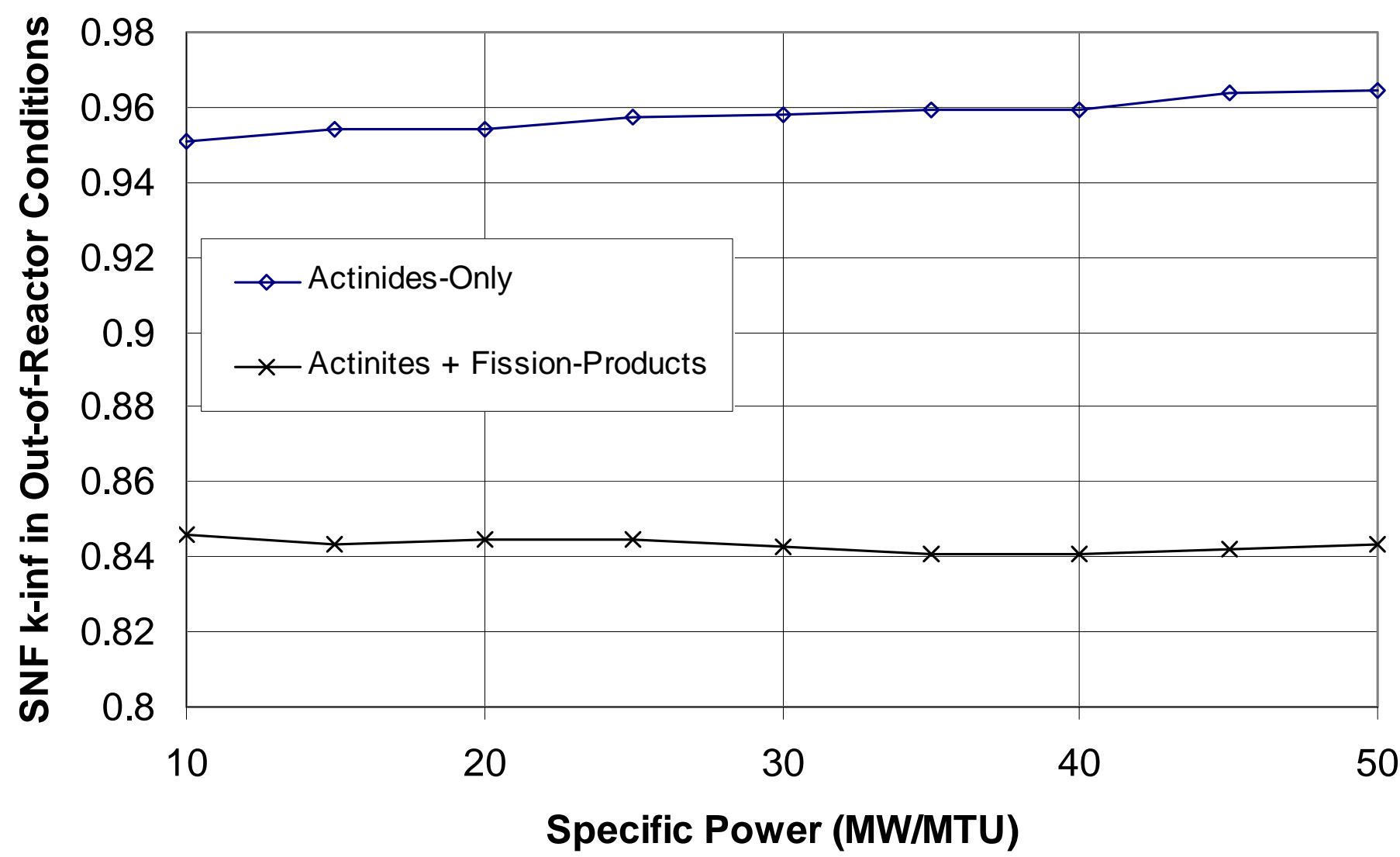

Fig. 39. Effect of specific power during depletion on SNF $\boldsymbol{k}_{\text {inf }}$ (40-GWd/MTU burnup, 5-year cooling). 


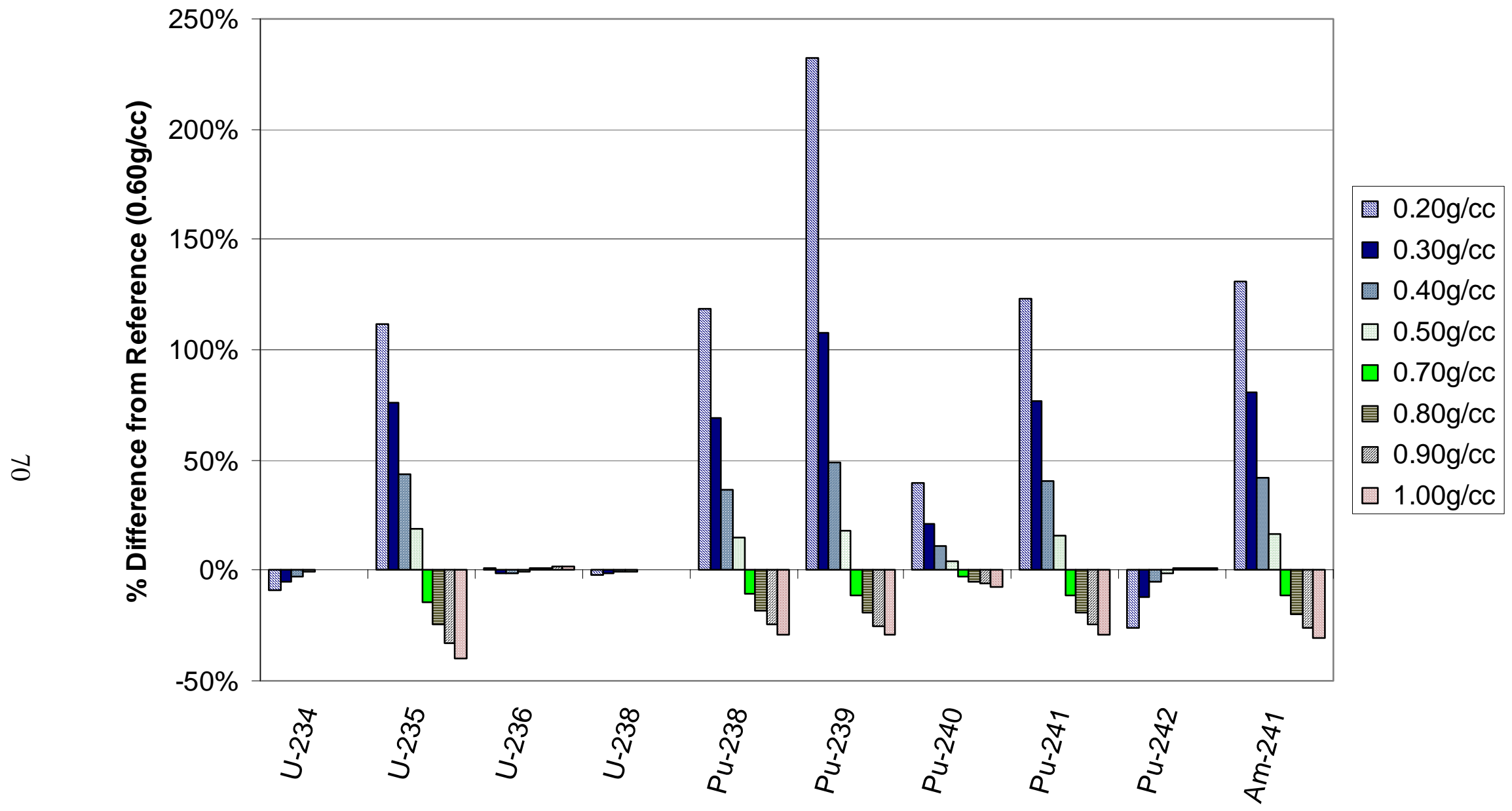

Fig. 40. Effect of moderator density during depletion on actinide densities (40-GWd/MTU burnup, 5-year cooling). 


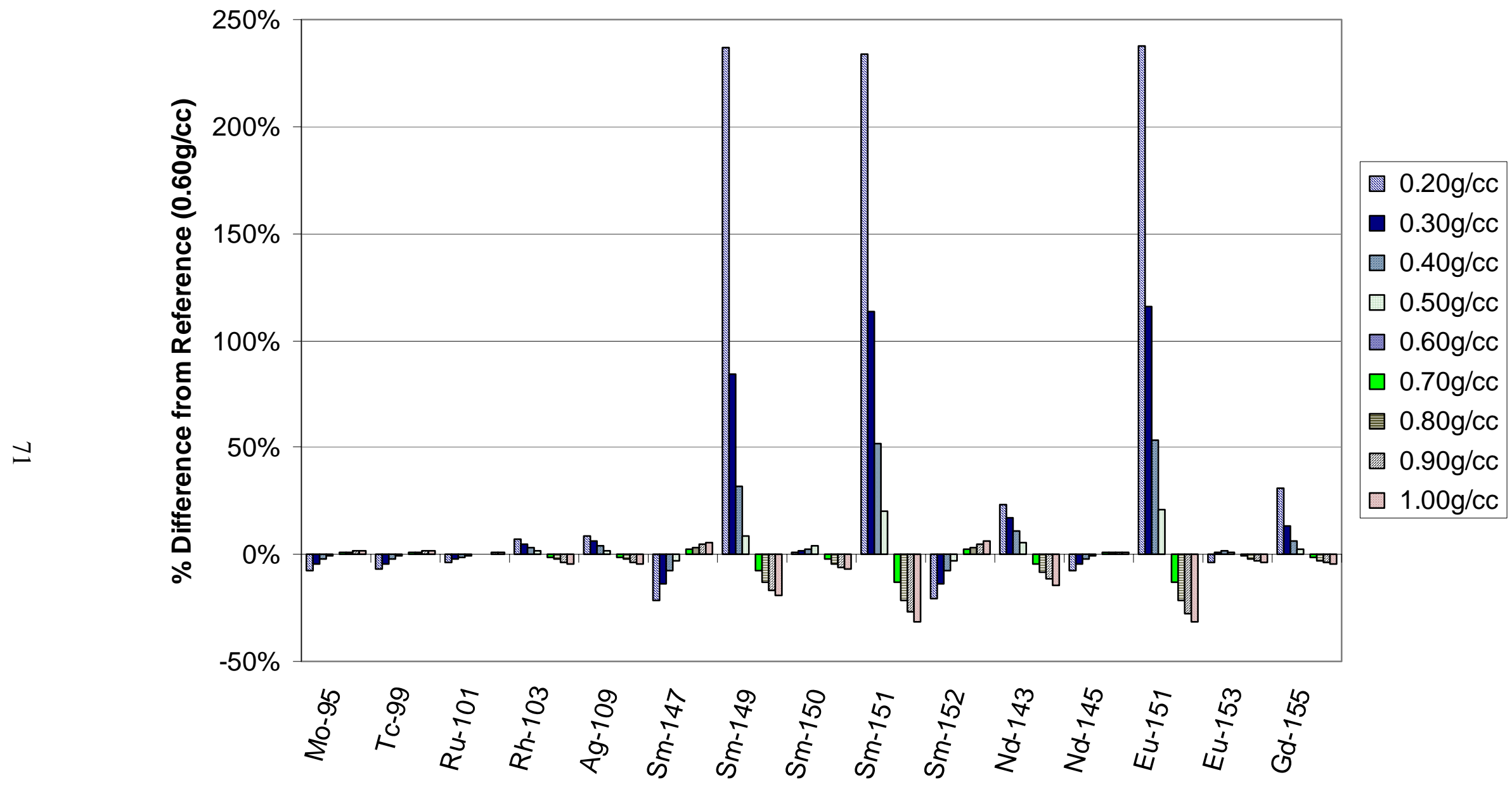

Fig. 41. Effect of moderator density during depletion on fission-product densities (40-GWd/MTU burnup, 5-year cooling). 


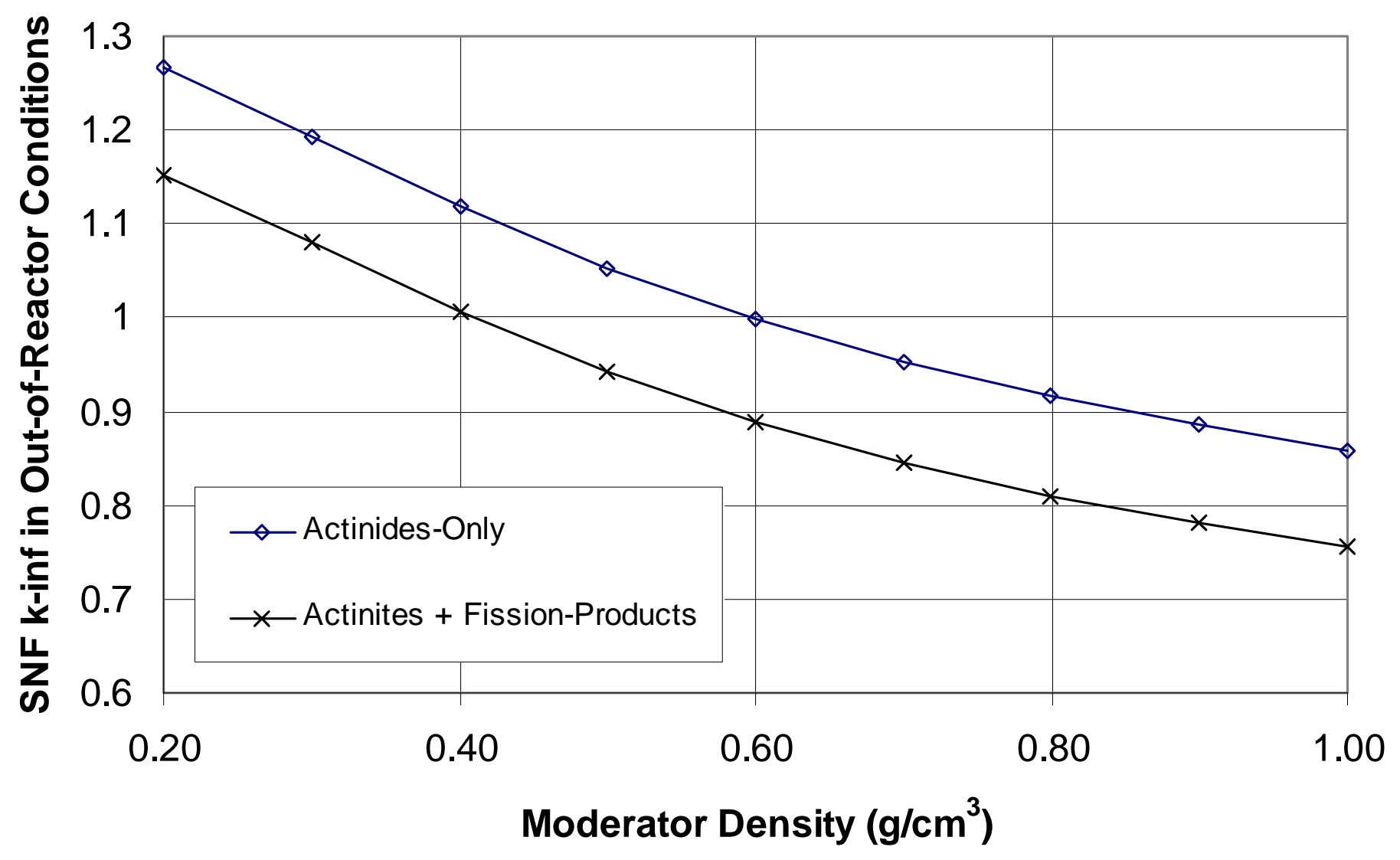

Fig. 42. Effect of moderator density during depletion on $\boldsymbol{k}_{\text {inf }}$ (40-GWd/MTU burnup, 5-year cooling). 


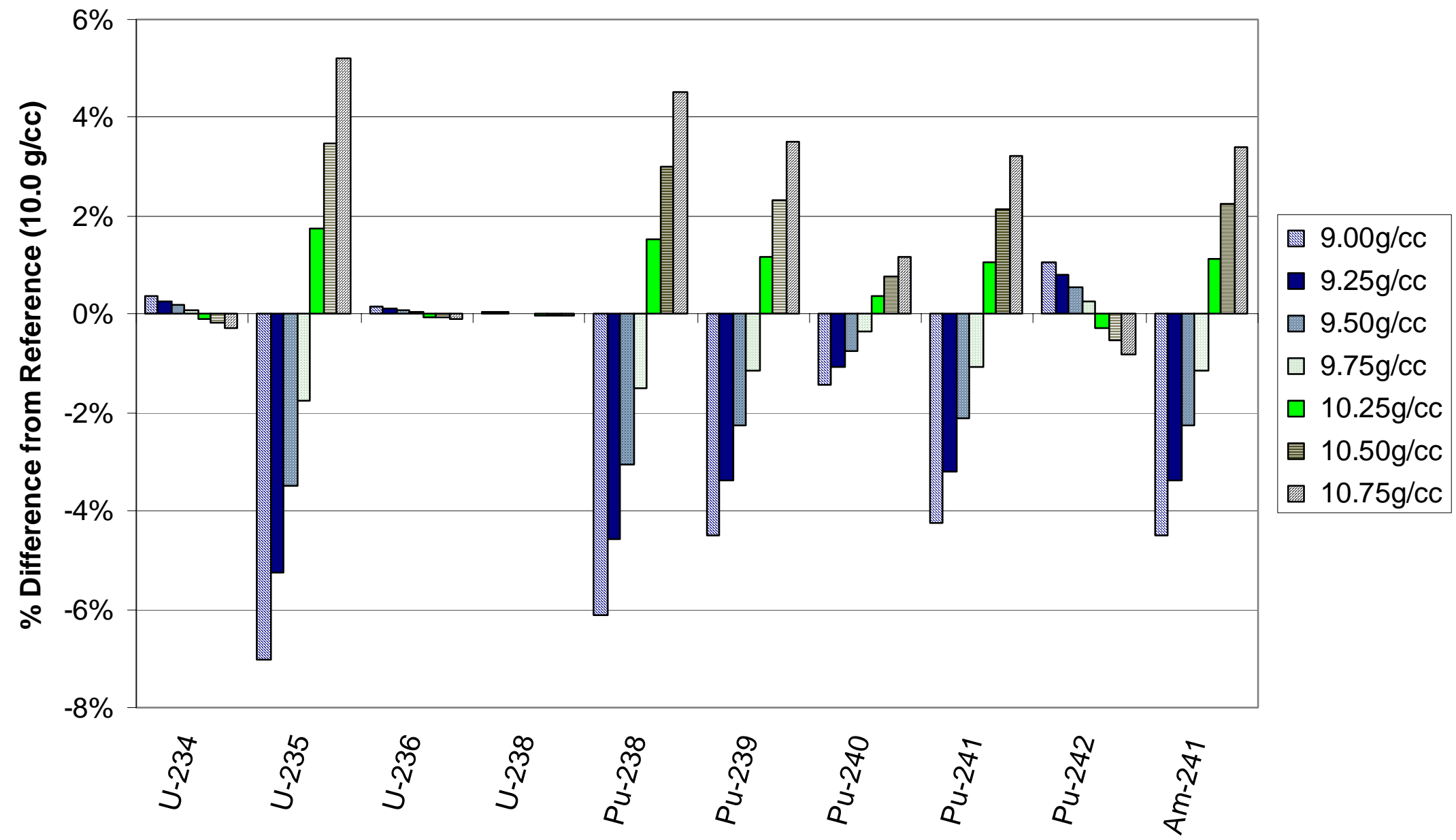

Fig. 43. Effect of fuel density on actinide densities (40-GWd/MTU burnup, 5-year cooling). 


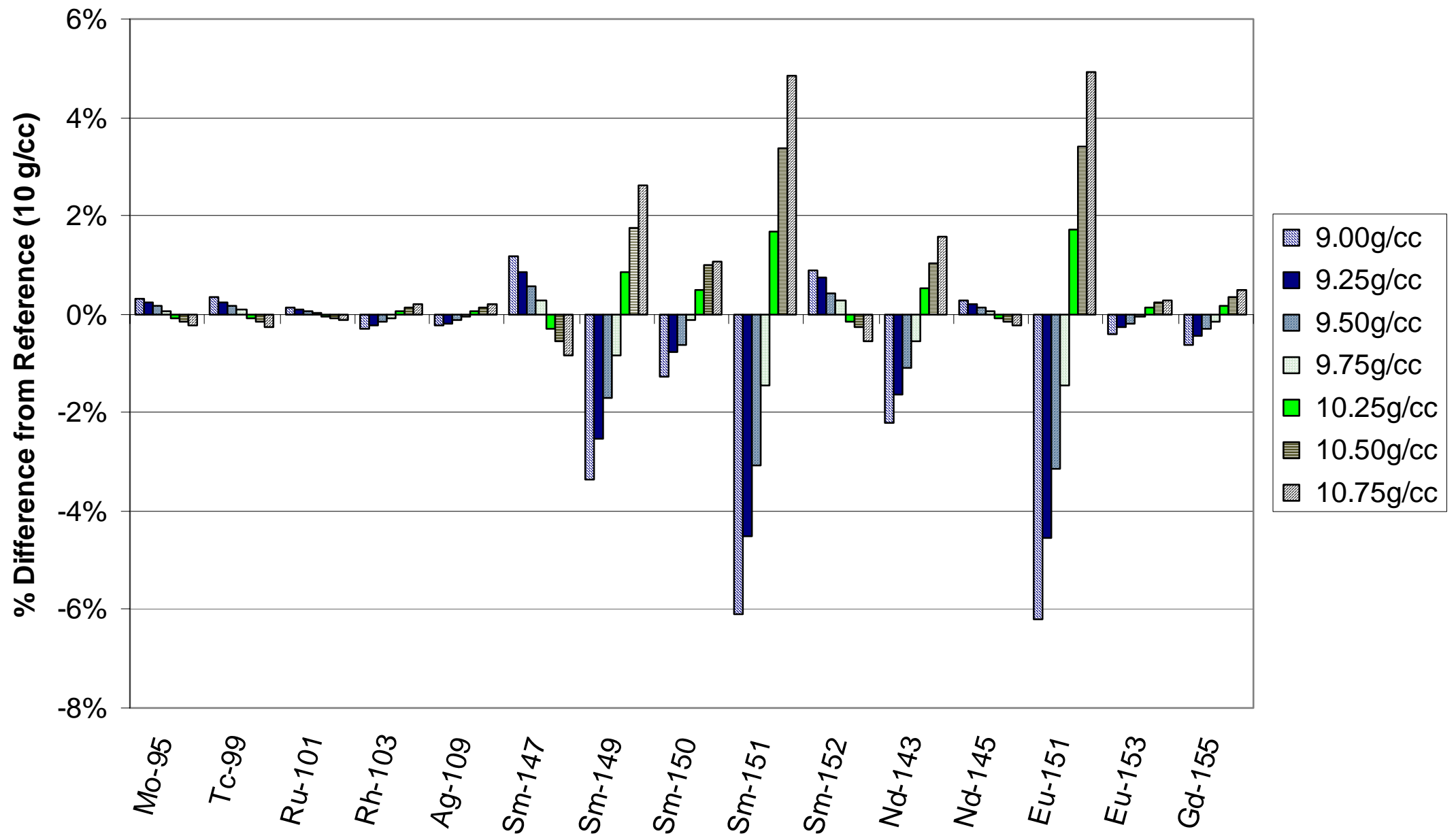

Fig. 44. Effect of fuel density on fission-product densities (40-GWd/MTU burnup, 5-year cooling). 


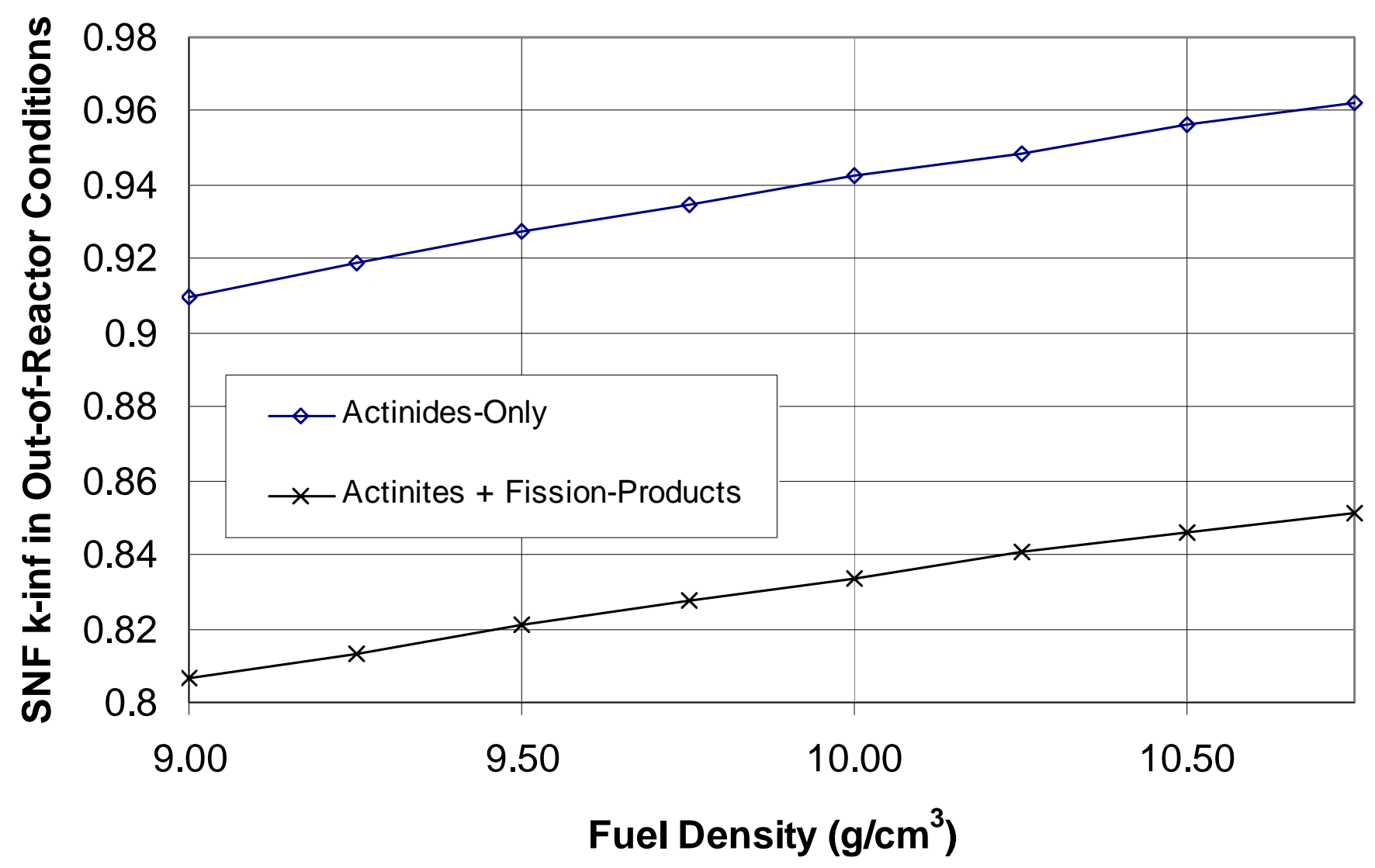

Fig. 45. Effect of fuel density on $\boldsymbol{k}_{\text {inf }}$ (40-GWd/MTU burnup, 5-year cooling). 


\subsection{FUEL TEMPERATURE}

The effect of fuel temperature in depletion calculations has been investigated for fuel temperatures ranging from 500 to $1300 \mathrm{~K}$. The actinide and fission-product densities are compared in Figs. 46 and 47. For the purpose of comparison, the reference corresponds to $900 \mathrm{~K}$. Consistent with other studies, ${ }^{3,14}$ variations in the fuel temperature have a relatively small effect on the density of important actinides. Specifically, as the fuel temperature increases, the fissile actinides $\left({ }^{235} \mathrm{U},{ }^{239} \mathrm{Pu}\right.$, and $\left.{ }^{241} \mathrm{Pu}\right)$ increase, which increases reactivity, and the fission products increase, which decreases reactivity. The rate of increase for the actinides is shown to be relatively constant over the temperature range considered here. ${ }^{241} \mathrm{Am}$ is also shown to increase notably with increasing fuel temperature.

The effect of fuel temperature (during depletion) on reactivity is shown in Fig. 48. Increased fuel temperature (during depletion) results in increased reactivity, approximately $3 \%$ over the range considered here. This increase is due primarily to the change in the actinides; the variation in the fission products with fuel temperature has a very small effect on the reactivity. Note that all criticality calculations were performed at $20^{\circ} \mathrm{C}$.

\subsection{FREQUENCY OF CROSS-SECTION LIBRARY UPDATES}

Fuel cross sections vary with burnup due to changes in nuclide concentrations and the resulting shift in spectrum. SAS2H can account for this variation by generating and utilizing burnup-dependent cross-section libraries. The SAS2H default is to use three cycles with one library per cycle, or in other words, three burnup-dependent libraries over the duration of depletion. The use of a greater number of libraries will better represent the changes in the fuel cross sections, however, at the expense of computer time. Thus, in this section, calculations are performed to determine the effect of varying the frequency of cross-section library updates used in the SAS2H calculation.

SAS2H depletion calculations have been performed using various numbers of library updates ranging from 1 library per $40 \mathrm{GWd} / \mathrm{MTU}$ to 1 library per $0.5 \mathrm{GWd} / \mathrm{MTU}$ (total of 80 libraries). The calculations used one library/cycle and varied the number of cycles to utilize more libraries during the depletion. The actinide and fission-product densities are compared in Figs. 49 and 50. For the purpose of comparison, the reference case uses 80 libraries, which corresponds to $0.5 \mathrm{GWd} / \mathrm{MTU}$ per library (for $40 \mathrm{GWd} / \mathrm{MTU}$ ). Figure 49 demonstrates that the important actinide concentrations are dependent upon the number of libraries used, with significant differences observed for the cases involving 5 or fewer libraries. Likewise, Fig. 50 shows significant dependence for several of the important fission products. The dependence is relatively minor (within a few percent) for cases using frequent library updates (e.g., 2 GWd/MTU per library).

The effect of the frequency of cross-section library updates used during depletion on reactivity is shown in Fig. 51. With and without fission products, the $k_{\text {inf }}$ is shown to converge to a constant value with approximately $10 \mathrm{SAS} 2 \mathrm{H}$ libraries (4 GWd/MTU per library). Significant overestimations in $k_{\text {inf }}$ are observed when less than $5 \mathrm{SAS} 2 \mathrm{H}$ libraries are used. Studies to establish standard user guidance for the frequency of cross-section library updates are ongoing. 


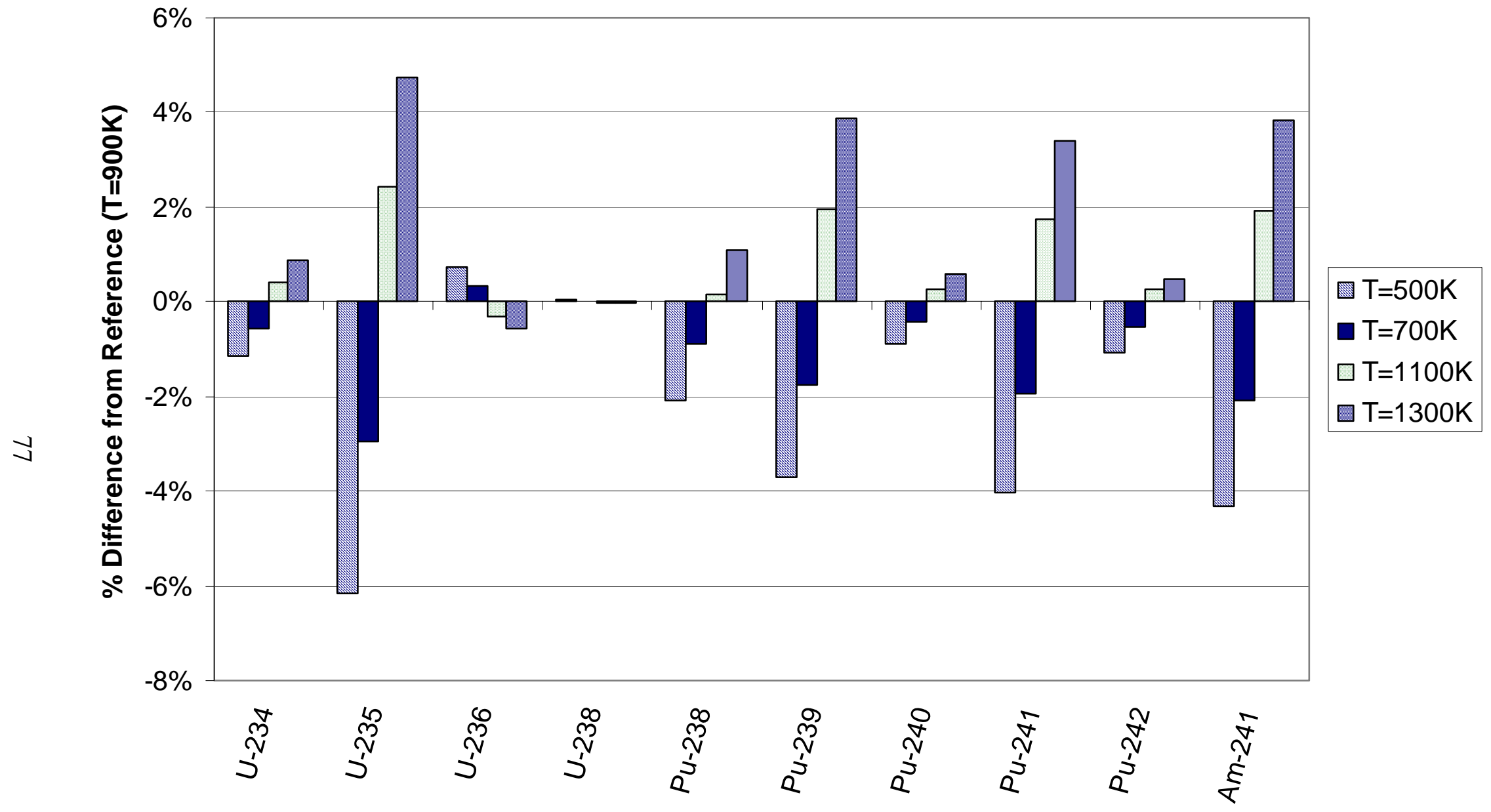

Fig. 46. Effect of fuel temperature during depletion on actinide densities (40-GWd/MTU burnup, 5-year cooling). 


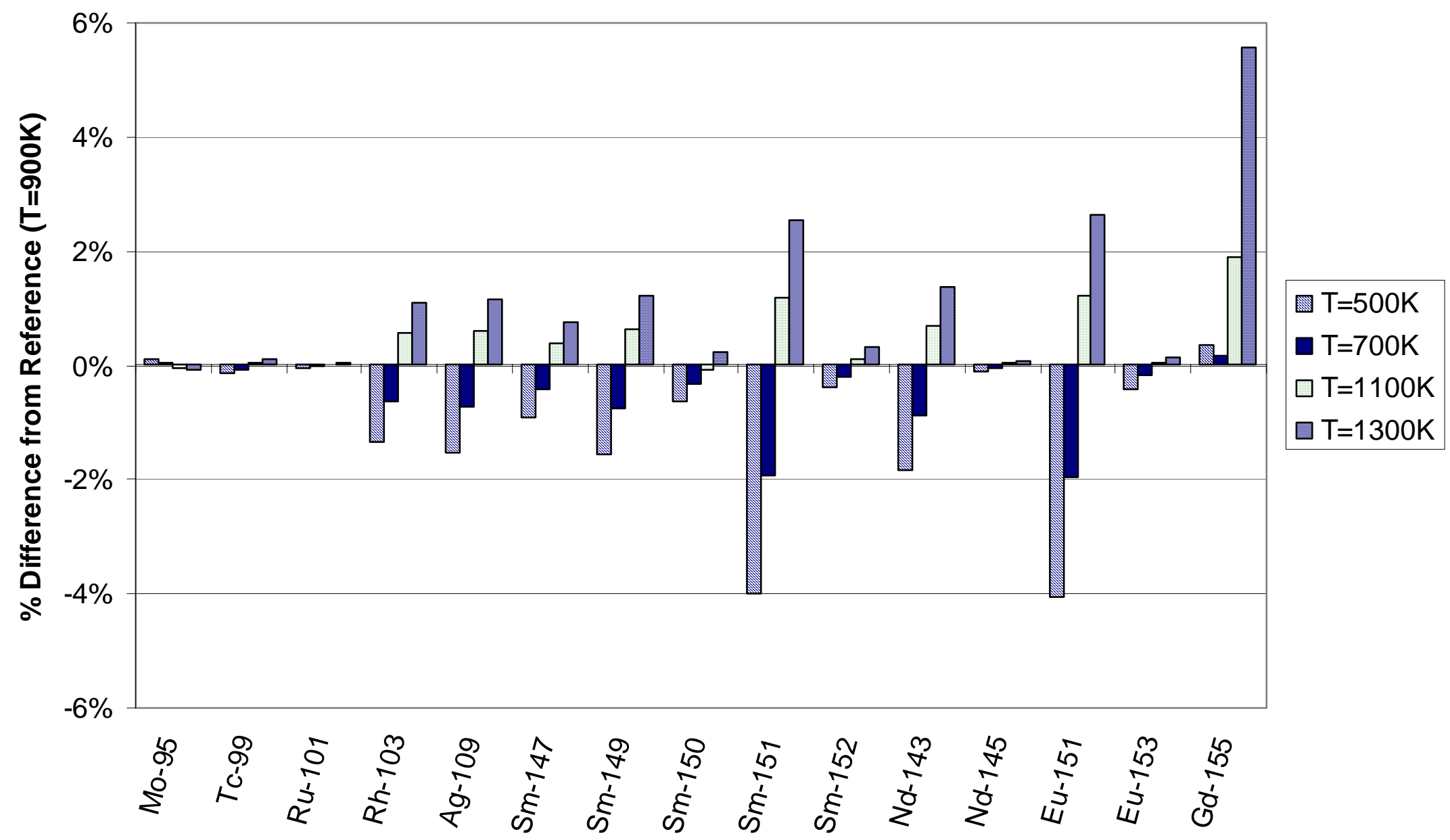

Fig. 47. Effect of fuel temperature during depletion on fission-product densities (40-GWd/MTU burnup, 5-year cooling). 


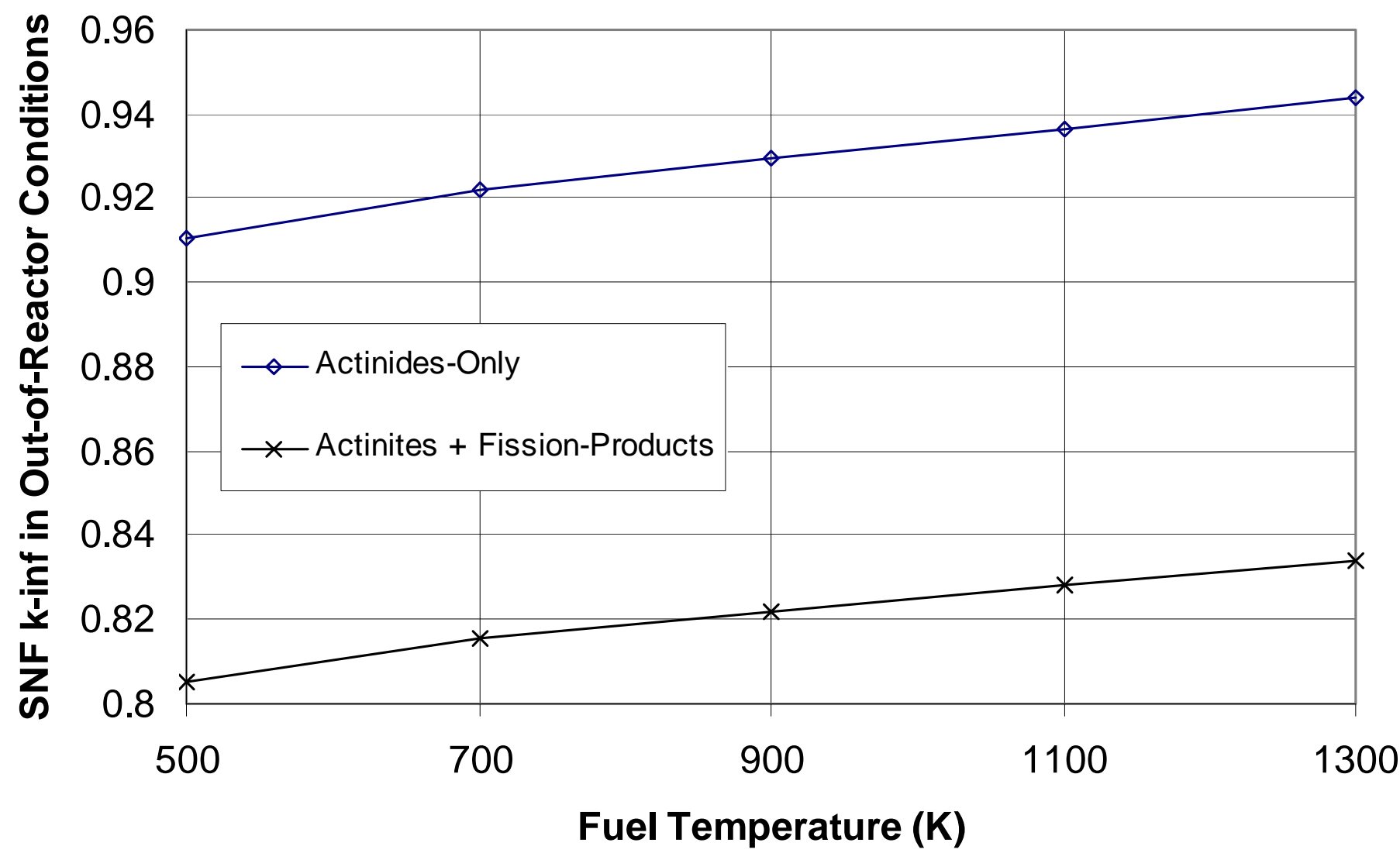

Fig. 48. Effect of fuel temperature during depletion on $\boldsymbol{k}_{\text {inf }}$ (40-GWd/MTU burnup, 5-year cooling). 


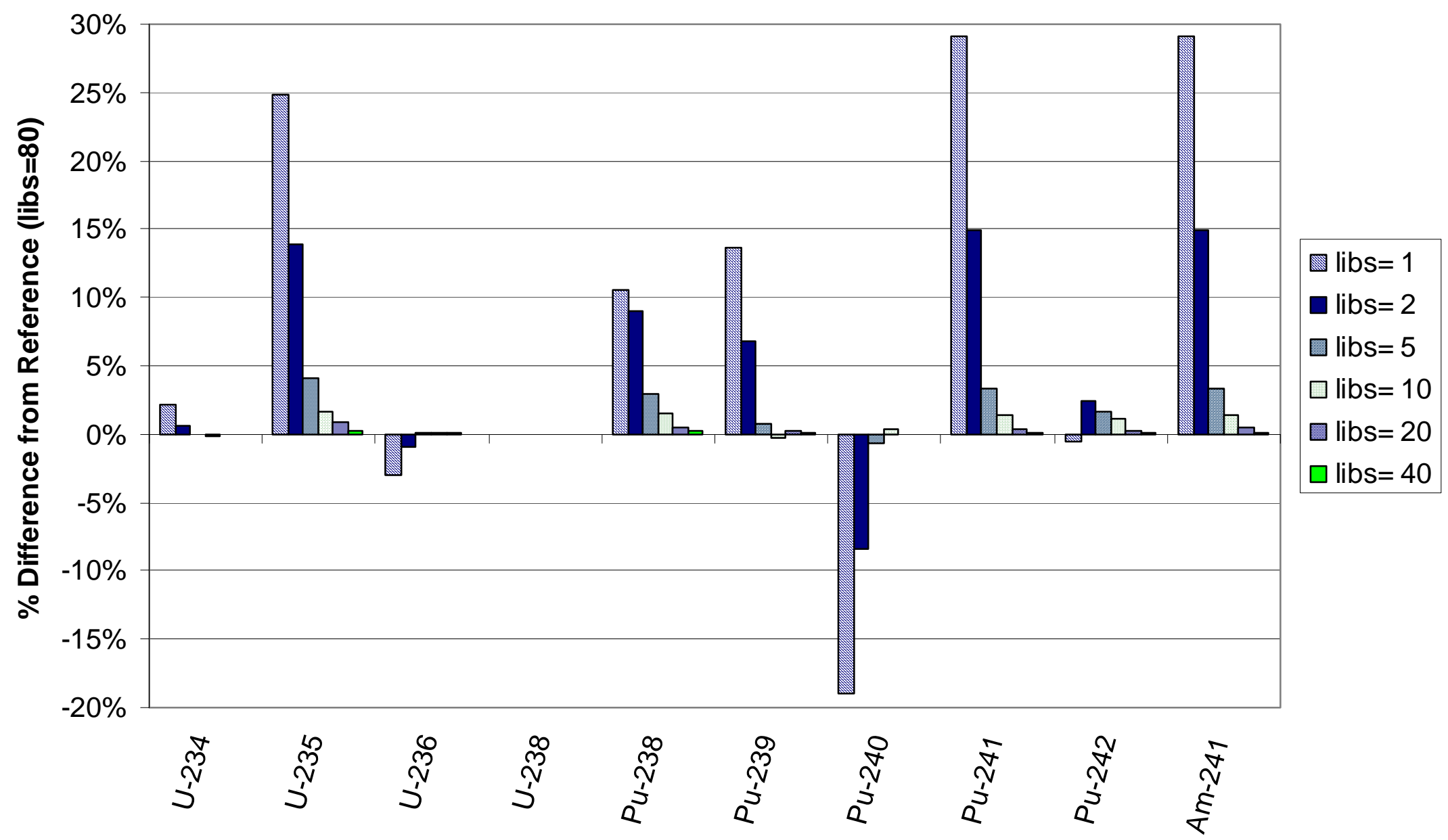

Fig. 49. Effect of the number of SAS2H libraries used during depletion on actinide densities (40-GWd/MTU burnup, 5-year cooling). 


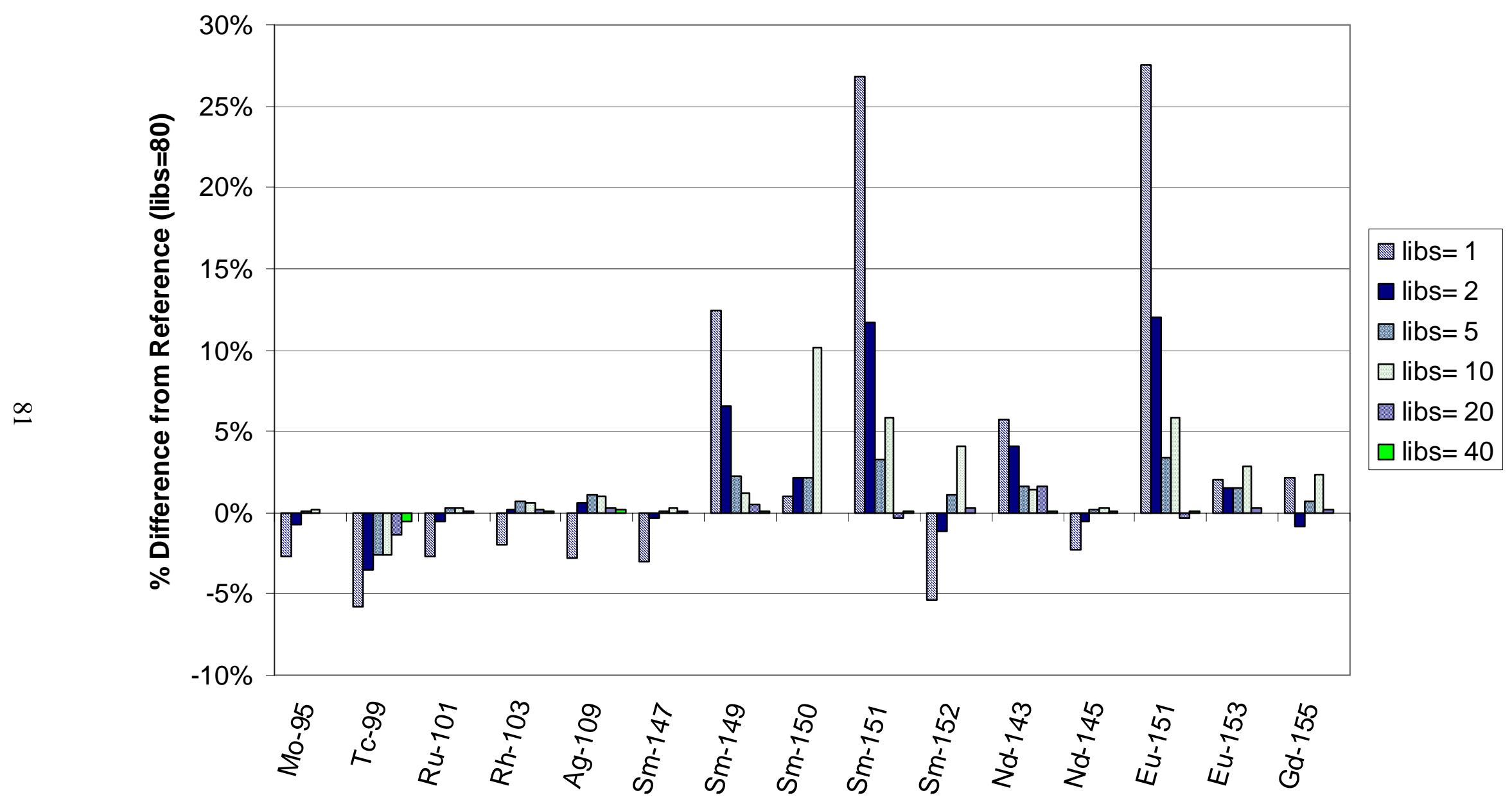

Fig. 50. Effect of the number of SAS2H libraries used during depletion on fission-product densities (40-GWd/MTU burnup, 5-year cooling). 


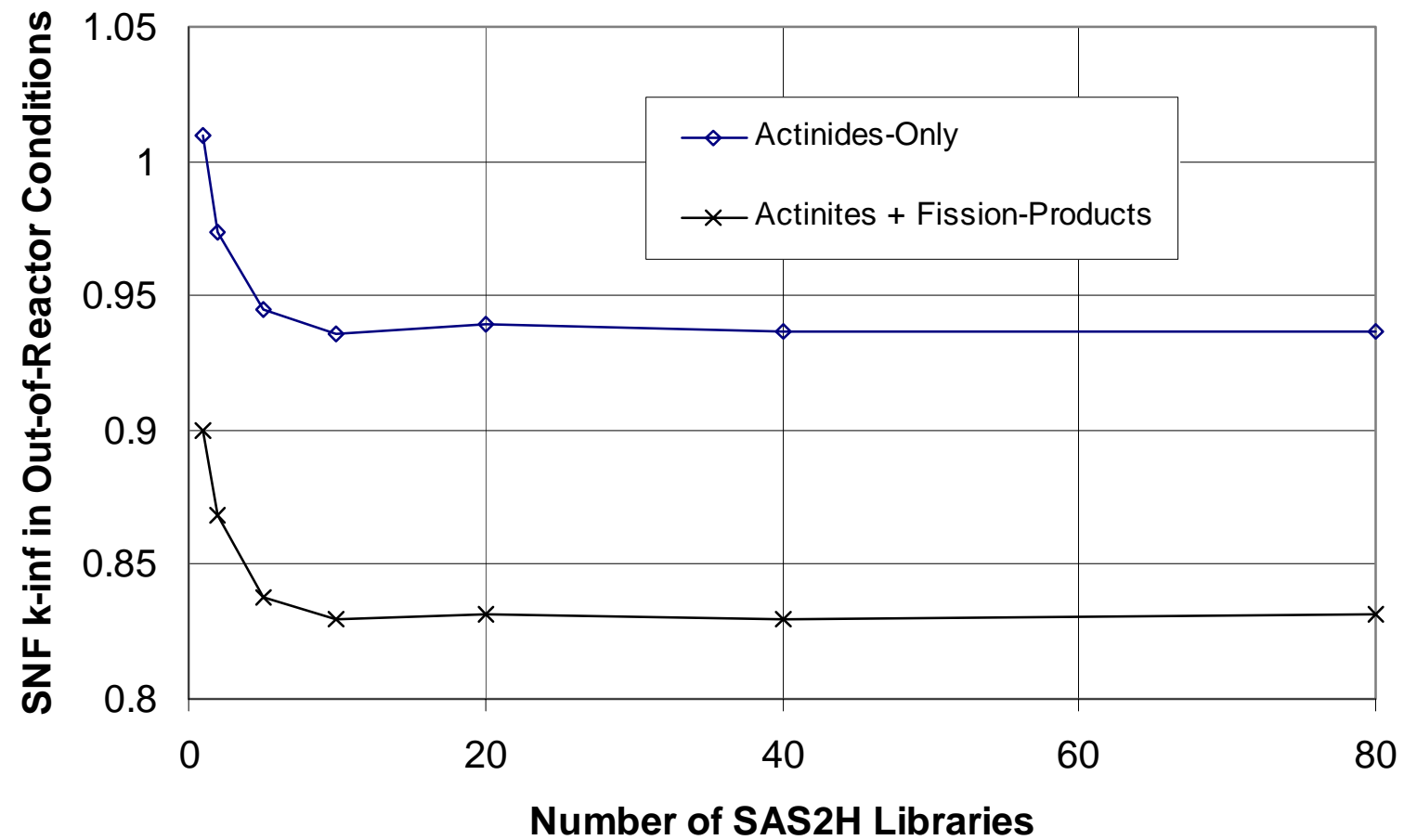

Fig. 51. Effect of the number of SAS2H libraries used during depletion on $\boldsymbol{k}_{\text {inf }}$ (40-GWd/MTU burnup, 5-year cooling). 
Careful examination of Fig. 50 reveals peaks in the overestimation of ${ }^{150} \mathrm{Sm},{ }^{151} \mathrm{Sm}$, ${ }^{152} \mathrm{Sm},{ }^{151} \mathrm{Eu},{ }^{153} \mathrm{Eu}$, and ${ }^{155} \mathrm{Gd}$ for the case using 10 libraries. Additional investigation into these peaks has identified a minor error in ORIGEN. The cause of this error has been identified, and modifications to correct this error are in progress. 


\section{EFFECT OF DEPLETION ASSUMPTIONS ON THREE- DIMENSIONAL CRITICALITY CALCULATIONS}

The ultimate goal of this work is to determine the sensitivity of $k_{\text {eff }}$ for a spent fuel package to various depletion assumptions. This goal is accomplished by using a series of SAS2H depletion calculations to represent axial burnup at each of several axial regions based on the local burnup. These isotopic concentrations are then used to make an approximate 3-D model (including axial leakage) of an axially burned fuel assembly, for which $k_{\text {inf }}$ is calculated for an infinite lattice of fuel assemblies. This approach lets one determine which depletion assumptions are conservative in estimating criticality (i.e., the depletion model that results in the highest predicted value of $k_{\text {inf }}$ for spent BWR fuel). This process was performed in earlier analyses of PWR spent fuel, 14 which served as a starting point for much of the work described here. The primary difference between calculations in this section and those in previous sections is the inclusion of axial variations in depletion. Consequently, the calculations in this section have axially varying fuel isotopics.

The criticality calculations discussed in this section were performed with KENO V.a at $20^{\circ} \mathrm{C}$ and utilizing the SCALE 44-group (ENDF/B-V) library. The actinides and fission products included in these calculations are listed in Table 5. Finally, all cases correspond to 5-year cooling.

\subsection{THE AXIAL-BURNUP MODEL}

It has been well established that the normal variation of burnup along the length of a spent fuel assembly results in a shift of the peak fission density away from the center, where the fuel is most reactive at the beginning of life. However, as the fuel depletes and the most reactive region shifts away from the center, the axial leakage increases. Thus, in order to assess the net reactivity worth of spent fuel, it is necessary to develop a 3-D representation of the assembly in which a burnup profile is included. To approximate the continuous distribution of burnup in a fuel assembly, a model was developed in which a single fuel assembly was divided into multiple axial regions. A burnup profile was assumed for the fuel assembly and approximated as discrete burnup intervals, representing the average burnup across the length of each interval. Depletion calculations were performed for each interval, assuming the actual operating histories but with varying specific power such that the correct burnup was obtained in each region at the end of the depletion calculations. Baseline operating parameters were obtained from detailed Assembly ZZ data. 
Prior to initiating sensitivity calculations for the various depletion assumptions, calculations were performed to determine the minimum number of axial regions necessary to accurately capture the axial effects, and thus, establish the axial model for subsequent sensitivity calculations. This step was done to reduce the number of calculations required to perform sensitivity calculations, since a separate depletion calculation is necessary for each axial zone in a 3-D model. The fact that burnup is fairly constant near the center of BWR fuel suggests that a number of central axial zones can be combined with no significant effect on the axial model, as demonstrated for PWR fuel in ref. 3 The initial model was based on 24 axial zones (the form in which Assembly ZZ data were provided); one axial zone at each end for the low-enrichment blanket fuel, and 22 zones of standard fuel. Note, the standard fuel configuration (i.e., pin enrichments and gadolinium concentrations) is shown in Fig. 1 and does not vary over the center 22 axial zones. The 24-zone axial burnup distributions for each of the 13 state points of Assembly ZZ are illustrated in Fig. 52 In addition, the axial variations in the moderator density and fuel temperature for each of the state points are shown in Figs. 53 and 54, respectively. The presence of axial variations in pin enrichment and/or gadolinium concentrations, which are known to exist in many BWR fuel designs, would have an effect on the axial burnup distributions.

Depletion calculations were performed using the detailed operational parameters. The predicted isotopics for each axial zone were then fed into a corresponding 24-zone KENO V.a model to calculate the value of $k_{\text {inf }}$ for an infinite array of assemblies with water reflection on both ends. Next, the two central zones were collapsed and properties (e.g., specific power and fuel and moderator temperatures) were averaged to create a single central zone. SAS2H depletion calculations and the KENO V.a criticality calculation were repeated in a similar manner. This collapsing procedure was repeated by successively increasing the number of axial zones combined in the center region, to a minimum 3-zone model, required to maintain the properties of the blanket material at the ends. The entire process was performed for various burnups between 5 and $60 \mathrm{GWd} / \mathrm{MTU}$. The resulting $k_{\text {inf }}$ values as a function of the number of modeled axial zones are shown in Fig. 55. Error bars due to Monte Carlo uncertainty are on the order of the size of each of the plot symbols. For all burnups considered, the calculated value of $k_{\text {inf }}$ is not sensitive to combined cells for models containing 11 or more axial zones. Thus, the remaining sensitivity calculations were performed using an 11-zone axial representation, consisting of the original five axial zones at either end, with the central 14 zones combined into a single axial zone with averaged properties.

As discussed earlier, the reactivity of BWR fuel increases with burnup to a maximum or peak reactivity where the gadolinium is nearly depleted. When considering the axial-burnup profile, it becomes apparent that the axial zones will not reach their peak reactivity simultaneously. Rather, the gadolinium will be depleted earlier in the zones near the axial center, and thus, the reactivity will peak at the center while significant gadolinium is still present at the ends. This characteristic results in interesting axial behavior, which is evident in Fig. 55, for burnups below $\sim 20 \mathrm{GWd} / \mathrm{MTU}$. Similar to PWR fuel, the axial-burnup distribution results in increasing reactivity with increasing burnup. However, the magnitude of the reactivity increase associated with the axial-burnup distribution is shown to be much larger than that which is typically observed for PWR fuel. It is important to note that these results are for a single assembly, and thus, even though the trends are expected to be representative of typical BWR fuel, the magnitudes may not be. Therefore, further study in this area is necessary. 


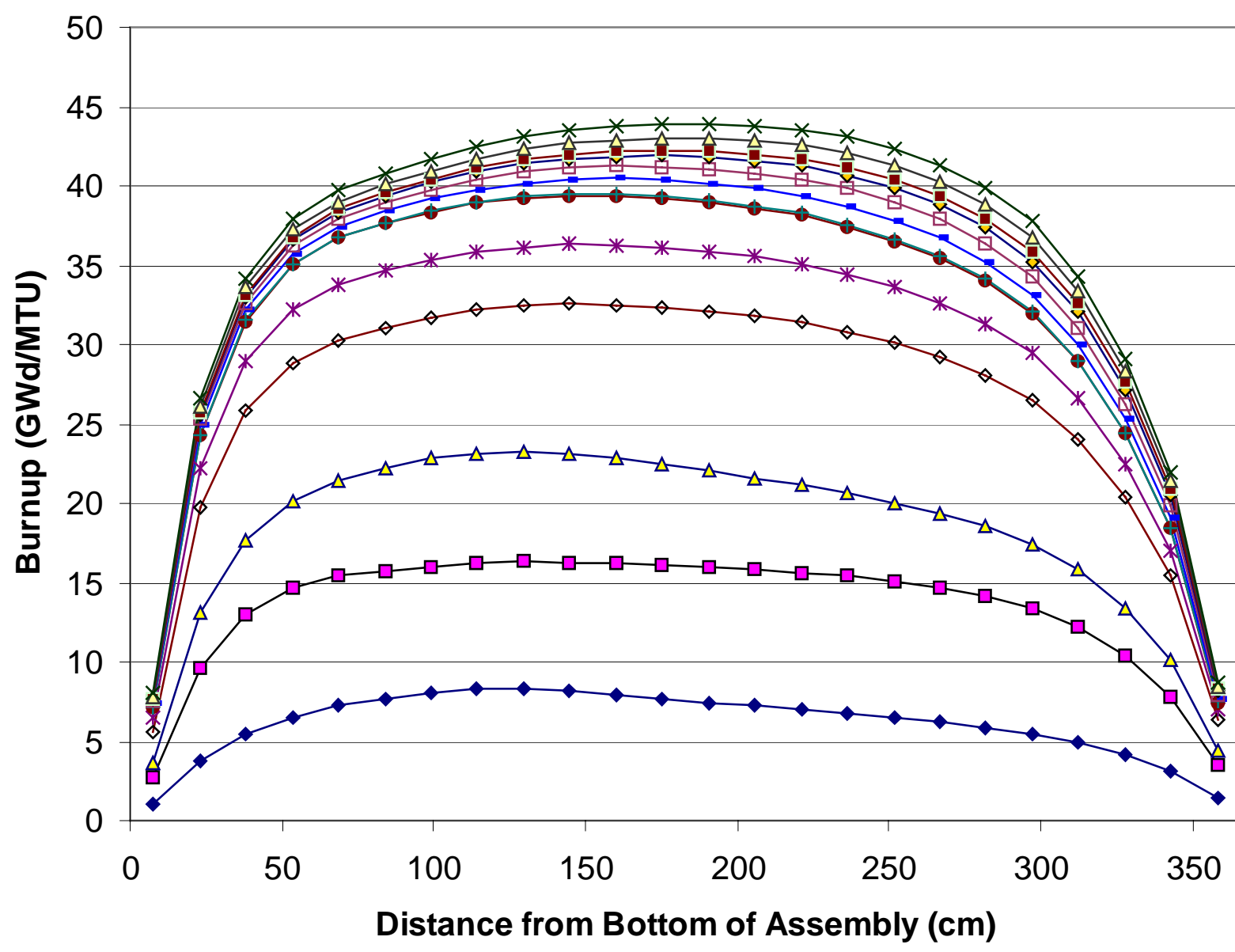

$\longrightarrow$ SP 1 (6.10 GWd/MTU) $\rightarrow \mathrm{SP} 2$ (13.43 GWd/MTU) $\triangle-\mathrm{SP} 3$ (18.35 GWd/MTU) $\multimap$ SP 4 (26.71 GWd/MTU) $\rightarrow$ * SP 5 (29.80 GWd/MTU) —SP 6 (32.38 GWd/MTU) — SP7 (32.47 GWd/MTU) - $\mathrm{SP} 8$ (33.31 GWd/MTU) $\square \mathrm{SP} 9$ (34.10 GWd/MTU) $\leadsto$ SP 10 (34.71 GWd/MTU) ——SP 11 (35.06 GWd/MTU) $\triangle-\mathrm{SP} 12$ (35.69 GWd/MTU) $\leftarrow \mathrm{SP} 13$ (36.47 GWd/MTU)

Fig. 52. Axial-burnup profiles for various state points (SP) of Assembly ZZ. 


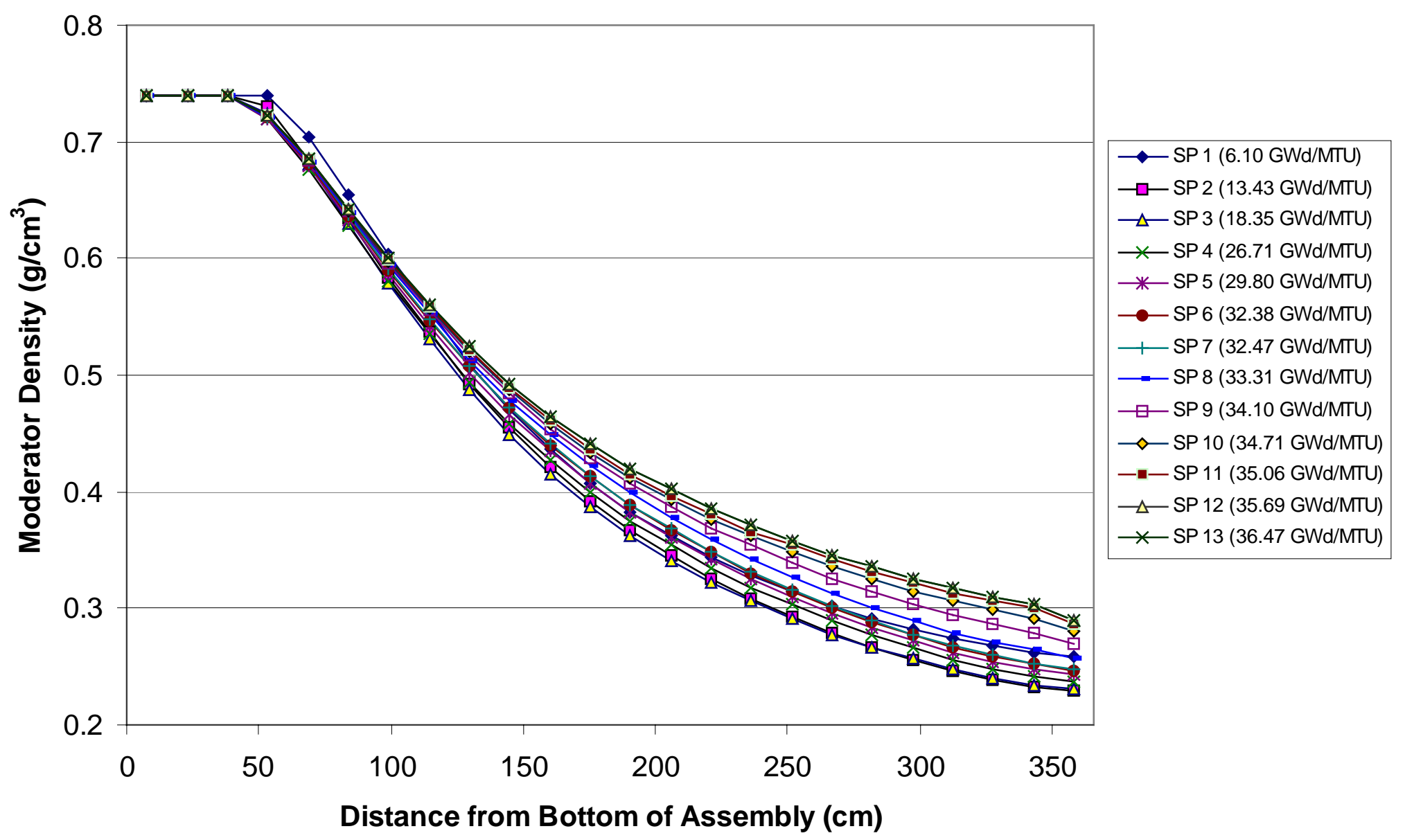

Fig. 53. Axial-moderator-density profiles for various state points (SP) of Assembly ZZ. 


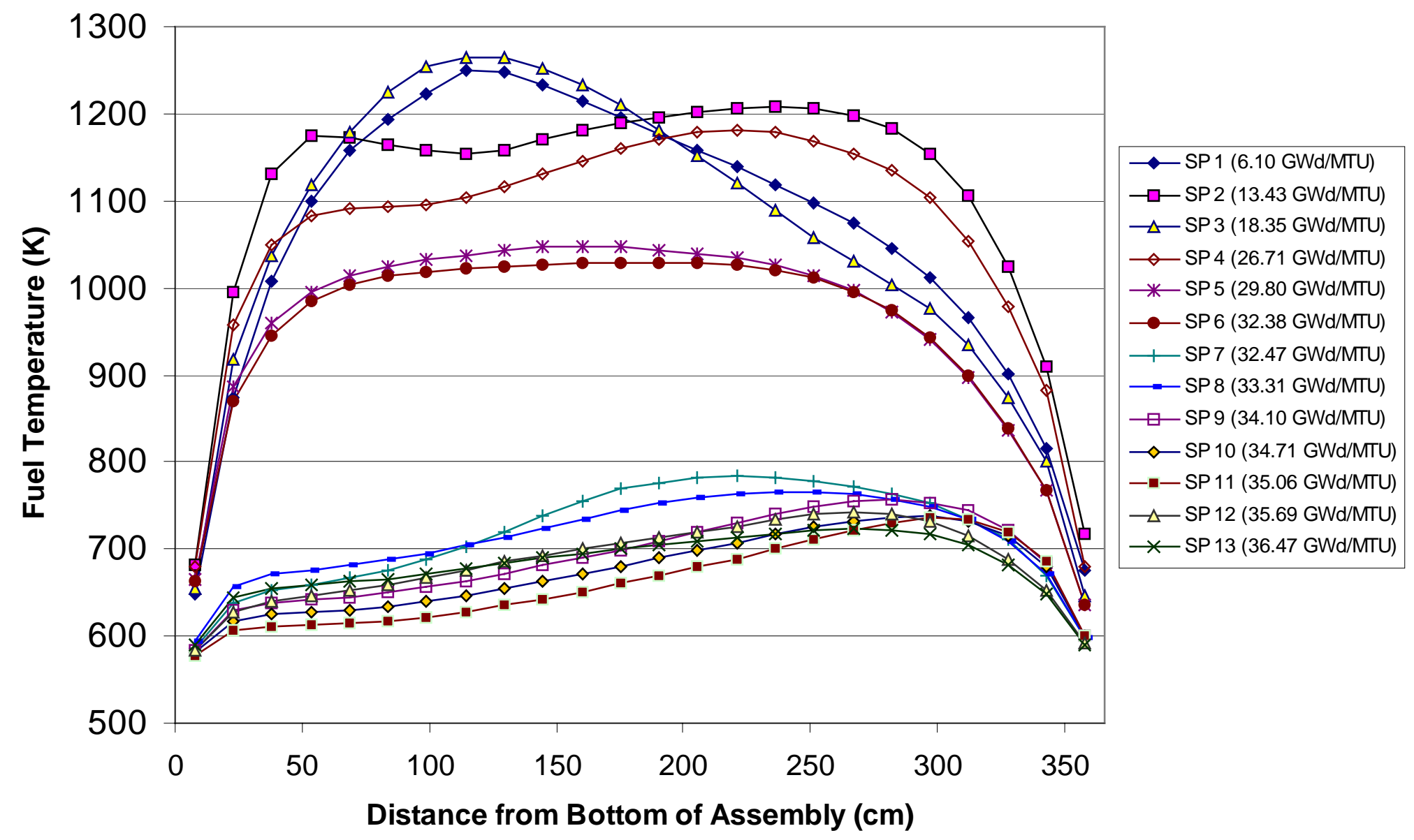

Fig. 54. Axial-fuel-temperature profiles for various state points (SP) of Assembly ZZ. 


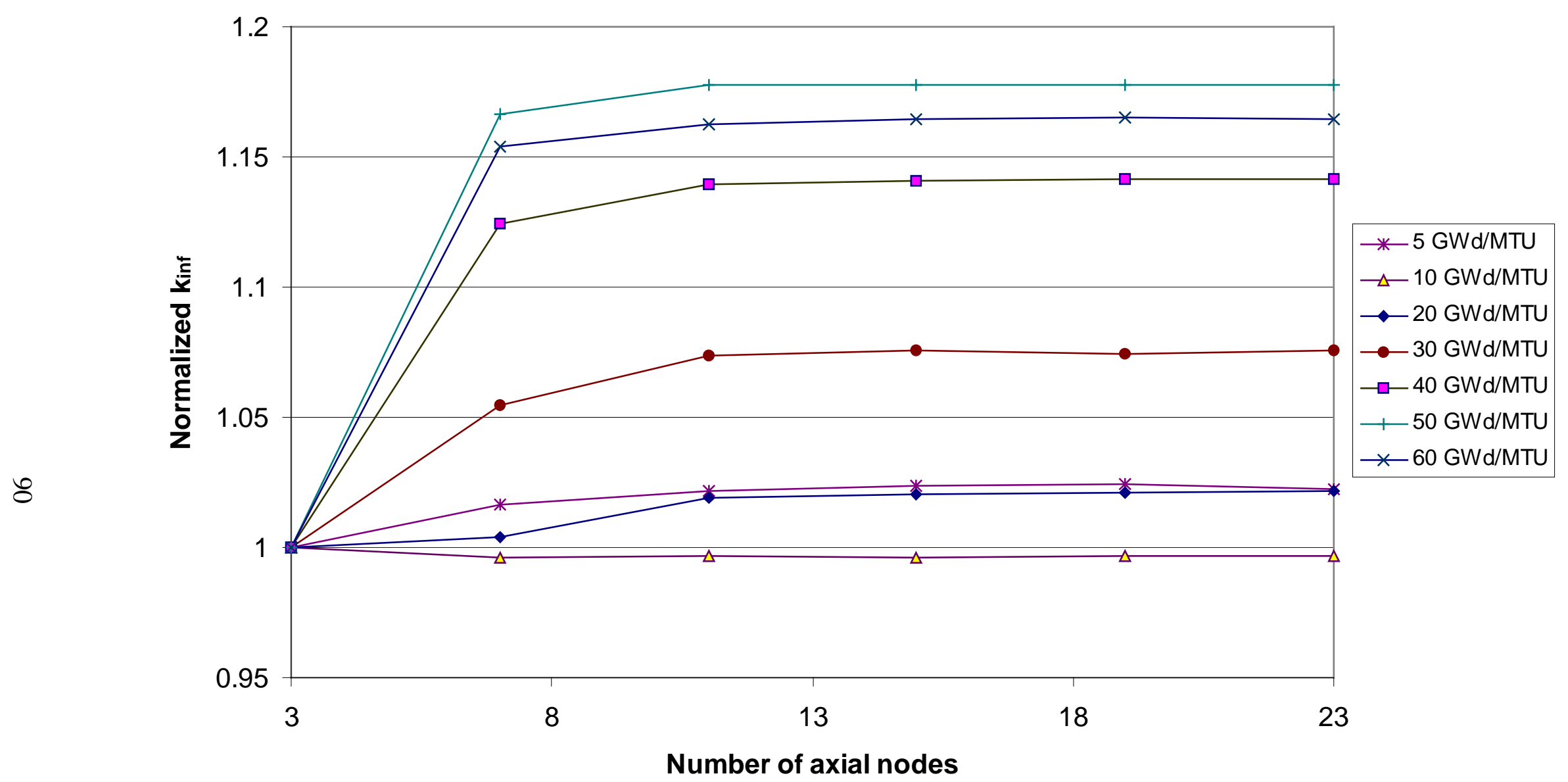

Fig. 55. Value of SNF $\boldsymbol{k}_{\text {inf }}$ as a function of the number of axial zone. 


\subsection{MODERATOR DENSITY}

Reference 3 demonstrated a strong coupling between depletion predictions and the assumed moderator density for PWR fuel. The nature of moderator density variations in BWR fuel designs makes this a more significant issue for BWR fuel depletion. Moderator densities for specific statepoints over the entire life of the fuel assembly were provided with the Assembly ZZ data and are shown in Fig. 53. These data show that the moderator density in each axial zone remains relatively constant as a function of burnup, although for this assembly the moderator density in the upper regions initially decreased, then increased to a maximum near the end of life. Such variations are expected to be operationally dependent. Thus, for simplicity it may be best to assume a bounding value for a moderator density over the life of the fuel assembly. This study was performed to assess the direction of conservatism (i.e., whether the lowest or highest estimate represents the conservative bound), and to determine the magnitude of this conservatism as a function of burnup. This goal was accomplished by performing a series of calculations assuming nominal conditions, but with axial-uniform moderator density varying from 0.2 to $0.8 \mathrm{~g} / \mathrm{cm}^{3}$, which bounds the range of moderator densities provided in the Assembly ZZ data. SAS2H calculations were performed assuming initial enrichments of 3.0, 3.75, and 4.5 wt $\%$ ${ }^{235} \mathrm{U}$, and for burnups of 10,30 , and $50 \mathrm{GWd} / \mathrm{MTU}$. Results are plotted in Fig. 56, with $k_{\text {inf }}$ normalized to the value computed for minimum density $\left(0.2 \mathrm{~g} / \mathrm{cm}^{3}\right)$ for the purposes of comparison. The results show a close-to-linear response (within the stochastic uncertainties in the Monte Carlo $k_{\text {inf }}$ calculations); hence, linear fits were applied to the data to more easily illustrate trends. No error bars are plotted because the uncertainty in each $k_{\text {inf }}$ calculation is on the order of the size of the plot symbols. These results clearly indicate that $k_{\text {inf }}$ is maximized (the depletion model becomes more conservative) with the lowest moderator density, and that conservatism increases with increasing fissile depletion and decreasing initial enrichment. It is believed that this is a spectrum-driven effect, resulting from increased plutonium production and fission, and a concurrent reduction of ${ }^{235} \mathrm{U}$ depletion due to spectral hardening that occurs as moderator density is decreased.

It is worth noting that the reactivity associated with a case assuming an axial-uniform moderator density equivalent to the lowest actual zone moderator density is nearly equivalent to the reactivity from a case assuming the actual moderator density distribution. Results for uniform lowest moderator density are typically 0.2 to $0.3 \%$ higher than those corresponding to the actual axial moderator distributions (as shown in Fig. 53). Thus, the assembly reactivity is controlled by the top low-density region, which suggests that assuming a bounding value for the moderator density does not introduce a significant penalty. 


\begin{tabular}{|c|c|c|}
\hline - $10 \mathrm{GWd} / \mathrm{t}, 3.0 \mathrm{wt} \%$ & $\longrightarrow-30 \mathrm{GWd} / \mathrm{t}, 3.0 \mathrm{wt} \%$ & $\longrightarrow-50 \mathrm{GWd}$ \\
\hline - - - - $10 \mathrm{GWD} / \mathrm{t}, 3.75 \mathrm{wt} \%$ & $--+-30 \mathrm{GWd} / \mathrm{t}, 3.75 \mathrm{wt} \%$ & - - - $50 \mathrm{GWd} / \mathrm{t}, 3.75$ wt $\%$ \\
\hline$-\diamond-10 \mathrm{GWd} / \mathrm{t}, 4.5 \mathrm{wt} \%$ & $-\star-30 \mathrm{GWd} / \mathrm{t}, 4.5 \mathrm{wt} \%$ & $-\star-50 \mathrm{GWd} / \mathrm{t}, 4.5 \mathrm{wt} \%$ \\
\hline
\end{tabular}

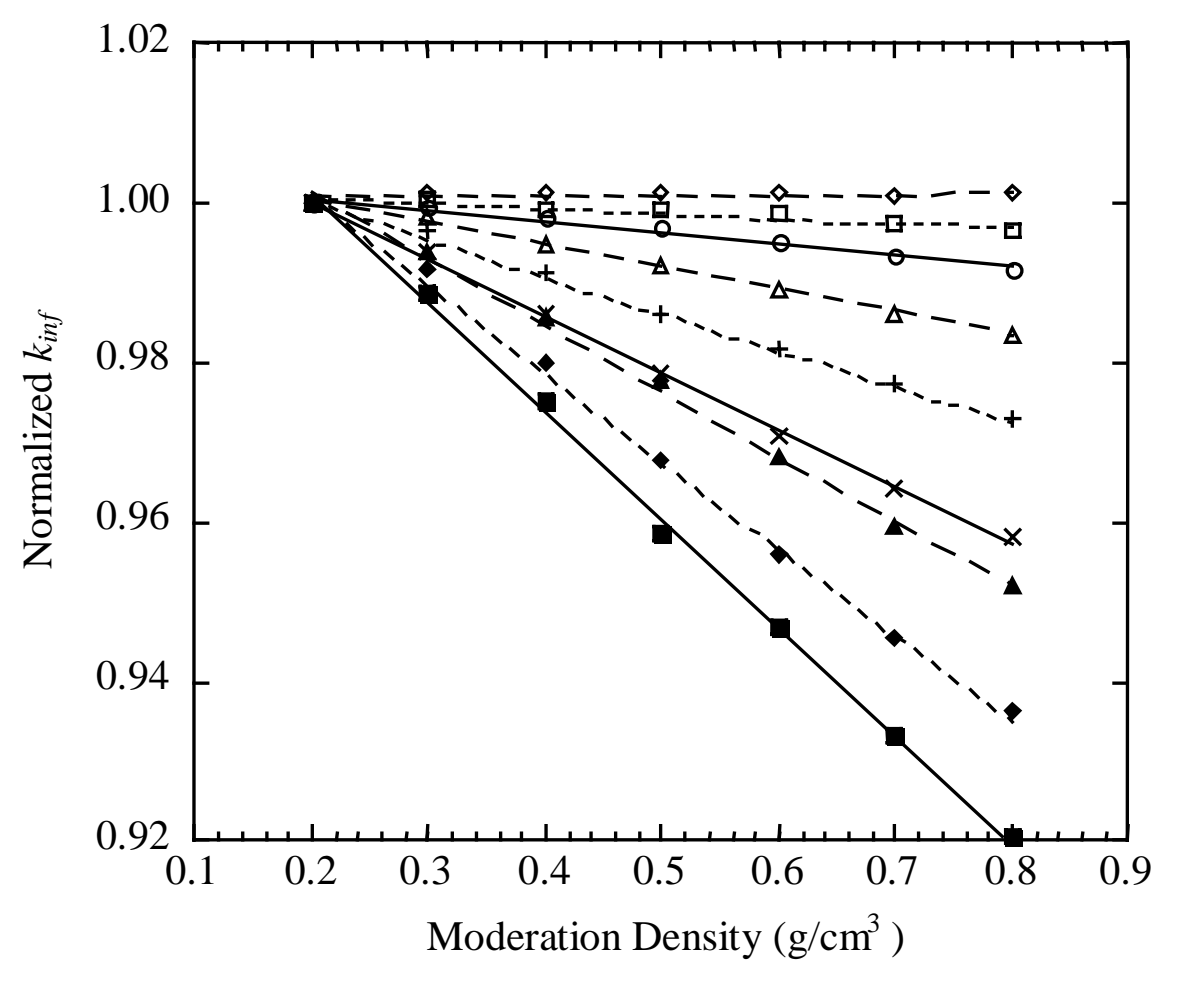

Fig. 56. Effect of depletion moderator density on $\boldsymbol{k}_{\text {inf }}$. 


\subsection{FUEL TEMPERATURE}

SAS2H calculations were performed to assess the effect of assumed fuel temperature in much the same manner. Fuel temperatures for specific statepoints over the entire life of the fuel assembly were provided with the Assembly ZZ data and are plotted in Fig. 54. These data show the significant axial variations in fuel temperature. With the exception of uniform fuel temperature, the actual data from Assembly $\mathrm{ZZ}$ operations were assumed in each depletion model. Sets of calculations were performed, varying the fuel temperature from 500 to $1300 \mathrm{~K}$ for various burnup states and initial enrichments. The fuel temperature range was chosen to bound the variations in the Assembly ZZ data. Results are shown in Fig. 57, with $k_{\text {inf }}$ normalized by the value calculated for $500 \mathrm{~K}$ for each burnup/enrichment pair. Again, the response appears to be linear, as illustrated by the linear fits to the data. Error bars due to Monte Carlo uncertainty are on the order of the size of each of the plot symbols. The results demonstrate that $k_{\text {inf }}$ increases with an increase in the fuel temperature during depletion, and that, like moderator density effects, the effect of temperature increases with burnup. This behavior is probably due to Doppler broadening in ${ }^{238} \mathrm{U}$, resulting in enhanced plutonium production and less ${ }^{235} \mathrm{U}$ depletion, which is similar to the spectral hardening effects observed with decreased moderator densities. The magnitude of the reactivity effect of fuel temperature is relatively small when compared to the magnitude of moderator density effects shown in the previous section.

\subsection{SPECIFIC POWER}

SAS2H calculations also were performed to assess the effect of assumed specific power. With the exception of the uniform specific power (for the various cases), the actual data from Assembly ZZ operations were assumed in each depletion model. Sets of calculations were performed, varying the specific power 10 to $50 \mathrm{MW} / \mathrm{MTU}$ for various burnup states and initial enrichments. Results are shown in Fig. 58 with $k_{\text {inf }}$ normalized by the value calculated for $10 \mathrm{MW} / \mathrm{MTU}$ for each burnup/enrichment pair. Consistent with studies shown in refs. 3 and 14 , the general trend is for reactivity to decrease with increasing specific power. However, a notable exception to this trend is observed for the high-burnup cases, where a peak in reactivity corresponding to a specific power of $\sim 20 \mathrm{MW} / \mathrm{MTU}$ is shown. Although the magnitude of this peak is relatively small (less than $0.3 \%$ ), this behavior demonstrates that it is not necessarily conservative to use the minimum specific power. Error bars due to Monte Carlo uncertainty are on the order of the size of each of the plot symbols. 


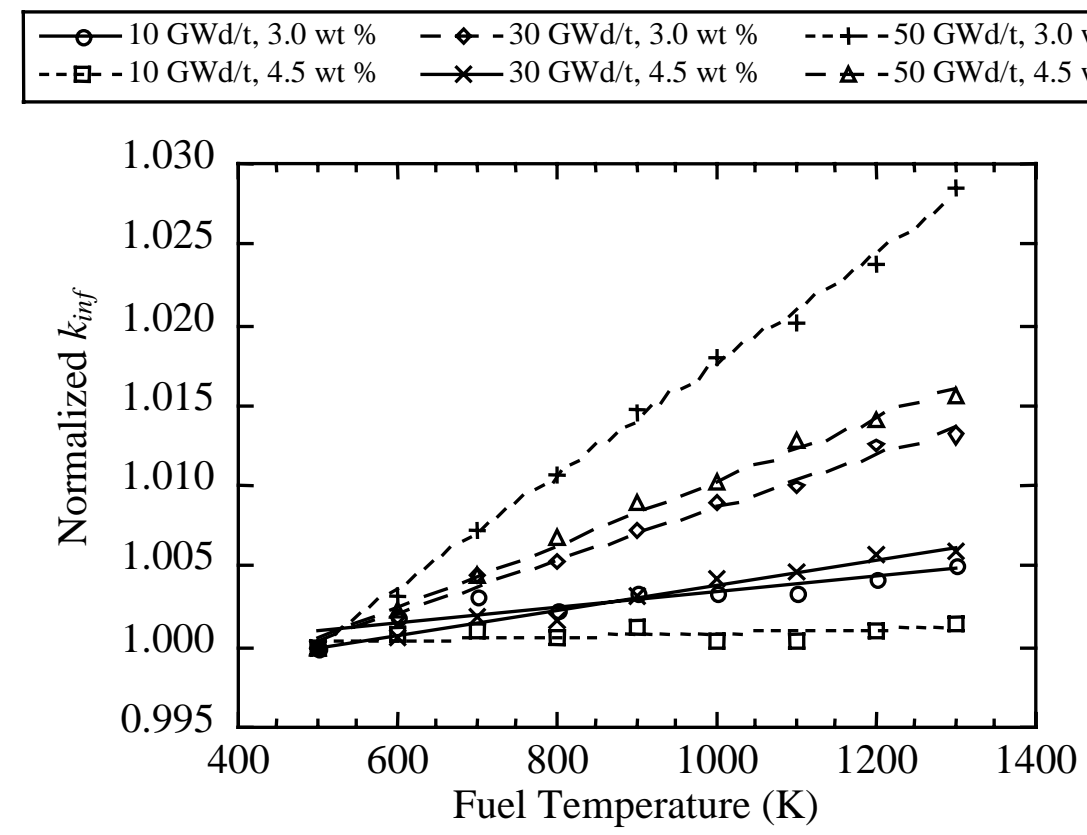

Fig. 57. Effect of depletion fuel temperature on $\boldsymbol{k}_{i n f}$. 


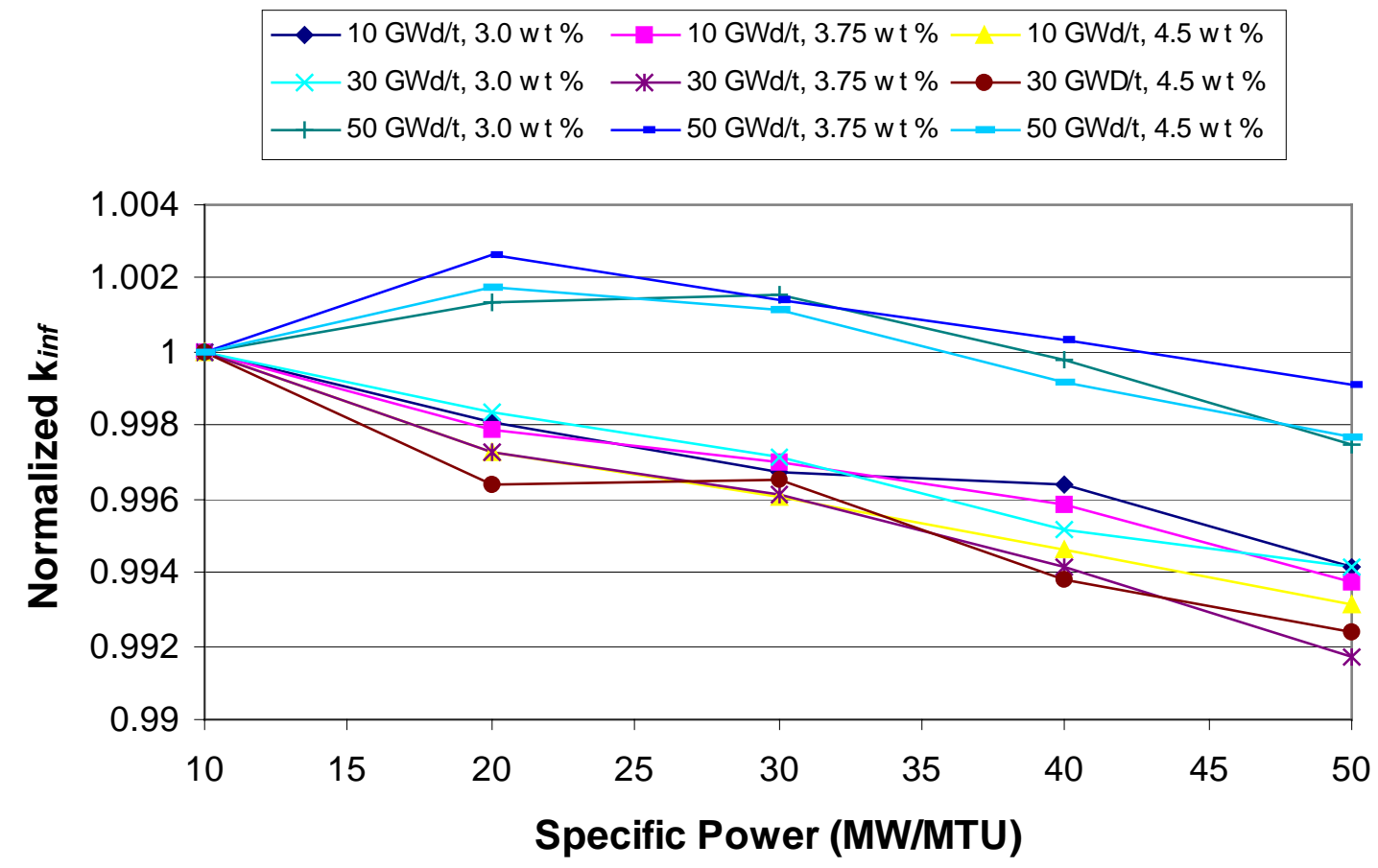

Fig. 58. Effect of specific power during depletion on $\boldsymbol{k}_{i n f}$. 


\subsection{OPERATING HISTORY}

The final issue examined in this study was the effect of the reactor operating history. Since the operating history of spent fuel varies significantly between different assemblies, it is necessary to determine an operating history that is bounding in terms of its effect on reactivity, or to define a simple operating history and have a quantified margin associated with that history that will bound the effect of operational variations.

The calculations performed here were not an attempt to define a limiting profile or an appropriate margin; rather, they were performed to determine which operational parameters (e.g., specific power variations over time, downtime lengths, etc.) had the most significant effect on the reactivity worth of fuel after a 5-year cooling period. Table 14 summarizes the operating histories studied. These histories essentially represent three burn cycles, with downtime assumed in the middle of each cycle in addition to inter-cycle downtime. Histories 1 through 11 were applied in PWR studies described in ref. 3. History 12 was added to represent another operating pattern observed in BWR fuel, based on available Assembly ZZ operating data. History 13 represents the actual Assembly ZZ burnup history.

As with the earlier calculations, operating history effects were calculated for a variety of initial enrichments and burnups, representing a range of fissile depletion. The full operating history was applied for each burnup state, by scaling the average specific power for each fuel depletion model. Results are plotted in Fig. 59. Behavior for histories 1 through 11 are consistent with trends observed in ref. 3 and in a similar study that used 3-D criticality calculations 14 both for PWR analyses. However, it is clear that histories 12 and 13, with very low-power operation for the last fuel cycle, represent the most conservation depletion histories with respect to $k_{\text {inf }}$ calculations.

It was postulated in ref. 3 that the low-power operation results in a lower equilibrium concentration of ${ }^{155} \mathrm{Eu}$ during the last cycle, and that equilibrium conditions are reached during the length of a cycle. The lower ${ }^{155} \mathrm{Eu}$ concentrations at discharge result in lower ${ }^{155} \mathrm{Gd}$ inventories post-shutdown and a higher net fuel reactivity. These results presented here are consistent with this hypothesis. The effect is likely compounded by other decay products that are daughters of important fission products (e.g., ${ }^{147} \mathrm{Sm}$, which is produced by the decay of ${ }^{147} \mathrm{Pm}$ with a 2.6-year half-life). However, the net effect, for very highly burned fuel, is on the order of $0.5 \%$. Thus, the effect of operating history is much less than the effect of fuel temperature and nearly an order of magnitude less than the effect of moderator density. 


\section{Table 14. Description of operating histories analyzed}

(1) Six 180-day full-power periods, no downtime

(3) Six 180-day full-power periods, separated by 45 -day down periods (20\% downtime)

(5) Six 180-day full-power periods, $10 \%$ downtime, $30 \%$ downtime in $3 \mathrm{rd}$ and $4^{\text {th }}$ periods

(7) Six 180-day full-power periods, $10 \%$ downtime, 720 -day downtime between $3 \mathrm{rd}$ and 4 th periods

(9) Six 180-day periods, $120 \%$ power in first two periods, $90 \%$ power in remaining periods, $10 \%$ downtime

(11) Six 180-day periods, $120 \%$ power in last two periods, $90 \%$ power in remaining periods, $10 \%$ downtime

(13) Actual operating history profile from Assembly ZZ data
(2) Six 180-day full-power periods, separated by 20 -day down periods ( $10 \%$ downtime)

(4) Six 180-day full-power periods, separated by 77 -day down periods ( $30 \%$ downtime)

(6) Six 180-day full-power periods, $10 \%$ downtime, $30 \%$ downtime in 5th and 6th periods

(8) Six 180-day full-power periods, $10 \%$ downtime, 720 -day downtime between 5 th and 6 th periods

(10) Six 180-day periods, $120 \%$ power in 3 rd and 4 th periods, $90 \%$ power in remaining periods, $10 \%$ downtime

(12) Six 180-day periods, $120 \%$ power in first four periods, $60 \%$ power in remaining two periods, $10 \%$ downtime 


\begin{tabular}{|c|c|c|}
\hline$-10 \mathrm{GWd} / \mathrm{t}, 3.0 \mathrm{wt} \%$ & $\leadsto-30 \mathrm{GWd} / \mathrm{t}, 3.0 \mathrm{wt} \%$ & $\longrightarrow-50 \mathrm{GWd} / \mathrm{t}, 3.0 \mathrm{wt} \%$ \\
\hline - - ㅁ -10 GWd/t, 4.5 wt \% & $--x--30 \mathrm{GWd} / \mathrm{t}, 4.5 \mathrm{wt} \%$ & $\ldots--50 \mathrm{GWd} / \mathrm{t}, 4.5 \mathrm{wt} \%$ \\
\hline
\end{tabular}

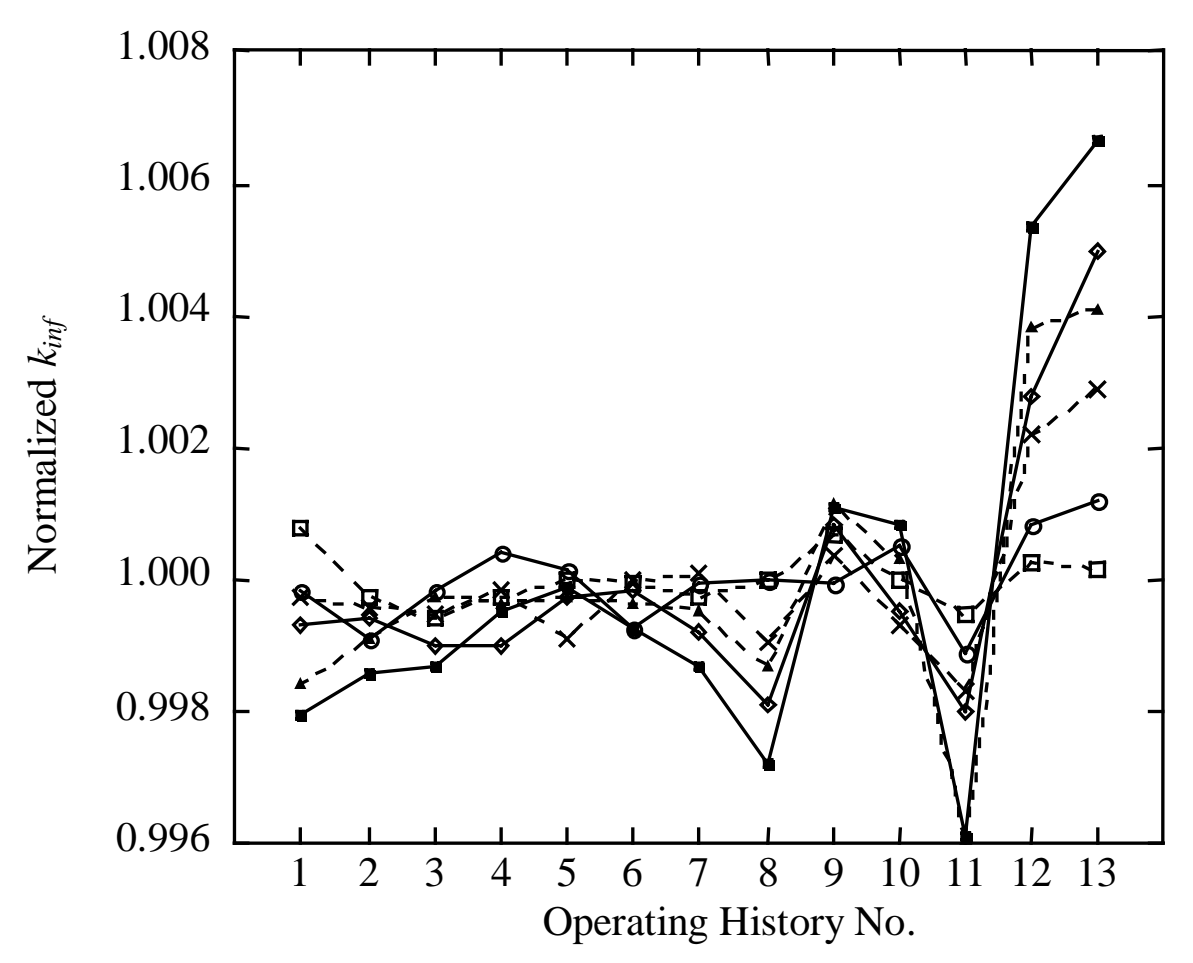

Fig. 59. Effect of operating history on $\boldsymbol{k}_{\text {inf }}$. 


\section{CONCLUSIONS}

This report has described initial scoping analyses performed to achieve a better understanding of the modeling issues associated with BWR fuel depletion calculations that are relevant to burnup credit. Results have been summarized here, and additional calculations are planned. Calculations completed to date have demonstrated similar trends to those observed for PWR spent fuel calculations 3

The heterogeneous lattice of a BWR fuel assembly design requires approximations in 1-D depletion analyses that are not encountered in the more homogeneous lattices common in PWR designs (without integrated burnable absorbers). A comparison of SAS2H and HELIOS calculations for the important actinide and fission-product concentrations was performed. In general, SAS2H is overpredicting nuclide concentrations relative to HELIOS, with the significant exception of ${ }^{235} \mathrm{U}$. The underestimation of ${ }^{235} \mathrm{U}$ was shown to be associated with the limitation of a single fuel enrichment in SAS2H and increases as a function of burnup. Validation analyses performed for BWR fuel assemblies relative to chemical assay measurements have shown similar biases, although much of the hias is believed to be due to uncertainty in moderator densities in the vicinity of fuel samples 13,15

A number of alternative geometric modeling approaches were investigated and assessed based on comparisons to HELIOS results. Even though minor improvements (relative to HELIOS) over the SMA for some of the nuclides are shown, none of the modeling approaches considered herein represent a significant improvement over the SMA. However, the two-fuelregion model performs nearly as well as the SMA for all burnups, and thus, may find some use in the future. Although it is desirable to calculate all nuclide concentrations accurately, many nuclides do not have a significant impact on reactivity. Therefore, calculated $k_{\text {inf }}$ values, based on the calculated spent fuel isotopics from both HELIOS and SAS2H, were compared. Even though relatively large differences are observed at low burnups where the gadolinium is still present, the calculated $k_{\text {inf }}$ values (based on isotopics from HELIOS and SAS2H SMA) for burnups beyond approximately $10 \mathrm{GWd} / \mathrm{MTU}$ are within $0.3 \%$ for the actinide-only cases and within $1 \%$ for the actinide-plus-fission-product cases. This close agreement can be attributed to offsetting differences in the isotopics calculated with SAS2H (e.g., the underestimation of ${ }^{235} U$ is offset by an overestimation of ${ }^{239} \mathrm{Pu}$ and ${ }^{241} \mathrm{Pu}$ ) and the low importance of several of the nuclides for which large differences in concentrations were observed (e.g., ${ }^{238} \mathrm{Pu},{ }^{243} \mathrm{Am},{ }^{109} \mathrm{Ag}$ and ${ }^{151} \mathrm{Eu}$ ).

Based on the calculated results, the indication is that the approximations in the 1-D SAS2H model provide an adequate representation of depletion dynamics for a heterogeneous 2-D BWR assembly. Although not as accurate as an explicit model, the 1-D approximation appears to yield consistent results such that a reasonable bias and uncertainty could be determined in the estimation of assembly-averaged isotopic concentrations. The simplicity and relative speed of the SAS2H approach for modeling complicated systems are clear advantages over more rigorous approaches. The effects of variations in the basic depletion parameters on the calculated isotopics and $k_{\text {inf }}$ were also examined in this study, including specific power, operating history, moderator density, fuel density, fuel temperature, and the number of SAS2H cycles. 
A major goal of this work has been to determine the sensitivity of $k_{\text {inf }}$ to various depletion assumptions. To this end, the effects of variations in the depletion parameters on the calculated reactivity were examined, including moderator density, fuel temperature, and operating history. Trends observed here are consistent with those observed in the study of PWR depletion modeling, as is the magnitude of the effect, and significant differences in the approach required to conservatively model the depletion process between BWR and PWR designs are not expected.

The work reported herein has been based on code-to-code comparisons and parametric analyses of depletion models. However, such comparisons must be augmented with direct comparisons to measured data. Reference 15 describes a set of calculations used to validate SAS2H against radiochemical assay data. However, those data are insufficient in depth or applicability for the general population of BWR fuel. Other candidate fuel measurements have been identified and will perhaps be analyzed in the future. However, there remains a lack of well-qualified measurement data applicable to most modern BWR designs. 


\section{REFERENCES}

1. O. W. Hermann, S. M. Bowman, M. C. Brady, and C. V. Parks, Validation of the SCALE System for PWR Spent Fuel Isotopic Composition Analyses, ORNL/TM-12667, Lockheed Martin Energy Research Corp., Oak Ridge National Laboratory, March 1995.

2. O. W. Hermann and M. D. DeHart, An Extension of the Validation of SCALE (SAS2H) Isotopic Predictions for PWR Spent Fuel, ORNL/TM-13317, Lockheed Martin Energy Research Corp., Oak Ridge National Laboratory, September 1996.

3. M. D. DeHart, Sensitivity and Parametric Evaluations of Significant Aspects of Burnup Credit for PWR Spent Fuel Packages, ORNL/TM-12973, Lockheed Martin Energy Research Corp., Oak Ridge National Laboratory, May 1996.

4. S. M. Bowman, M. D. DeHart, and C. V. Parks, "Validation of SCALE-4 for Burnup Credit Applications," Nucl. Technol. 110, 53 (1995).

5. Topical Report on Actinide-Only Burnup Credit for PWR Spent Nuclear Fuel Packages, DOE/RW-0472, Rev. 2, U.S. Department of Energy, September 1998.

6. Spent Nuclear Fuel Discharges from U.S. Reactors - 1994, SR/CNEAF/96-01, Energy Information Administration, U.S. Department of Energy, February 1996.

7. Yucca Mountain Site Characterization Project: Disposal Criticality Analysis Methodology Topical Report, MP/TR-004Q, Revision 0, U.S. Department of Energy, Office of Civilian Radioactive Waste Management, Las Vegas, Nevada, November 1998.

8. O. W. Hermann and C. V. Parks, "SAS2H: A Coupled One-Dimensional Depletion and Shielding Analysis Module," Vol. I, Sect. S2 of SCALE: A Modular Code System for Performing Standardized Computer Analyses for Licensing Evaluation, NUREG/CR-0200, Rev. 6 (ORNL/NUREG/CSD-2R6), May 2000. Available from Radiation Safety Information Computational Center at Oak Ridge National Laboratory as CCC-545.

9. J. J. Casal, R. J. J. Stamm'ler, E. A. Villarino, and A. A. Ferri, "HELIOS: Geometric Capabilities of a New Fuel-Assembly Program," Intl. Topical Meeting on Advances in Mathematics, Computations, and Reactor Physics, Pittsburgh, Pennsylvania, April 28May 2, 1991, Vol. 2, p. 10.2.1 113, 1991.

10. SCALE: A Modular Code System for Performing Standardized Computer Analyses for Licensing Evaluation, NUREG/CR-0200, Rev. 6 (ORNL/NUREG/CSD-2/R6), May 2000. Available from Radiation Safety Information Computational Center at Oak Ridge National Laboratory as CCC-545. 
11. David Henderson, Waste Package Design, Framatome Cogema Fuel Company, Las Vegas, Nevada, to M. D. DeHart, Oak Ridge National Laboratory, 1999, personal communication.

12. J. L. F. Lacouture, C. C. Campos, and J. L. E. Torres, "Validation of the HELIOS Code for BWR Lattice Physics Calculations,” Trans. Am. Nucl. Soc. 79, 315 (1998).

13. B. D. Murphy, Prediction of the Isotopic Composition of $\mathrm{UO}_{2}$ Fuel from a BWR: Analysis of the DU1 Sample from the Dodewaard Reactor, ORNL/TM-13687, Lockheed Martin Energy Research Corp., Oak Ridge National Laboratory, October 1998.

14. M. D. DeHart, Parametric Analysis of PWR Spent Fuel Depletion Parameters for LongTerm Disposal Criticality Safety, ORNL/TM-1999/99, Lockheed Martin Energy Research Corp., Oak Ridge National Laboratory, October 1999.

15. O. W. Hermann and M. D. DeHart, Validation of SCALE (SAS2H) Isotopic Predictions for BWR Spent Fuel, ORNL/TM-13315, Lockheed Martin Energy Research Corp., Oak Ridge National Laboratory, September 1998. 


\section{APPENDIX A}

\section{SAS2H INPUT FILES}


Input File for SAS2H SMA Model - $\mathrm{UO}_{2} / \mathrm{Gd}_{2} \mathrm{O}_{3}$ rod in the center

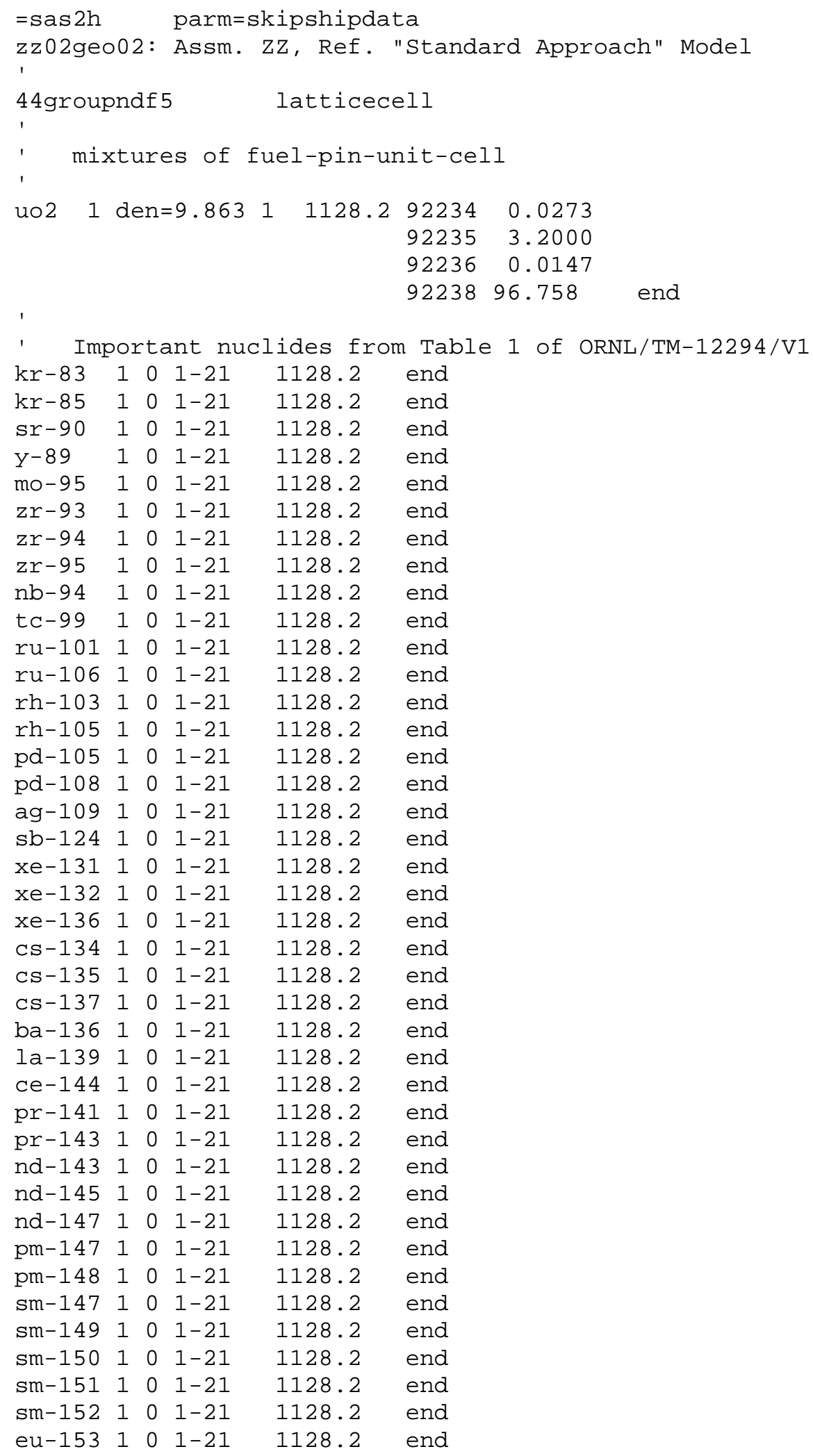




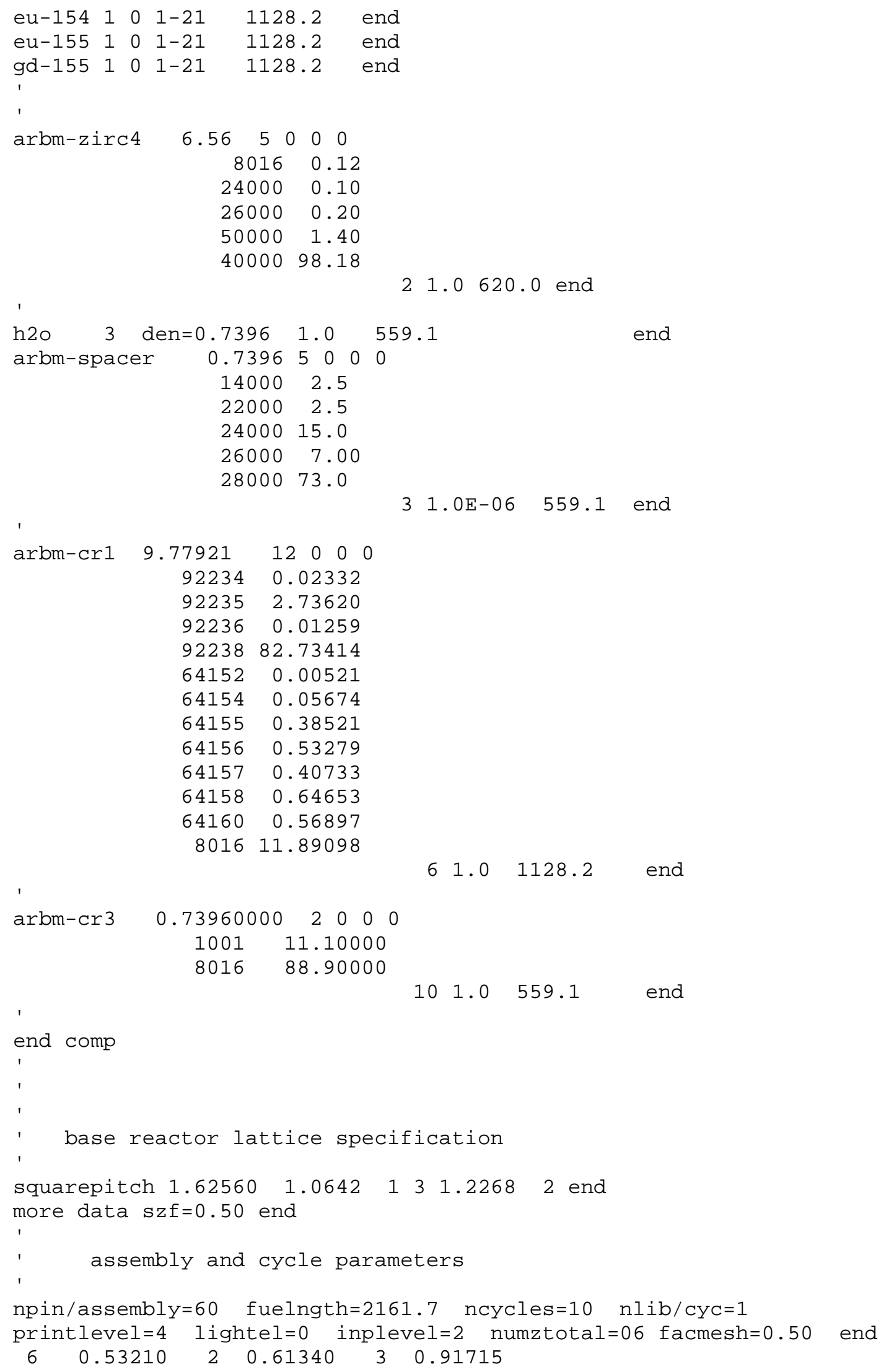




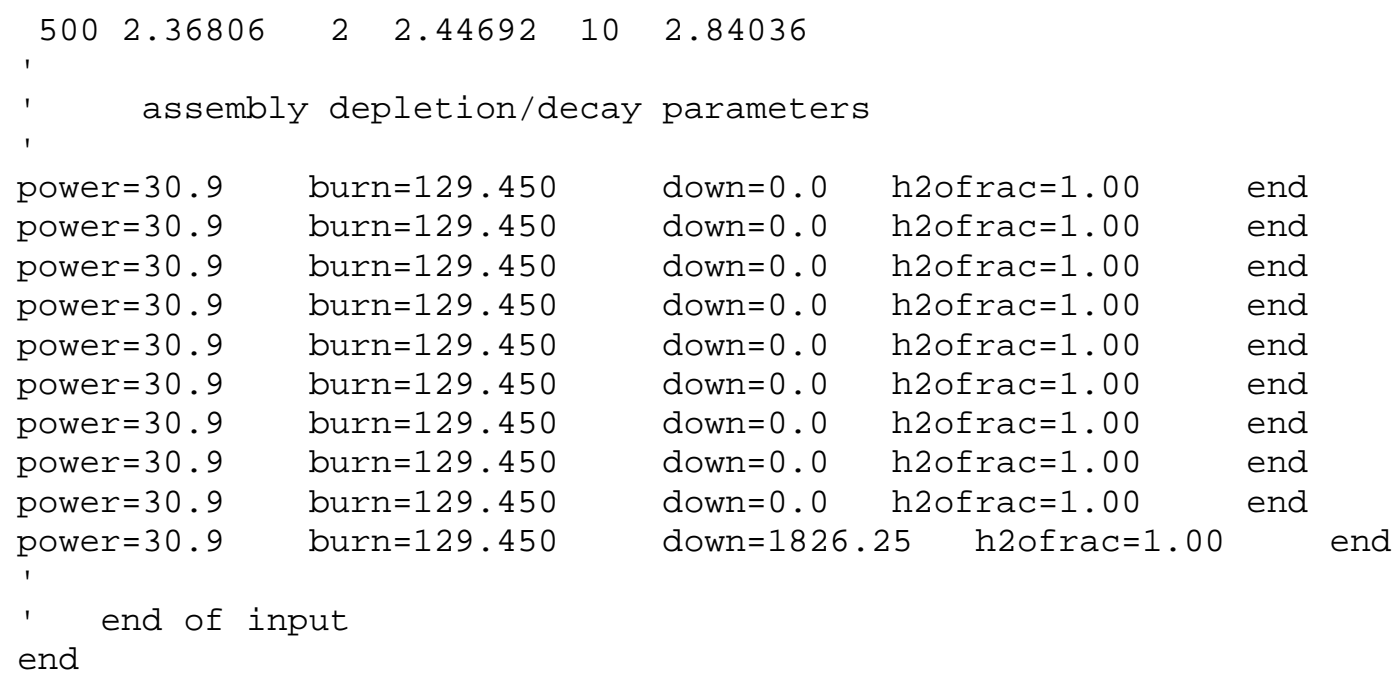


Input File for SAS2H 1FR01 Model - Single-fuel-region model with water rod in the center and the Gd smeared throughout single fuel region

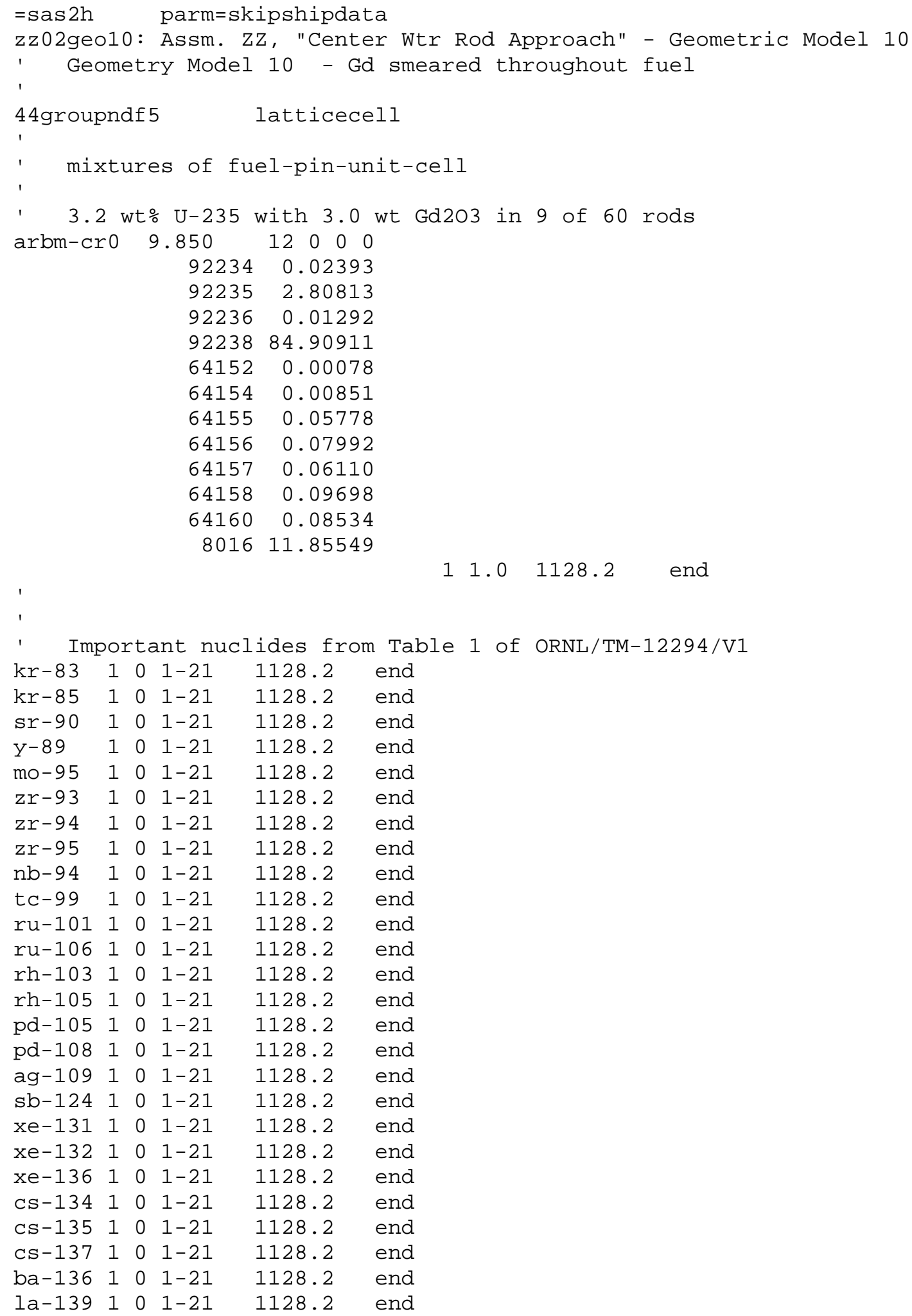




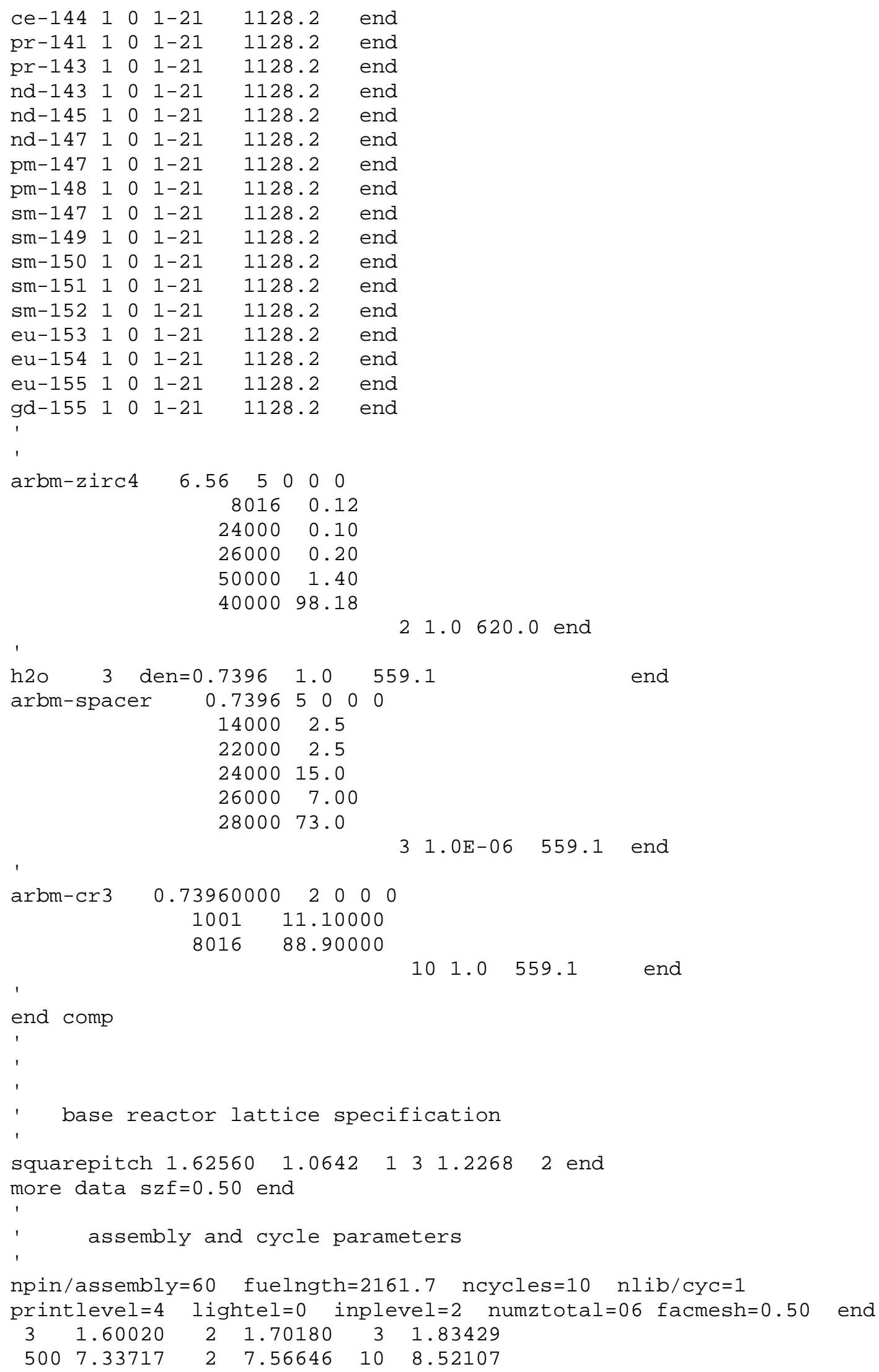


I

' assembly depletion/decay parameters

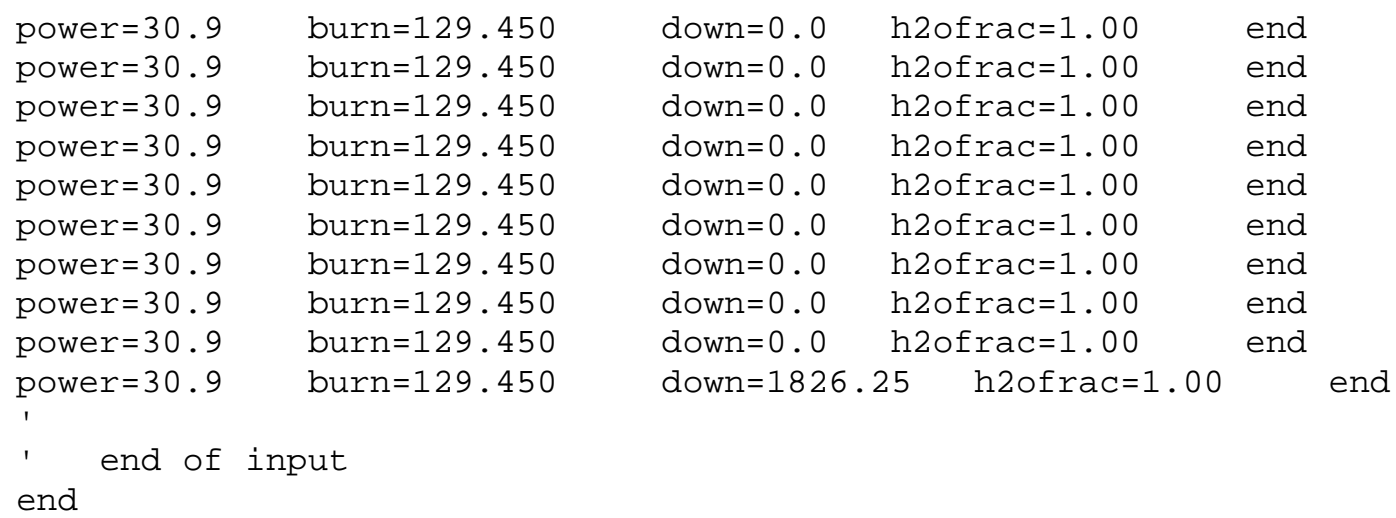


Input File for SAS2H 1FR02 Model - Single-fuel-region model with water rod in the center, $\mathrm{Gd}$ is not included in the model

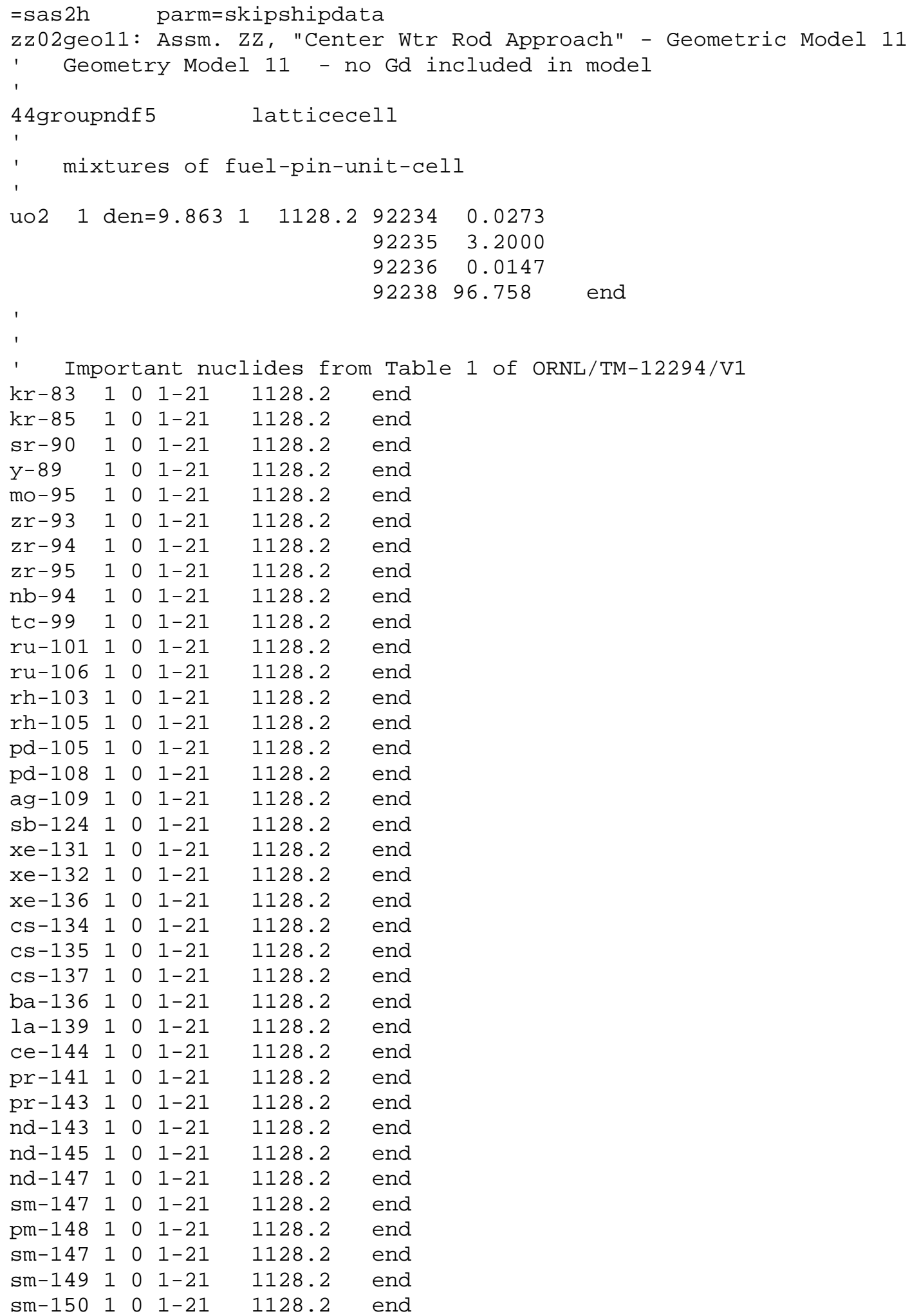




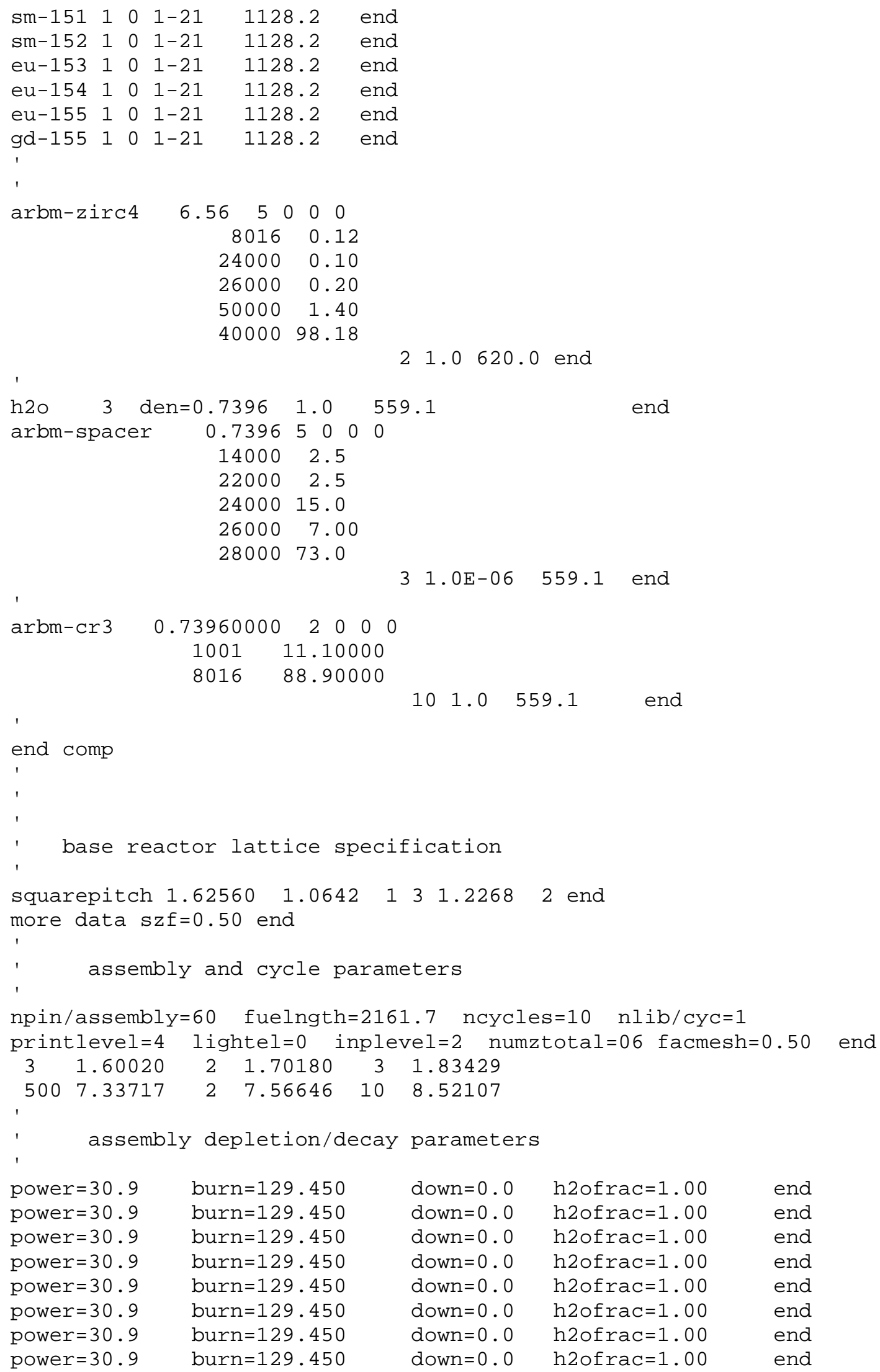




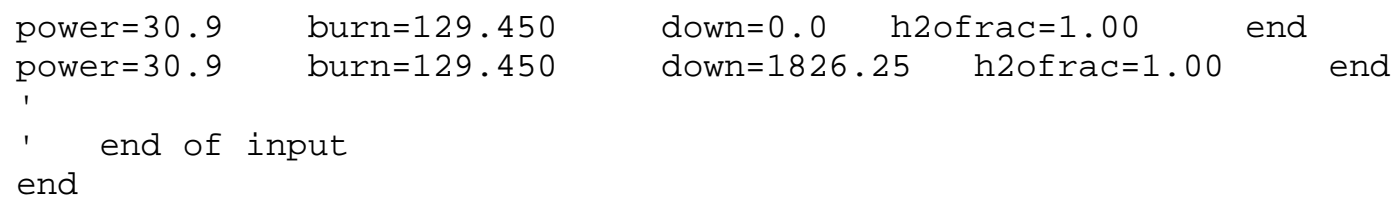


Input File for 2FR01 Model - Two-fuel-region model with water rod in center and Gd included as a thin cylindrical shell with inner radius corresponding to the equivalent inner radius of the central fuel "box"

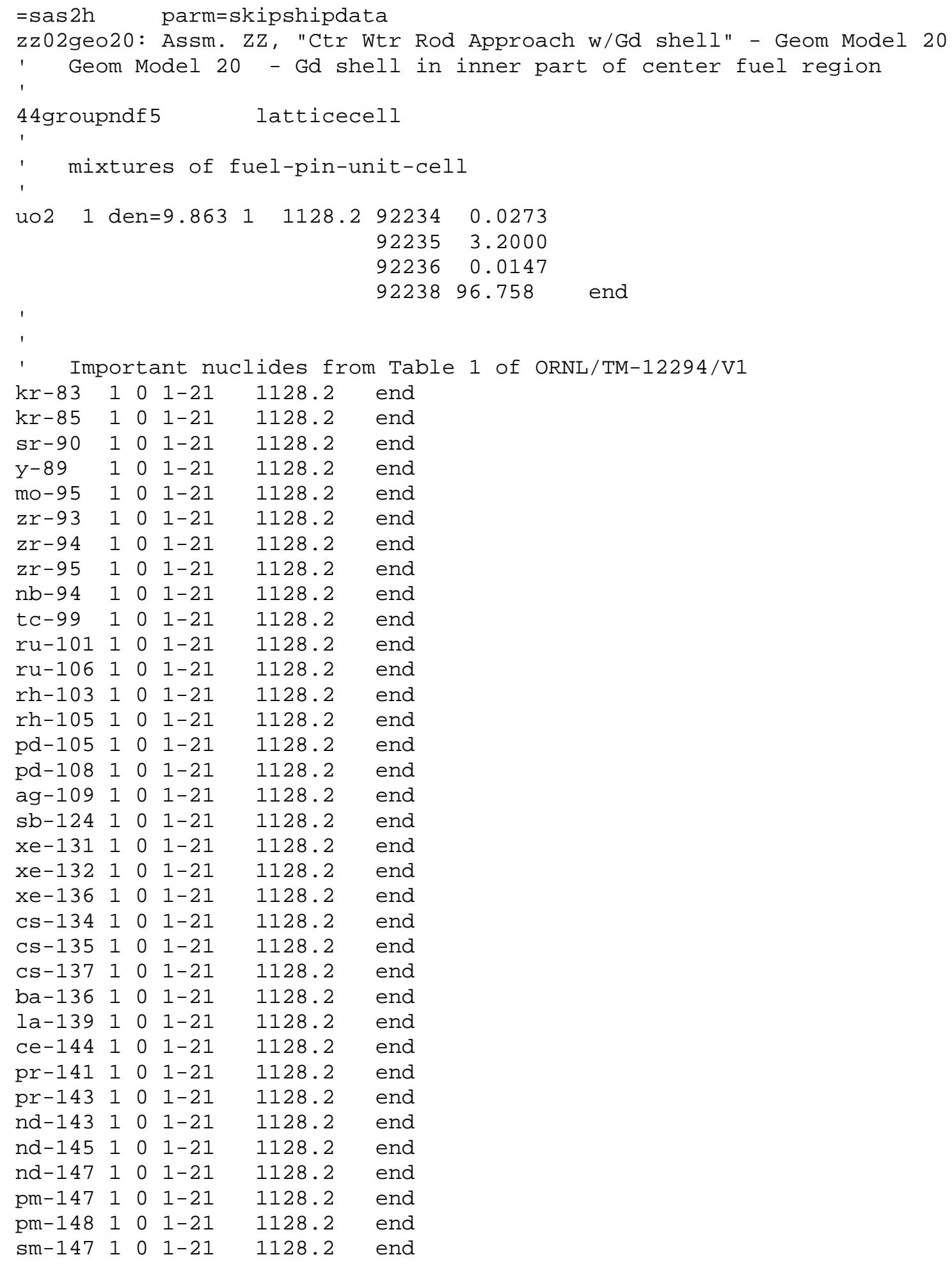




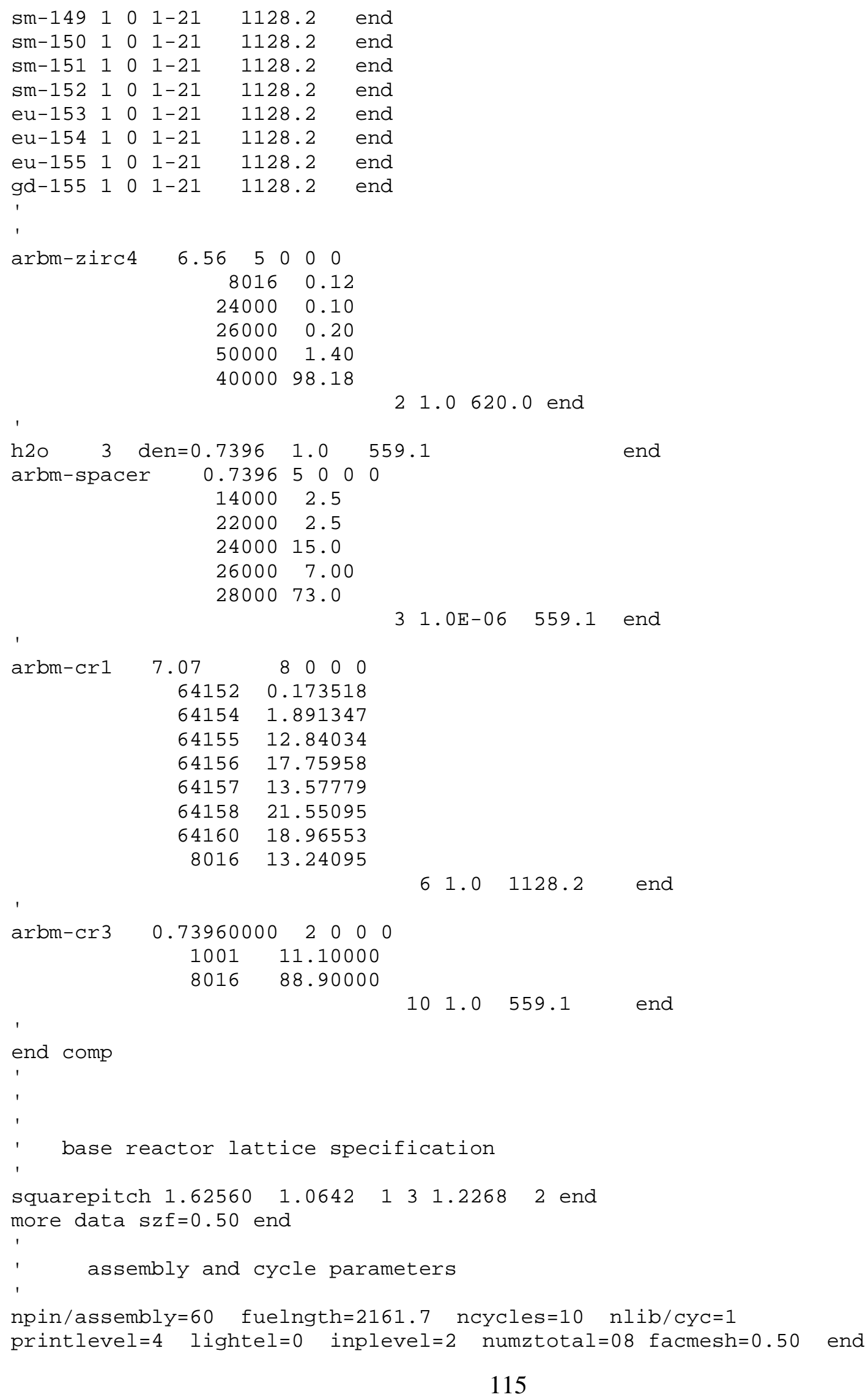




\begin{tabular}{|c|c|c|c|c|c|}
\hline 3 & 1.60020 & 1.70180 & 1.83429 & & \\
\hline 500 & 3.66859 & 3.68289500 & 7.33717 & 7.56646 & 8.52107 \\
\hline ' & assembly & depletion/decay & parameters & & \\
\hline \multicolumn{2}{|c|}{ power $=30.9$} & burn $=129.450$ & down $=0.0$ & h2ofrac $=1.00$ & end \\
\hline powe & $r=30.9$ & burn $=129.450$ & down $=0.0$ & h2ofrac $=1.00$ & end \\
\hline powe & $r=30.9$ & burn $=129.450$ & down $=0.0$ & h2ofrac $=1.00$ & end \\
\hline power & $r=30.9$ & burn $=129.450$ & down $=0.0$ & $\mathrm{~h} 2$ ofrac $=1.00$ & end \\
\hline power & $r=30.9$ & burn $=129.450$ & down $=0.0$ & h2ofrac $=1.00$ & end \\
\hline power & $r=30.9$ & burn $=129.450$ & down $=0.0$ & h 2 ofrac $=1.00$ & end \\
\hline power & $r=30.9$ & burn $=129.450$ & down $=0.0$ & h2ofrac $=1.00$ & end \\
\hline power & $r=30.9$ & burn $=129.450$ & down $=0.0$ & $\mathrm{~h} 2$ ofrac $=1.00$ & end \\
\hline power & $r=30.9$ & burn $=129.450$ & down $=0.0$ & h2ofrac $=1.00$ & end \\
\hline power & $r=30.9$ & burn $=129.450$ & down $=1826.2$ & 25 h2ofrac $=1.00$ & 0 end \\
\hline ' & end of in & & & & \\
\hline
\end{tabular}


Input File for 2FR02 Model - Two-fuel-region model with water rod in center and Gd included as a thin cylindrical shell with radial-center corresponding to the equivalent radial-center of the central fuel "box"

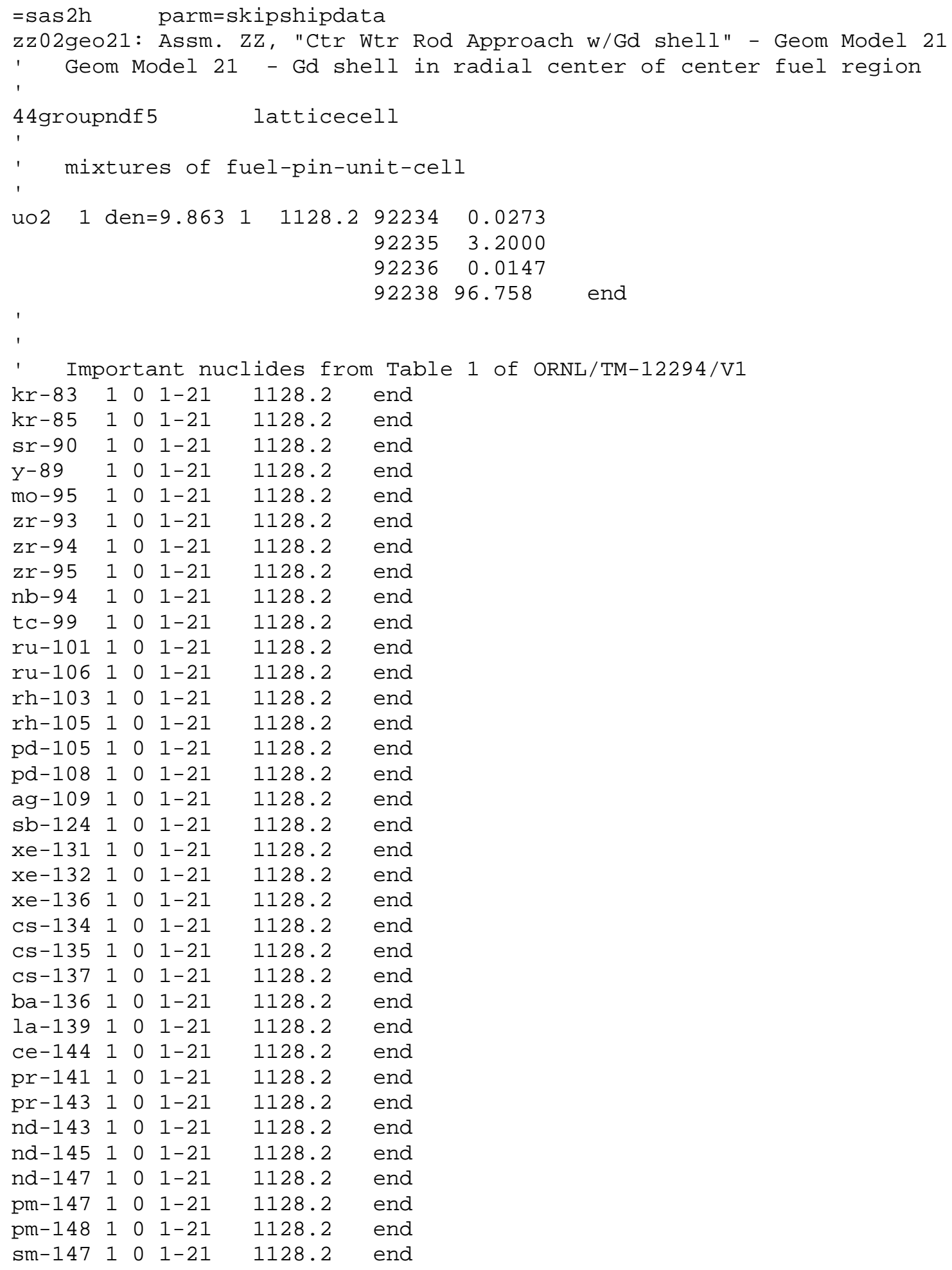




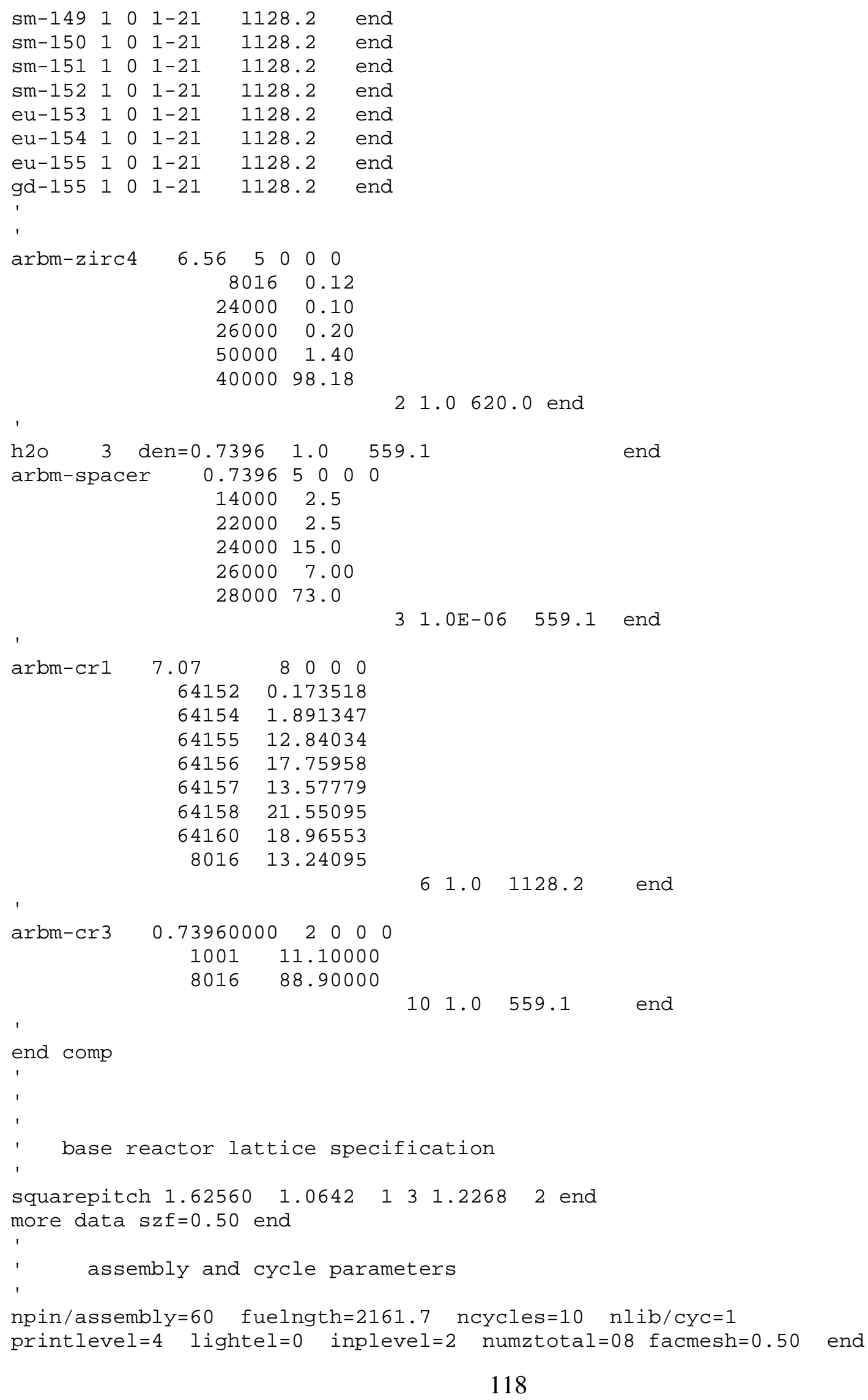




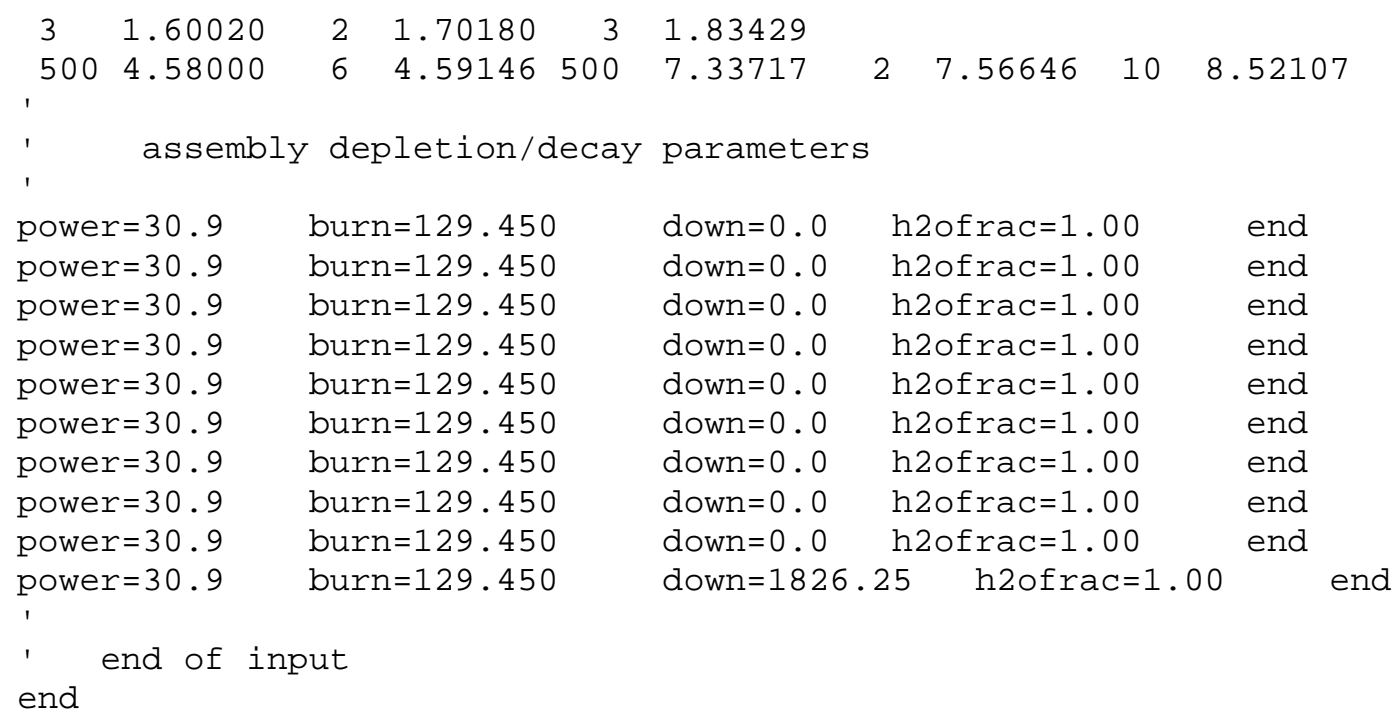


Input File for 2FR03 Model - Two-fuel-region model with water rod in center and Gd included as a thin cylindrical shell with outer radius corresponding to the equivalent outer radius of the central fuel "box"

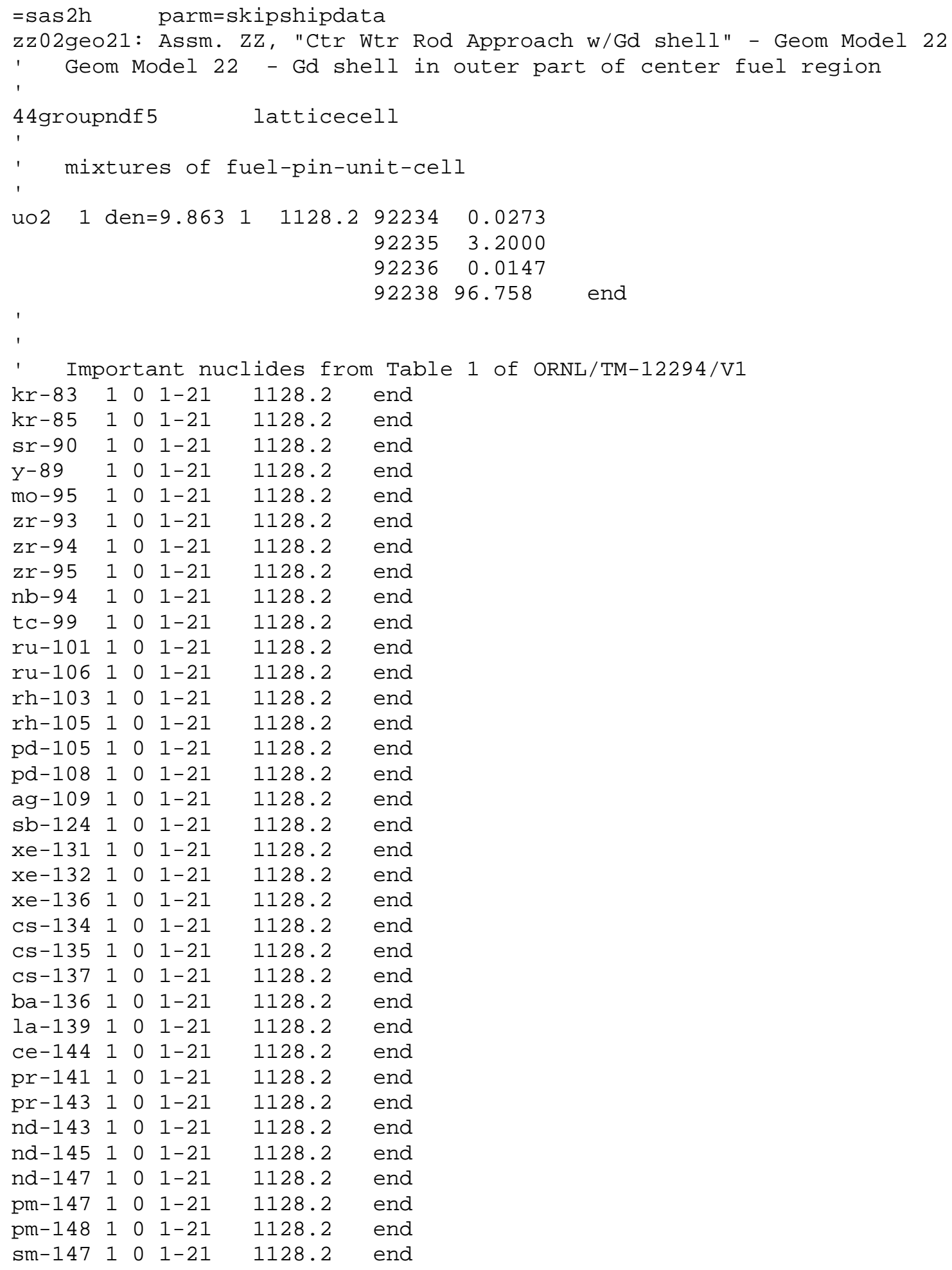




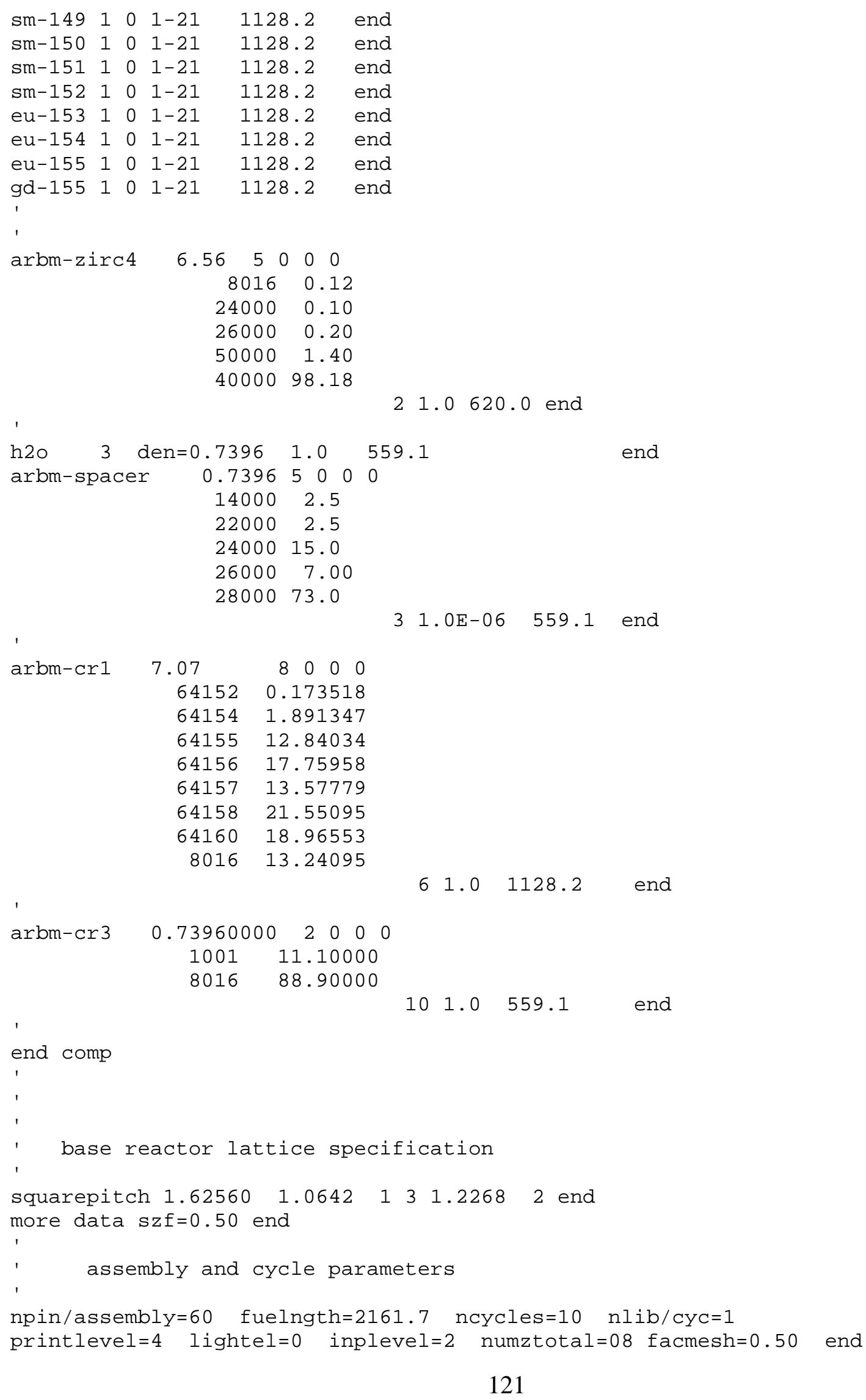




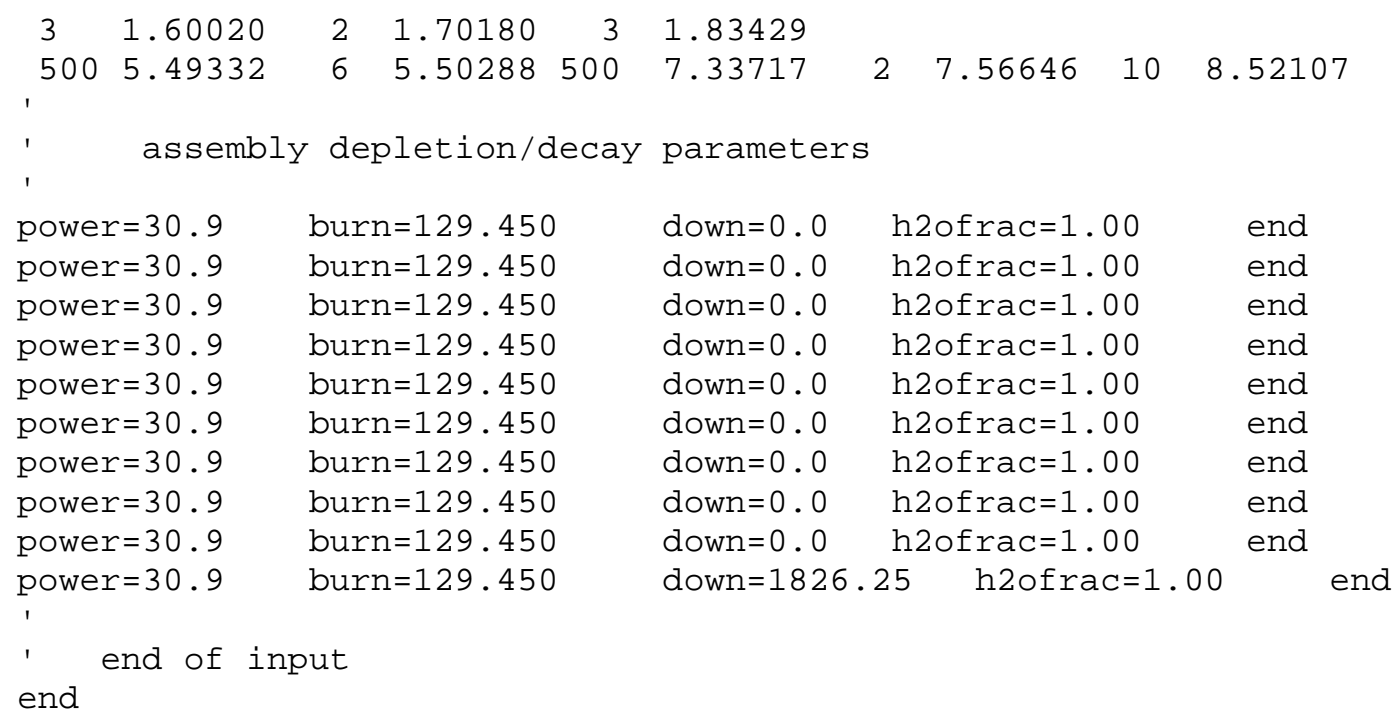


Input File for 3FR01 Model - Three-fuel-region model with water rod in center and Gd smeared throughout the central cylindrical fuel region, which corresponds to the central fuel "box"

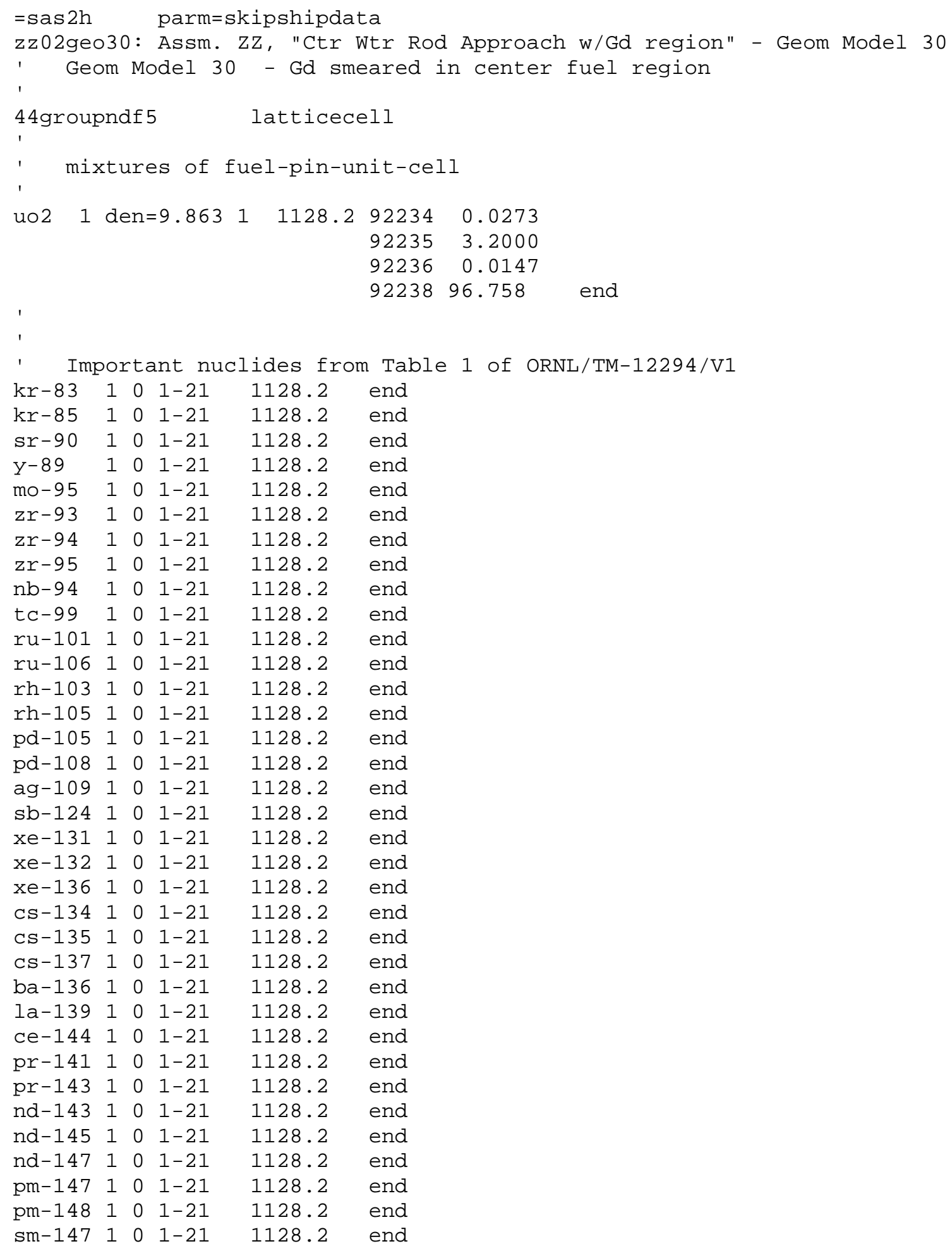




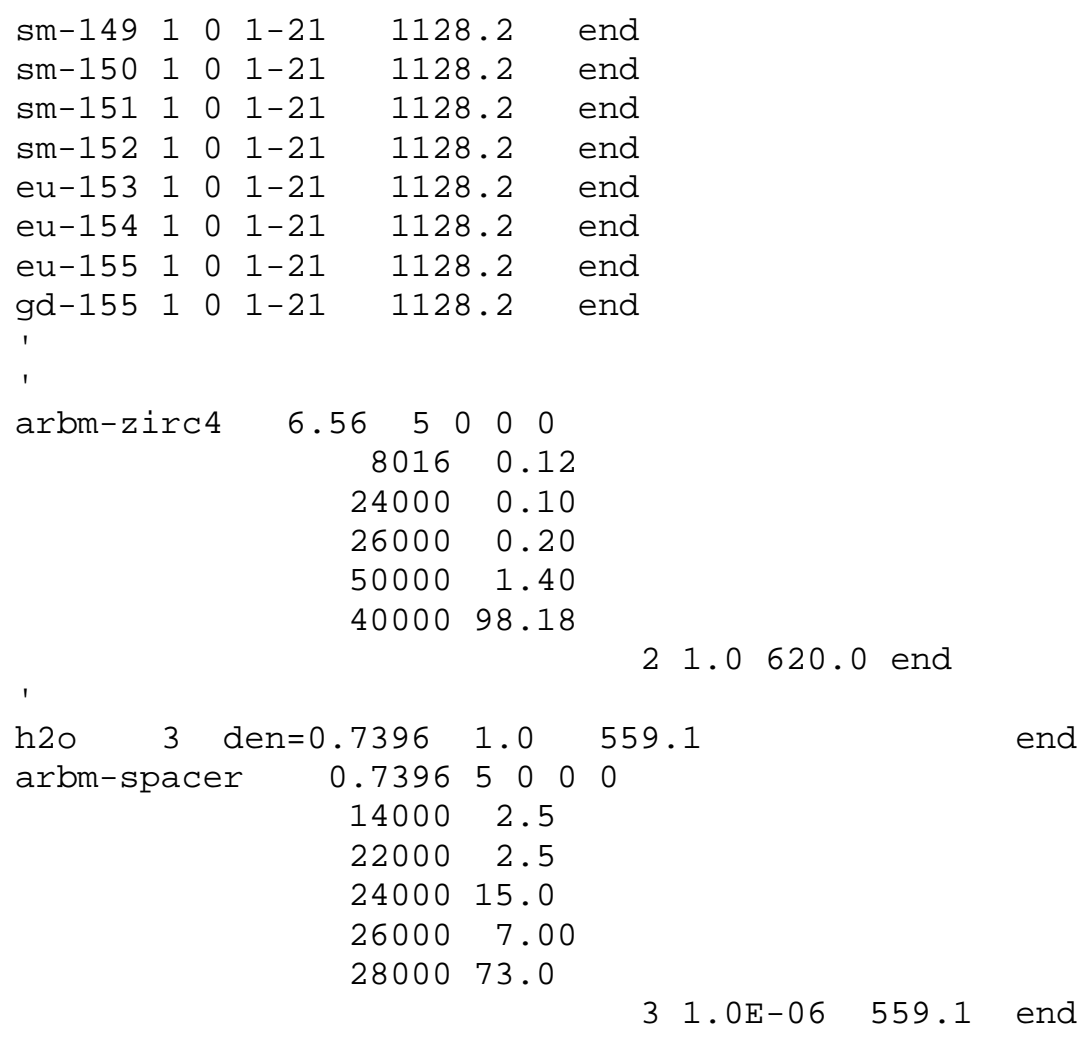




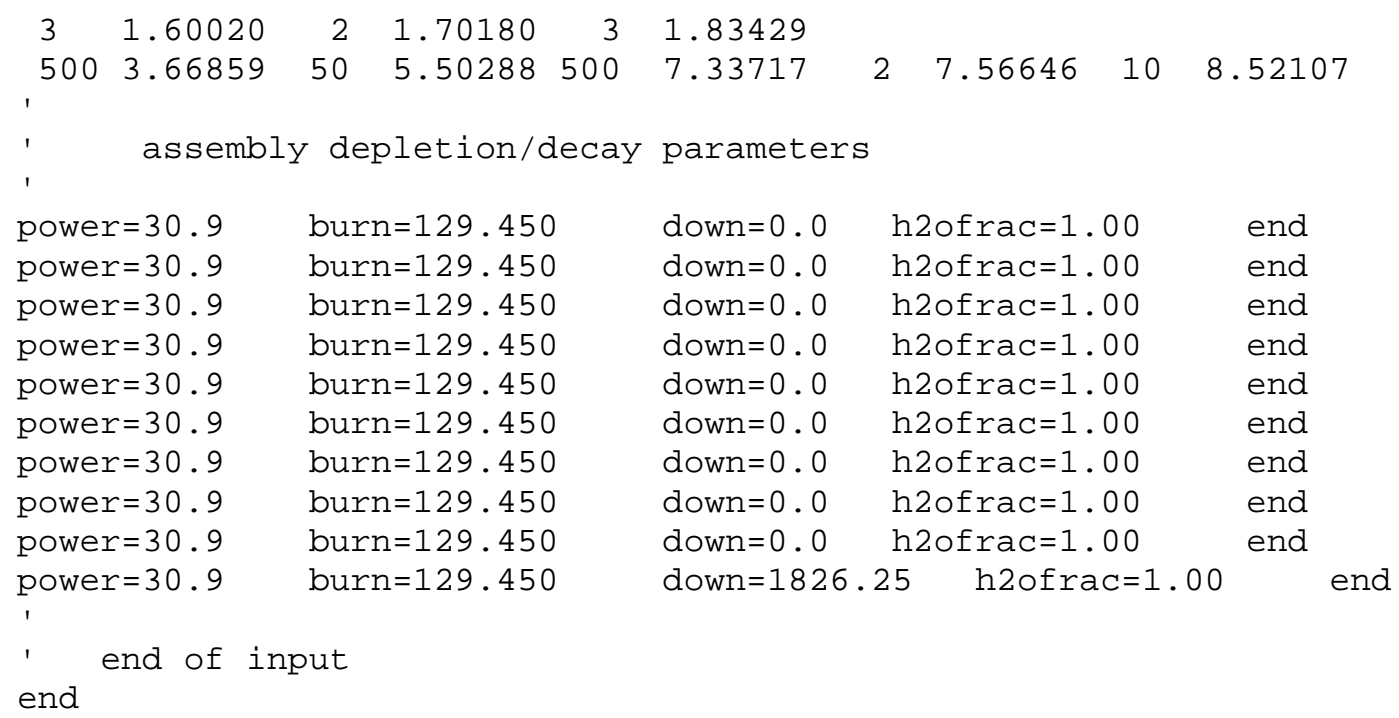


ORNL/TM-1999/193

\section{INTERNAL DISTRIBUTION}

1. S. M. Bowman, 6011, MS-6370

2-6. B. L. Broadhead, 6011, MS-6370

7. W. C. Carter, 6011, MS-6370

8-12. M. D. DeHart, 6011, MS-6370

13. M. E. Dunn, 6011, MS-6370

14. K. R. Elam, 6011, MS-6370

15. R. J. Ellis, 6025, MS-6363

16. M. B. Emmett, 6011, MS-6370

17. I. C. Gauld, 6011 , MS-6370

18. J. C. Gehin, 6025, MS-6363

19. S. Goluoglu, 6011, MS-6370

20. D. F.Hollenbach, 6011, MS-6370

21. C. M. Hopper, 6011, MS-6370

22. M. A. Kuliasha, 6025 , MS-6435

23. A. Loebl, 6025, MS-6435

24. S. B. Ludwig, PRI, MS-6495

25. B. D. Murphy, 6011, MS-6370
26. C. V. Parks, 6011, MS-6370

27. L. M. Petrie, 6011, MS-6370

28. R. T. Primm III, 6011, MS-6370

29. C. E. Pugh, 9201-3, MS-8063

30. J.-P. Renier, 6011, MS-6370

31. R. W. Roussin, 6025, MS-6362

32. J. C. Ryman, 6011, MS-6370

33. C. E. Sanders, 6011, MS-6370

34. C. H. Shappert, $4500 \mathrm{~N}$, MS-6237

35. T. E. Valentine, 6025 , MS-6362

36-40. J. C. Wagner, 6011, MS-6370

41. R. M. Westfall, 6011, MS-6370

42. Laboratory Records-RC 4500N, MS-6285

43. Central Research Library 4500N, MS-6191

\section{EXTERNAL DISTRIBUTION}

44. M. L. Anderson, Framatome Cogema Fuels, 1261 Town Center Drive, Las Vegas, Nevada 89134

45. M. G. Bailey, NMSS/SFPO/SLID, U.S. Nuclear Regulatory Commission, MS O13-D13, Washington, DC 20555

46. C. J. Benson, Bettis Atomic Power Laboratory, P.O. Box 79, West Mifflin, PA 15122

47. G. H. Bidinger, 17016 Cashell Road, Rockville, MD 20853

48. J. Boshoven, Transnuclear West, Inc., 39300 Civic Center Drive, Suite 280, Fremont, CA 94538

49. M. C. Brady Raap, Battelle, Pacific Northwest National Laboratory, P.O. Box 999 / MS K834, Richland, WA 99352

50. R. J. Cacciapouti, Duke Engineering and Services, 400 Donald Lynch Boulevard, Marlborough, MA 01752

51. D. E. Carlson, NMSS/SFPO/TRD, Spent Fuel Project Office, MS O13-D13, Washington, DC 20555

52. J. M. Conde López, Consejo de Seguridad Nuclear, Jefe de Area de Ingeniería Nuclear, Subdirección General de Technologia Nuclear, Justo Dorado, 11, 28040 Madrid, Spain

53. D. R. Conners, Bettis Atomic Power Laboratory, P.O. Box 79, West Mifflin, PA 15122

54. W. Davis, Framatome Cogema Fuels, 1261 Town Center Drive, Las Vegas, Nevada 89134

55. T. W. Doering, EPRI, 920 Morning Sun Court, Las Vegas, Nevada 89110 
56. D. D. Ebert, RES/DSARE/SMSAB, U.S. Nuclear Regulatory Commission, MS T10 K08, Washington, DC 20555

57. F. Eltawila, RES/DSARE/SMSAB, U.S. Nuclear Regulatory Commission, MS T10 E32, Washington, DC 20555

58. R. N. B. Gmal, Gesellschaft für Anlagen-und Reaktorsicherheit (GRS) mbH, Leiter der Gruppe Kritikalität, Forschungsgelände, 85748 Garching b. München

59. P. Grimm, Paul Scherrer Institute, CH-5232 Villigen Psi, Switzerland

60. N. Gulliford, Winfrith Technology Centre, 306/A32, AEA Technology PLC, Winfrith, Dorchester, Dorset DT2 8DH, United Kingdom

61. A. Haghighat, Mechanical and Nuclear Engineering, 137 Reber Building, Pennsylvania State University, University Park, PA 16802

62. S. Hanauer, U.S. Department of Energy, RW-22, Washington, DC 20545

63. G. Harms, Sandia National Laboratory, PO Box 5800, Mail Stop 1143, Albuquerque, New Mexico 87185-1143

64. L. A. Hassler, Framatome Cogema Fuels, 3315 Old Forest Road, P.O. Box 10935, Lynchburg, VA 24506-0935

65. D. Henderson, Framatome Cogema Fuels, 3315 Old Forest Road, P.O. Box 10935, Lynchburg, VA 24506-0935

66. R. A. Knief, XE Corporation (XEC), P.O. Box 90818, Albuquerque, NM 87199

67. H. Kühl, Wissenschaftlich-Technische Ingenieurberatung GMBH, Karl-Heinz-BeckurtsStrasse 8, 52428 Jülich

68. W. H. Lake, Office of Civilian Radioactive Waste Management, U.S. Department of Energy, RW-46, Washington, DC 20585

69. D. B. Lancaster, Nuclear Consultants.com, 320 South Corl Street, State College, PA 16801

70. C. Lavarenne, Institut de Protection et de Sûreté Nucléaire, Department of Prevention and Studies of Accidents, Criticality Studies Division, CEA - 60-68, avenue de Général Leclerc, B.P. 6 - 92265, Fontenay - Aux - Roses, Cedex, France

71. R. Y. Lee, RES/DSARE/SMSAB, U.S. Nuclear Regulatory Commission, MS T10-K8, Washington, DC 20555

72. Y. L. Liu, Argonne National Laboratory, 9700 S. Cass Ave., Bldg.308, Argonne, IL 604394825

73. M. Mason, Transnuclear, Two Skyline Drive, Hawthorne, NY 10532-2120

74. A. J. Machiels, Electric Power Research Institute, Advanced Nuclear Technology, Energy Convervation Division, 3412 Hillview Ave., Palo Alto, CA 94304-1395

75. L. Markova, Ustav jaderneho vyzkumu Rez, Theoretical Reactor Physics, Nuclear Research Institute, Czech Republic, 25068 REZ

76. C. W. Mays, Framatome Cogema Fuels, 3315 Old Forest Road, P.O. Box 10935, Lynchburg, VA 24506-0935

77. N. B. McLeod, JAI Corporation, 4103 Chain Bridge Road, Suite 200, Fairfax, VA 22030

78. D. Mennerdahl, E. Mennerdahl Systems, Starvägen 12, S-183 57 Täby, Sweden

79. K. A. Neimer, Duke Engineering \& Services, 400 S. Tyron St., WC26B, P.O. Box 1004, Charlotte, NC 28201-1004

80. P. Noel, Framatome Cogema, 1261 Town Center Drive, Las Vegas, Nevada

81. I. Nojiri, Japan Nuclear Cycle Development Institute, Environment and Safety Division, Tokai Works, Muramatsu Tokai-mura, Naka-gun Ibaraki-ken 319-1194, Japan 
82. J. C. Neuber, SIEMENS AG, KWU NS-B, Berliner Str. 295-303, D-63067 OFFENBACH AM MAIN, Germany

83. A. Nouri, OECD/NEA Data Bank, Le Seine-Saint Germain, 12 Boulevard des Iles, F-92130 Issy-les-Moulineaux, France

84. Office of Scientific and Technical Information, U.S. Department of Energy, P.O. Box 62, Oak Ridge, TN 37831

85-86. Office of the Assistant Manager for Energy Research and Development, Department of Energy Oak Ridge Operations (DOE-ORO), P.O. Box 2008, Oak Ridge, TN 37831

87. H. Okuno, Japan Atomic Energy Research Institute, Department of Fuel Cycle, Safety Research, 2-4 Shirakata-Shirane, 319-1195 Tokai-mura, Naka-Gun, Ibaraki-ken, Japan

88. P. M. O’Leary, Framatome Technologies, 3315 Old Forest Road, P.O. Box 10935, Lynchburg, VA 24506-0935

89. O. Ozer, Electric Power Research Institute, 3412 Hillview Ave., Palo Alto, CA 94304

90. T. Parish, Department of Nuclear Engineering, Texas A \& M University, College Station, TX 77843-3313

91. V. A. Perin, NMSS/DWM/HLWB, Office of Nuclear Regulatory Research, MS T7-F3, Washington, DC 20555

92. B. Petrovic, Westinghouse Electric Company, Science and Technology Department, 1344 Beulah Road, Pittsburgh, PA 15235

93. J. S. Philbin, Sandia National Laboratory, PO Box 5800, Mail Stop 1143, Albuquerque, New Mexico 87185-1143

94. M. Rahimi, NMSS/DWM/HLWB, Office of Nuclear Material Safety and Safeguards, MS T7-F3, Washington, DC 20555

95. E. L. Redmond II, Holtec International, 555 Lincoln Drive West, Marlton, NJ 08053

96. C. Rombough, CTR Technical Services, Inc., 5619 Misty Crest Dr., Arlington, TX 760174147

97. D. Salmon, Framatome Cogema, 1261 Town Center Drive, Las Vegas, Nevada 89134

98. H. H. Schweer, Bundesamt fuer Strahlenschutz, Willi Brandt Str. 5, D-38226 SALZGITTER, Germany

99. G. Sert, Institut de Protection et de Surete Nuclear, Department de Securite des Matieres Radioactives, B.P. 6 - 92265, Fontenay - AUX - Roses, Cedex France

100. D. N. Simister, Health and Safety Executive, Nuclear Installations Inspectorate, St Peter=s House, Balliol Road, Bootle, Merseyside L20 3LZ

101. M. Smith, Virginia Power Co., P.O. Box 2666, Richmond, VA 23261

102. T. Suto, Power Reactor and Nuclear Fuel Development Corporation, Technical Service Division, Tokai Reprocessing Plant, Tokai Works, Tokai-Mura, Naka-gun, Ibaraki-ken, Japan

103. H. Taniuchi, Kobe Steel, Ltd., 2-3-1 Shinhama, Arai-Cho, Takasago, 676 Japan

104. D. A. Thomas, Framatome Cogema, 1261 Town Center Drive, Las Vegas, Nevada 8913104.4

105. P. R. Thorne, British Nuclear Fuels plc (BNFL), Nuclear and Radiological Safety, R101 Rutherford House, Risley Warrington WA3 6AS, United Kingdom

106. J. R. Thornton, Duke Engineering \& Services, 230 S. Tyron St., P.O. Box 1004, Charlotte, NC 28201-1004

107. S. E. Turner, HOLTEC International, 230 Normandy Circle East, Palm Harbor, FL 34683 
108. A. Wells, 2846 Peachtree Walk, Duluth, GA 30136

109. B. H. White, NMSS/SFPO/TRD, Spent Fuel Project Office, MS O13-D13, Washington, DC 20555

110. C. J. Withee, NMSS/SFPO/TRD, Spent Fuel Project Office, MS O13-D13, Washington, DC 20555 
